
$4 !$

1.657

V. 



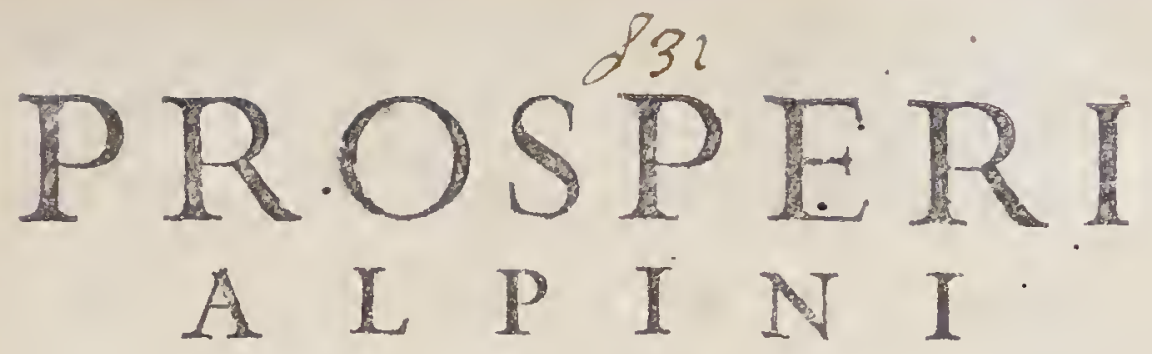

DE PLANTIS AEGYPTI L I B E R.

IN QVO NON PAVCI, QVI CIR CA herbarum materiam irrepferunt, errores, deprehenduntur, quorum caufa hactenus mulca medicamenta ad vfum medicinę admodum expetenda, plerifque medicorum, non fine artis iactura; occulta, atque obfoleta iacuerunt.

AD IOANNEM MAVROCENVM Antonij Filium Patricium Venetum Clarifimum.

Accefsit etiam liber de Balfamo aliàs editus.

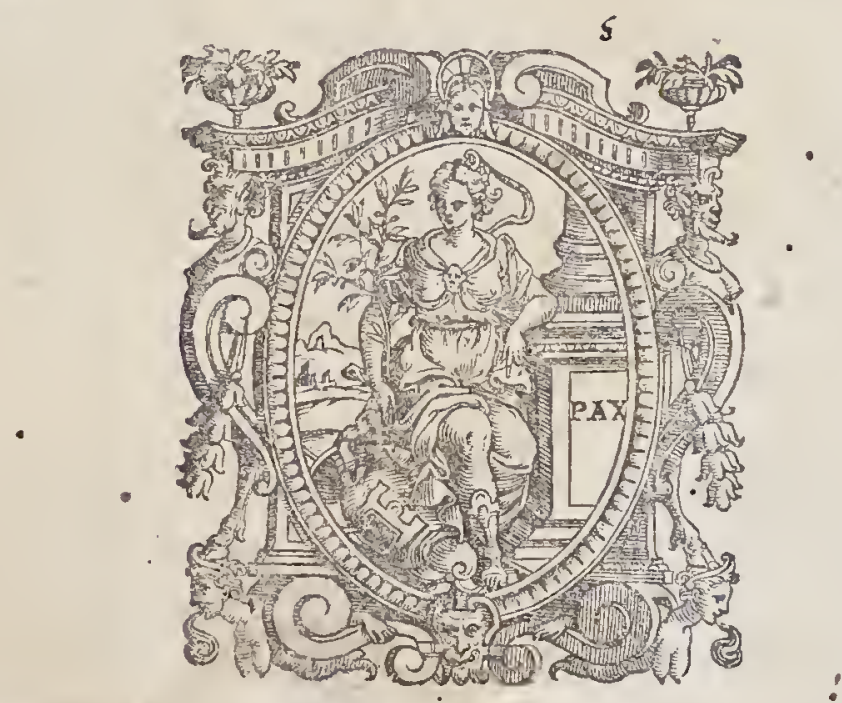

VENETIIS, M: D: X C I I.

Apud Francifcum de Francifcis Senenfem. ! 


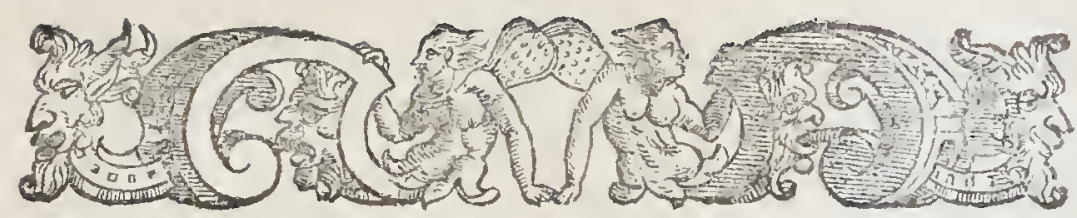

\section{OAN N I}

\section{MAVROCENO A N T O NII FI L I O \\ Patritio Veneto Clarif́simo.}

PROSPER A L P I N S. S. D.

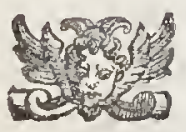

ERTM LCANTARVM cognitionem, IoanWI 1 nes Maurocene Clariffime, àmagno illo T) A Chirone Centauro Saturns filio, wel ab

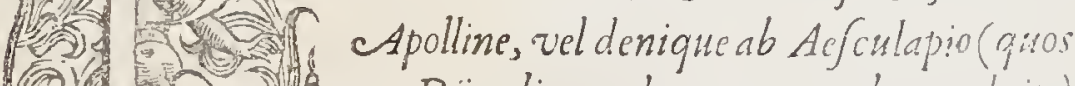
(1) (U) pro Dÿs aliquando cceca mortalutas coluit)

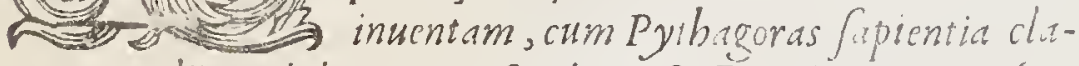
rus, tum alij prodiderunt. Poftcág; per pectis ad corportum fani satem ipfarum apud omnes admirandis vivibus, muitu nin finlum fapientiffimi Philo fophi, inter quos Domocritus dari nom: nis vir, iffius fientia amore multas regiones peragraut, werm etiam maximi Reges (quorum nomina id fignfiantia bususq́; in aliquibus plantis conferuantur) in earum fudio piurimum infudarunt. Non eft itaque cur cuipiam mirmm videatur, footpede plantis, quasulim in locis cAesyiti in$\int p e x i, a c o b j e r u a u i, ~ l i b r u m a$ me confriptum, nunc in licem

$$
\text { a } 2 \text { adi- }
$$


aditurus, ibi viro generis nobilitate, ac fingularium virtto tum clivitate Illiftri dicare voluerim; Cumprafertim omniums ctiam difciplinaium fudijs te m.xime delectari fiom. Sperauienim ex bac noua firpium bifforia, te non parum uolutiatis fufceptüum. Accedit etiam, grodcum bic Plantarnins liber, quemuna cum alÿs libris, de medicina Aegytionum wocatis, tuog; Illufriffmo patri dicatis, nuper coniunxeram, nunc fudioforum commodo Jeparatim fit cdendus, Tibitar. guam patri, cui in primis cum alijs fuerat definatus, proo piori offerrendus crat. Quod eò libentius feci, ut plurimam in te quoque ac reliquos fratrcs, quibus femper fui addictiffmus, meam obfrtiantiam perfpectam redderem. Accipe itaque zir Clarifime, boc munufculum à me bilari vultu (etenim fimaiss guid vel preftantius, quo te dignum fcio, nunc b.buiffem, tibilibentius adbuc obtuliff(cm) atque ip um vt aे detractorum linguis defendas, te etiam, atque ctiam rogo. Vale diufrelix, meique memor: Venetïs cAnno Salutis. bumane. M. D. XCIl. 


\section{LECTORI OPTIMO.}

Are 1 OS T libros de medicina Aegyptiorum, (e) en tibi, optime lector, libellum cxhibemus, qui eft De plantis A egypti, quem pri mo cum illis libris coniunxeranus, nunc verò tuis commodis confulentes, feparatim imprimendum curauimus. Accipe igitur hilari animo munufculum hoc meum, in quo id faltem affequati uidemur, ut ob rerum uarietatem, \& peregrinarum Atirpium hiftoriam, atque eorundem effigies, egregie, ut opinor delineatas, non indigna penitus elegantioribus auribus fripfife abitremur. Vale. 


\section{N D E X \\ OMNIVM CAPITVLORVM QVAE IN TOTOOPERE \\ C ONTINENTR.}

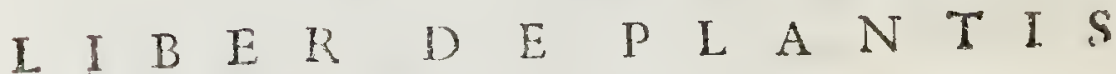
Aegypti Capita.

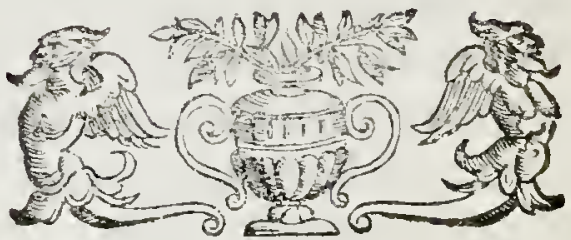
$0 \times m$ VR deplantis in Aegypti locis prouenientibus
fol. (4) De Cafsia ritula, Chaiarxäbaryocata. Cap.l. A N Q Qung 7 ris. Cap. III.

(2) Dc Acaria. Cap. IIII. fol.4 - C. De Paliuro Athenci, Nabca appellato.Cap.V.f.7 De Sycomoro Giumez uocata. Cap. VI. fol.s

De Pahna lachcl. Cap. V\$1.

J)eScbetten. Cap. V11I.

De Tamatifco Atlè vocata. Cạ. IX.

De Tamarindo Dcrelfide rocata. Cap. X.

De Agiahalid. Cap. Xi.

De Vzes, atque an fit Lycium ind :m, rap. XII.

fol. 10

fol.1.

fol. 13

fol. 15

fol. 16

fol. 17

De Ligutro A egyptio, elhanne, nol tamahondi vocato. Cap. XIII. fol. 18

Dc Baifamo, Balaffan ab Acgyptijs uocato. Cap. XIIII. fol.20

De Calat feulan. Cap. Xiv. fol.25

De Bon. Cap. XVI.

DeBaobab. Cap. XVII.

fol. 26

fol. 26

De Cofsipio arborco, Cotne Mregiarappellato. Cap. X V III. fol. 28

De Smbac Arab, fute Gelfmino Atabico. Cap. XIX. fol.29

De Phafcolo nigro lablab rocato. Cap. XX. fol.3o

De 
De phafeolo rubro, Abrus vocato. Cap. XXI.

fol. 38

De Mauz feu Muґa. Cap. XXI1.

fol. 32

DeSesban. Cap. XXIII.

De Sophera. Cap. XXIII I.

fol. 33

fo. 134

De Beidelfar. Cap. XXV.

fol. 35

De Achaouan Abiat, ideft Artemifia alba. Cap. XXVI. fol. $37 . \mathrm{k}$

De Bammia. Cap. XXVII.

De Melochia. Cap. XXVIII.

fol. $38 . \mathrm{k}$

fol.39.k

De Zatarendi. Cap. XXIX.

De Pifere longo. Cap. XXX.

De Abfus. Cap. XXXI.

De Sefamo feu Semprem. Cap. XXXIY.

De Culcas fue colocafsia. Cap. XXXIII.

De loto A egyptio Nuphar vocata. Cap. X XXIIII.

De Stratiote, Haihalem maoui uocato. Cap. XXXV.

fol. $40 . \mathrm{k}$

fol.40.k

fol. 37

fol. 37

fol. 39

fol. $4 \mathrm{C}$

fol.4I

fol. 42

fol. 43

De Cypero. Cap. XXXVII.

De Chatè, Abdellaui, \& Batecha el naui. Cap. XXXVIII. fol.44

De Neiemelmalib, fiue gramine crucis. Cap. X L. fol. 47.

De Melilo to Aegyptio Alchimelech uocato. Cap. X L r. fol. 48

De kellù,pfyllio, melanthio, cappare, vrtica, folano fomnifero, coriandro, ocymo, hyolciamo albo, conyza, nuce methela, Secamonc̀. Cap. X LII.

De plantis per iter obferuatis. Cap。 XLIII.

fol. 53 


\section{LIBRI DE BALSAMO C A P I T A.}

E Balfami planta, fucco, fructibus, \& virgis effe loquen fat dum. Cap. 1. fol.62 Aribalfami planta, eiusqúue fuccus, fructus ac virgx nunc repcriantur, \& in quibus locis proueniat.

Cap. LI. fol.63 Plantx, quxab antiquis Arabix medicis Baleffan, à Gracis Bairoul:or \& a Latinis Balfanum uocabatur, fructum, fucciq́ue defcriptio. Cap. LlI. fol.67

Veri opobalfami coguitio vnde fumatur, \& qui ex antiquis verè hune fuccumlitteris prodiderint. Cap. I11\%. fol.70 De notis, quibus verum opobal famum à non vero, Syncerum ab adulterat o tutò cognofcitur, ac difcernitur. Cap. V. fol.gz. Vericarpobalfani, \& xilobalfami cognitio, \& confideratio. Cap.VI. fol. 75

Cur Petri Bellonij obferuationes in Aegypto circa baliami plantam fact $x$ hic adnotat $x$ fint. Cap. VII.

fol. 78

Aegyptij balfami obferuatio ex Petro Bellonio in libro X. itinerariarum obfcruationum, capite XXXIX. collecta. Cap.VII I. fol.78

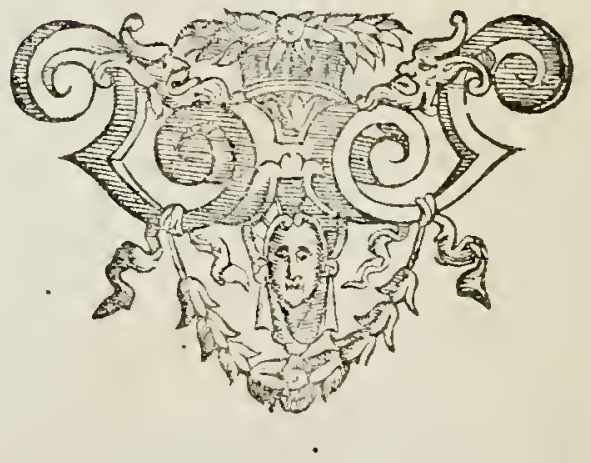




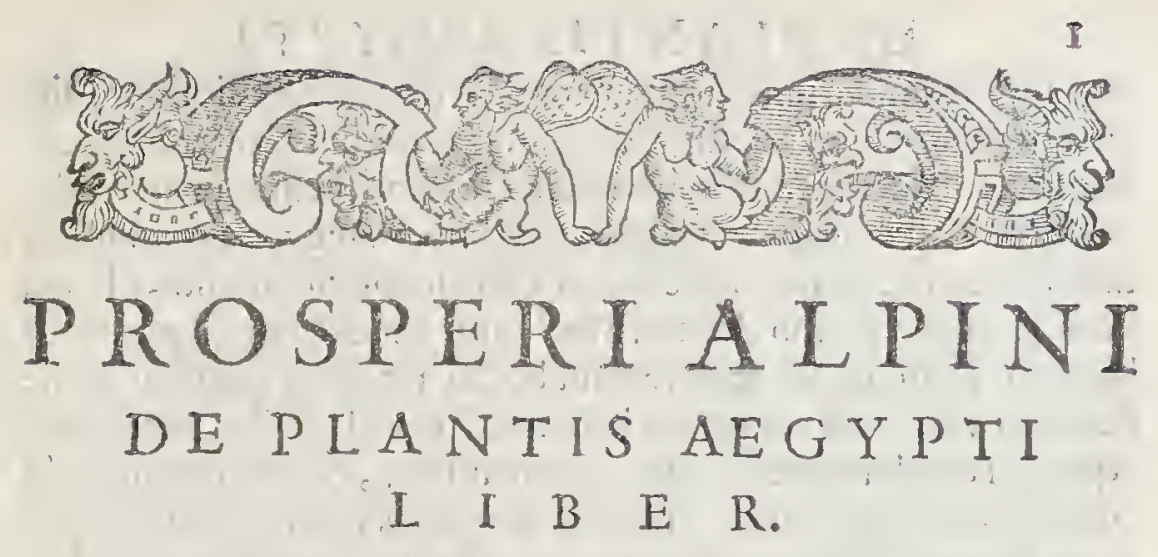
CVRDE PLANTIS IN CAEGYPTI LOCIS provienient:bis fit agendum. Cap. 1 .

\section{ALPINVS, GVILANDINVS.}

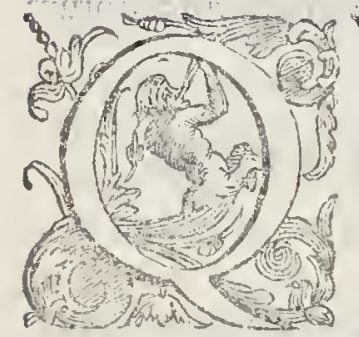

VIN T A nunc agitur dies, ex qua in virida rium nos colloquendi caufa conuenimus, in quo vbi medicine eius, quix penes Aegyptios habetur, hiftoriam ad finem perduxerimns, ni hil aliud de illorum medicina dicendum nobis fuperfuiffe, arbitror. Quare alijs nos fermo nibus hac dic in folito huius amoeniffimi viridarij reeefit, futh horum arborum vmbra fedentes, animum recrean bimus. GVI LAND. Quid ? an non etiam illorum locorum plantex agnofcendx fuperfunt? de quibus quidem te fermonem quoque facturtm aliàs es pollicitus : cum ipfarum hiftoria, ob varias in medendo utilitates,ad fermones hactenus de Acgyptiorum. medicina inter nos habitos maxime pertinere uideatur? nec enim minus s $x$ his vtilitatis, arque voluptatis, quam ex illis nos effe fufcepruros fiperamis cum à nullo hactenus ill'g rectè obferuatę,ac tra ditie fine, maximeque quo ad ipfarum veras ichones, quas nemo profectò hricufque recte \& accurate cognouit . Quod quidem ex Caffra Acgyptiara, quam vulgus medicorum, fiftulam, aut folutiuam vocat, Palinto Aihenei, quam ij Napca appellant, ex alcanna Auicenne fcilicet liguttro Aegyptio, Cypro à nonnullis dieto:ex balfamo, Acatia, Lycio, Tamarifco, Faba Acgyptia, Strathiote, atA que 


\section{DE PLANTIS AEGYPTI}

que alijs quamplurimis nofri temporis plantarũ fudiofis prorfus igno tis, plane eft manifeftu. Itaque Aegyptiarum plantarum fic ab omnibus defiderata hiftoria, non eft a te nunc filentio prxtereüda. ALPIN.Polteaquam te has plïtas, quas loca Aegyptia producant, titopere ex ma audire delectat, cur ego tui obferuátifmus, tibi pla ne morem gerere non debeo ? Illas igitur hac die, quoad potero di ligentius, tibi omnes aperire tentabo, ac preterea quos hre ad me dendum vfus apud eas gentes habeant. GVILAND. Nunquam equidem de plurima tua erga me humanitate, \& beneuolentia du bitare potui. Quare nihil optatius, ac gratius mihi contingere poterat. Pluresq́uc ideo nunc tibi gratias habeo:tuaq́ue erga me hẹc animi promptitudo effet nunc multis laudibus efferenda, quod mi nime faciam, ne fummam ruam modeftiam offendam. At hęc nunc omittamus, neque in his hodiernum tempus conteramus. Vbi itaque in viridarij huius amico receffu, quo Solis radij pertingere nequeunt, fub iftac vmbra confedimus, vt plantarum illarum hiftoria principium facias tempus fuadet; ac primum ab arbosum parratione exordiens de cafia fitula agito.

\section{Decaflufiftula, Chaiaruambar vocata. Cap. IP.}

\section{A L P I N V S.}

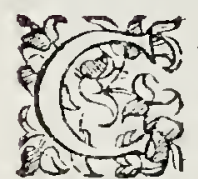

A S S I A fiftula, quam Aegyptij Chaiarxambar apperlant, eft arbor nuci, trunco, ramis, folijsq́ue proxima, wí cus corticem habet plantim, mollcm, atque cineritium, qualis omnino in crefeenti nuce fpeetatur. Folia multo plura quàm in nuce, alax adligata pendent, in alis folı decem fpeEtantır : torque ex qualiber ferè ala pendere obferuantur, vtrinque ordinarim quinque pofita; funt etian huiufe arboris folia nucis folijs duplo loggiora, \& in extremo aculeata. Flores fert aureos, multos, feucojjs proximos, fed multo maiores, numerofioresćue, florum anagyridis inftar, alæ adligatos, ac pédentes;alc frquidéomnes innţ meris ferme foribus onufte ac graues deorfum uergere cernuntur. funt etiam hi valde odorat, prefertinque orience Sole. Aegyptij diluculo par Caffiartm loca deambulare frepius odoris caufa confuenerint : quippe alira à caflijs, eximium ac gratiffmim odorem forancibus;ad ipfos delata,oblcetantur. Apudillos cnim forentes arbouss 


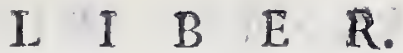

arbores acr matutinus perpetuò eximium, ac fuauiorem odoren te dolet. Flos quilibet in medium multa capillamenta, tenuiffma, rofarum Aofculis fimilia habet, qux paulatim crefcentia, in crafiores fiftulas poftea mutantur.fpectantur primo ipfa tenuiffima obliqua, ac obtorta, dcincepfque magis pcraucta, craffiora euadunt, ac mam gis recta; tandemq́ue iuftam magnitudinem adepta, rectisfima, ut Calami fiunt. Fiftulæe maiores cannic crafforis magnitudine fpectĩ tur,atque duorum ferè cubitorum longitudine. Arbor forere incipit menfe Iunio,foret toto etiam menfe Iulio Alexandrix \& Cay. ri.Pelufij vero nunc Damiatx, caffas menfe etiam Septembri forere vidi.Canna vel filtule toto anni fpacio maturantur, totoq́ue anno femper hæ in arbore manent, quas Aegyptij Iunio tantum menfe Cayri collignnt, quo tempore multx, parux, recenter ex primis floribus productę virides fpectantur,phacfeolorum filiquis ual defimiles: qux paulo poft cref́centes, paulatim viridem colorem in nigrum commutant. Has recentes \& paruas, virides aqua in primis cbullitas faccharo illi condiunt. Quarum fic conditartm ingês copia in varias regiones afportatur. Qux Pelufij in arboribus legun tui, corticem habêt craffiorem, \& parum intus fubftantix obtinent. Cayrinx uerò, \& Alexandrinx cortice conftant tenuiori,multaq́ue fubitantia intus plenx, ex quo hx cretcris omnibus bonitate prexferuntur. Qux, vt aliàs quoque ditum of, duplicis funt differentix : etenim aliquxe alix fubrubrx, quas Abes vocant, à colore illiufe gentis, cernuntur: qux funt omnium optim $x$, \& alix nigr . Quod de caffijs aliqui dixere, optimas cannas manibus concuffas fonum non cdere, ibi planè falfum obferuatur, quando omnes re. centes motix fonum edant, atque etiam in arboribus cannas à uentis motas, feminibus intus motis, multü fonum edere quotidie propè eas habitantes,audiunt. Quod etiam dulces filiqua faciunt.qux uerò ex caffijs nô fonant, ab Aegyptijs vituperantur, opinātibus id ob aqueam humiditatcm intus collectam, vitiata pulpa accidere. Neque immature colliguntur, ut alıqui referunt. Emuntur vero frefrepius ab aduenis mercatoribus fenio confect $x$, cum ingens copia fiep in iedibus ad ea rem paratis, annos ad vfque quadraginta adferuetur. Collectas enim ex arbore continuo in opportuna lo. cafic ij claudnnt, ut nullus aer ingrediatur, cum ex minimo aeris contatu cafsiç corrumpantur. Hincóp; fxpisfime ad nos vetuftatix ui tiatx ac etiam acide mitti folent.quam ob rem rogatos effe uelim

$$
\text { A } 2 \text { omnes }
$$




\section{DE PLANTIS AEGYPTI}

omnes pharmacopolas,ac medicos, ne poft hac fe decipi finant, \& femper ex illis feligant' recentes, quarum fubftantia fubdulcis eft, antiquasque acidum, ponticumque faporem fapientes effugiant . Acgyptij cafijs non utuntur recentibus, fed faltem poft quartum menfem:quando quidem iuniores, recencioresque inutiles neque ì noxa immunes obferuantur. Vtuntur uero, atque noftri quoque ficcunt, fifularum pulpa ud in bolis, nel in potionesparata. Eft hac putpr quo ad calorem temperata, atque humida fupra primum gradum, bik móve, ac etiam pituitam à ftomacho, atque venis mefenterij educit, \& fanguinem calidiorem contemperat, atque puriorem reddit. Abisina uocata cocteris in urbe Cayri prafirtur ad. morbos biliofos, ac melancholicos, precipuę́que in affectibus peetoris, à diftiliatione acutorum humorum concitatis, quibus mire fubuchit. Pulpa hac cum faccharo candido, \& liquintia pro fecreto uti folentad renum, ueficúque uitia: :num cnim exinguit immodicum calorem, humoresq́ue ab his partibus abftergit, atque per urinam expellit:proinde ipius frequenti vfu homines fe à calculis pręcauent. Ea etian viuntur ad tufin anciquam, difpicam afthma, \& orthopnem cumagarico pro caludis aticulortm doloribus, maximeque in podagra, dolentibus partibus, emplattrimo do ipfanadkibent, nec non ad calidas infammationes codem modo eius ufum fequuntw. Siliquas vero cafineru, proinde ac phafeoli panas urides in aqua prius parme ebullitas, \& nox in umbra ab humiditace ficcaras, facharo, at melle condiñ arque ad vum feruant puctorum delicararumáue nulierum; exhibent uxo ad

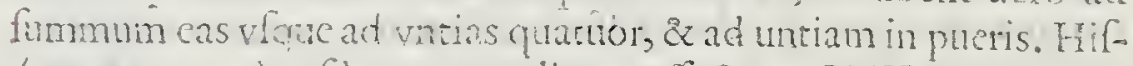
gue viuntur ad cofom nuper dictos affeeus. GVILAND. PIacuirmihi hęc carinam hitoria, fed cupio ut tu mili \& cafirix; \& aliarum, quas obfruani, phancarum figuram oftendas, quando te probe omnes delinculfe, ac pinuffe ceriò tcian, quod nemo antea recte id nobis pectiteriz. Qumobrem prits uifa caltix ar. bosis ichone, alias plantas narrare tnih pergito. 


\section{$\therefore \therefore$ L I B E R .}

CASSTA FISTVLA; CHAIARXAMRAR.

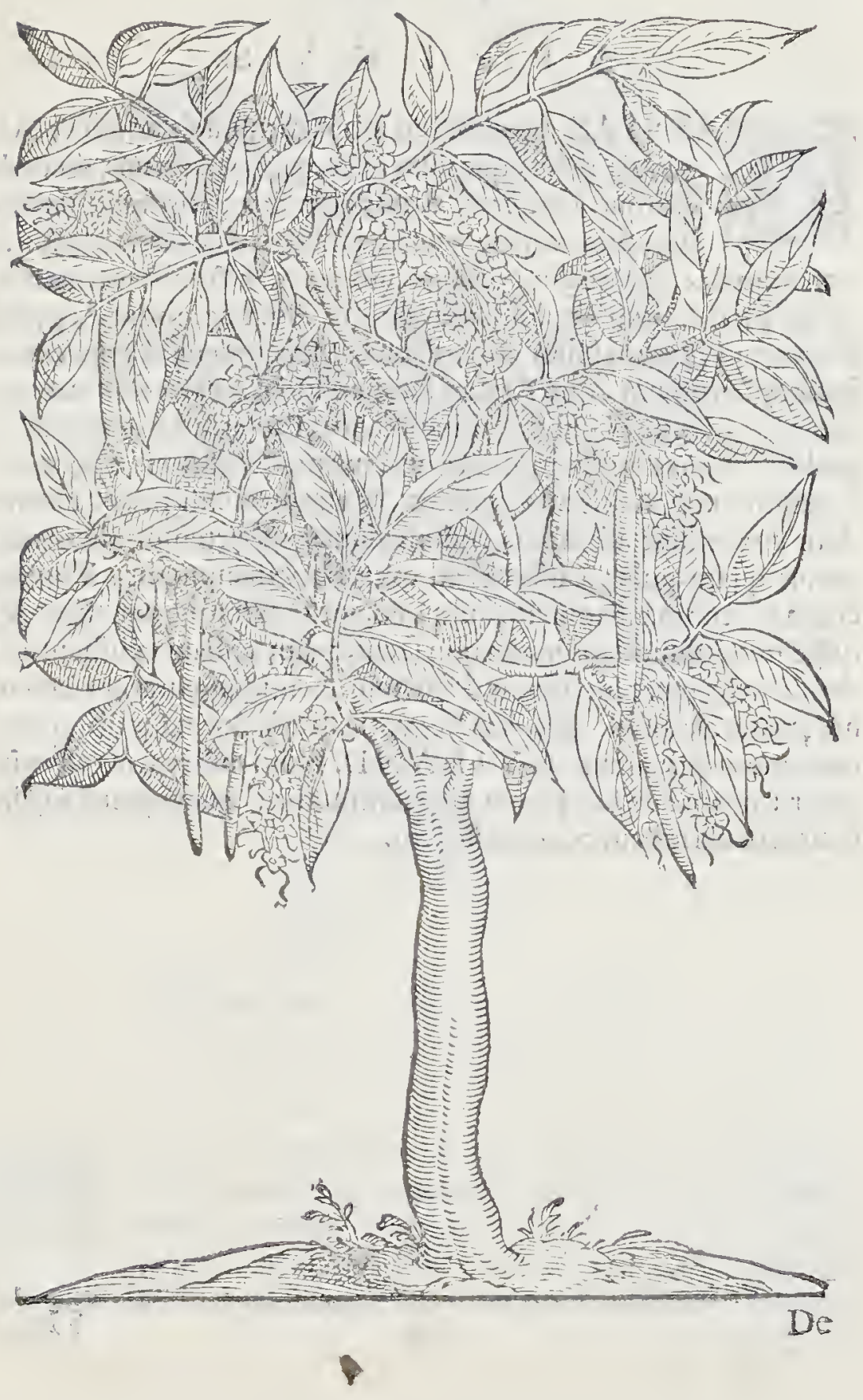




\section{DE PLANTIS AEGYPTI}

\section{De friguis chulcibus, carub, ab c Aegiptïs rocatis. Cap. 111 .}

\section{A $\quad I \quad P \quad I \quad N \quad V \quad S$.}

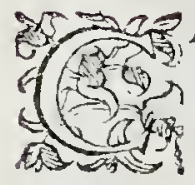

S SI AE proxima eff arbor carub, uel carnub ab Acgyptijs dicta, quęcum in Aegypto nafcatur, dicenda quoque à me erat. Arbor eft nobis notisfima, cum ha. rum arbortim in multis etiam Italix locis multa fit copia, quales funt, quę in Neapolitano agro, \& Apulia cernuntur: in ijs locis etenim copiofifsimi aluntur. Ex hacarbore Aegyptij filiquarum tantum ufum cognofcunt ; Mel quidem ex ipfis extrahunt dulcifsimum, quo Arabes facchari loco, cafsias folutiuas recentes ac paruas, zinzibere, mirabolanos, Tamarindos, atque alios multos fruetus condiunt. Huius quoque mellis ufus eft frequentifinus uice ueri mellis ad Clyfteres, \& aliqui etiam per os fumendum concedunt ad fubducendum aluum: ipfo etenim aluus non minus quàm pulpa caffix ibi ad excretionem mouetur. Vtuntur etiam in rennm inflammationibus eo, intus extraq́ue appofiro. Ad tuffientes, afthmaticos ipfum non fecus, quàm caffiam exhibent, val dećue ipfos iuuat, nố minus decoctum ex filiquis paratum eadem hęc pręftat. At modo de fpina Aegyptia,acatia uocata,multis hacte nus ignota loquamur. G V I L A N D. Nihil mihi carius effe nũc poterit, quante de hac planta dicentem audire, quem planè in illis locis eius ueritatem cognouiffe fcio. 


\section{I B E R, : 4}

\section{SILIQVA DVLCISCARVB。 \& carnub uocata.}

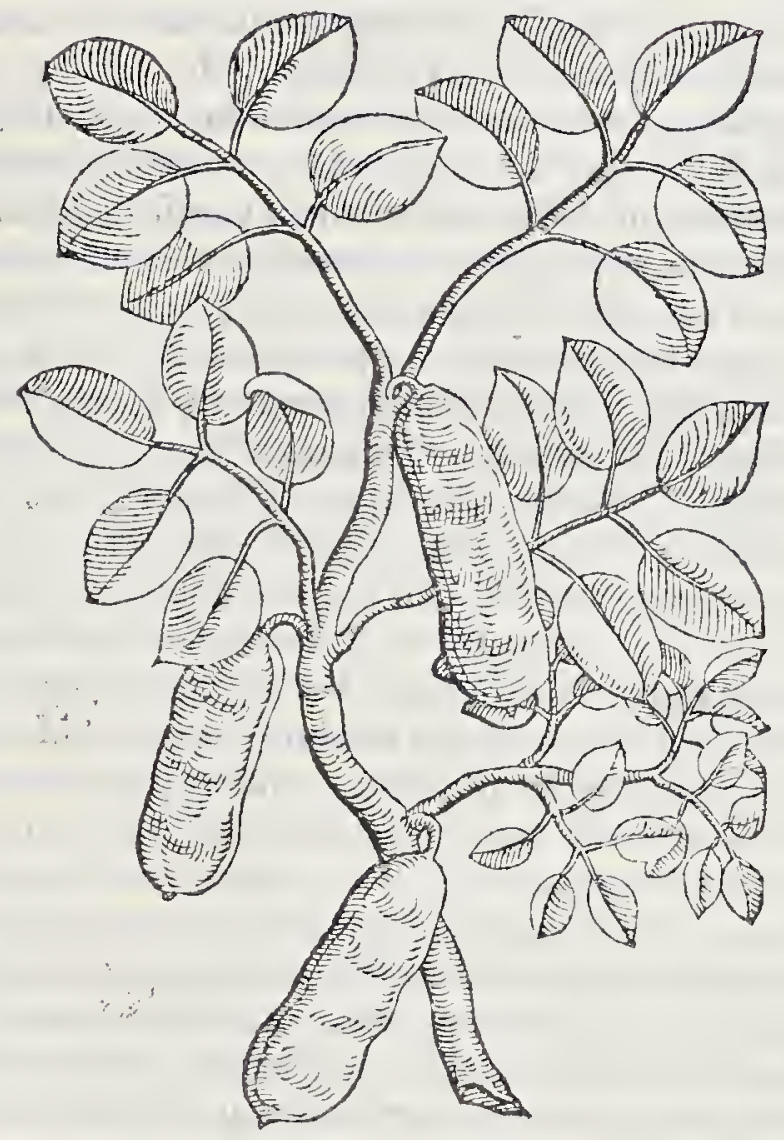

\section{DecAcacia Cap. 1111.}

\section{A I $\quad \mathrm{P}$ I $N$ V $\mathrm{S}$.}

Q7. If C A C I A, quam Sant Aegyptij appeilant, in Aegypti TSy locis à mare remoris nafcitur: huiusć; arbores copiofif(3) five in montibus Synai, pene rubrum mare politis pro - veniunt. Crefcuntque ad mori magnitudinem, ramof que furfim latius expandentes; quod etiam Diofcorides admo suit, 


\section{DE PLIANTIS AEGYPTI}

mit, dicens, aj borcm non in rectum fe attollere. Caudes quanta ef prun magnirudo cenitur cörticemque haber nisisum, afperum, malcis acutiffmis fpinis munitum. Atbores, qux in predictis montibus fpectantur, fpinis albis horridifimx exifunt, afperrimoque Cortice trücus cernitur: Folia oblög a parva muntifsime incifa ha het, tanaceri proxima. \& Flores partos, pallidos fubfauos, atq; ctiā albos, rotundos, paruos lanx loccos imirantes, platani fitudibus forma planè fint is his tamen lone minores, in hil aliud fios hu infec arboris uiderur, quàm mollis lantyo pariú ro:üdumq́ne globulum eformans, non ingati eftodoris. W Cayri aluntur, fores habent fimos uel paliidos, \&e çue funt in möribus Arabię,albos. Ex florbus filiqux lupinorum am ile proferuneur, iplis neruntamen minors, inprimis uirides, \& nox nigre apparent; qux fomina dulcium filiquarim feminibus funt fimilia, sx in hiliquarum folliculis funt condufin. folla, Bores, ac fructus guftm afperitate mula ac ftipricitate f riunt . Ex immaturis filiquis, uirdibus fuccum exprimunt, quem enquant, un indurent. Nónulli eriam ex filijs,foribus imperf itis ficcum parant, fed eo eft hic bonitate inferor. Cayri Corarijad denigrandas pelles multam copiamilliutee fucci abfu munt. Huius aboris mas atque fomina reperitur, Mas quiden. fpinis eft horridus, futetus non edit. Femina fpinis parcioribus, mollioribusque refera ef, eaque intra ramos non habet, fed tantùm extra. Q ne abor elf fęcundifima, A rereq; oricncibus Pleiadi bus, Nonembrio Menfe incipit, ix rurfum iffem occidentibus; feili cetmenfe Murto.bisque in anno fruetus fert, atque matura. Sthe dubio hanc arborem of neram antiquorum Acaciam, tel finam. Aroyntiam, ex notis afimandim ef: precipueóne quin nulla alia arbor finofa in Acegpto repericur, qux magis notis acicion triburis refpondear, arquemulo magis quod illi Kachan quoguis nominant. GVILAND.Hinc ego mulos non poffun non whe

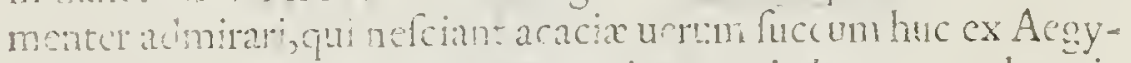
po querdir comporari. Nanc enim pauci pharmacopale cxifunc Pur, hite Venerij, qui cum fuccum ignorent, quem Oricntalem acation anpllane, ad illuferefurci, quem multi pro acatia fublitum:- differentiam, qui ex fyluefthus prunis à quibufdam Farm. Veque minus etiam miror nomullos, quod hanc platum. non i Clarisimorum Venetorum confulummedicis,uel pharmacopolis in Aegypto mulios annos uerfacis acceperine, potiufyum 


\section{I B E R:}

ex Grxcia, quam acatix feracem fuife nemo antiquorum dixit, ve luti multi, quòd in Acgypto hæc planta viuat, fpinam Acgyptiam ipfam nominarunt: Huiufmodi itaque plantæ genus nó ex Gręcia ut Andreas Mattheolus Bizantio fe habuiffe ait, in quio tamen non parum deceptus fuit", fed ab Acgypto foret petendum, in qua omnes fcriptores acatiam copiofifsime prouenire affirmarunt . Tibiq́; zcatix illam imaginem, quam Mattheolus pinfit, planè falfam efle notifsimü ex dictis puto. A L P I N. Aliud de acatia erit animad. uertendum, quippe multos fic etiam erraffe, ut putarint gummam, quam arborem hanc ferre multi meminerunt, apud nos utique nó reperiri, neque ex Acgypto veram comportari, quod ipfam forma vermiculari conftare Diofcorides prodiderit. Gummamque hanc, quàm falfo Arabicam appellant, aiunt, e fle $\mathrm{f}$ milcm potiusaliart $m$ arborum, quippe ceraforum, prunorum, perficorum, pomorum, pyro rumque gummis . Quare veram Arabicam,vel Aegyptiam, quix in Caudice acatix arboris, ut fcriptores herbarum prodiderunt, gigni tur,nequaquam reperiri. GVILAND. Quid tu ea de refentis? cgo nero horm efle nugas puto. A L. P I N. Hoc certe fcio, me frpifsime hifce manibus Cayri in Viridarijs multis acatixarboribus refertis, ex ipforum truncis multam collegiffe:ac pręfertim in Viridario propè ędé Veneti cófulis pofito, in quo funt multę arbores acatiç;ex quibus Gúma manat,pace Diofcoridis dixerim,nö tota, fed pauciffima, quę vermiculari forma fpectetur, neq; tota alba,ac clara. Vno etenim colore, ac vna figura neutiq; omnes acatix arboris gummę fpectantur.talemq́; formã uel figuram accipit gumma, qualem motus fucci è cortice manantis fit, nam interim ubi ad modum eft craffus, non multum deorfum mouetur, fed natim ferè excretus coalefcit, granofaque gumma tunc fit, tenuiore vero fucco exeunte, multumq́ue fluxili, aliquaudo oblongam gummam reddit.atque vno verbo dico, me videffe gummas acatiarum, figura atque colore plerasq́ue cerafarum prunorum ue gummis haud diffi miles. Præterea fies quoque, totam gummarum quantitatem, quæ ad nos ex Aegypto conuehitur, effe acatiæ arborum:quando nulla ibi arbor fit hac excepta, qux gummas educat.Aegyptus fiquidem ac Arabia, prunis, cerafis, pomis, atque alijs gummofis arboribus om nino caret. ex quo non ex alia, quàm ex acatia gummas Arabes ac Aegyptij colligunt. G V I L A N D. vera loqueris, fed dic quęfo etiam eius medicos vfus, quos tu apud eam gentem probè obferua.

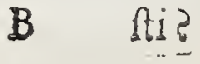




\section{DE PLANTIS AE GYPTI}

- $\mathrm{n} \div$ A L P I N. Aegyptijacatic arboris utuntur fucco, ex fitiquis immaturis cxprefro, vel ctiam ex floribus, folijs, uel ex trutibús ctian. Succi haius ufus apud eos frequentifimus eft ad oculos roborandos, eatue ab infammationibus, quiv ibifunt frequentiffimx, tuendos:ad oris, auriumq́ue omnia vlcera.nec non ad labiorum fiffuras. ad dentes collabentes roborandos, atque firmandos. fucco in pliluercm redacio, pofablutionem ex decocto ciufdem fucci, vel folionm vel florum parato, factam, vtuntur fupra gingiuas afp rfo, ac co dentibus confricatis. Säguinem fpuentibus diag mam fingulomane aliquo liquore diffolutam, potandam offeunt, mirasć; ad quancumque fangtinis Auxioncm fumandam femper vires habuiff apud cos cognium eft. Ego fepifsime hoc folo auxilio multas mulieres ab immodico vteri profuuio penè mortuas reuixiff, atque fanatas fuffe cero feio. In ijs quidem, que has immodicas patiuntur vacuationes, clyfteribus ex acatie folionim;florumque decocto paratis, in vterum iniectis vtuntur atque ctiam fucco puluerizato, prędicto cum decoeto diffoluto, atque immiffo. In alui Auxionibus eodem modo zũ clyfteres frequentät, tü per os fuccum fęliciter exhibent. Ad anum,vterumó; foras procidenté fucco difoluto cum foliontm, flarum que decoeto, nihil habent pre stärius, ac fiequentias, quo vtancur. Ad eos, qui ex quarumq́ue cau fa articulos debiles habent, fomentum, ex 1jsdem omnibus paratú pro profentaneo auxilio habent. neque imerito.cum acatia prçua lidisfinat adfringendi vi predita fit. Omnes eius fomento vtuntur ad defendendos articulos ab humorum decutfu. atque non minus in ijfdem tume factis; atque intlammatis, prafertim in princi pio dim himores adhuc in curfu cxiftunt. Hincque ufus ad podagricos dolores fr quenifimus eft, maximanque uim habet aca tia, ut à podagricis incurfibus homines praferuct. Non defunr, qui ad ca mala non modo foris fumenti, ucibalnei modo acatia uturitur, uerum ctiam fucci modicum per os fumere ante fuxionis tempus prealiquot dies confuefount, ut ipfe interne uix anguftions factx minus curfui humorum pareant. Aliqui; stiam cy frcco acair, a que aceto linimentum parant, ad liniendos areiculos debilitatos, quo fanè mirifice eos roborant, ac fir mant. Mutos noui recenter à podagra tentatos, vfuafiduo acatix planè conualuifl:; qui finguiis diebus per horam ad minus pedesin decosum acatie calidum derincbant; coq̣ue fomentabătur, pedesque 


\section{I B E R.}

pedesq́uc abferfos linimento ex fucco acatix, opobalfamo, accto. que parato ctiam inungebart. Ad pudiendorum, alianmaque debilium partiã alcera difficilia, fucci aqua pluties loti poluerizati ufus

ct illis faniliariffimus, decouto etiam uruntur, ad exficcandas puftulas omnes, prefcrtimq́ue Gallicas, fed deco. Etum parant ctiam cum modico ligni Guaiaci. In pueris etiam ad acores in capite orientes, \& decoeto, \& pulucre utuntur. hicque acatix eft ufus apud cam gentem nunc frequentatus.

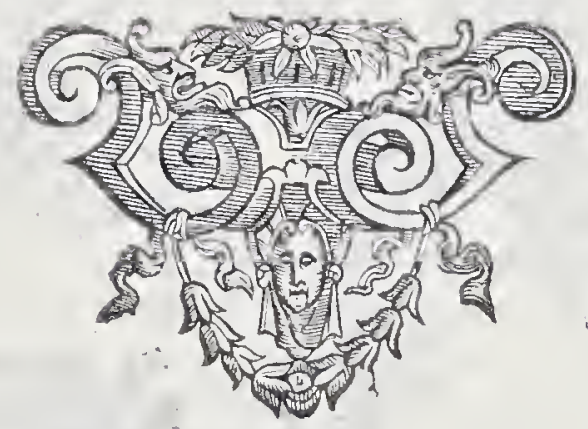

$B=A C A$ : 


\section{DE PLANTIS AEGYPTI}

\section{ACATIA, SANT, ETKAKIA:}

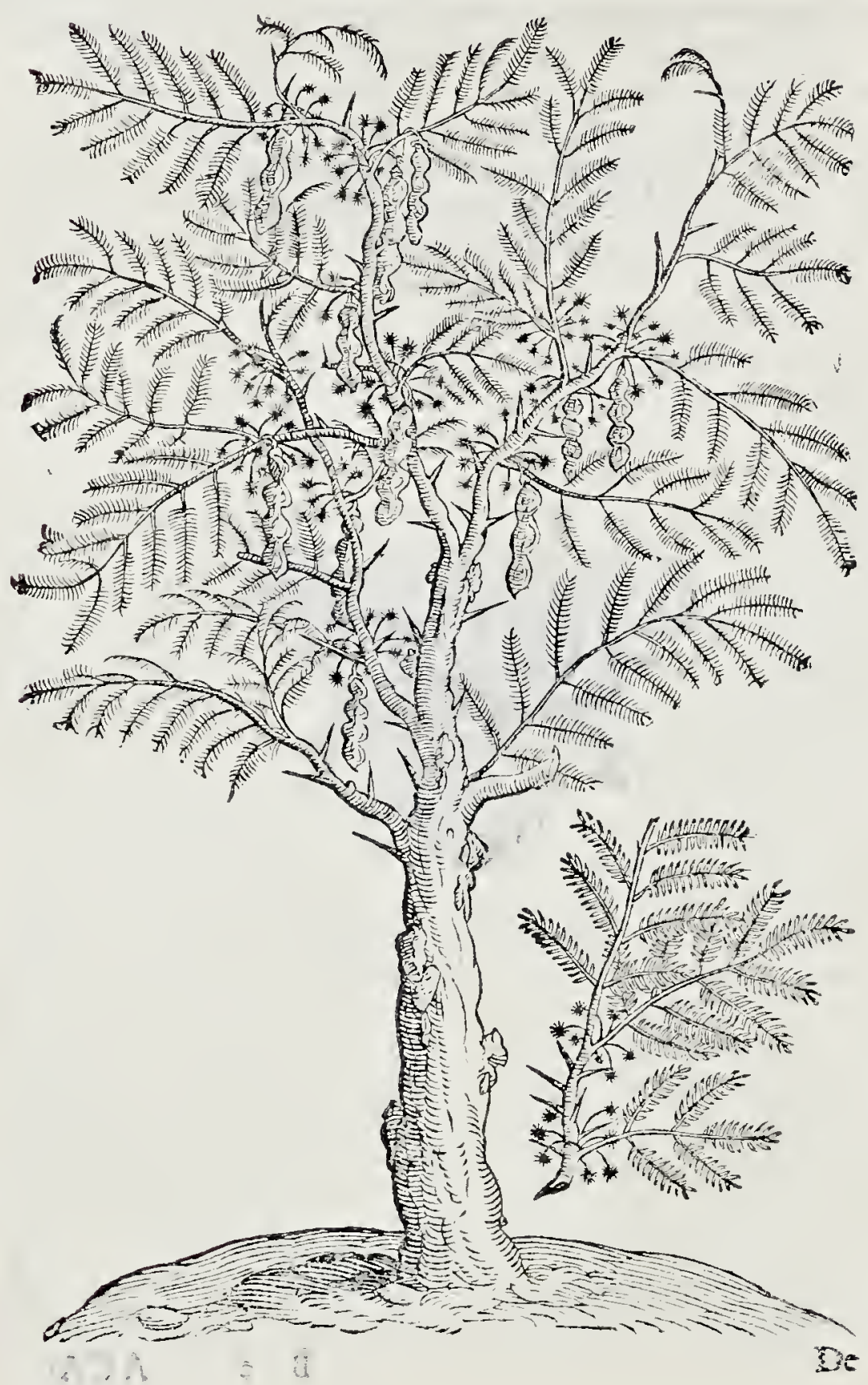




\section{I B E R.}

\section{De Paliuroe Athenai, Nabca appellato. Cap $V$.}

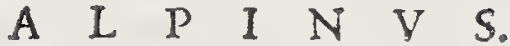

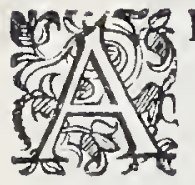

R BOR in Acgypto, quam illi Nabca dicunt, loti magnitudine fpestatur, inftar acatix fpinofa, folia ferens iuiubę proxima, ueruntamé latiora, \& fores iúubę flori bus quoq; planè fimiles, albos ac paruos, à quibus erum punt pomula rotunda, odorati, dulcia,guftuiq; ualde fuauia, $c$ crafo. rum maiorum Marofticenfum appellatorum $x$ mula, quę apud primates Aegyptios,ac Turcas funt in magno pretio. Arbor bis in anno, fcilicet vere, ac autumno floret, fructusq́ue maturat, frecund iffimaq́ue exiftit, veruntamen uere fructus non perfecte maturant, nec,ut in Autumno perficiūtur,pleriớ; enim ipforũ prius putrefcút, quàm maturefcant. Autumno perfecti fsima ac optima euadunt. G V IL A N D. Sine dubio hanc arborem effe paliurum \& connorum olim ab Alexandrinis appellatum, Athenęi foriptis confat. De qua arbore fic in lib. r 4. Ccripfit: Meminit de ijs Agathocles Cy zicenus his verbis hbro hiftoriarum patrix tertio: Cum in fepulchrum fulmen irruifet, arbor ex tumulo pullulauit, quam illi conno rum nominant. Ef autem planta vlmi picexáue magnitudine, nihil que minor. Truncos habet frequentes, \& oblongos, fpinasq́ue paulum proininentes : Folium eft tenerum ac viride, phyçque fimillimum. Fruetum bis quotãnis producit, vere filicet, ac Autumno, qui dulcis eft omnino, \& oliur, oleaftrique ftuctui fimilis. Carnem ofque illi fimile habet: at diff.rt, fucci voluptate, cuius fructus etian viridis comeditur. A L P I N. Sine dubio puto prędictam arbo rem effe cannorum, fuc paliurum eandem, quam Athenẹus prodidit. etfi fructus ofque non uideatur omnino fimilis Nabca fructui, ac off, quando ij fimiles pomis fint, offaque rotunda, \& non oblon $g a$, qualia in olinis cernuntur exiftant . Nufquam tamen in Acgypto ex ficcatis illis fructibus farinam ficri apud eos animaduerti. Sed precipuus vfus ipforum eft recé i.m, ac viridium pro cibo.eis fiquidem omnibus, atque noftris, cerafa mandere, confuetndo eft. Sed nunc ad eius vfum in medicina explicandum tranfeanus. G V I L A N D. Fruttum vfum effe videtur, Arabibufq; notiffumus, de quo Serapio fic fcripfit. Sadar dux funt fpecies, vna efs

. 


\section{D) DLANTIS AEGYPTI}

$x$

frmandam ad que mała fuccum etiam ex ipfis immatur is $\mathrm{ex}$ prefum, fumliariter tum per os fumptum, tum Clyferibus inicetú fequneur.ventur etiam ijfdem fruetibus ficcatis, atque in aqua in fufragua enim infufion is ipforum vtuntur, ut distum ef, ad relaxa ticnem incefinorum, atque etiam ad ulcera inteftnorum.Sed ma turorm ficatorum decostum, uel infufio familiarifsima eft ad on n's peftictas febres : aiunt enim hos fiuctus miram aduefus vene nofas qualiutes, \& putredinem efficaciam habere, corr; Atrenue ro borare. Succus perfecte maturorum optimus eft ad purgandam bilcm à itomacho, atque à primis ductibus venarum. In ommibus putridis febribus infufione ex ipfis parata libenter ad fedandum ca lorem utuntur. Efui fumme iucundi exiftunt hi fructus, prexcipueque maturi, tamen parum nutriunt, facileque, ut cerafa, in ftoma. cho corrumpuntur, fi immoderate ipforum cfui indulgeaturs, ftomachusquue offenditur. GVILAND. Non defunt multi, qui ( neque immeritò) inter inubas hanc arboré recenfent, quo factum eft,vt mirum non fit, aliquos ctiam uiros doetifsimos iuiubam paliurum effe vo. luiffe.Sed arboris huius nunc detegas

figuram.

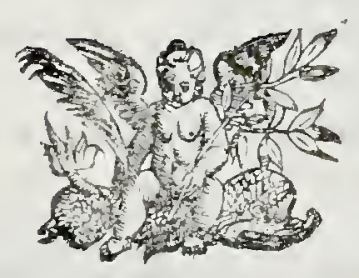


I. I B E R. : 8

NABCA PALIVRVS ATHENEI CREDITA

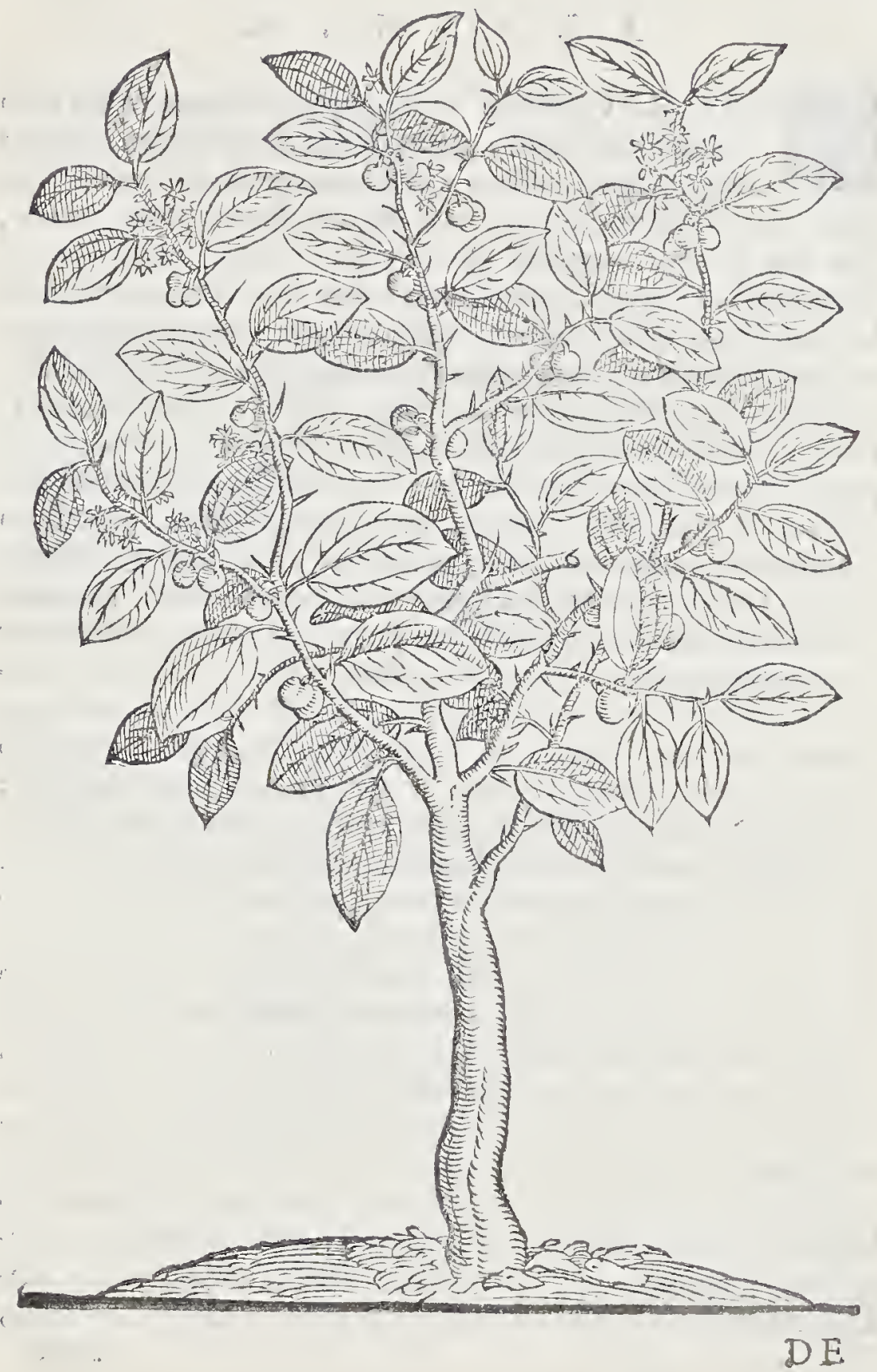




\section{DE PLANTIS AEGYPTI}

\section{De Sycomoro Giumez vocata. Cap. VI.}

\section{A I $\quad \mathrm{P}$ I $\mathrm{N} \quad \mathrm{V}$ S.}

\section{(1)}

$R$ B O R valtifima ab Aegyptijs Giumez vocata, in Aegypto prouenit, quam noftri Sycomorum, ac ficum Aegyptiam appellant . Hanc proceram arborem in arenofis, fterilibusq́ue Aegypti locis Natura fagacisfima perduxit, fub qua poffent homines ab iniuria radiorum ardentium folis aliquando fe tueri . Maxima fiquidem arbor eft, ramosq́ue fic latifsime fpargit, ut magnam umbram viatoribus prebeat, qux in huiufmodi calidis locis, arenofis, ac ferè folis calore inflammatis, libenter expeti ab omnibus foleat. G V I L A N D. in lib.2. de alim. facult. Galenus fcripfit, fe Alexandrię Sycomorum uidifle paruę ficui fimilem: quamobrem crefcentis adhuc,iuuenisque $S_{y}$ comori, \& non adulti magnitudinem fpectaffe arbitror:quod tam grandem arborem, omnibus communcm, ipfe non animaduerterit . Diofcorides melius ipfam defcribens, dixit. Sycomorum aliqui etiam ficaminum, ideft morum uocant, cuius fructus Sycomortim, propter incficacem guntum appellant. Arbor eft magna, fico fimilis; frondofa, multo lacte abundans, folijs mori, pomum ter, aut quater amno fert, non ramis, ut ficus, fed caudice ipfo caprifico non diffimile, dulcius groffis, fine granis interioribus: quod non maturefer, nifingue aut ferro fenlpatur. A L P IN. Hac defcriptio ueram utique Sycomori figuram exprimit, fed ubi air, folijs moriadderem crafloribus, candidioribus, atque afperioribus, quod tace folia non nifi magnitudine ac forma, à ficus fo lijs differant. GVIL A ND. Vnde Aegyptij dicunt tantam hanc arbore habere cum fico \& moro fimilitudinem, in qua utrurque fogra fpeetatur? A L P I N. Infitioncm fici fupra morum flures illorum affrmant, ucluti Muram infitam quo que fuiffe cannẹ faccharu ferentis fupra radicem colocaflix aliquibus eft fuafum: quod tamen nondum experientia verum effe didici. Sine dubio in hac arbore, truncus, rami, cortexq́ue ipforum, fructus, lac, foliorum afperitas, colorque fici apparet; \& foliorum figura, magnitudo moro refpondet. Fructusquue tarde, neque perfeete maturefcere, atque faporem aqueum \& iucundum habere: hinc aiunt, 


\section{I B E R.}

mori frigiditarem impedire, quominus fruetus perfectrm naturarionem confecuantur. Huc arbor, ut muiti etian meminermat, fic eft foccunda, ve nunquàm multis fructibus carcat, qui caudici adnafcuntur, minimeq́ue ramis, neque fructum hxe arbor producit,nifi prius multis verberibus frepe laceretur, fic ut candicis quoq; cortex vulneretur, ex quibus uulneribus lac continuò exit, unde ra mus paruus, ficus ferens interim ternos, interim quinos, interim feptenos, \& plures ctiam. Hæc arbor ex feminibus non nafcitur, cum ficus feminibus careant, fed ramis infertis propagatur, eftéue exijs, qux citò crefcunt, diutiffmeq́uc, quod mirum uidetur, viuunt. Quxpiam Sycomorus in Mattherea uifitur, qux fic ab habitatoribus credita eft antiqua, ut omnes pro certo habeant in il. lius trunci cauitate quadam olim Verginem beatifimam, iram $\mathrm{He}$ rodis Hicrofolima fugientem, illuc fe recepiffe, \& Chriftum puerulum Seruatorem noftrum per multos dies occultaffe: ex quo ca arbor apud multos in multa ef veneratione, maximèque cius trunci meatus, qui Chriftum occultauit, quem ipfi Dei magni fpiritum fuiffe fatentur. Fabulofum of quod dicit Matthxolus, truncos ramosque huiufce arboris nunquàm ficami, ni prius in aqua proijciá. tur, \& morentur aliquantulum. Vfus ficuum in cibo eft ftomacho nocuus, ipfumque laxat, labefactat atque fubuertit . Eos uero ficus utiliter comedunt, qui uel itinere, uel fole incaluerint,refrigerationeque opus habent, \& humectatione:fructus fiquidem hi

frigidi temperate exiftunt, multumq; humidi aluum facile lu

bricant, atque relaxant.tumores omnes calidos, atc; du ros ficubus emplaftri modo vf fanant. Pauci funt, qui fuccum,ut meminit Diofcorid. ex trun

co vulnerato colligant:affirmant tame

prefentaneum effe auxilium ad

emolliendos fcirrhofes tumo

res, atque ad peftem non

ignobilem ufum

habere. 


\section{DE PLANT'IS AEGYPTI}

SYCOMORVS GIVAEZ A PIELLATA.

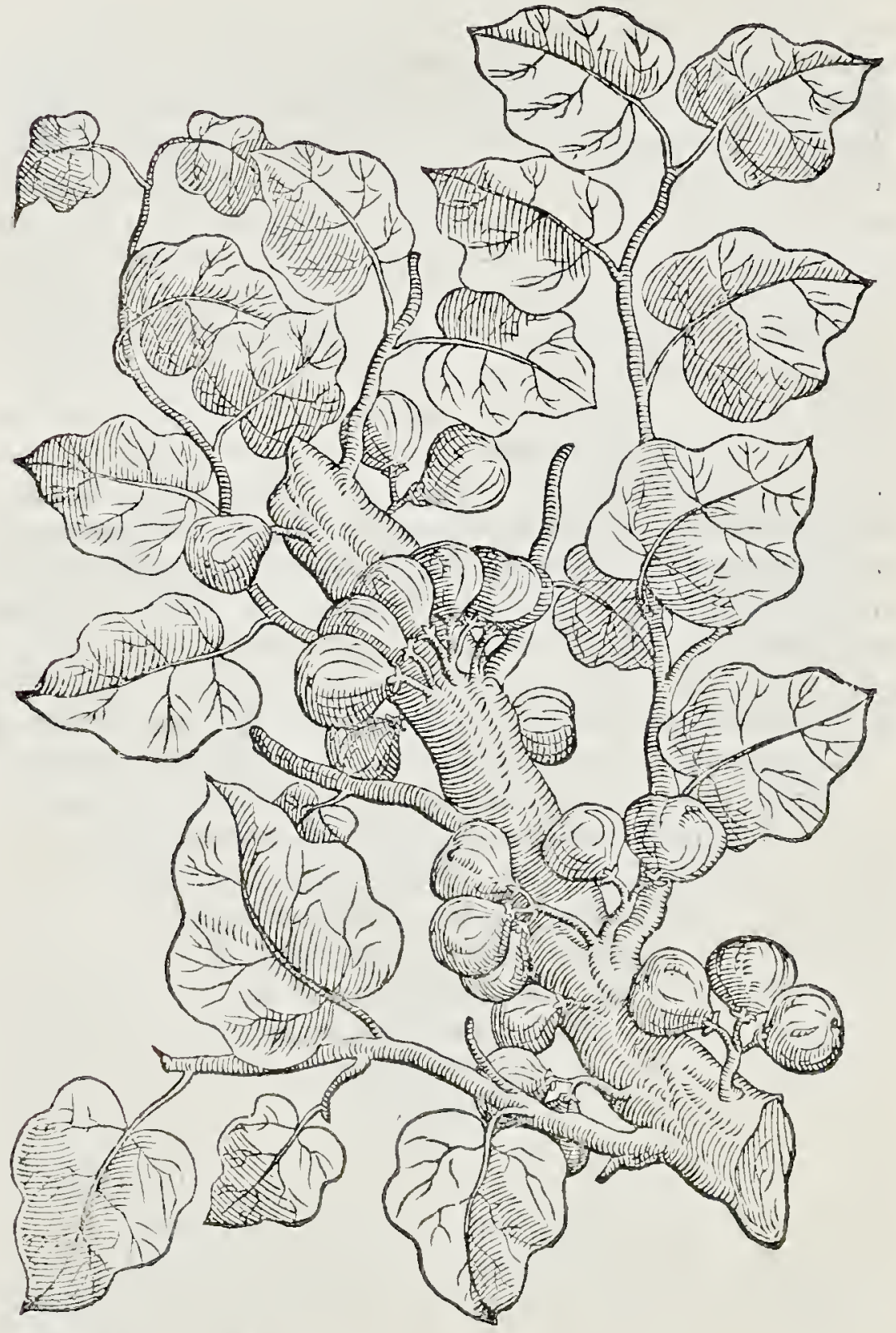

De 


\section{De Palma Dachel. Cap. VI1.}

\section{A L P I N V S.}

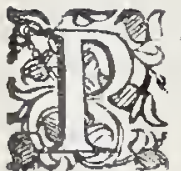

A L.M A notiffma eft arbor non modo Aceyptijs, Ala bibus, Syris, alijfquè orientahbus populis, fed Iralix quoque multis populis, de qua ob id paucis mihi agen dum puto. Arbor eft fimplici caudice in reetrm fe atro lens, uiginti paffum \& amplius altitudine. Folia enfibus fimilia habet, deorfum cannarum modo decidentia. Vere floret. Ramus enim quodam inuolucro oblongo, veficx modo, ad ver vfque claufo, \& tunc aperto preditus, flores emittit paruos, albos, odoratos raccmatin deorfum ab inuolucro refidentes, ac pendentes. Martio fiquidem menfe in uolucra illa fuis alis adligata aperiuntur, è quibus globus filorum infinitorum profilit, forefque his filis, vel capil lamentis appenfi cernuntur, à quibus dactili parui virides, vuartm racemos immitantes producuntur, qui Autumno maturantur.Varij hi fructus inter fe obferuâtur magnitudine, figura \& colore. Alij ctenim oblongi magni, crafsi, perinde ac pruna alba (qux Iulio menfe in agro Baffanenfi maturantur) fpectantur. Alij funt parui, longi,glandibus quercuum fimiles, alij rotundi, craff. Alij virides alij albi,alij Haui,alijq; rubri, immaturi omnes guftu afpero ftyptico què feriunt, maturi dulcifsimi.qui vero propè funt, ut perfecte ma turentur,guftum Caftanearü,dulciorem, fuavioremquè reprehefen. tant. H.xc arbor alternis tantum ann is copiofiores fructus edit, neque (quod dictt valde mirabile videtur) fomina concipiunt, ac fructificăt, ui in ramis maris foeminę ramos aliquis permifcuerit,ac fe quafi of culari permiferit. Plerique fominas ut foecundent, non ramos, fed puluerem intra maris inuolucrum inuentam fupra fomi narum ramos, atque cor fpargunt, vel alij fores maris pulueris loco fpargere folent. ni enim Aegyptii hoc fecerint, fine dubio foemi nx vel nullos fructus ferent, vel quos ferent, non retinebunt, ne que hi maturefcent. G V I L A N. Haud credendam iftam palmarum conceptionem, quę fit arte à te narrata, arouere videntur innume ridakili, qui in Arabix defcris feruntur; in quibus fyluchrium palmarum fylux reperiuntur, quę finc homintim cultu optimos fructus ac copiofos producunt, retinent, ac maturant, ex quo iudi- 


\section{DE PLANTIS AEGYPTI}

co feminas ad focuditatem moucri non ramis, vel pulucribus,aus floribus mirium, vt Plinius, atouc alij quoque meminerunt, fed magis non fecus qlam alix arbores radicum marium, atque forminarum contactu facere folent, fe ad focunditatem parare . A L. P I N. Arabes palmarum cultus periti refpondebunt, palma rum foecunditatem in Arabiç defertis, licet arte non far (quando in his locis ha arbores, vt dictun eft, fune vlla cultura fruetus producant)adiumare ventos, maritum è ramis pulueres, forefquè ad ramos feminarum afportantes. Radicum veriuf; fexus palma. ram mutuan conithetionem efle conceptionis cautam, dicendum non puto, quando fic breuioribusradicibus palma omaes donate fint, ve ctif fere fimul cohæreant, nullus tamen radicum contaetus inter eas effe polnt mirabilećue dictu, palmarum altifimos valtinmosćuecaudices feu truncos poffe fic breuibus, tcnuioribus, paucioribusque radicibus in aercm fubfifere, neque fua multa grauitate, ventisque ctiam vehementibus ficpe ipfos quarientibus humi có cidere. Accedit, quod caudicis poftrema pars humi proxima,pó dus totius arboris fuftinens multo gracilior, atque debilior reliquo candice criftit. Hinc plures Acegptiorum hoc miraculo duEti dixcre,palmas nó tera radicibus attrata , fed acre ex fublimio ri arboris parte ali, ac viuere. quod hac etiam coicetura fibiipfis per fuadent. Quia fi palme fublimior pars, quam cor ipfínocant, excida sü, vniuerfam pluntam ilico arefere obferuarüt:quo d non accidit. inferiori radicum concifa parte. Non eft alia vlla arbor palma humano generi vtilior, fiquidem ex truncis domorum trabes faciunt, ex ramis, parictes, multaq́; alia lignca vafa ad vum,que Cuffaz no minantex folijs flabella \& fportas, è caudicis cortice funes pro na uibus.fructuum verò vtilitas faris omnibus nota eft. Sed quem ipfi ad medendum ufum habeant, nunc quoque dicam. Ex fructibus tria funt praxcipue, quibus fanitatis gratı vtuntur, quippè fpartum, puluis fparto, ucl inuolucro contenta, atque dactili . lpari igitur membrana tum puluis facta vtuntur, tum ex ca parato decocto. Pul uis maximum vium habet per os fumpta ad Diarthecam, lienteria atque dyfenteriam, nó minufq; ad omnes alias vel fanguinis, vel alteritis humoris innaturales vacuationes firmandas: prxcipue verò ad hepaticum fuxum, hemorrohidum, atque vteri cruentam vacua tionem, at que ad fputum fanguinis. Hoc puluere quoque vtuntur ad fumanda vicera cepafcentia $a_{3}$ d vue selaxationem, ac ad denriux 


\section{I : B : E R}

commotionem. Decceto ad omnia predicta quoque vtuntur, fed fxpe cum co mifto predictó puluere . auticullos débiles apsosq́; fiuxionibus mirum in modum iplum iuuat, eos frrmando \& roboran do. Puluere vero albo in inuolucro veris tempore inuenta, quando fcilicet palmx forere incipiunt, vtuntur familiarime, ad faucium raucedinem, tuffum, \& ophtalmias cí faccharo mifto. Eftque ipfe dulcis fubadfringens, mulicres eum habent familiarifimum, ad firmandos menfes retinédumé; fotum. Eundem vrique vium ha bent dactilı immaturi tum in cibum vitati, tum ipforü decoetĩ , ad fpütum fanguinis, \& quãcumq; fanguinis vacuationé cohibendã: \& ad lienterias, diarhxas, \& dy fenterias:ad uomitü fangunis, hxmorrhoidas exiccandas, atque ad vicera vulneraque fimplicia perfanan da . in frequeutiffmo vfu ad nuper dictos affectus habent fyrupum ex dactilis immaturis confectum.ijfdem dactilis vtuntui probe maturis, qui tunc admodum dulces exiftüt, cum obfcura adfrictione idcirco eos frequentant ad faucium raucizatem, tufim, difpnxam, pleuritim,ac peripneumoniam.nó minufque ipforum decoctum fre quentatur ad adiuuandas variolarum in pueris excretiones

Vocant arbotem Dachel, \& ramum cui apperifi funt daEtyli Samarrhich, dactylorumq; inuolucrum, dux,

ac dactylum recenter enixum prorfusimimaturum talla, \& grandiorem factum nin,

\& ramich perfectionem fue penc. maturum, Maturumq; bellan.

Siccos maturos tamar, \& qui fere putridi funt rotob, foliag; ar boris Zaafo

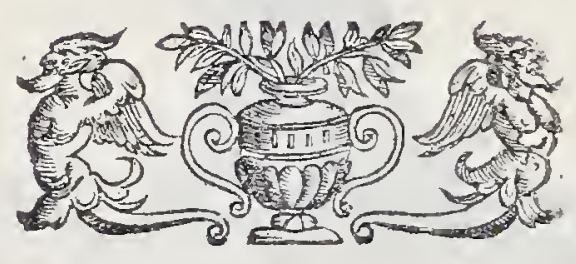




\title{
DE PLANTIS AEGYPTI
}

\author{
I A L M A D A C H E I.
}

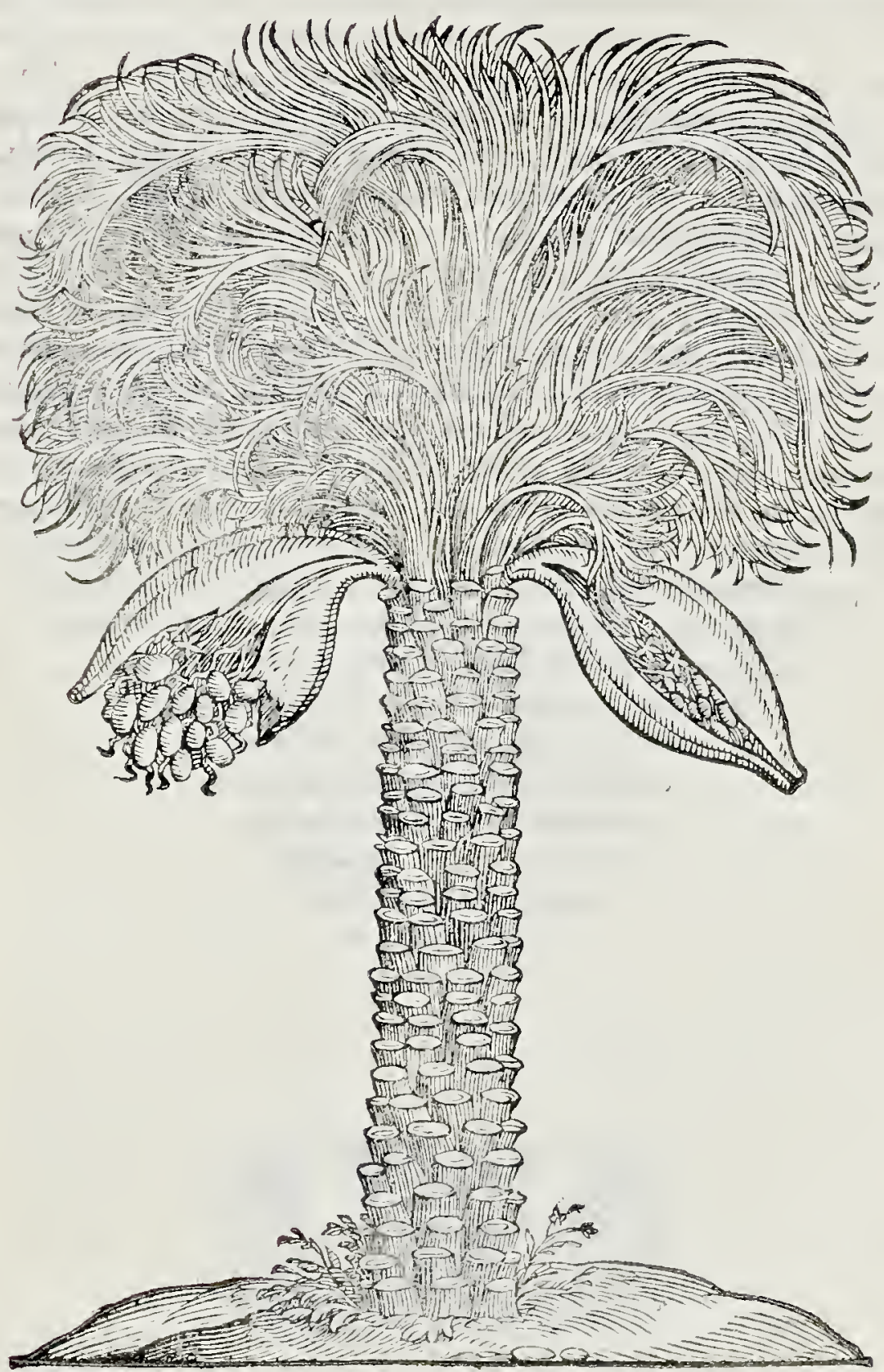

De 


\section{I B E R.}

\section{De Sebeftern. Cap. V111.}

\section{A I $P$ I $N$ V S.}

EBESTEN arboris in Acgypto nafcentis duplex ge nns reperitur, aitcrum fylneftre pruno finile, atque domefticum alterum folijs latioribus, crafforibus a feluefri differens. V traque arbor flores fert albos, paruos, ge ranij proximos, à quibus fruetus crefcunt paruis prunis rotundifq; fimiles quorum nuclei tricoftaci cernuntur. Illa arbor fert fructus minores, tarde maturefcentes, imperfectiores, ijs, quos domeftica Scbeften profert, qui func maiores, melioresćue. toto autem an no in arbore fruetus ccrnuntur. Vcre Aorent, Autumnoq́uc fruetus maturant . ex pulpa ipforum optimum uifenm conficiunt, quippe Scbeften maturos contundentes, atque lauantes. Sunt aliqui, qui matichando, pulpam ab offe lingua expuentes, vifcum parant; quantitatem hornm fructum in uafe collestam, parum quoad aquea humiditas abfimatur, bullientes. Vifco vtuntur omnes cmplaftri modo ad omnes fcirrhofos tumores.ipfe quidem calidus ent in primo gradu, atque humidus in fecundo, vimq́ue habet ateractoriam attenuatoriam, \& refoluentem;refoluit omnes tumores, \&i emollit omnen duritiem. Aliqui ad tunim ex eo paratos bolos clim faccharo candido, \& radicis liquiritix pulucre multis diebus filmunt. Fruetuum vfus familiariflimus ef ad turim, difpnęam,orthopn ęam,pleuritim, peripneumoniam;

$\&$ ard vocis raucedinem, parato ex ipfis deco cto, quo etiam ad multas febres vticon fuefcunt, præfertim pectore aliquam noxam patiente. Sed

nunc de Tamarifco

loquamur. 


\section{DE PLANTIS AEGYPTI}

\section{SEBESTEN DOMESTICA.}

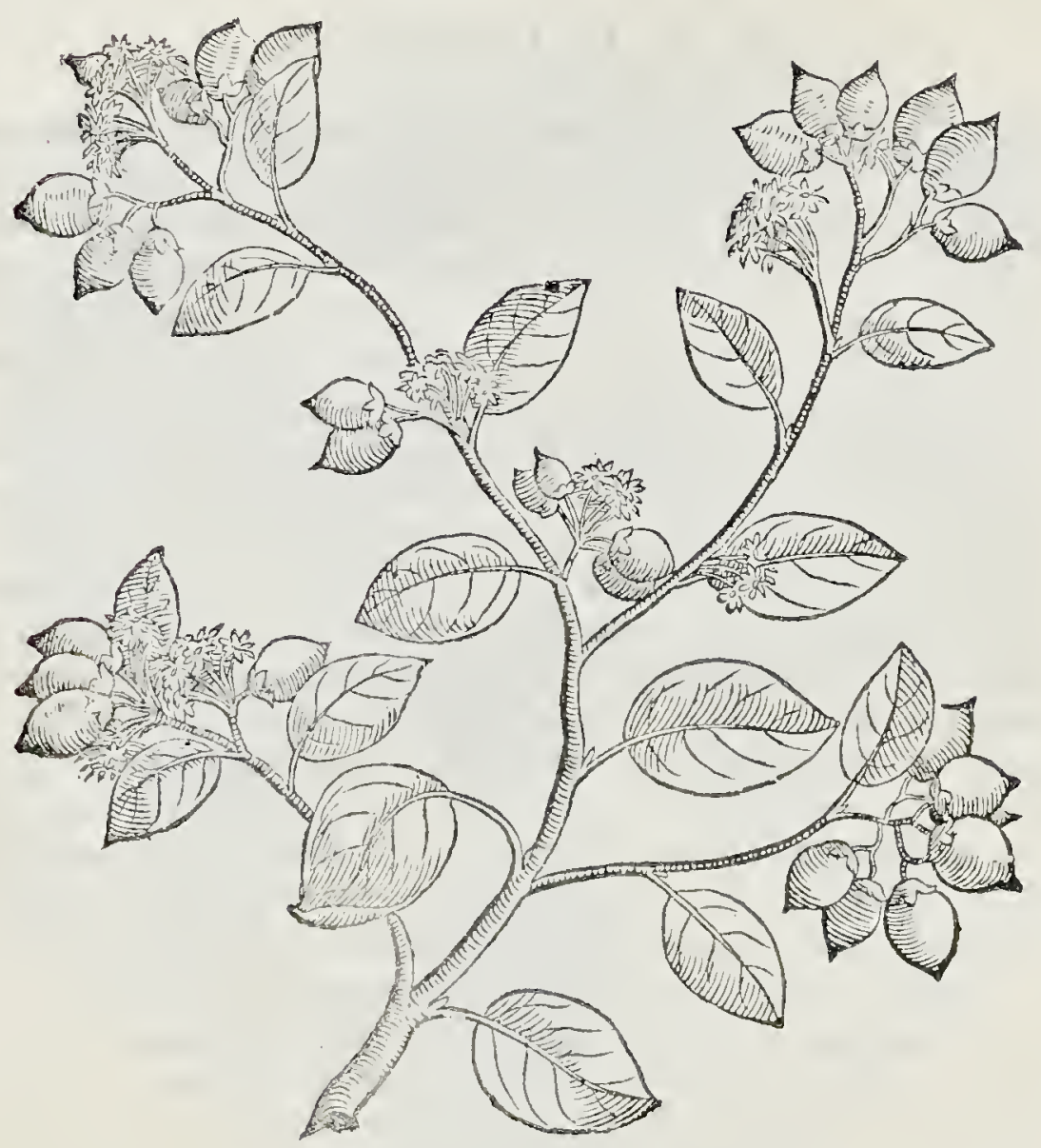

$S E_{s}$ 
I. I B E R:

13

SEBESTEN SYIVESTRIS.

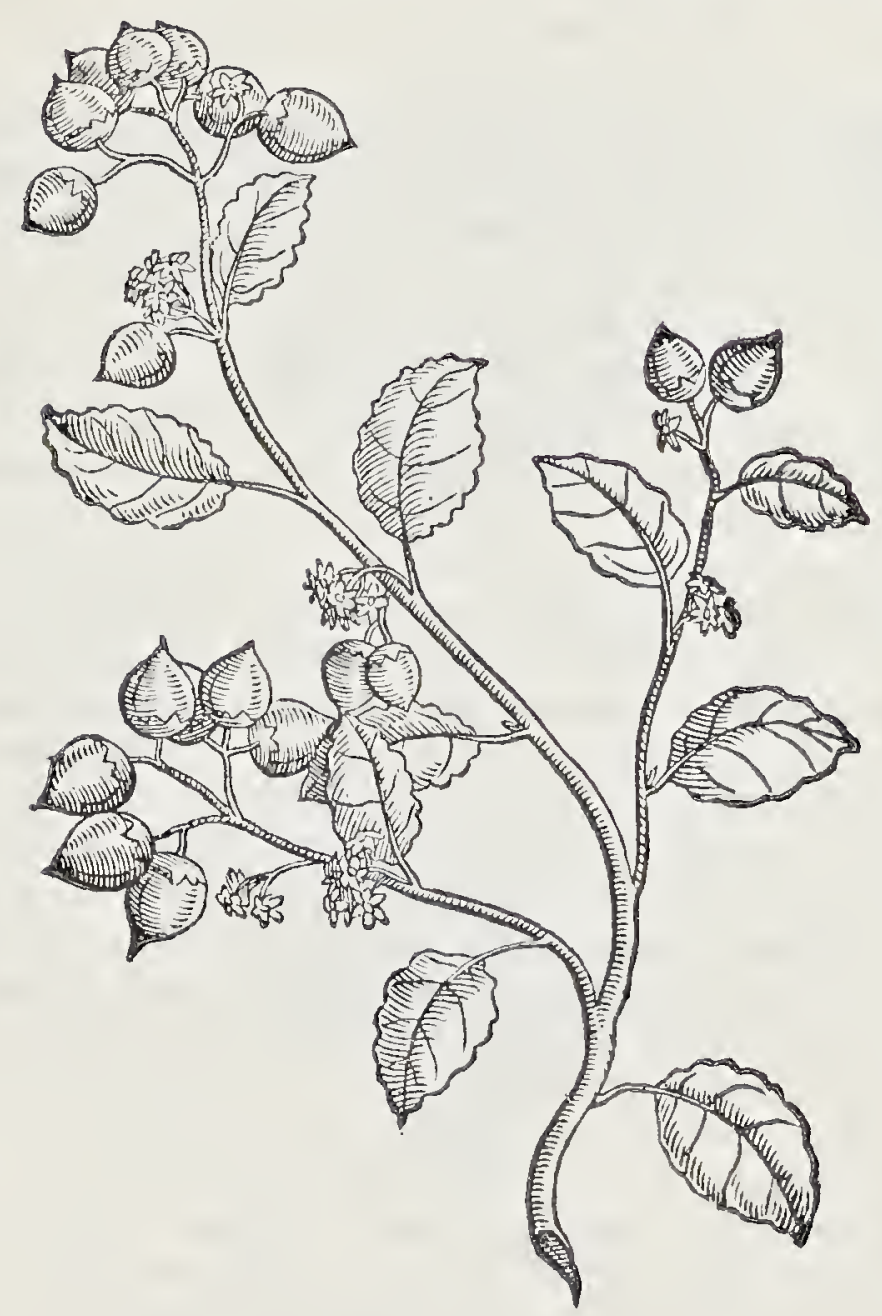

D De 


\section{DEPLANTIS AEGYPTI \\ DeTamarifcoatle rocata. Cap. IX.}

\section{A $\quad L \quad P \quad I \quad N \quad V \quad S$.}

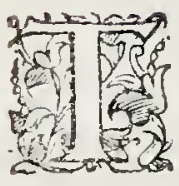

A M A R I C I, quem miricam \& tamaricem Diofcom rides nuncupat, fylueftris genus, Italixe eft nociffmum nafciturque propè fuminum ripas, aridaćuc is faxofa vel arenofaloca, potiusque apud fignantes aquas, yt docuit Diofcorides . de hoc non loquimur, quando ipfo Aceyptus plane carcat. Alterum vero tamarici donefticum genus in Acgypto fpectatu, proceritate figuraque acmodum à lylucfri diucrfum, quod ad magne oliux magnitudinem crefat audioq́ue etiam fupra Aegyptum in loco fahitabijs populisvocato,crefecre ad magnx quercus magnitudinem, cuius ex lignis carbones faciunt, quibus tota Aceyptus, \& Arabia vtitur.cx coque ligno mul ta vafia conticiunt, ad multorum egrotantium vfim. Folia fert fyl. uétris tamarici folijs proxima, tamen longiora, \&z graciliora, appa rentque multa capillamenta viridia, qualia in aliquibus equifetis vifuntur, ramo appenfa, femper virentia, fruetus fert paucos, raros, virides, nucum magnitudine, duros, lignofos, fine nucleo, \& videntur eiufdem fubftantix effe cum gallis: omnes uero figura inter fe differunt, quamquam in omnibus afpera \& inequalis ob. feruetur, quando alij longi, alij breues, alij rotundi, alij lati, alij craffi, alijque gtaciles exiftant. Vfus Tamaricitum in Acgypto, tum magis fupra Acgyptum, ubi horum arborum copiofus eft pro uentus, eft ad ignem maior, quandó nulla ferè alia ligna ad combu rendum habaant. Folia huiufce arboris ufum habent ad lienem in duratom, obitructam, \& refrigeratam. Vafaquè ex ligno, ut dictum ct, conficintur, quo lichofi uti confuefcunt:ob eiufquè multam, qux cx hoc ligno habeturatd id morbi genus utilitatem, mira ri noa debamus î Plinius (quod tamen fabulofum eft) dixerit, fues affuctos cibum capere in uafis è ligno tamarici confectis, liene carere. Mulieres decocto ex Cortice parato utuntur per os fumpeo, ad fifendas menftuas puroationes, ex quo parant etiam infeffones, \& clyfteribus in utcrum inijciunt decootum. idem quo que frutus facere aiunt . ijs fiquiden utuntur in fputo fanguinis,

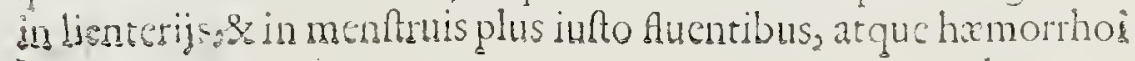
darum 


\section{I B E R.}

darum immodico fuffu dentes eriam commotos,atque collaben tes ipforum decoeto firmant : atque in ijs concitatum dolorem de mulcent . Vtuntur etiam ad oculorum lippitudines incipientes, in colirijs,atque ad oris ulcera. Cinis quoque corticum \& fruetuum ulcera curat. De ligno uero multi decoctum, non fecus quam no ftri ex ligno Indo ad curandam luem gallicam facere foleant, pa. rant, quod exhibent leprofis, fcabiofis, atque alij s multis, puftulis \& ulceribus affeetis, feliciori cum fucceffu.

Idemque faciunt in melancholicis, ictericis

nigris, \& hydropiciš ex refrigera.

to obftructo, ac indurato liene concitatis.arborem

illi uocant

Atle.

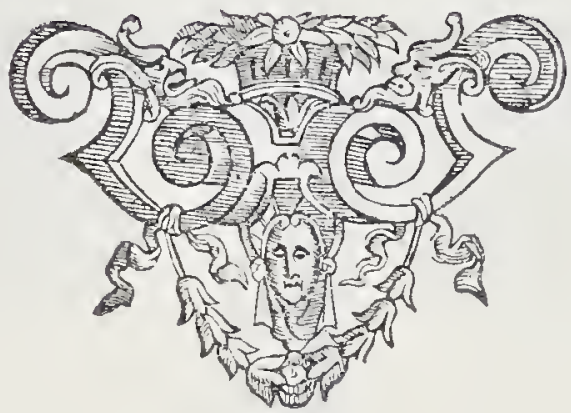

D 1 T A 


\section{DE PLANTIS AEGYPTI}

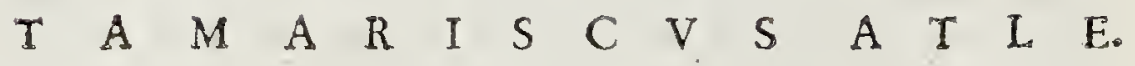

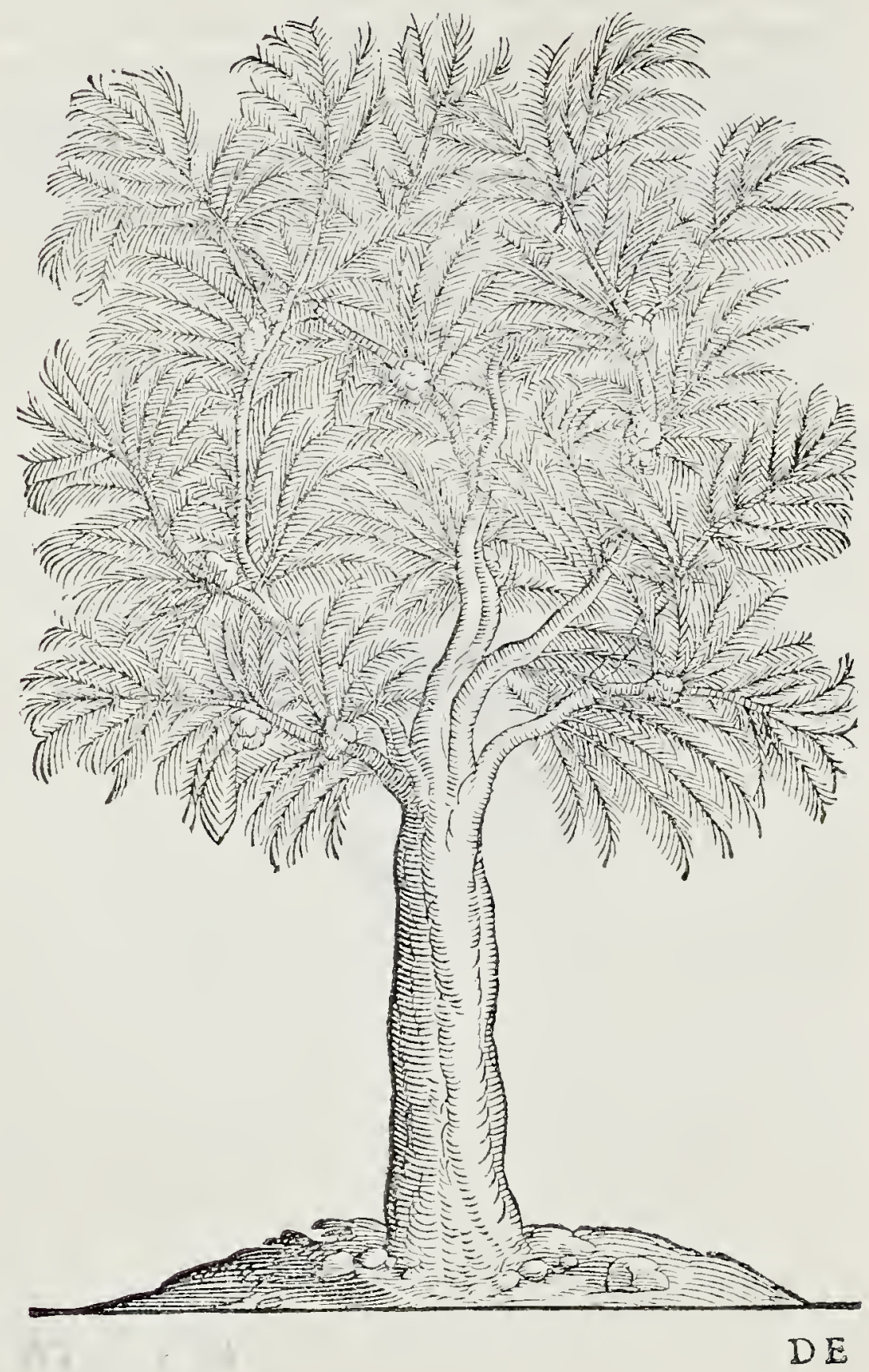




\section{I B E R.}

\section{DeT amarindo derelfide uocata. Cap. X.}

\section{A I P I N V S.}

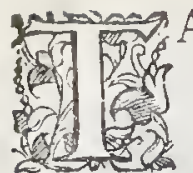

A M AR I ND VS, quem derelfide appellant, arbor eft pruni magnitudine, ramis denfis:myrthi folijs lesbã proximis prædita: flores fert albos mali auräcij foribus perquamfimiles, è quorum medio excunt cuatuor fila alba, \& tenuiffma, ex quibus filicur craffe, producuntur primo uiri des, tandem maturx cincritix, qua intus nó nulla femina craffa in $x$ qualia, duraquè, atq; pulpam nigram gufui acidam, continent. In Aegypto non funt admodum hie arbores copiofix, neq; funt patrix: ex folici etenim Arabia atque ficthiopia illuc conuchuntur, in ui ridarijfq; feruantur. Miraculi loco habetur, quod dicieur, unam arborem in deferto Diui Macharij, propè monafteritim Afiriorim, viuere, in quo folo nulla alia planta uiuit. Hec phanta hoc mirabile habet, quod eius folia folem femper fequnntur, folifo; fequia dicun tur:nä ipfo occidente omnia infe clauduntui, codemó; oriente ape riuntur,atq; hęc motio tantam uim habere in ijs obferuatur, ut fili quas dum habent occidente Sole, cafdem folijs in fe areifinme clau dant, \& retinere fpectentur.eodemq; oriente, apperiantur, filiquafque relinquant. Hanc foliorü conuerfioné plurbus Aceyptijs aliis plantis communé animaduerti, quippe acarix, Abrus, abfus, Sesbá, atq; Tamarindo. Vtuntur folijs Tamarindi in pueris ad uermes necádos, at q; etiam ipforum uel infufo, uel dẹcocto ad foluendín aluí. acida funt folia atc; gutui non infuauia. Arabes códiutr filiquas feu cannas huius arboris paruas ac uirides faccharo, uel melle carnub, tü etiam grandiores factas atq; maturas. condiunt ipfarum pulpam faccharo, quam per itinera, qua in defertis Africx locis conficiút, fecú uiatores deferüt. Qư frepe, calefacti, ac ex calore itinereq; infămati ualde ficientes retrigerantur, atq; ficim reftingunt, per aluum plurimũ calidorú hurnorũ fubducétes arq; vacuantes. In febribus ve rò peftilentibus, atque omnibus alijs ex putridis, exurentibus, aquá, in qua multa copia Tamarindorum infufa fuerit cum faccharo ebibunt:potus fi quidem frtientibus ex:calore iucundisfimus eft, maxi meó;;refrigerat, \& frtim extinguit. Ad omnes deniq; fobres putridas à biliolis, exuftifq; humoribus concitatas, \& ad hepatisớ; atq; renu calefactiones ac infammationes, pręterea ad gonorhęam vfum $T_{3}$ marindorum frequentant; vocant derellide.

$$
\because
$$




\section{DE PLANTIS AEGYPTI}

\section{TAMARINDVS DERELSIDE APPELLATA.}

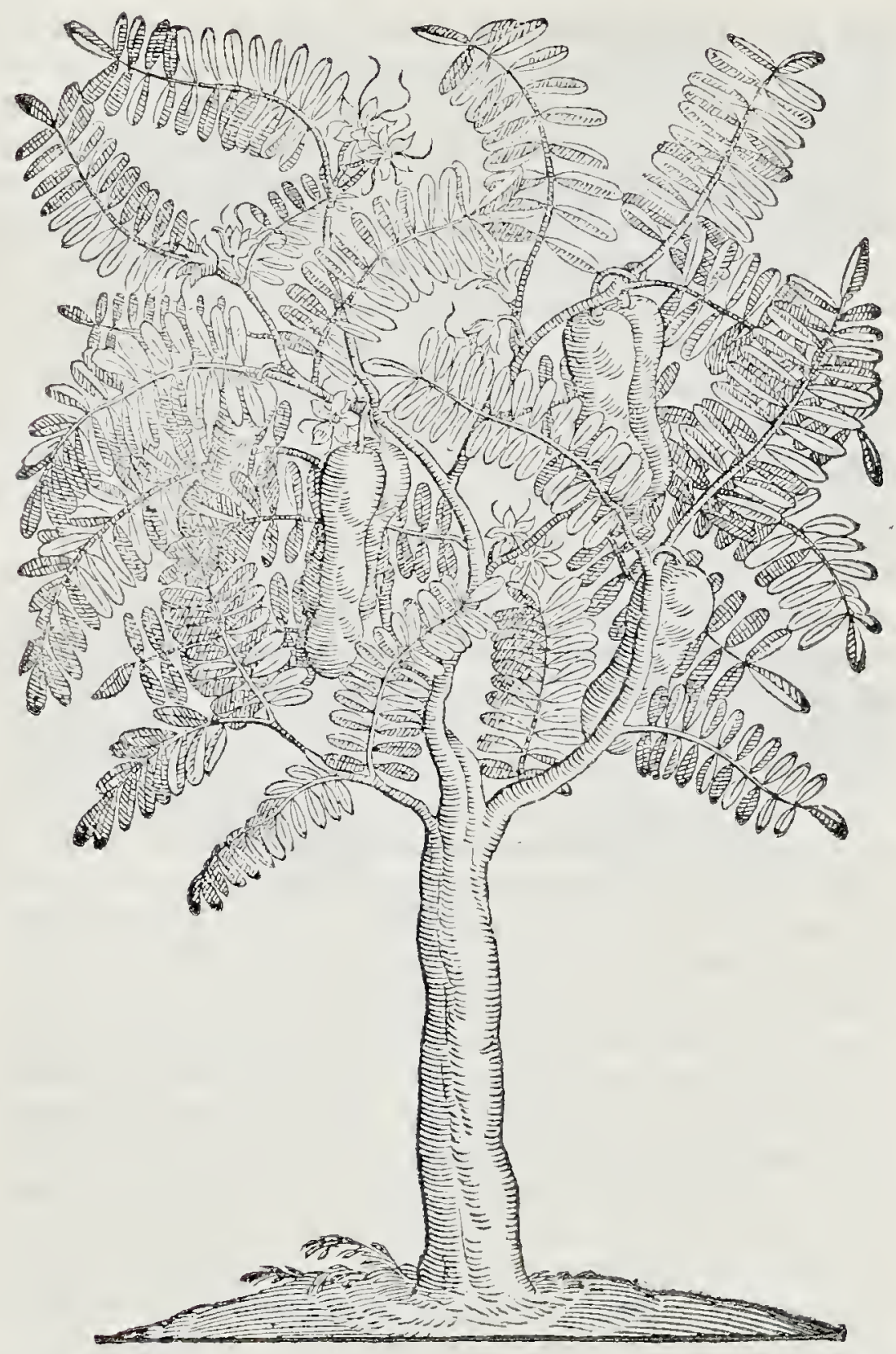




\section{I B . E R.}

\section{Dectgiahalid. Cap. XI.}

\section{A $\quad L \quad P \quad I \quad N$ V $S$.}

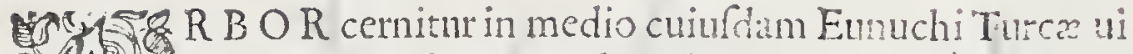
ridario, quod partum ab xde Veneti Confulis difae ex Aethiopia afportaca, nagnitudine pirifylueltris, nmis raris non mutis, in rectum inęqualiuer delatis, or linatim acutiffimis, mult is fpinis obfita, folia prefeferens buxi proxi ma, tamen latiora, pauca, rara, fingula, bina requalibus interttitijs ad nata. Flores habet paruos, albos, Hyacinthi orientatis floribus fimi les, fed minores, à quibus prodcunt fructus nigri cbuli finiles, guftu fubamáros ac adftringentes . Folia guftum acido fapore ferimnt, cü aliqua adfrictione. Huins arboris foliorum vfum ad pueros vermi bus vexatos, in Aethiopia audiui effe familiariffmum. Quid ? an non licium hanc arborem effe putandum eft, cum Diofcorides de hoc fic fcripferit: Licium, quod aliqui pixicantham uocant, arbar eft fpinofa, ramis trium cubitorum, aut longioribus, folig buxi, den fis, fructu piperis, nigro, lrui, amaro, denfóque cortice, pallido, non diffmili lycio madefacto, radicibus multis oil iquis lignolis.

G V I L A N D. Agihalid,vt ex tua deferiptione, quam vidi,non fiutex, fed arbor videt ur. Lycium vero frulicem potius effe, quàm arb orem, ex Diofcoride didi. cimus. Proterea hic fiutex folijs denfis

\& non raris cernitur, qualia

in tuo agihalid

exiftunt . 


\section{DE PLANTIS AEGYPTI}
A G I A H A L I D.

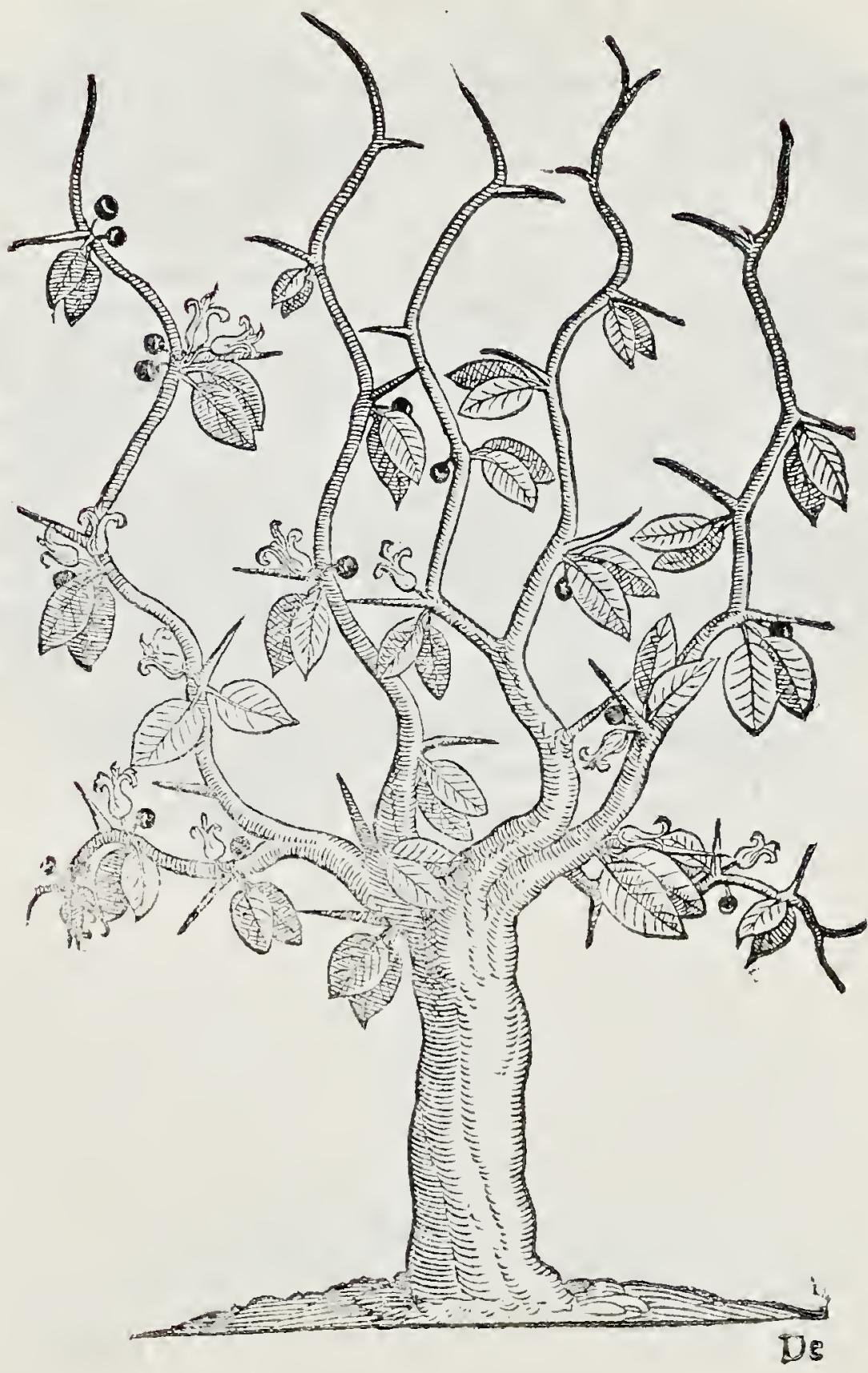




\section{I B E R.}

\section{De Vzeg;atgue an fit Lyciumindum. Cap. XIl.}

\section{$\begin{array}{llllllll}A & L & P & I & N & V & S\end{array}$}

O R T A S S E arbor illa agihalid rocata, pro Lycio 20 afpernanda non effet. Sed nunc verum Lycium Indum tibi prodam:quem fruticem longe ab Alexan dria Ciui tate fupra ripas rami Nili calig vocati, decem millia paffum inueni: quem incolx Vzeg appellant eft igitur frutex mul tis ramis rectiffmis, ab radicibus multis, duris, liguofis o blique incedentibus, longitudine trium rubitorum \& plus obferuatis, furfum affurgens, ramifque fpinç acutiffimę, \& longę multẹque in funt, quo rum quxdam foliolis veltita fpectantur. Folia vero huiufce fruticis funt oliux fimilia,ijs tamen candidiora \& anguftiora, vel minus lata. Flores Agihalid planè fimiles habet, quippe paruos albos, Hyarinthi orientalis forma \& magnitudine xmulos: à quibus fructus ni gri partu producütur, 'buli fructibus prorfus fimile, 'cles guftu ama ri \& adfringentes. GVIL. AN D. Cui dubium hanc arborem Lyciü Indicum fore iudicandum, modo Diofcoridi credédum fit, qui ipfum his profectò verbis defcripferat, dicens: Tradunt Indicum fieri Lycium ex frutice Lonchitide appellato: id fpinarum generi afcribitur, ramos rectos habens ternum cubitofum longitidine, maiorefuc̀, rubo craffiores a radice numerofos.fractus cortex ru befcit folio olex fimilis. Ex huius fruticis radicibus forfitan verum fuccum à nobis defideratum illi colligunt, ipfumque pro vfu illis non deeffe puco. A L P I N. Quamquam ibi multa copia Ly rij circunferatur, tamen nefcio an ex hoc illum frutice conficiant. quando neque hanc plătain copiofe in Aecypto prouenire cognouerim, neque fcio illis effe notä. Siquidcm Lycium ab illis vfitntum falfum ac adulteratum che arbitror. Hic enim fuccus, qui ex Arabir locis afportatur, durus eft, nigerque exterins,acatize fucco val. de fimilis. fractus intus colorem aloes prefeferre viderni', odore ob fcuro, non ingrato, apore fubduci, adfringente, nullius amaritudinis participe:vifcofuff; eft, digitifque contrctatus adhęret. ex qui bus verus Lycius à me is non crediturppęertinque cum neq; am ritudinem habeat, neque igne fuccenfum, fue ignimurn, rubefcent edere fpumam, ut multi de vero Lycio tradiderunt, obfenrmus . E GYIL. 


\section{DE PLANTIS AEGYPTI}

GV I L.Sed cur tu verum fuccum ex Vzeg perquirere non fudix Iti, caq́ue via certam Lycij fucci cognitionem yenatus non es. A L P I N. Hanc plantarn tantum vbi in patriam recirem mihi fpe Etaffe contingit, quando ex vrbe Cayri Alexandriam per Nihm Aumen nauigans, propè hanc vibem fupra ciufdem fluminis, vt iam dictum eft, ripas, nonnullos frutices fere fxpen faciontes, cum foribus \& frutibus iam maturis infpexerim. Ex quibus ramum decer. pfr,atque mecum Alexandriam detuli. Quo frutice faris confiderato, Lycium effe ipfum cognoui.neque ipfo cognito tempus nihi fu perfuit ad experiendum eius fuccum à radicibus cxpreflum. quippe coaftus, quamprimum Alcxandriam peruenerim, naum nos pro itince ibi morantem confendere, experiri non porui fuccum, qui pro Lycio circunfertur.inter calidum \& frigidum medium conftituunt:fed fupra prinum gradum ficcum . ftipticum,proinde omnibus vlceribus loto vtúaur,prefertimó; ad oris, aurium, narium, ani, inteftinorumó; vlcera. vfus maximus ef in colirijs ad ophtalmias arcendas, mulieres enim paratum linimentum ex Lycio \& antimo nio habent, quo quotidie oculos liniüt, vt oculos defendant ab hu morum fluxionibus. co ctian illi ad ventris fluxtim vtütur; non mi nusó; ad dyfenteriam. Ad fputum fanguinis eo maxima fpe vtun. tur, non minufá; ad vteri proflutum cohbendum, co pefí modo intromiffo:ad vleeraque pudendorum, prefertim ad caries illum fie quentant, ad gingiuas corrofas \& ulceratas, nec non ad dentium

commorionem. in lienterijs dyfenterijs, atque in fluxu he-

patico, clyfteribus co vii confuclant, atque non minus ipfo aliquo liquore diffoluto atque ebibito,

Nulli dubium quod illirum quancumq; par tem à curfu humorum valenter defen-

dit.ex quo ipfum podagricos do lores retardare, compcrtum eft. Vzeg apm pellant. 


\section{L $\quad I \quad B \quad E \cdot R$.}

VZEGLYCIVM INDICVM CREDITVM.

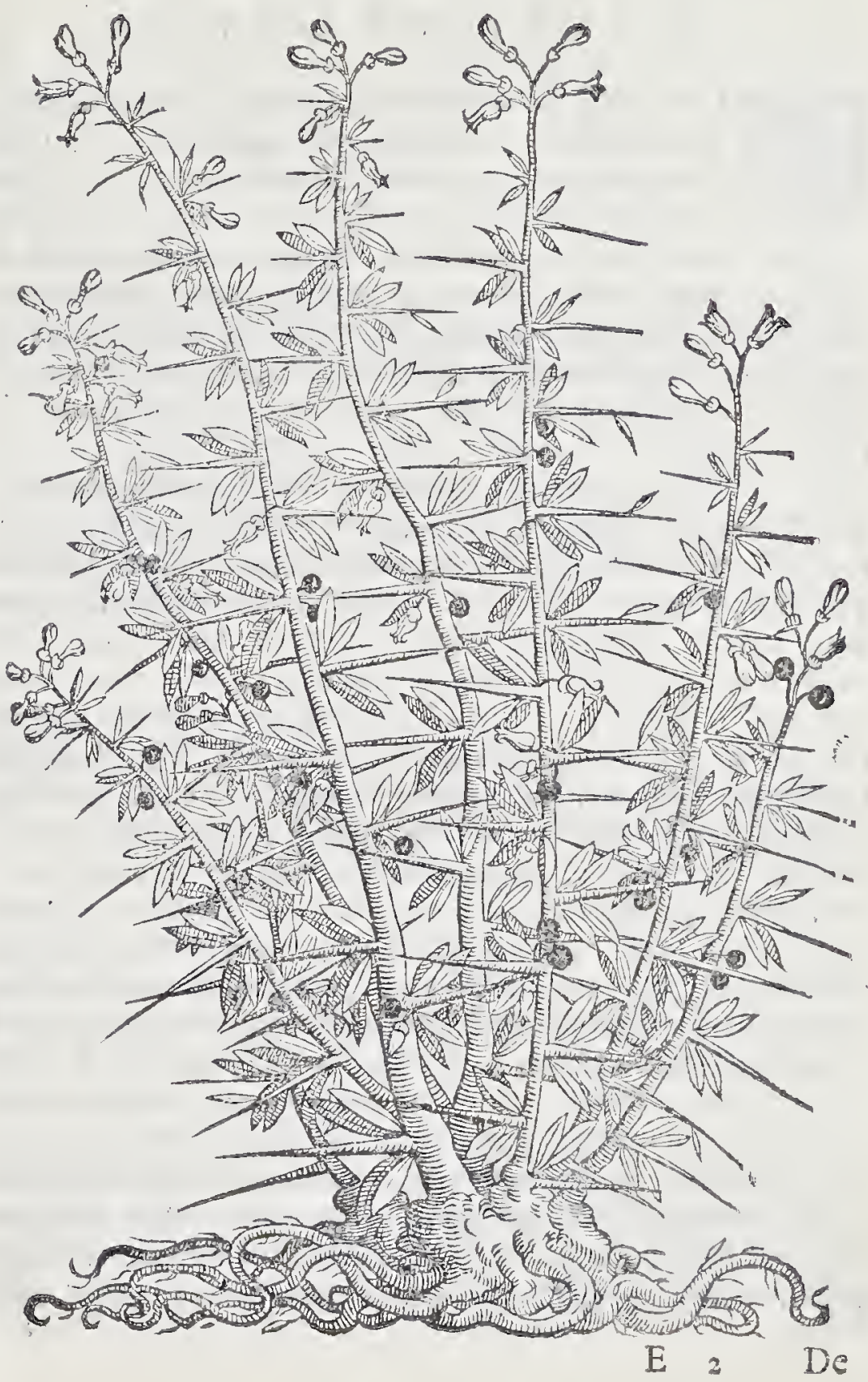




\section{DE PLANTIS AEGYPTI}

De Ligiftro cAegyptio, elhanne, veltamarbendicocato.
Cap. XIII.

\section{G V I L A N D I N V S:}

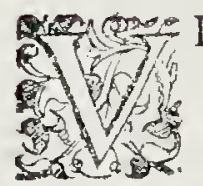

I D I S T I ne tuibiligutrum Acgyptium, quod Acgy ptij elhanne, ac tamarhendi appellant . Ibi fiquidem ipforum maximum effe reditum audio. ALPIN. Sxpifime infpexi, ibique ea arbor tum copiofinima, ct, tum etiam omnibus notifima : etenim ex folijs magna ibi funt comarcia, etenimijs vtuntur ad tingendum aureo colore. Vere hee arbor liguftro fmilis apparet, floribus fructibufque exceptis, in quibus videtur aliqua difsimilitudo inter elhanne, \& ligu ftrum, nam \& fi fores racemarim perinde atque liguftra fpargant, tamen \& colore, \& figura, \& odore ab his differunt. Alorum fiquidem elhanne non albus color, fed cincritius eft, florefque figura fambuci floribus proximi apparent, illis tamen funt minores. odor ctiam elhanne eft admodum acutus, \& liguftri fuanior. Fructibus non minus inter fe differunt, quando liguftri fint bacc $x$ Suniperi fimiles, \& elhanne femina rotunda coriãdros imitantia cxi ftant . Fert ctiam folia liguftro minus lata, anguftioraque \& candidiora. Fructus, vt iam dixi, femina nigra,parua, multa folliculo concludunt, qualia in granis vuarum cernuntur. GV I L A N D. Quid? dubitas, efie hunc arbutum liguftrum ? certe inter liguftrum, \& hunc aliquam effe differentiam, negandum non cft qux foli diuerfitate ctiam accidere poffet; quando omnibus confter, quantum eedem plantx in diuerfis locis natie inter fe differant figura, atque ctiam fxpe facultate . vt in thabarbaro, \& rhaponrico videtur, quorum radices, vifu, guftu, eadem videntur, nihilominus ficultate manifelte differre compertum eft. At de clhanne quanquam aliquo pacto fruticis figura, floribus, \& fuctibus à liguftro differat, tamen ad cofdem valere morbos cognitum eft, quibus liguftrum fubuenire Diofcorides, atque alif prodiderunt . fed quid plura? cum apertiffme Diofcorides voluerit hanc arbotem effe liguftrum . ve ex ipfius verbis planè con ftat, qux hxc exifunt. Liguftum arbor eft, qux circum ramos folia fert oliuz proxima, fed lation, teneriora, \& magis viridia 


\section{I B B E : R.}

\& Alores albos mukcofos, atque odoratos . cius fruftus eft niger " rambuci fruetui fimilis. Nafcitur electifima in Afcalone \& $\mathrm{C}_{2}-$ " nope. Folia adtrietoriam uim habent, quare commanducata vlceribus oris medentur, illita, feruidis inflammationibus, " carbunculifque profunt.decoctum eorundem igne ambufta, capil- " lum uffant trita folia, quæ in radicule fucco maduerint. Flos ex aceto fronti illitus capitis dolorem fedat. Et de elhame, $\infty$ quam Alcanna Auicennas vocat, hxe ferè eadem prodidit, dixit quidem, folia habere adfrictoriam facultatem, in vulneribufque eandem vim cum draconis fanguine habere, conferreque decoctum foliorum, calidis inflammationibus, \& exuftis ab igne particulis, \& oris vlceribus: \& cum aceto conferre capitidolenti. AL P I N. Verè elhanne Aegyptiorum liguntrum effe Diofcoridis, confat, multo magis, quod nunquam in Acgypto Italicum liguftum inueniatur, in Canopeque tantum elhanne reperiatur, qua ibient copiofifsima differt vero hic locus ab vrbe Alexandrix decem millibus paftum G G I L A N D. Hinc quaque apparet hane arborem eff: Cyprum Plinij, de quo ip- Cap.ro. fe lib. natmalis hiftoric xxiij. fic feripfit: Ligutem cadem arbor eft, qux in oriente Cypros, atque in Aegypto nafci criam "Cap. 24. his verbis libro r2. Cyprus in Aegypto eft arbor ziziphi folits; femine Coriandri, fore candido, odorato. Coquitur hoc in $»$ olco, premiturq́ue pofter , quod Cyprus vocatur. pratium ci in " libras quinque optimum habetur è canopica in ripis Nili nata, fe - ", cundum Afcalone Iudex. Tertium Cypro Infula odoris fuauitate. Quidam hanc effe arborem dicunt, qua in Italia ligu- ", frum vocatur. A L P IN. Flores funt in vfu frequentifsimo do, lenti capiti appofiti, non tamen cum aceto, vt Diofcorides, at- „, que alij meminerunt. quod fi feciffent, manifefius, vt arbitror ijs foribus iuuarentur, intus medicamenti ui aceto penetrationem adiuuante, deducta. Ex foliis puluerem conficiunt, quem atchenda illi appellant. Hac mulieres vtuntur ornatus gratia, manus ac pedes colore aureo tingentes. non autem in fucco lanarix, vel Atruthij, vt ait Diofcorides, fed fimplici aqua eam mifcentes, aquam auream faciunt, qure aureo colore tingit, quod arcanum noftre mulieres $f$ agnouiffent pro deaurandis ipfarum capillis, nil haberent, quo fecurius vterentur, neque fub radijs folis fe uresent, varijfque modis caput laderent. ex hat puluere, 


\section{DE PLANTIS AEGYPTI}

cumagria mulfa parata vtuntur, ad humidos pedes fuxionibus obnoxios, ac multum exudantes foetentesque emplaftri modo pedibus ipfis appofita,ac per horam reteta. maxime enim pedes, \& qua fumque alias partes corporis,appofita exficcat,ac adfitringit. Nihil habét, quod exudantes pedes plus exiccet, quam prędieta iftae maf fa appofita, \& aliquandiu retenta:puluere etiam hoc ad ulcera oris, gingiuarumque, \& pudendorum maxime utuntur.

\section{LIGVSTRVM AEGIITVM ELHANNE SEV Tamaharendiucl Alcanna Auicennx.}

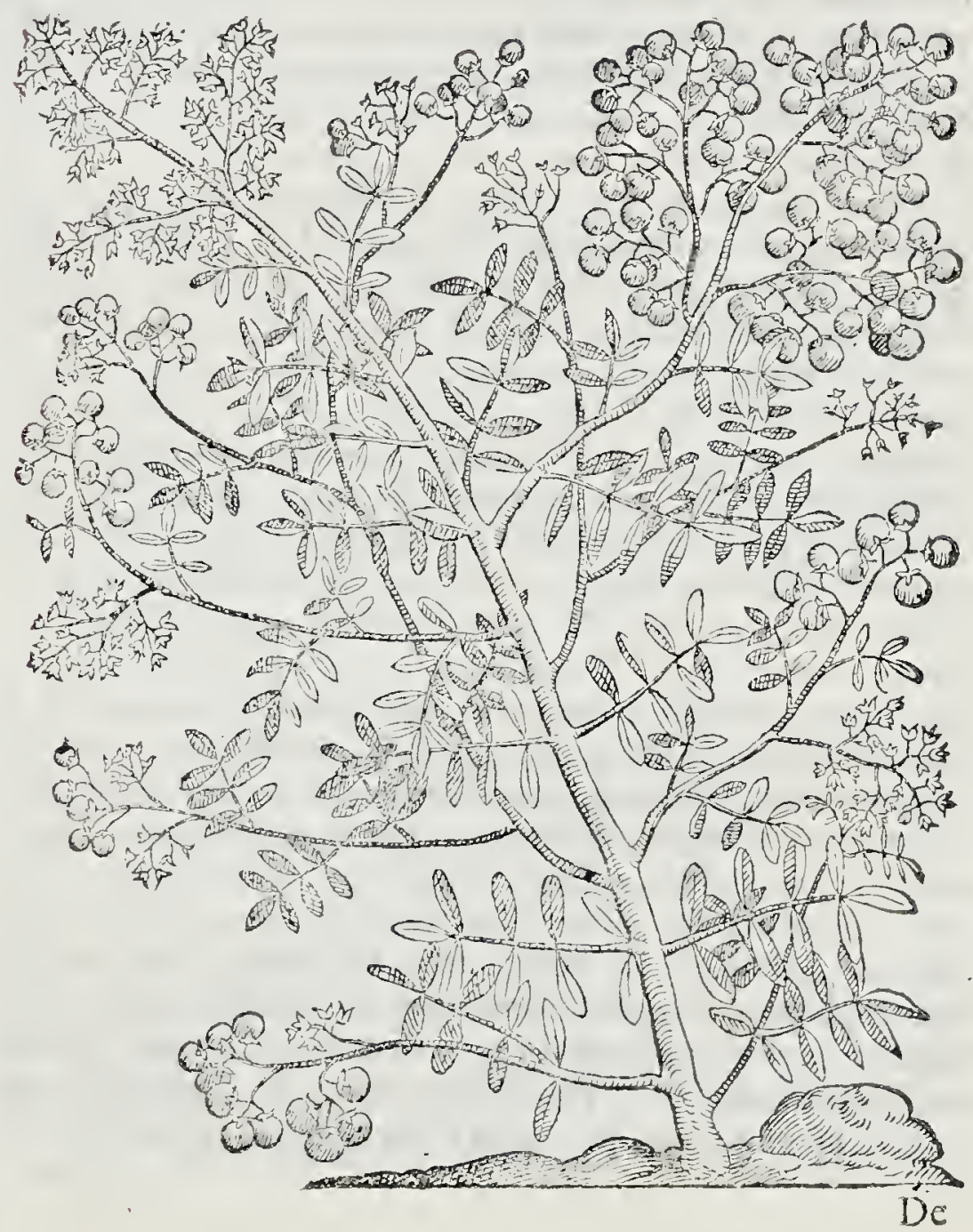




\section{I. B E E R.}

De Balfamo, Balaffan ab cAegyptïs rocaio. Cap. XI11\%.

G VIL A N D I N V.S.

gefor V NQVID balfami planta amplius in Acgypto viDe uit? A L IN. Nequaquam, fed in Arabia foclici, G 1 quam Balfami feracem omnes trim Acgyprij, tum AraI. Theophrafus, Plinius, Inftinus atque ali $\mathrm{jex}$ anticuis feriptoribus permulti, qui Balfamum tantum in Aegypro \& in Iudea olim vixiffe prodiderunt, decepti funt. A L P I N. Sine dubio illos non modo de loco Balfami patrio, fed etiam de arbore quo que, fucco, fructibus atque aliis deceptos fuife arbitror, ex quo criam dubitandun effet ipfos balfami arborem uiuethtem nufquam uidiffe. GVIL A N D. Rem ualde admirabilem predicas, de qua tibi non ita facilemedici certam fidem adhibebunt; quxfo an non Diof́coridi, Tcophracto, Plinio, ferapioni atque alijs grauifsinjs fcriptoribus de Balfamo magis quâm cibi credendun putas, qui in docenda herbarum Atirpiumợue materia, cęteris preferunturga fide digniores habentut? A L. P IN. Exfi in dialogo olin Cayricó foripto Ballami veritaté planè manifeftam me reddidif: puto,nibi lominus quando me munc ve veram Balfami hiftoram narrem prouecaft, vt tecum de ipfa colloquar, atque commenter cfingere nunc non pofim. quare iterum eadem, quix olim feripfinunc repetere, cum res agatur tanti momenti, non me pigebir, \& ne longius $\mathrm{em}$ producam, dico. Arabiam fẹlicem Balfamilocum patrium perpetuò fuiffe, ac nunquam Acgypum, ac Iudcam Baifani terram parriam fuife, facile hinc conijcitur, quod omnes, qui de planta Balfami mentionem fecerunt, eam in viridarijs folum cuftoditam, minimeq́; in alijs incultis locis fpote natam, ptodiderü, v: Theophraftus, Plinius, Solinus \& Strabo figillatim meminerunt. Plinius ait: fed omnibus odoribus prafertur Balfamum vni terræ Iudex conceffum, quondam in duobus tantum hortis, vtroque regio, altero ingerum viginti nō amplius, altero pauciorum. \& Stra bo: de Baifamo Vallis Hierici fribens, dixit: Vbi \& regia eft, \& Balfami viridarim, qux arbor aromatica eft \& fruticofa, cytifo 


\section{DE PLANTIS AEGYPTI}

\& terebintho perfimilis. Nulli dubium eft plantas peregrinas in vi ridariis tăr î̉ fumma cura cuftodiri, \& patrias nō folum in viridarijs vel hortis, fed multis alijs in incult is locis fpóte natas obferuari.fed cur ftudeo tibi perfuadere Balfami plantas in Iudea aduenas fuiffe, cum Iofeph lib.5.de antiquitatib. Iudaicis rem planè claram effecerit, qui ibi meminerit, Sabam reginam primam ex Arabia Balfami plantam in Iudeam dono Salomoni Regi tuliffe : ex qua po. ftea alix propagate fuerunt. De Balfamo Aegypti cadem dicenda funt, cum eam plantam ibi in viridario prope locum el Mattharia vocato, fumma diligentia perpetuờ cuftoditam vixifle, omnium Aegytiorum relatione liquido conftet: quod omnes antiqui ac it niores fcriptores fatentur, minimeg; in alio Acgypti loco incultó vnquim viuere inuentam fuiffe, nó femelq́; ibi perijffe, atq; ex Ara bia rurfum afportatam infertamó ; ac renouatam fuiffe, omnes Cay rini afirmant. Anno à partu Virginis Beatifime $M D L X X V$. Aegypti prefeetus Eunuchus Mefinor nominatus, dum quadam partes Aegypti uiferet, prefertimque el Mattharia, quem locum ob Virginis Batiffmx honorem ac obferuantiam fingulis hebdow madi die Veneris, que diem ifti,ac nos dominicum fantificat, adi reac uifere, in ipfoq́ue loco orare confueuerat proxime cum effet in viridario, videns omnes plantas Balfami exaruiffe, ac perijfe è Mecha quadraginta plantas afferendas curauit, qux fane in codem viridario inferte fuerunt, paucifque annis rurfum curato$\mathrm{rmm}$ negligentia periere.Quamobrem Acgyptii Balfamum fomper ex Arabia habuerunt . qux res fcitu ibi non eft difficilis, cum frepius multi è Mecha per rubrum mare Cayrum veniant. Iter quidé ¿C Cyro in Meccham eft facillimum, \& frequentatiffimü.verum nó effec inutile wunc me hilloriam peregrinorum, qui annis fingulis illa loca religionis cavfa, ateunt, atque uiftant, fubnedtere, fic einim certiolia de loco, ex quo veniat nunc Ballamum, habere poteris. nec non vode Rex Turarun multum opobalfami habeat GVILAND). Perplactit mihi ex te audiuffe Arabiam foclicemnunc, perpetuóçue fuife Baffani feracem, ex Acgyptiorum Arabumgue têmonio. Quod uerifimum exiftimo, quando Dicforides, Th:ophraitus, Plinius, Solinus, Serapio, Scthus, ato glue alif fripum reliwnent foltum Acgypto ac Iudex fuife olin Ballaman coce Tum, Qubus ferigrorihus plena fides fortaffe haud

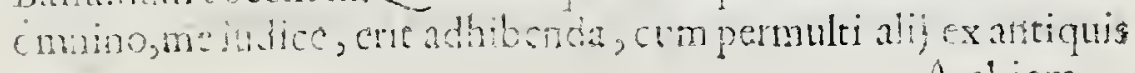
Arabiam 


\section{I B E R.}

21

Arabiã olim quoque Balfami feracem fuiffe teftatum reliquerint. Diodorus etenim Siculus in 2. libro fuarum hiftoriarum, Balla- , mum in quadim Valle Arabix nafci, \& non alibi memorix prodi- " dit.\& Strabo in 16.lib. Geograph.ait: His proxima elt focliciffima " Sabeorum terra, qux maxima natio eft,apud hos thus \& my rrha, \& , cinamomum nafcitur, in ora etiam Balfamum, \& aliaquxdam her- ", bula valde odorata, \& Paufanias lib.9. De Viperis vero ijs, quæ in ", Arabia inter Balfami arbores verfantur, diuerfum quidem accepi. Sed cur nos magis Diofcoridi, Theophrafto,atq; aliis de Balfamo quam Aegyptiis \& Arabibus propè Balfameta natis credere debebimus, pracipue quia incertus fum illos vnquam viuentem Balfamum offendiffe, ac infpexiffe, \& hi in Balfamilocis nati ( quando omnium cum prifcorum, tum huius ętatis feriptis firmiffime conftet, Aegyptum Balfami plantas aluiffe) quam facile potuerunt has plantas vidiffe, ac vere agnouiffe, à quibus cum conftet Acgyptum has ex Arabia habuiffe, cur amplius dubitabimus Arabiam effe patrium Balfami folum ? qux res apud Aegyptios \& Arabes demonftratione nulla opus habet ' cum hi omnes certò fciant non modo fuperiori, fed prefenti quoque xtate Balfami innumeras plantas in Arabia adductas viuere, atque omnes, quas hactenus Aegyptus ha buit, exinde exportatas \& frepefrepius eo modo renouatas fuiffe. Apud me itaque amplius dubium non erit, Diofcoridem, atque alios Balfamum folo Acgypto, ac Iudex conceffum olim fuiffe affe rentes, plurimum deceptos, idque ex aliorum relatione magis, quä ex.vera fcientia litteris prodidiffe. Sed tu tamen ne obliuifcaris ia propolitam peregrinorum Aegyptiorum hiftoriam nunc recéfere: qux mihi gratiffima erit . A L P I N. In Arabia fœelici ciuitas eft primaria Meccha dista, quxeft ad mare rubrü lita:ab ipfaque alte ra Medina vocata, diftat itinere octo dierum, in qua eft fepulcrum Mahemet is ipforum pfeudoprophetx. ad quod fingulis annis ex Aegypto duodecim vel quindecim millia percorinorum fe conferunt, facrificaturi, \& holocaufum oblaturi. His preficitur Dux qui dam, qui trecentorum militum prefidio illos cmnes peregrinos Meccham, Medinamq́ue conducar; $\&$ mox Cayrum reducat incolumes ab iniuriis Arabium, qui non raro in his defertis, cos inuadunt, \& occidme ac depredantur. Viuunt enim Arabes hi rapina victum quxritantes, funtque frocifimi, atque audacifimi, habentóue cquos velocifimos, quibus vtantury lcgeque funcitum etiả habent, 


\section{DE PLANTIS AEGYPTI}

inabent, ve alicubi nunquam confiftere queant, fed continuo equi zent, degentes fubtentorijs. Peregrini itaque duce illo, quem Hamirag appellant, resta $M$ acchain pergunt, deinde redemtes profici fcüzur ad fepulchrum Medinæ, quod iter perficiunt diebus quadra ginta: Medina \& Maccha per alios viginti morantur. Turcarum Rex M dinam mittit duos prefectos, quorum alter facris praen, \& alter prophanis \& militibus. Mecchx vero, qux Turcarum impe gio non omnino obedit,preent quidam Arabum princeps, quem Se riph appellant, hoc nomine vocant omnes, qui a Mahemet oriüdi funt, \& fe illius coguatos firipto oftedunt. Habet hic princeps equi tum anmatoram decem millia, \& viginti quoque millia peditum: quibus timens à Turca fibi hacitincris occafione infidias fieri, ftatim cüaudit pregrinos ad fua loca appropinquare, recedit à Meccha \& in montes fe recepit, vbi ufque dum abierint peregrini, mora tur, quibus quotidie minatur, nifi difcedant poft viginti dies, fe aquas intercepturum, quando aque omnes deflume ex montibus. Muttit Rex Turcarum huic Seriph munera hrec, quippè chlamydẻ auratam, ciusq́; filijs \& fratribus centum \& quinquaginta millia au reorum fingulis annis, pro quibus muneribus ipfe Regi Turcarum dono mitrit quadringentas petias lineas Indicas fubtilifimas, $\mathrm{Cu}$ iufmodi effe biffun, de quo memin ere facre litteræ, exiftimari poteft. Amplius cum eo biffo mittit ctiam Regi opobalfami tres quatuortue libras, \& pr.xfecto Cayri libram, atq; Hamirag peregrinorú femilibram. Sunt etiam alij duo duces fuc Hamirag cum multis pe regrinis, fcilicet alter è Damafco, \& alter ex Arabix foelicis locis, Meccham \& Medinam uifitatum venientes, quibus omnibus donat parum opobalfami. Poftquam omnes Aegypti, Damafci, Ara bixeque peregrini Meccha difeedunt, ad montem quendam proficifcuntur, quem appellant Arafat, ad cuius radicem eft locus, quem Maure vocant, vbi facrificant in memoriam facrificij, quod fecit: Abrahan, credentes illum efie locun facrificij. In medio uero itine re, quod redeundo conficitur, mons eft arenofus, in quo multas bal fami plancas viuere affirmant, quas miraculo Mahemetis in fterili. illo monte natas affirmant. Cxterum ne ex hac hiftoria dubites, tan tum opobalfami habere Seriph, fcito, ibi à Seriph opobalfamum fo lerelocari,foluuntque, ut audio, aliquot millia aureorú in fingulis znnis; $\&$ g!n habent ab ipfo conductum, quibus volunt vendür opo balsamum,atque hec eft hiftoria de peregrinorum ad eas urbes itio 


\section{L $I \cdot B \cdot E \cdot R$.}

here, bu cx ea ctiá f́ias vnde ad Turcas tätum opobalfami accedar. atque vt etiam tuam hac de re retineas, fententiam; quippè Aram biam folicem cffe proprim balfami folum, Acgyptum uero peres grinum. G V.I L A N D. Quam gratiffmum mihi fuit, ex te dili gentem peregrinorum Aegyptiorum peregrination h hiftoriam au diuife, nee non ex Arabia folum Regem Turcartum opobalfamum haberenunc uero illius plauta eft à te deferibenda. ALPIN. Balfa mum arbufculum eft uiticofum, quod crefcit ad altitudinem elhan ne, feu liguftri, uel cytifi, folia pauciffima gerens rutx proxima, non - ramen, ut dicebat Diofcorides, ijs candidiora, fed potius lentif́ci fo lijs fimilia cernuntur, fcilicet colore viridi, fubalbido, perperuoque virentia.Eius lignum gummofum, lenique apparet colore exterius fubrubro, cuius ramuli codem colore côfpicui funt, longi, recti, gra ciles, paucis folijs inordinatim referti,foliaque fimul terna, aut qui Da, aut feptena al $x$ adnata aliquo pacto lentifci foliorum amula. Sunt ramuli odorati, gummofi, digitisq́u contreetati eis tenacitex adhærentes. Flores fert paruos albos acatix floribus proximos, ter nos fingulis alis appéfos, quafi in vmbellar forma, fumme odoratos, odor paululo temporis refoluitur, à quibus femina promanant fia wa folliculis nigris fubrubefentibus conteta, valde odorata, intufque humorem flautum melli perfimilem habentia, fapore fubamaro parumqú acri linguam ferientia, opobalfamum q; redolentia, terebinthi fructurm figure \& magnitudinis æmula, extrema aculcata \& me dium craflum obtinentia . opobalfamum xftate a fearjicato cortice caudicis diftillat, ftatimq́ue eductum colore albefcit, \& pofeà in uiridem,tertio in atrem, atque demum melleum mutatur. ftillatum ctiam eft clarum, quod mox turbatur,craffec feit, \& tertio tenuiffmum atq; clarifimum fit, tandemq; fenio confectum, vt tere binthina craffefcit.olet in principio recentifime diftillatum acutiffimo at que eximio odore, quod multis capiti dolorem cócitare folet, \& aliquibus etiam fanguinem ex naribus promoure odoris uero illa acuties ac vehementia ac in Zebet fit, tcmpore obtundi tur, \& gratior euadit, fenio vero confectum uix fentitur in eo ali. quis odor, \& ob id Diof corides dixerat inutile (ffe antiqut m. ER etiam in principio leuifims m, \& dilui facillimr m, ita ut ix in acua uel hacte ex alto ciftillet, in imum uafis refidere nö pariatur.clarum ucro aureumque redditum, ac ab cmni fece pergatiff mu m medio cri lęuitate proditum sfr, 1 ta yt inftillatum in aqua, etf fundím pe-

$$
\text { F } 2 \text { tat, }
$$




\section{DE PLANTIS AEGYPTI}

sat, tamen citò rurfum in fupcriciem aqux feratur, cun caque citò refoluatur.qux omnia quo annofius, co obfcurius habet. Hincquuc meritò dicebat Diofcorides, optimum Balfami fuccum cffe re centem, validi odoris, fyncerum, non ad acorem vergens, dilui faci lem, læuem,aditringétem, ac modice mordētem guftü. GV ILAN. Dubium in colore natum eft, cum tu dixeris in primis opobalfamú ftatim eduetum colore albefcere, atque hunc colorem breui tempo re in viridem olcofum mutari, $\&$ mox in aurcum, \& tandem in mel leum, \& Diofcorides, quem tu haud negabis. verum opobalfimum infpexiffe, dixerit ipfum colore labtefcere. ALPIN. Succum Balfa$\mathrm{mi}$ in aqua infillatum \& liquatum coloren lactis accipere Diofco rides feriptum reliquit.quod veriffmü ct. quinimo hoc eft fignu in feparabile proprium, quod fidelius oftédt verum fuccü balfami ab alijs vitiatis pro opobalfamo ì multis receptis. Multa de opobalfami fynceri \& adulterati notis, effent à nobis dicéda, nó minufq; de carpobalfamo, \& xilobalfamo, de quibus medica métis dubij funt fere omnes recétiores medici, fed quia aliàs de his omnibus fuffifime à nobis in Dialogo de Balfamo friptum eft, qux omnia cum te iampridem legiffe \& cófideraffe, certo f́ciam,nolo tempus amplius in ijs cófumere, fed fermoné noftrum ad alia traducere,proinde qui abfolutam ac perfectam plätx, fucci,fructuum, \& uirgarum rarione audire, ac agnofccre cupiunt, dialogum illum legere nó grauentur, ad quem te quoq; pro alijs quie de balfamo iupereffent, dicenda, re mitto, Balfami plätam apud me viuenté veriffmam Iacobus Cóta renus Senator Clariff.Ioannes Vothus nobilis Anglus, Fran. Ferre rius Gallus, Ioachimus Iungermanus Germanus, Marcus Fenarius Venctus pharmacopola \& plures alij viderũt, uerumó́; ctiam opobalfamum ab cius foliorum alis difsectis inftillauiffe - quod multis maxime mirum fuit, cum aliàs Italiä hãc plātam habuife, nufquä apparcat.ufus tame in medicina, quos apud Acgyptios habcat opo balfamum, carpobalfamim \&x xilobalfamum,tibi quoq; detegere, ac refere nunc conabor.ab opobalfami dotis ciefumpto principio. GVILAND. Gal. pancos ufus Balfami in medicina hinc nouiffe putädü crit,quod ipfe in lib.6.de fimpl.med.facult.omnium fimpli cium medicamentorum ufus copiofe docédo, de balfamo nihil ad hanc rem protulerit,ue cx eius his uerbis cóltat, Balfamum deficcat \& excalfacit fecundo cxceffu. cft autem tenuium partium adeo, ut odoratum fit. Sediquor eius fubsiliorum etiam partium eft, quàm ipfa 


\section{I B E R.}

23

ipla planta,non tamen adeo calidus, vt quidam exiftimant, tenuita ", te partium falfi. Porro fructus eius perfimilis genere facultatis eft, cieterum longè in fubtilitate partium inferior. Scd age tu dic vfus il $\#$ lius apud Acgyptios frequentatos. A L P I N. Nullum certe ibi eft medicamentum, quo magis, ac frequentius gens illa medendo vtatur, quàm opobalfamum, quod quidem illi ferc ad omnes morhos, ac fymptomata adhibent ad of ; maxime, qui vel cx fimplici temperic frigida \& humida, ucl à frigidis humidifque fuccis, uel à ucnen is, concitan tur. fumma cum laudc eo utütur ad omnia uulne ra, quo mirifice curantur. quod ego expcrientia in Petro Mariano Veneto mercatorc, in capite à Turcis nocte quapiam ufq; ad os per frme lign is vulnerato, didici:balfamo fiquidem inunkta ea uulnera perdicm tantum, ferè omnino coaluerunt, \& eo quam pauciffmis dicbus;ut is teftis cffe potelt, perfectè fanatus eft : utuntur etiam ip fo ad ulcera fordida, qux co mundantur, atque fanantur. In uenena tis, \& demorfis à ferpentibus, atque ictis à fcorpionibus tum epotü, tum illitum maxime iuuat. In peftc, vt ab eius contagio defendanrur, nihil maius habent, quo utilius \& tutius utantut, fingulis dicbus eius femidragmam degluticntes. Multasq̨ue etiam putridas febres co cpoto illi fanant, largiori ab ipfo erumpente fudore. In chronicis febribus à crudis frigidifque humoribus, obftructionibufque ui fcerum, nihil utilius ac preftantius experiuntur, quam opobalfami binos fcrupulos, uel dragmam per os quotidic cxhibere, libcrat cnim ualcnter uifcera ab obetructionibus, calorcmćue naturalcm fouédo crudos humores concoquit, ac digerit. Hincá; c eius ufus ad omnes frigidos morbos, ac fymptomata, aptld cos ef frequentiffmus. Oculis uifum depcrditum, atque auribus audieum inftillatun. reftituit,aurium que dolores fanat. prxterca ad conuulfos ex humi ditate ac frigiditate, ad uertiginofos, epilepticos, rcfolutos, tremen tes, ad tuffimque ex frigido humorc, orthopnæam, \& omnem fpirã di difficultatem, pulmonum fluxiones, humiditates, \& dolores, ad ftomachique frigiditatem, cruditates, atque ad omncs fatuum mo leftias, ad utcri frigidam humidamque intempcriem, ad prefocatio nes, dulores, fterilitatem, albos, fluores, ad interceptam urinam ex frigiditate, flatu, uel lapidibus, ad calculofque in renibus tialenter frangendos, ac abfergendos, ufus opobalfami eft apud omnes illos populos notiflimus, \& ad hæc omnia mala prefätiffimü illia $a x i l i u ̈$. experiuntur. Mulieres uero Aegyptix fteriles co tum epoto tum 


\section{DE PLANTIS AEGYPTI}

fuppofito, tum fuffito foliciori fucceffu fxpe ad remouendan fteriLitatcm utuntur. Non minori in ufu etiam habent, ad pulchram faciem eficiendam, quando eo ipfa illita à rugis defendatut. audio etiam aliquas eo ad conferuandam faciei pulchritudinen ac iuuen sutem non inutiliter ufas fuife. GV I L A N D. Sed quomodo hre illo ad conferuandam iuuentutem utuntur. hic enim ufus quam quam in ore multorum fit, nihilominus a nullo id difcere potui. A L P I N. Vt mulieres faciei cutem, dũ iuuenes funt, perpetuò conferuare poffint, opobalfami ufum in hunc modum fequĩtur $\mathrm{Bal}$ famanda enim mulier (ut fic loquar) in balneum calidum in primis moratur quoufq; multum incaluerit, quo tempore cutem opobalfamo multoties copiofe illinit, à qua linitione per horam \& amplius in balneo ualde calido, quouf q; rete cutis opobalfamo imbibatur \& arefat,morata, balneũ egreditur, folitaq; nunia exercet, $p$ manetq; fic, facie atque pectore opobalfamo inuneta per tres ad mi nus dies, in quibus nunquam perunctam cutim abluit, uel mundat: ac tertia die ab inunctione rurfum in balneum eodem iam dicto modo fe confert, facicmque ac pectus ualde calefactum copiofo opobalfamo multotics perungit: aliqux funt, qux uel decies una die cutem inungunt, obferuantes commodum interuallum, quo recte curis peruncta totum opobalfamum imbibat, atque paululum arefcat, ut prompius fuccum intimius haurire queat. Quam opobalfumi unctionem hoc modo preftitam multoties moliuntur; falo tcm diebus triginta. In quibus cutem nunquam lauant,uel mundăe à quibus quindecim \& ctiam amplius, fic cute opobalfumo inũcta quiefcunt, quot fo; nihil liquoris oftedar, probeq; ab co ficcata fue sit quo ecmporc aqua fabartm ftillatitia, prius ad eas partes pramif fu modica olei amigdalarum amararum inunctione fe lauant, $\mathrm{cu}$ tcmque multis diebus abfterount . atq; hxc de uiribus opobalfami fint dicta.Seminum atq; uirgarum quoq;recentium ufus apud illos eft familiaris. Eis fiquidem ad omnia ferè ad quę opobalfamo, utun tur.prefertimg; ad robur ft macho conciliandü, cius enim pulue rem cü decosto frece nardi, ad binas dragmas exhibent. idé praftat decoeiu, quo maxime colore naturalé fouent, augent, \& robomancutüur \& ipfo in fprandi dificultate, tuff frigida, atque alijs morbis a frigiditate naficentibus. Vum frequentifimü haber pulเais, \& decoctir ad humidiates uteri exficcandas, eiufq; calorẽ uiuifi cancí. futhin cx his frequentantad morbos omnes veri à caufa frigida 


\section{I B E R :}

24

frigida concitatos.eodem modo \& ligni ufus eft. Succus enim, femi na, ac lignum ijfdem facultatibus donata funt, a d cademó́; vfun habent.verütamen opobalfamum efficatius poteft,coó; minus car pobalfamum,omniumq; minime xilobalfamum.at tempus eft, vt fi nito hoc fermone, nos ad alias plantas narrandas tranfeamus. G V I L. Iftorum trium medicamentorü vfus omnes etiä Diofco. des, Auicenas, atq; alij multi preclariffmi medici docuerāt, ex quo mirum non eft, fi ijs adhibitis ad multa mala uoti compotes Acgyptij hunt. Sed de Calaf tem: pus eft vt loquaris,prius tamen balfami ue-

ra uifa ichone, quam à Pertuis Bei tuo

familiari amico Turca Sangiach receptü, aliàs cx te audi ui, atq; ex tua uiuen. te planta deferi bere potui fti.

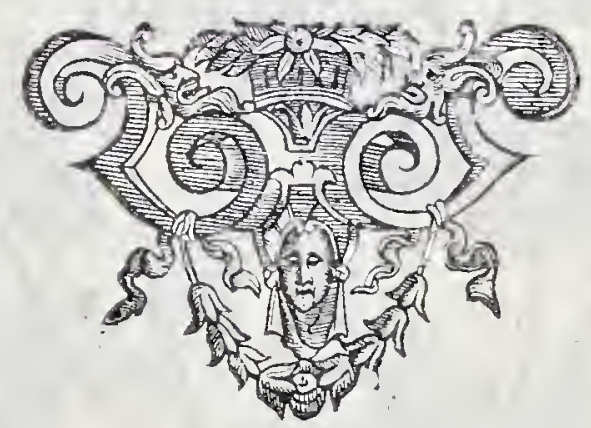




\section{DE PLANTIS AEGYPTI}

\section{BALSAMVM AB AEGYPTIS BALESSAN.}

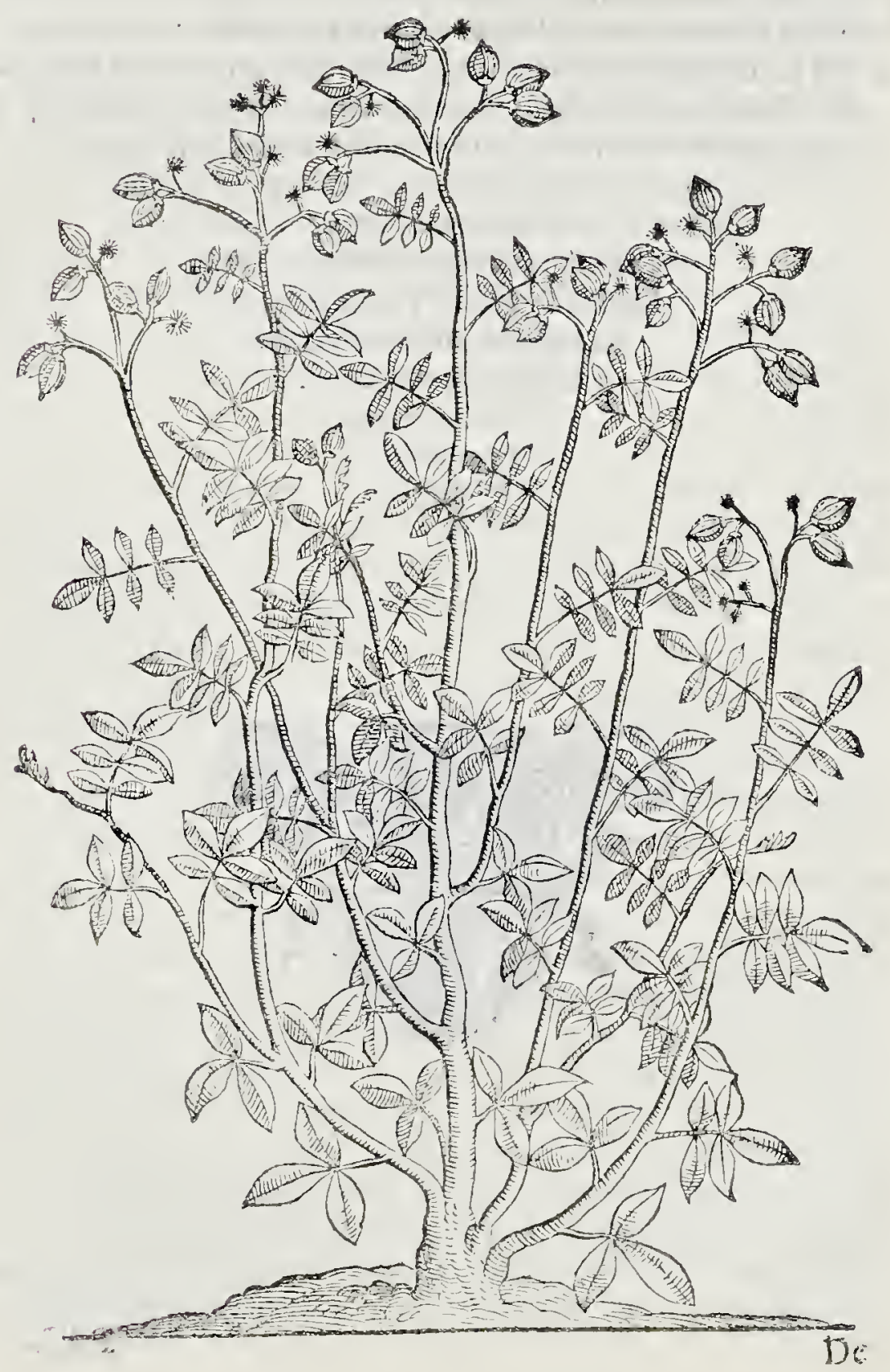




\section{I B E R.

$$
\text { DeCalaf feuB Bano Cap. XV. }
$$
A L.P I N V S.

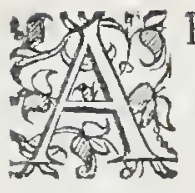

RB VSCV L.VM fruticofum in Acgypto reperitar; quod mea quidem fententia, Salicis genus exiftit, nafciturque in locis humidis, foliis aliquatenus Salici proximis, fed multo maioribus; quippe longioribus, ac $\mathrm{kgm}$ tioribus. Floresq́ue eius funt quidam globuli oblongi,albi, lanugi nofi, caudici pene foliornm radices nafentes, quotäque in arbore folia exifutt, tot flores emittit. crefcit arbufculum hoc ad viticis ma gnitudinê ramis multis, fiue ftolonibus rectis: ex floribus,vt audio diftillant aquam macahalef vocatam, quam infignes vires ad exfic candam putredinem, atque ad venena, \& cor recreandum habere, illipradicant. in febribusque pettilentibus ipfa pro fecreto auxilio apud illos habetur.Aquam etiam, in qua multi flores infuri aliquan diu manferint, uel in qua ebullierint, exhibent ad dolores capitis, atque ad virium recreationem, quam \& ipfam valide putrediniac venenis obfiftere experti funt.eftque ipforum decoetum, ac infufio in aqua parata, ad quofcumq́ue febricitantes, apud illos in maximo vflu。 


\section{DE PLAIIS AEGYPTI}

\section{A L A F, E T B A N.}

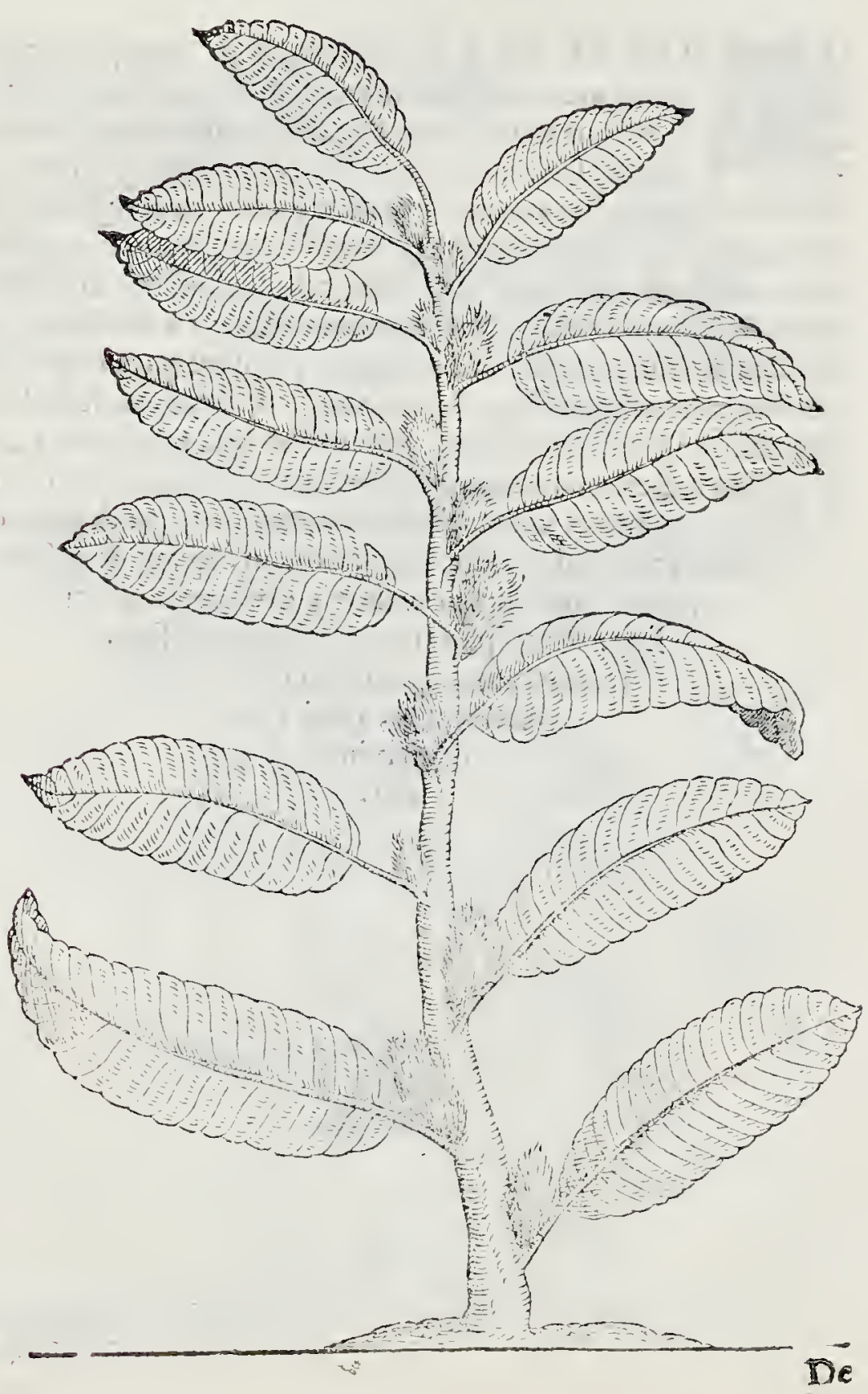




\section{I B E R: \\ 'De Bon. ' Cap. XV1. \\ A L P I N V S.}

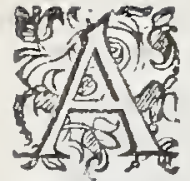

R B OR E M uidi in uiridario Halybei Turce,cuius tu ichonem nunc fpeetabis, ex qua femina illa ibi uulgatif frma Bon,uel Ban appeilata, producuntur: $x$ his omnes tum Acoyptij, rum Arabes parant decoctum uulgatiffimum, quod uini loco ipfi potant, uédirtećue in publicis ocnopolijs, non fecufquàm apud nos uinum : illiqúc ipfum uocant Caos ua. Hace femina ex foelici Arabia afportantur. Arbor, quam me in fpexiffe dixi,euonomo fimilis obferuata eft, fed tamen folia craffo ra,durioraque habebat, uridiora,perpetuoqutue uirentia. V fus eft illorum feminum omnibus notiffmus, ad parandum iam diku m dem coctum, quod quo pacto ab illis paretur, aliàs à me dietun cft, Vtuntur. tamen cius decoeto ad roborandum ventriculnmi frigidiorem, aduuandamque concotionem, \& non mints ad aus fercnidas à vifccribus obftructiones; in tumoribusque hepatis licnisque frigidis, \& antiquis obftuctionibus, foliciori cum fuc. ceffu decoetum, multos dies experiuntur . Quod etiam vtert m maxime refpicere uidctur, ipfum enim excalfacit, obftructio. nesq́ue ab co aufert, fic cnim in familiari ufu eft apud omnes Acgyptias, Arabasque mulieres, vt fumper, dum fuunt menfes, ip formin vactationem, huibis decoeti feruentis mulum paulatim forbillantes, adiuncne ad promotiendos ctiam, in quibus fuppreffi funt, vfurs huius decocti, purgato corpore multis diebus, vilifinus eft. GVIL. Auicennas de his feminibus meminit, fimilefq; ucl cordem vfus à te narratos de his feminibus memorix prodidit. ipfumque femen calidum in tertio, \& ficcum in fecundo gradu cóftituit, quod tamen verum non videtur, quando femen fapore dulcefcar, cum pauco amaroic nullamque acrimoniam prefcerat. Nhilominus ip fum obftuctionibus uifrerum, frigidifque thoribus hepa tis, vel lienis mulum conferie docuit. Sed ait, ficmacho naul am concicare, pituitamq́uc purgare, atque mula alia haxe fo mina pręfa re, experientia pencs Aceyprios didici. atque hxe cf arbor, quam Cayri olim infpexcram.

$$
\text { G } 2 \mathrm{BON}
$$




\section{DE PLANTIS AEGYPTI}

$$
B: O N \text {. }
$$

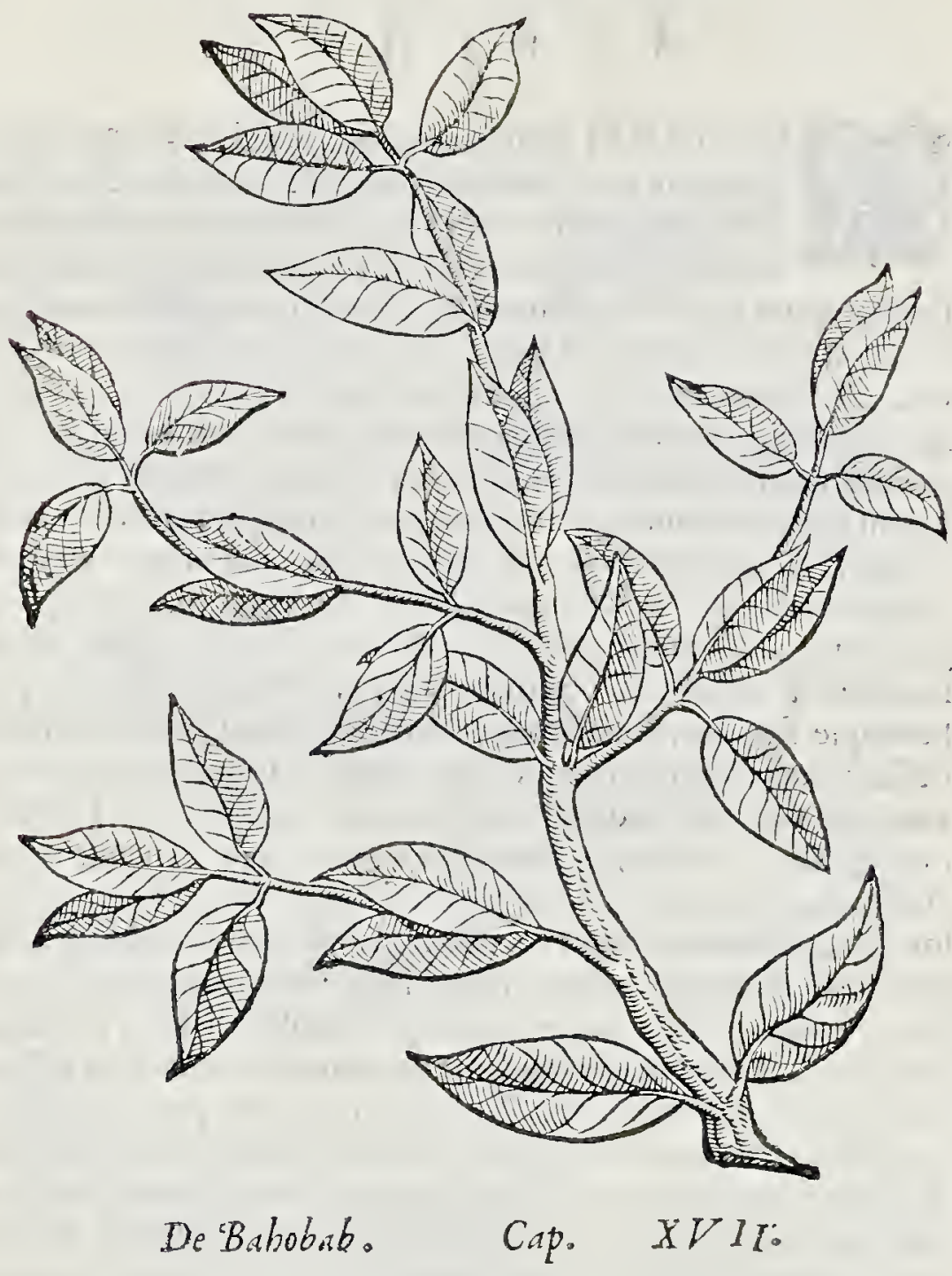

\section{$A$ I P I N V S.}

A $\mathrm{AHOB}$ A B eff fructus magnitudine mali citri, eucurbi6. 1 bitre fimilis, intus femina nigra, dura, extremis in unum fe 10. fumile $m$ habent, quix in recentibus eft humidar rubra, fapore acido, 


\section{I B E R. " 27}

non ingrato; Fruetus recenter ab arbore excifus, guftui admodum gratus eft, in Acthiopix inflammatis locis, acido fapore, quem con temperant diuites faccharo, fitim valenter extinguit, multumq́ue re frigerat. Ibi, vt audio, co vtuntur ad omnes calidos affectus, febrefque omnes putridas jprecipueque ad pettilentes, tum eius pulpam cum faccharo comedentes, thim fuccum expreffum cum faccharo porantes, vel ex co paratum fyupum accipiétes. Cayri etiam, quo loco recerís fructus non habetur, eius pulpa in puluercm parata ij vtuntur, qux eft terra rubra, adltringenti, acidoque fapore guftum feriens qualis in terra le mnia obferuatur: eftque apud multos familiariflimus illiufe terrx vfus ad peftiferas febres, tum ad fputum fanguinis, ad lienteriam, dyfenteriam, crientum q; hepaticum fluo. rem, nec non ad uteri menfes firmandos . alij eiufce terrie in fubtilifimum puluerem redactx dragmam cum a qua plantaginis diffolutam, ad eadem exhibent, alij decocto, alij infufo vtentes. Arborem qux hos fructus fert, vidi cgo in quodam viridario, folijs magnitudine ac figura, aurancijs valde fimiles.

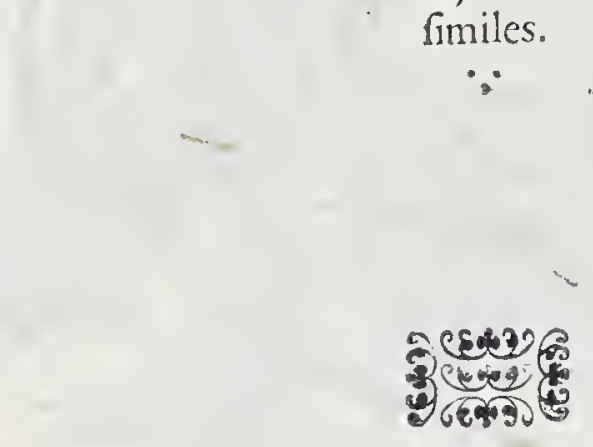




\title{
DE PLANTIS AEGYPTI
}

\author{
B. A $\bigcirc$ B A $\vec{B}$ 。
}

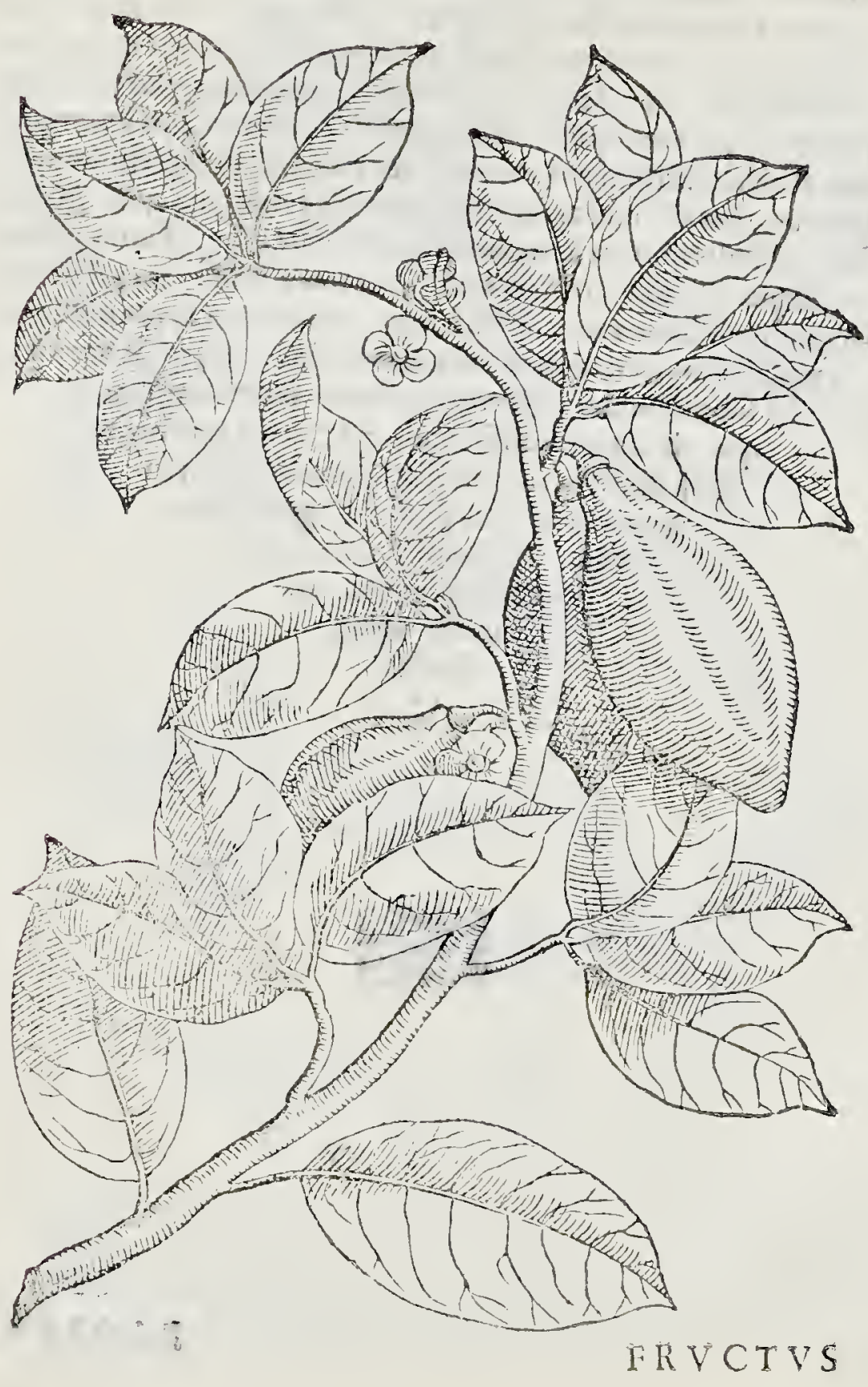



L I $B$ E R:

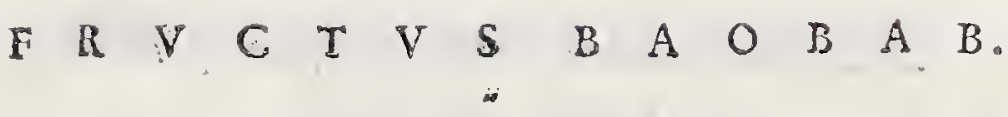

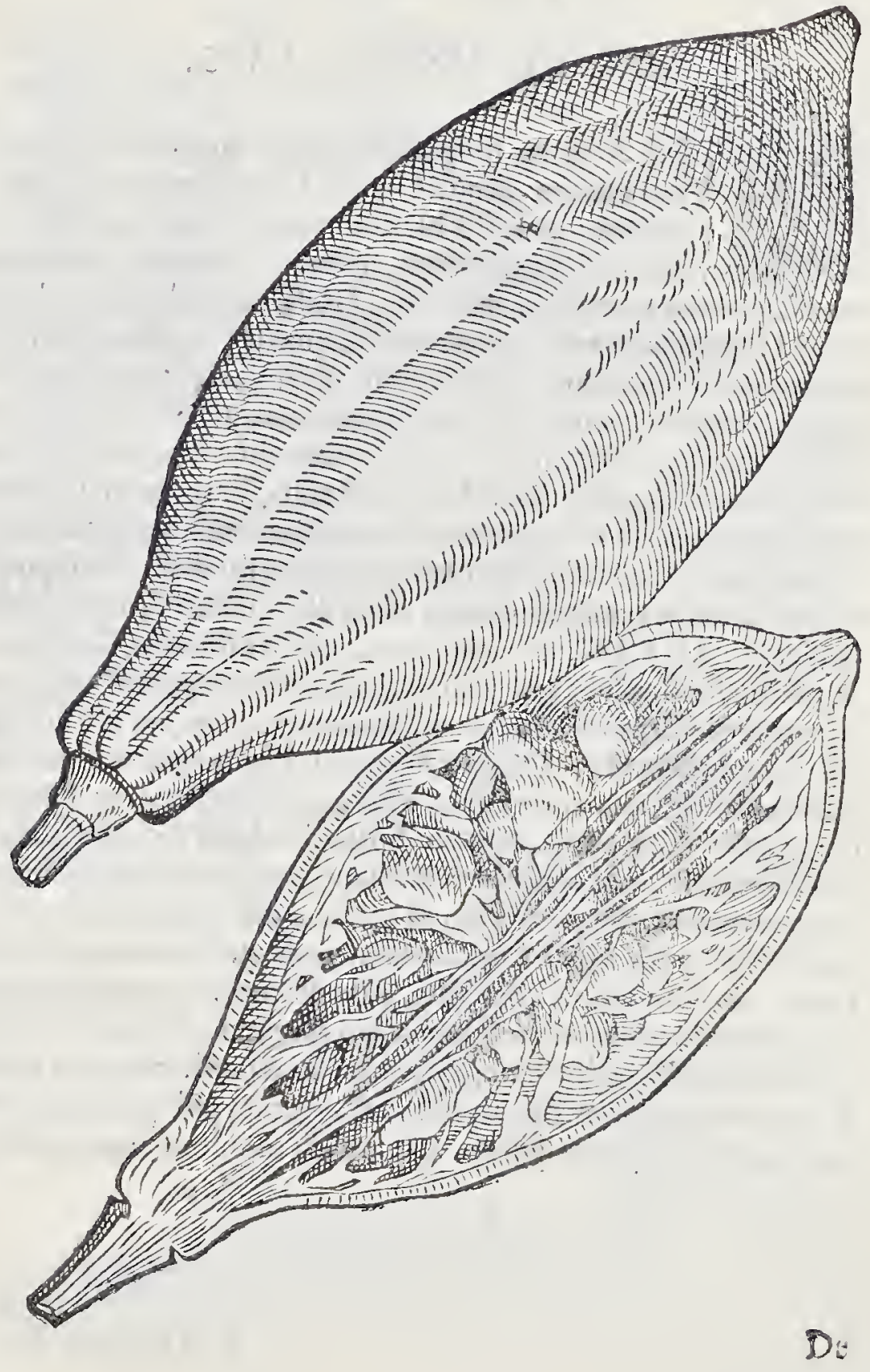




\section{FLANTIS AECYPTI}

De Goffeio arboreo, Gotne MJegiar appellato.
Cap. XV XI1.

\section{GVILA N D I N V .}

Trar V L T AM ne ibigoffipij copiam Aegyptij colligunt? 9. 1 / 3 Syria ctenim, atque Cyprus huius plurimam copiam

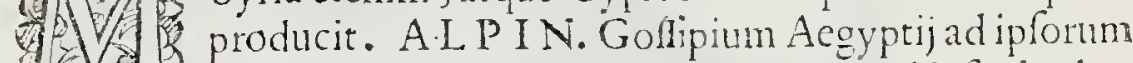
S. vfum aliunde aduehunt, neque enim apud ipfos herbacea illa planta, ex qua Syri, uel Cypri Goffipium colligunt, adnafci tur, fed tantum qux arboreus frucex eft, quxque in quibufdam tantum uiridarijs prouenit, pluribus annis uiuens, difimilis ab herbacea tantum proceritate, caudic is, ramorum, atque foliorum figura. Crefcit autem ad decem ufque cubitorum altitudinem, ftipite, ramisq́ue duris lignofis. G V I L. Quid audio ? arboreum Goffipiü ibi fpenari? noua certe omnibus herbarijs planta, nufquam hacte. nus uifa, aut cognita. Sed dic quefo multx ne ibi illius Goffypij plï tan nfemeur, ex quibus, queant ufum illius uftatiffimx lanuginis cxplere? A I P IN. Paucx, \& non nifi in uiridarijs, Goffipij arborcs illa fperantur, quz candem, quam herbaceum, ferunt lanuginem:que (ois modicam penes ipfos quantitatem) in ufu non eft, feci aliundeaduecta. Vtuntur Aegypij, linearum pctiarum loco, quibus noftri tantum utuntur ad ulcera, uulneraque omnia fananda: quando lineis peti,s, apud noftros ad uulnera ulcerag; frequen tata, illi non utantur . adhibent \& ipfa, uti noftrifaciunt, ad filuente fanguirem fiftendum. Seminum quoque mucylaginis ufus eft fre qumisimus ad omnes febres exurentes, atque uenena erofionem uentrir io, ix inceftinis inferentia. Ad tufsientes ex acrium, falforüquc inmorun diftillationibus, gorsipij plurimus eft apud cos ufus. In Arabia c $x$ hac xilni lanugine telas illas tenuifsimas (quas feffa il li appellant, arque multis byfum antiquorum effe perfuafum ent) parant, qux utique ob pulchritudinem ab omnibus comendantur. 


\section{I B E R.}

GOSSIPIVM ARBOREVM GOTNEMSEGIAR.

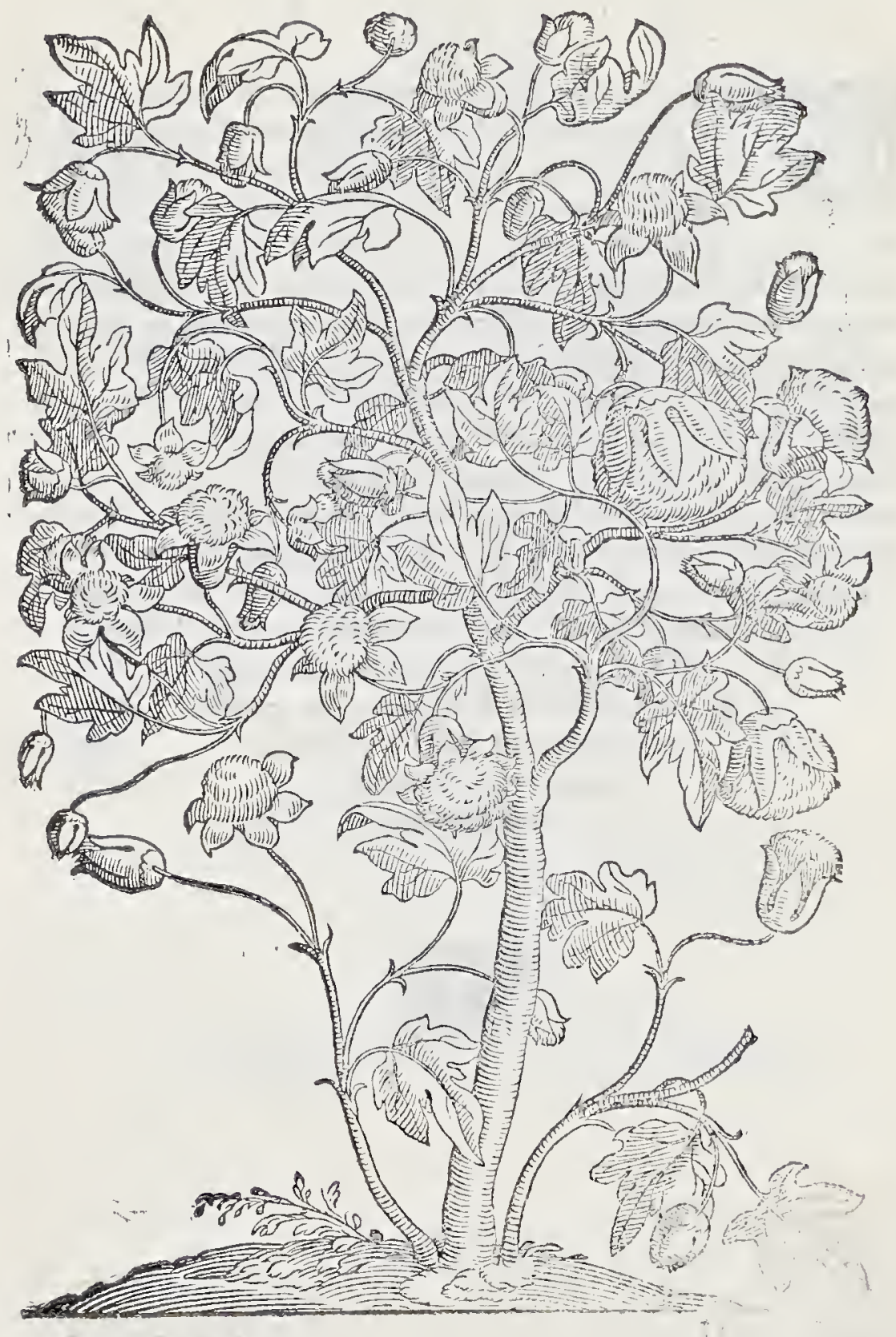




\section{DE PLANTIS AEGYPTI}

De Sambac Arab. fue Gelfimino cArabico. Cap. XIX.

\section{A I P I N V S.}

75 A Y R I eft frutex farmentofus, qui farmentis ferpen: 40 do altius fe extollit, folijs mali aurancij proximis, floa res albos, octonis folijs prxditos, omnino fimiles vulas garibus iefmini floribus, à quibus differũt numerofioribus folijs, magnitudine odoreque preualidion, ac fuatiori.vfus florum eft magis ad ornatum corporis, quàm ad fanitatem.nihilo. minus parant olcum, quo vtuntur mulicres in balncis ad vterum. calefaciendum \& laxandum, cius enim fcirrhofis tumoribus maxi. me conferre expertx funt, vt partum ctiam faciliorem reddant, olcum hoc \& bibunt calidum, \& ipfo liniunt extrinfecas uteri par. tes. Vtuntur quoque eo exterius inungentes thoracis regionem, tum per os ipfum calidü bibentes, ad tufim, anhelitulque difficultatem, \& ad pleuritim lethalem, in qua fputum maxima cum diffis. cultate educitur, \& ad peripneumoniam, atque ad dolores ychementes ftomachi, inteftinorum, atq; vteri; Parant hoc noftri vnguentarij ex dulcibus amygdalis atque vel fefani feminibus, ex quibus

odore florum iefmini imbutis oleum exprimunt valde odoratum. 


\section{I B E R. $\quad 30$}

SAMBACLESMIN ARABIGYM.

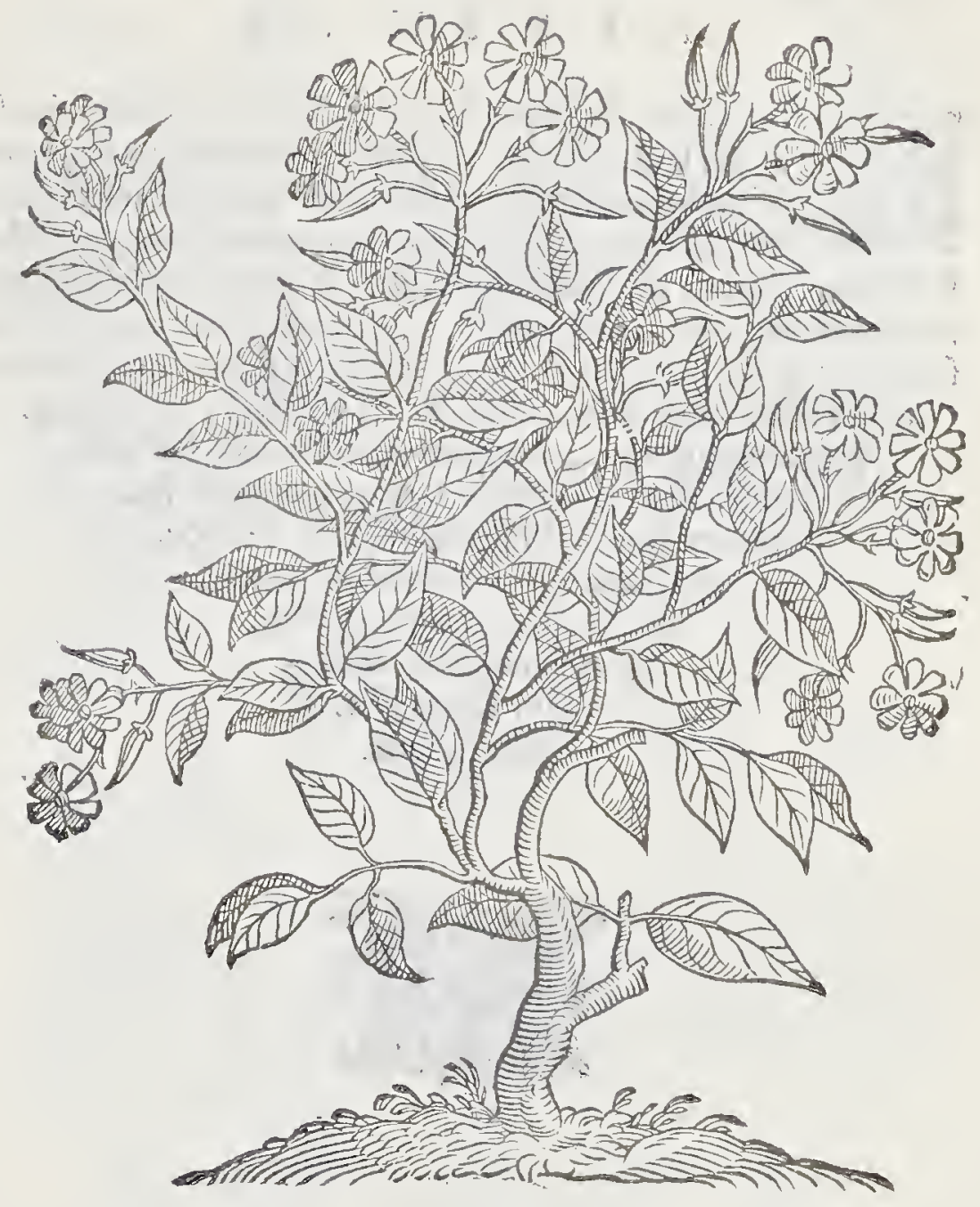

H \& De 


\section{DE PLANTIS AEGYPTI}

Dephajedonigrolabiab vocato. Cap. $X X$.

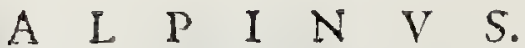

RJ ay ST arbor farmentofa, qua crefcit ad vitis magnitudinem, farmentisq́ue vitis modo extenditir, ac expanditur folijs, figuraque fimilis eft omnino vulgari phafeolo, flores ferr bis in anno, verc, ac autumno, phafeolorum floribus aliquatenus fimiles, à quibus filiqux long: inftarque fabarum latifimse cornuntur, quxe femina nigra phafeolis planè fimilia continent, quorum alia nigra, alia fubrubra ccrnuntur. Hxc arbor uiuit annos centum, \& amplius perpetuoquc viret. Aegyptij phafeolos illos in cibo frequentant, noftrisq́ue non minus guftui fuaues exiftunt. Mullieres utuntur decocto cum croco ad excitandos menfes. praterca utile eft ad tuffim \& difpnram, \& ad urinam fuppreffar mouendam.

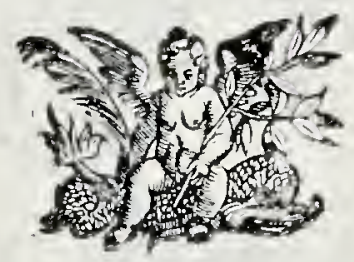


PHASEOLVS NIGER LABLAB.

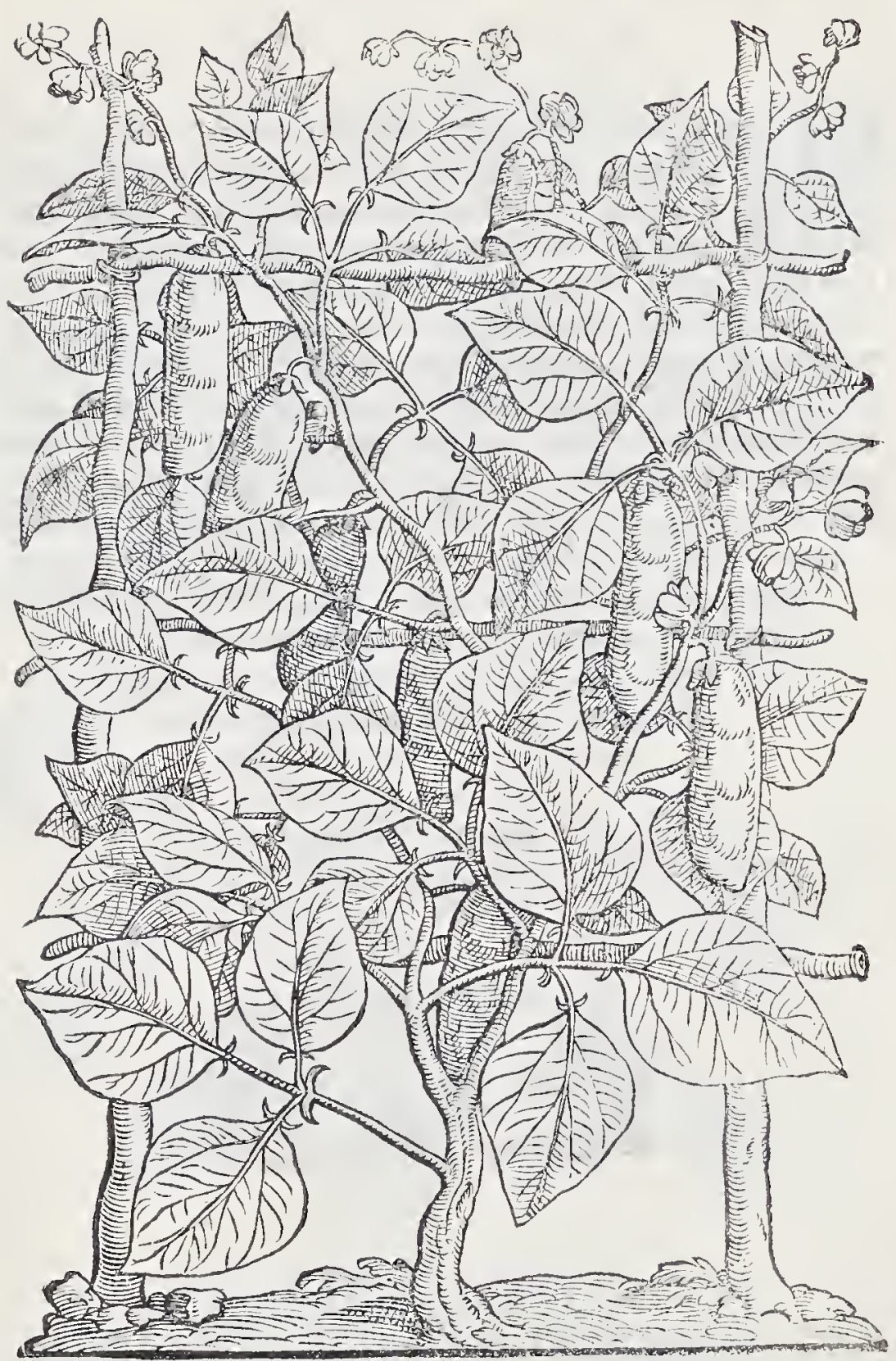

De 


\section{DE PLANTISAEGYPTI \\ De Phafolorubro, cAbrus voc.zto. \\ Citp. $X X Y$ \\ A L P I N V'S.}

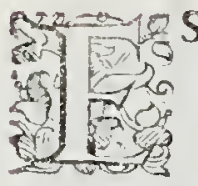

S T etiam arbor fruticofa, farmentofa, lolubilis, atque lahlab modo ferpens, ac altius fe extollens, latiufque fe expandens, folijs derelfide uel Tamirindi, plané fir milibus, fed longe minoribus : mouenturque etiam non fecus, quam de tamarindi folijs dictum eft, ad Solem: Occidente quippe Sole clauduntur, totaque claufa manent, quoufque Soldenuo oriatur, quo tempore rurfum aperiuntur. Flores audio ferre hanc arborem phafeolis proximos, atque filiquas, qux in tus habent femina parua, rocunda, rubra, dura, phafeolis omnino fimilia:qux quidem corallorum uniones, quas collo puellx geAure folent, omnibus plane videntur.phafeolorum guftum \& ip habent, quormm vifus eft ad cibum, ijfque Aegyptij in iure elixis uefci confueuerunt. Sunt vero creteris omuibus difficiliora, ex quo ftomacho maxime infeftę funt, Aatufo; multos concitant, \& hypochondria

cis valde noxia obferuantur, cgerrime que in ftomacho concoquuntur, \& prauum fuccum etiam generant.

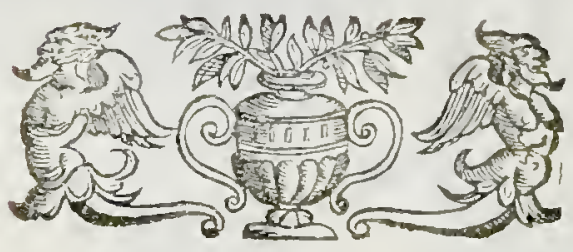


L I B E R.

A B R V S.

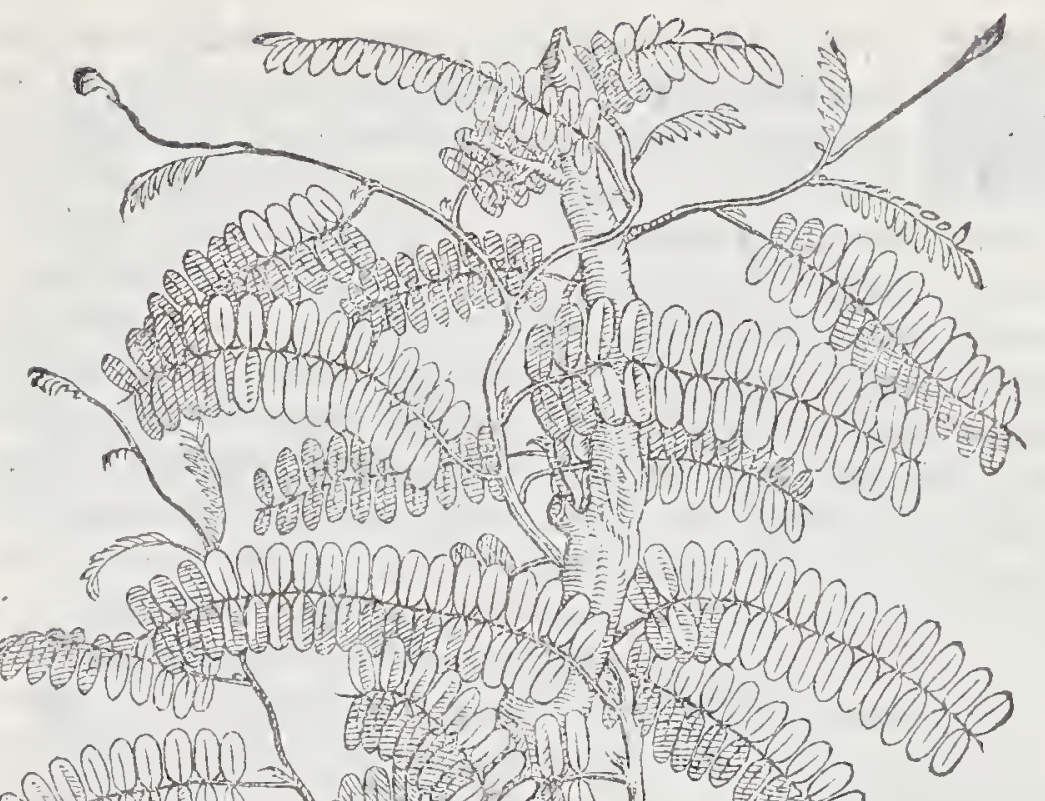

Ex

(1)

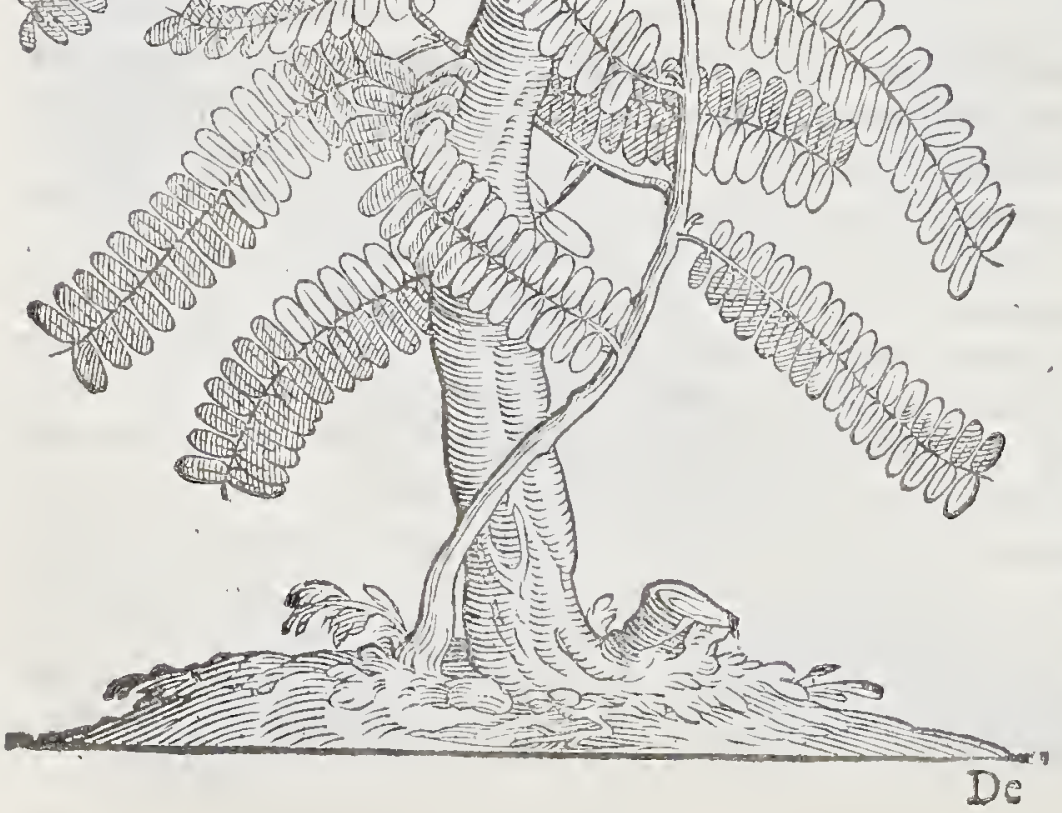




\section{DE PLANTIS AEGYPTI \\ De MauR Jeumua. Cap. XX11.}

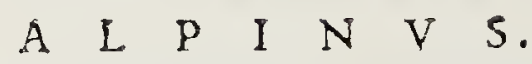

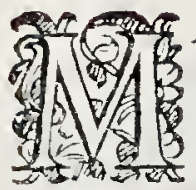

A VZ arbor apud Aegyptios vocata,crefcit in mulcis locis Acgypti, profertimq́ue Damiat $x$, olim Peluif; ad mali punici magnitudinem, fed ramis caret; nam inAar cannx folia fua fargit, qux fic longifima funt, \& latifima, utfex, feptemque cubitorum in quibufiam uifa lit longitudo, \& latitudo fere duorum . aiunt multi infitam hanc plantam olim fuiffe canne faccharinx fupra culcaffẹ radicem, uereque imago utriusq; in ea cernitur, longitudinem cannar ü, \& latitudiné culcaffix in folijs adepta perpetuo uiret, nunquam folia decidunt. Hæc planta fruetus fert multos, paruis cucumeribus fimiles fed racematim multos appenfos. Color ipform exterius aureus cemitur, corticesque fuauiflimum odorem, atque aromaticum fpirant. fubfantix ipforum cucumerorum perfimilis aliquatenus exiftit, fed eft tamen mollis, pingtis, lenta, dulcis, atque adprime fuanis, eam comedere affueris, feminum, uel nucleorum expers. Sto machum gravat, dificulter concoquirur, multum nutrit, ficcumque craflum ac léum generat, quo uifceria obftuuntur,prefertimque hepar: eft tamen auxilio tunientibus, fupiriofffue ex calore factis.eiufque decosto wiliter utuntur, ad tuffm ex calidorum hu morum deftillatione genitam, atque ad pleur $\&$ pulmonum infä mationem, at que ad renes infammatos, \& ad eos, qui mingunt dif ficulter.aint exian fructum efum, : l decostum afumptum, uene rem angerc. Fratum cortices cxiccatos multam uim habere ad roboranda omnin uifcera illi afimant, cordique opem ferre ex ip fis paratun decofum io aqua calaf. Vfufque huius decoti ad febres pefite es apudeos dicitur valde vilis:puluere quoque ipforum corticum in cordis nafionibus cí acla calaf diffolutam epo. tã. GVIL.Planta hxe rheophrafo fub nomine palme fuit nota, atque Serapioni, gu de ipfa ca, qux ad hominum falutem ex te re citancur, adm fere dixement. Nemincm ucro nouigqui,quod tu

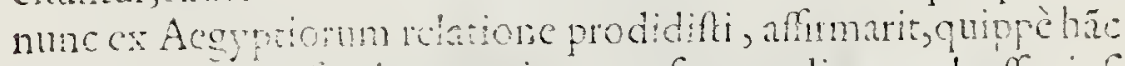

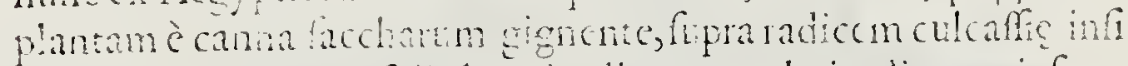

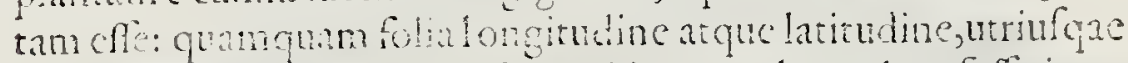

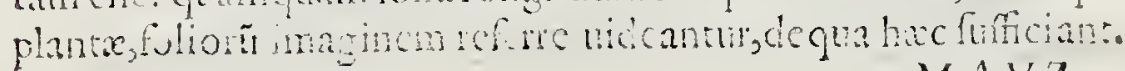
$M \perp V_{2}$ 


\section{I B E R:}

\section{$M \quad A \quad V \quad Z \quad M \quad V \quad S \quad A$.}

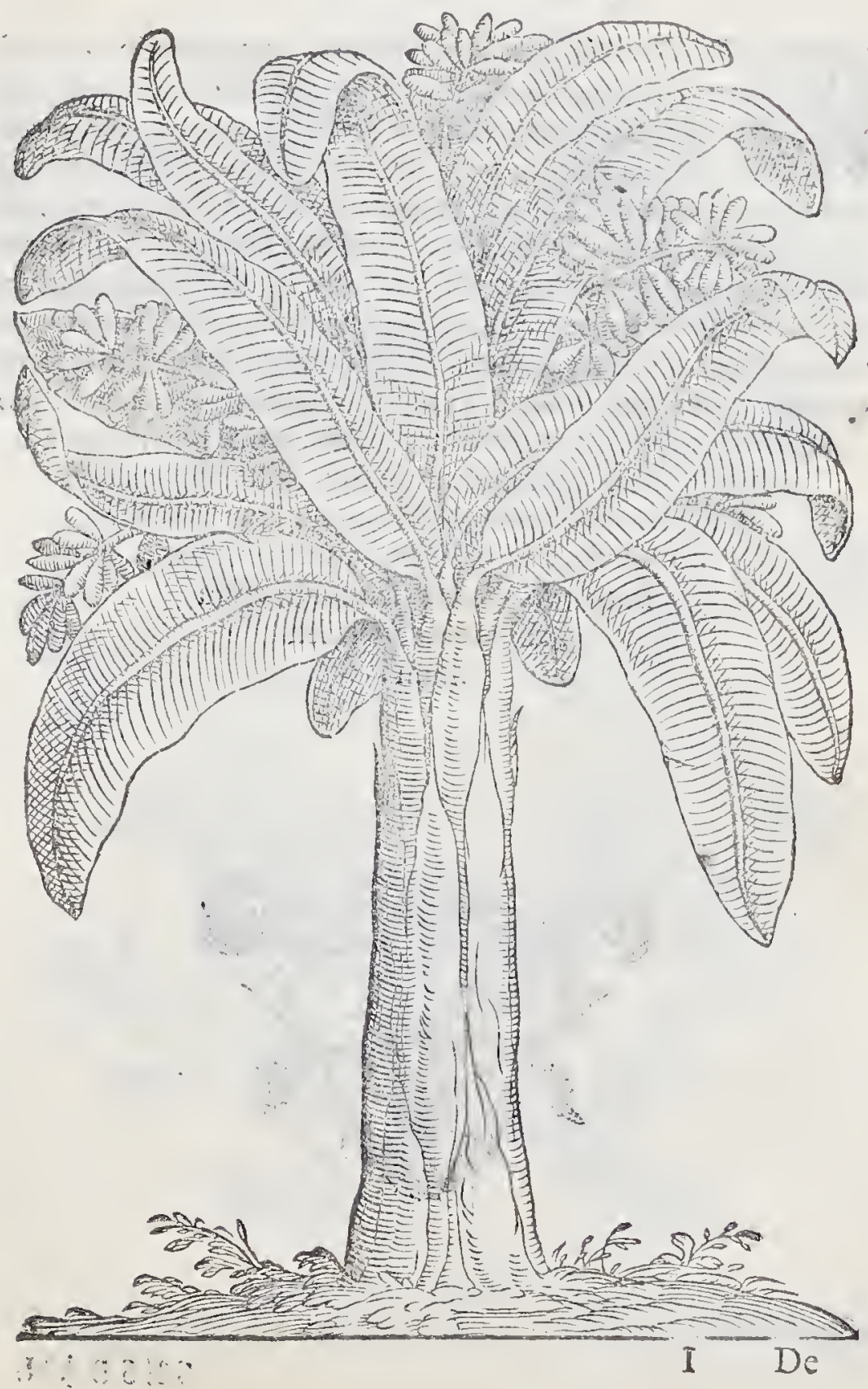




\section{DE PLANTIS AEGYPTI \\ De Scsban. Cap. $\quad X \quad X \quad l \quad l$. \\ A L I I $\mathrm{N}$ V S.}

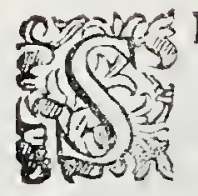

ESBAN ibifrutex eft myrchi magnitudine, folijs fecuridaca, fed longioribus \& anguftoribus, ramos habens herbaccos teneros. Alores fert croceos, anagyridis perquam rimiles, raccmatim multos ab ala vel ranulo pendentes, à quibus filiqux longx producuntur, fenugreco proximas, in quibus femina funt etiana feminibus fanugręci non parum finilia. His futicibus Aegyptij utuntur ad fepes texendas pro agrorum diftinctione. femina hos in medicina ufus habere noui, etenim aiunt, humentem ftomachum ftccare, roborare, \& ipforum quoque ufum tum in decocto, tum in pulucre affectant ad cohibendum quemcumque alui fluxum, atque non minus ad menftruorum immoderata protunia fiftenda, ex ipfis infignem vtilitatem expcriuntur: \& ut vno ver-

bo dicam, in omnibus vacuationibus, firmand is illorum feminum vfum

habent frequentisfimum.

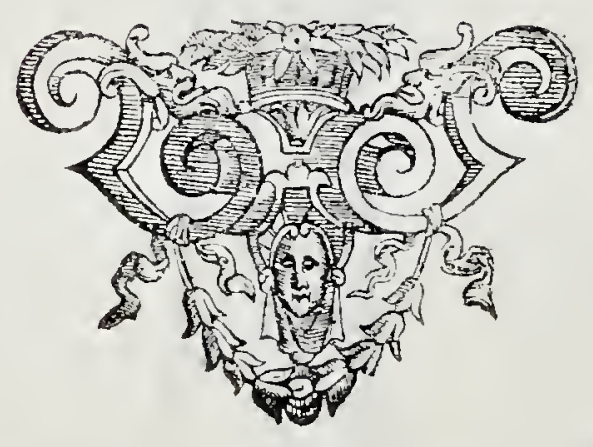

SESBAN. 


\section{I B E R.}

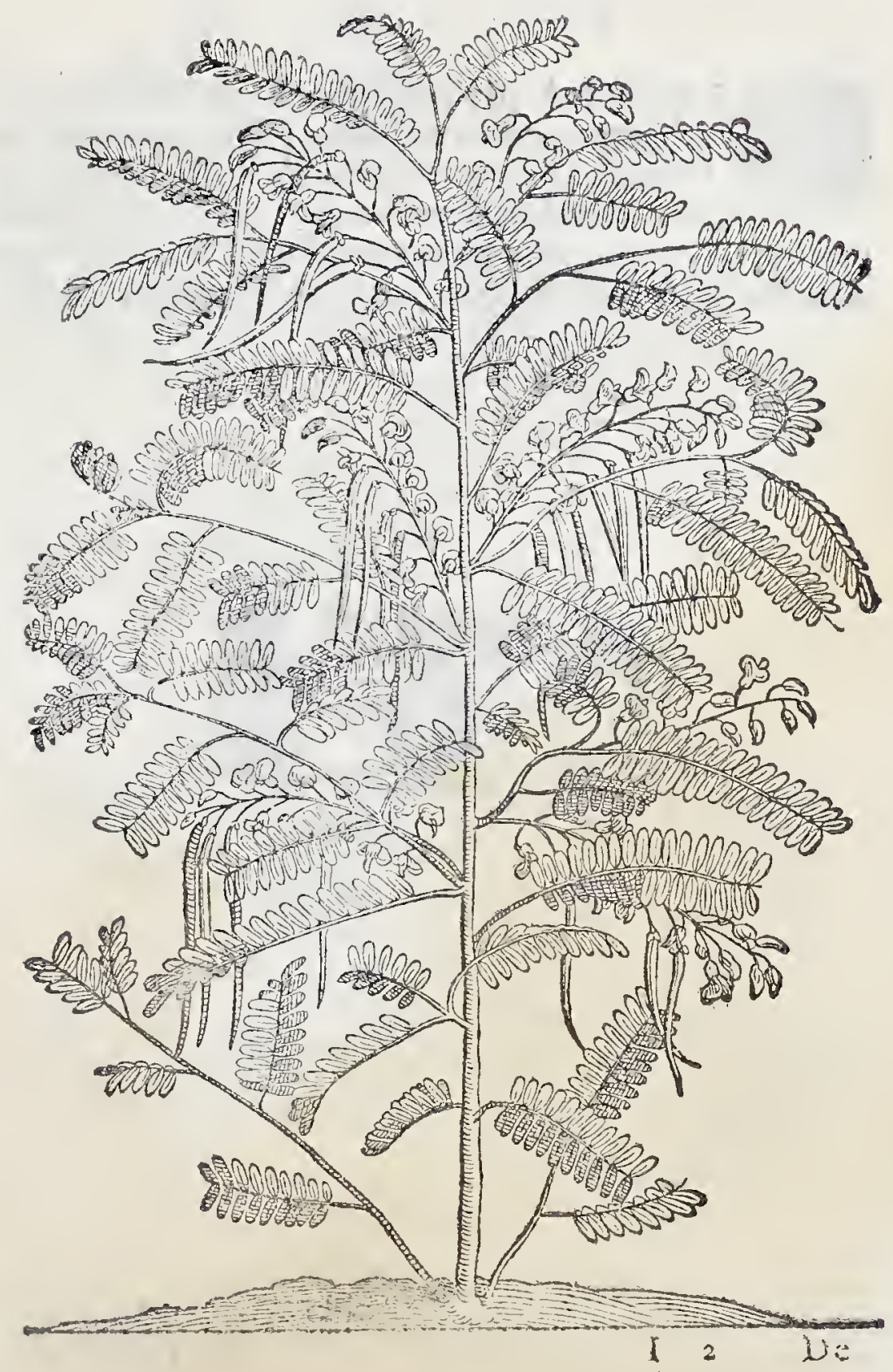




\section{DE PLANTIS AEGYPTI \\ Desophera. Capo XXIIIT: \\ A L P I N V V.}

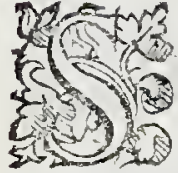

O PHER A cft planta fruticofa cubitalis altitudinis, galega proxima, duris ramis, folijs myrthi, tenuioribus mulris,verinq; ordinatim alę appéfis: foreses fert cro ceos,caffix florum amulos, inodoros; ex quib ins filiqux parux promanant, quatuor aut quinque femi:a habentes, Sesban plane fimilia .Aiunt femina effe uenenum hominib.s.

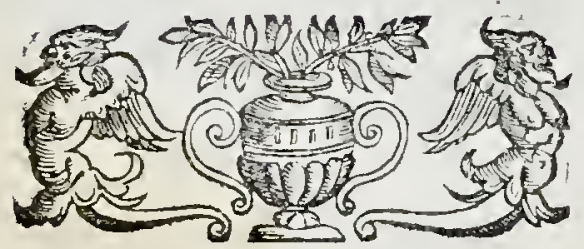




\section{I B E R。}

$S O P H E R A$.

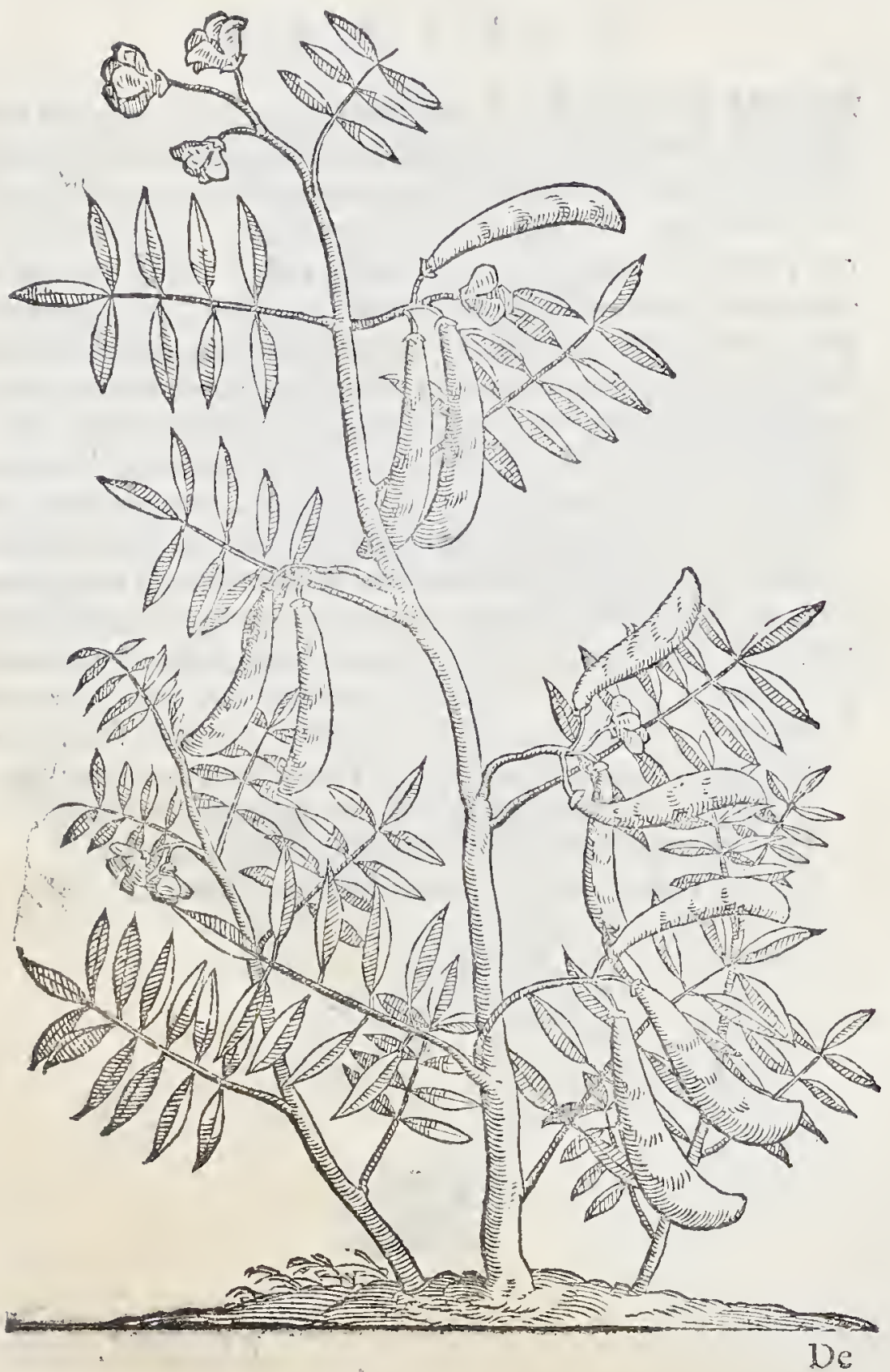




\section{DEPLANTIS AEGYPTI}

\section{DeBeidelfar. Cap. XXV.}

\section{A L P I N V S.}

Th EIDELSAR nafcitur in humidislocis prope Ale: andram in ramo Nili Calig vocato, \& Cayri in loco - Is prope el Matharia fere perpecuò humida ac fere pala Aris, ex aqua Nili ibi diu manente. eft planta herbacea, fruticora, multis folonibus ab radice rectis furfum ad duorum ferè cubitorum altitudinem fe extollens, folijs latis obló gis, rotundis, ut Aloes folia, craflis, \& candidis, ex quibus diffectis lac albim manat.totaque planta lacte abundat. flores fert croceos ranunculi foribus proximos, à quibus loco fructuum duo teltes inuicem adligati pendent, fat is homin is teftibus perfmiles, in qui bus alba lanugo \& femina parua, lata, lactucre feminum ęmula con tinentur. Folijs contufis, tum crudis, tum in aqua coctis utuntur cmplantri modo in frigidis tumoribus, \& doloribus. ex lanugine pa rant cubilii, quibus utuntur. Vtuntur etiam ea ad excipiendum ignem ex filice excufium, tanquam efca, ac pabulo. tota planta la Ete calidifimo, ac exurenti feater, quem plures in quiburdan uafis colliguniad expilanda coria, ca fiquidem in co lacte fialiquo tépore maneant, pilis nudantur. Lac quoqueficcatum preftantius corpora foluit, atque dyfentericos fuxus ctiamlethales facit. Eft ctiam proftantifsimum remedium ad impetiginem curandam, \& ad plures alias cutis infectiones fanandas, co fi inungantur par-

tes.

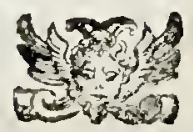




\section{I B E R.}

B E I D E L S A R.

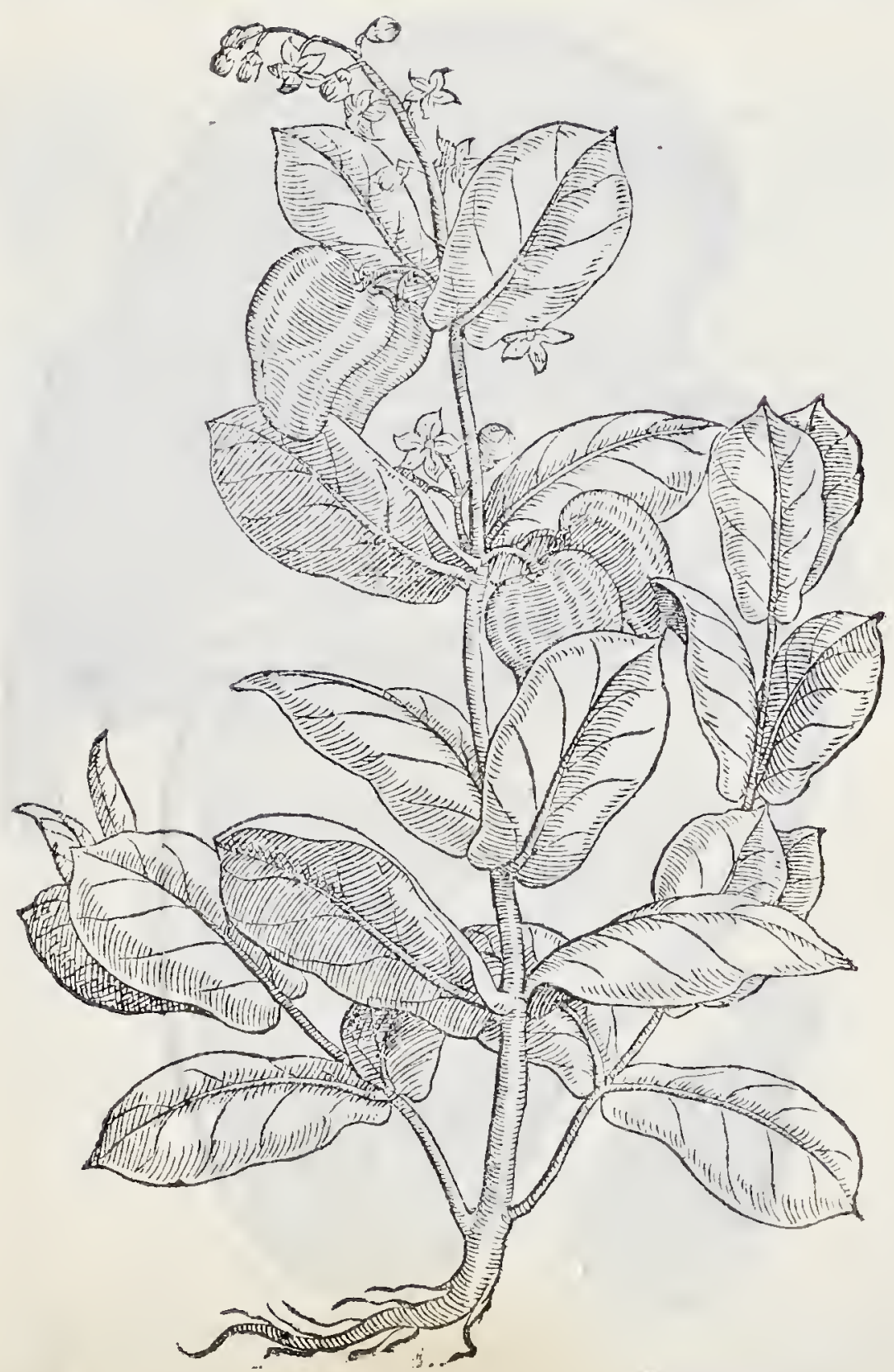

ERVCTVS 


\section{DE PLANTIS AEGYPTI}

\section{ER V C T V S B E I D E S A R.}

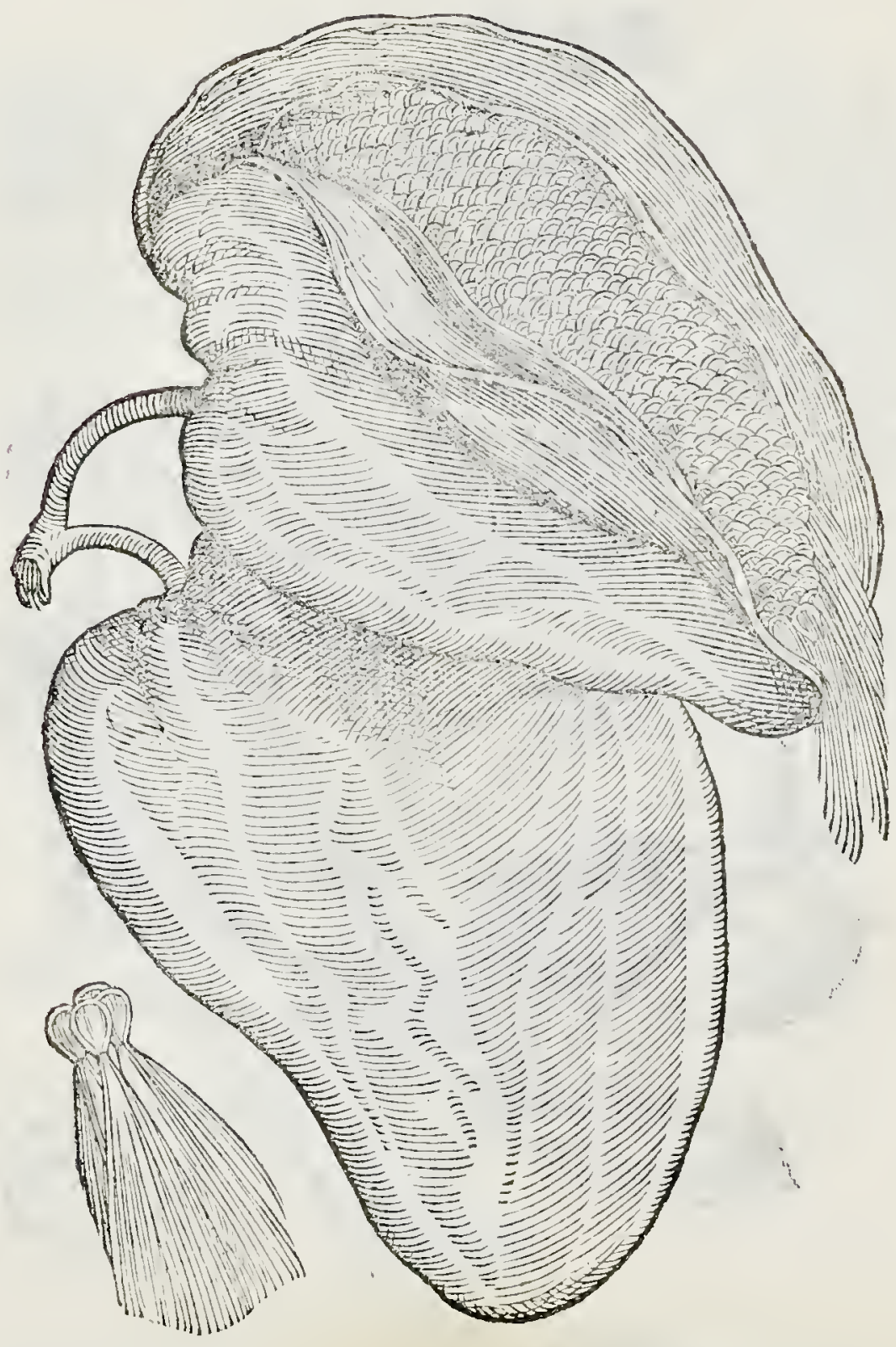




\section{De Achouanabiat, idefiartemifia alba. Cap. XXVI.}

\section{A $\quad L \quad P \quad I \quad N \quad V \quad S$.}

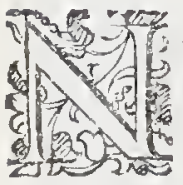

A S C I T V R Cayri in locis multis qurdam planta fruticofa, ramis denfa, quętrium cubitorum vfque ad altitudinem afturgit, folijs artemilix intus nigris, atque extra candidis, tota planta lanuginofa, feu hirfuta,florefque fur vmbellx modo, multos, aureos, fenccioni proximos, qui tandem in pappum degenerant flores, foliaque funt parum odorata, fapore fubdulci cum aliqua ftipticitate. hanc volunt multi ipforum effe Achaouam maiorem ac albam, quippe artemifie feccicm, ex quo ipfi eam appellant Achnouam el chebit abiat; Cuam plantam noftri temporis herbarij alij cinerariam, alij Iacob.earn marinam, vocant. Aegyptij ea ad multa vtuntur,quippe de. coetmin $\mathrm{Cx}$ folijs paratum ad rentim, veficxáue calculos pollere aiunt, nec non ad fanandas vifecrum antiquas obftructiones, præfertimque ad vtcri obltructiones, frigiditatem, ftrangulatio$n \mathrm{~cm}$, fterilitatem, inflation em, atque ad menfes interce pros renocandos, proinde paratis ex folijs, flori-

bufque in aqua infeffionibus mulieres hyfericx maxime iluantur. G V I L.

Noua quidem eft planta. Antio quis incognita, nifi fub arthemifix fpecic quis ipfam reponat.

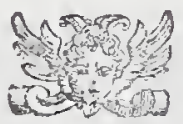




\section{DE PLANIIS AEGYP il}

\section{A C H A O V A N A B I A T.}

0

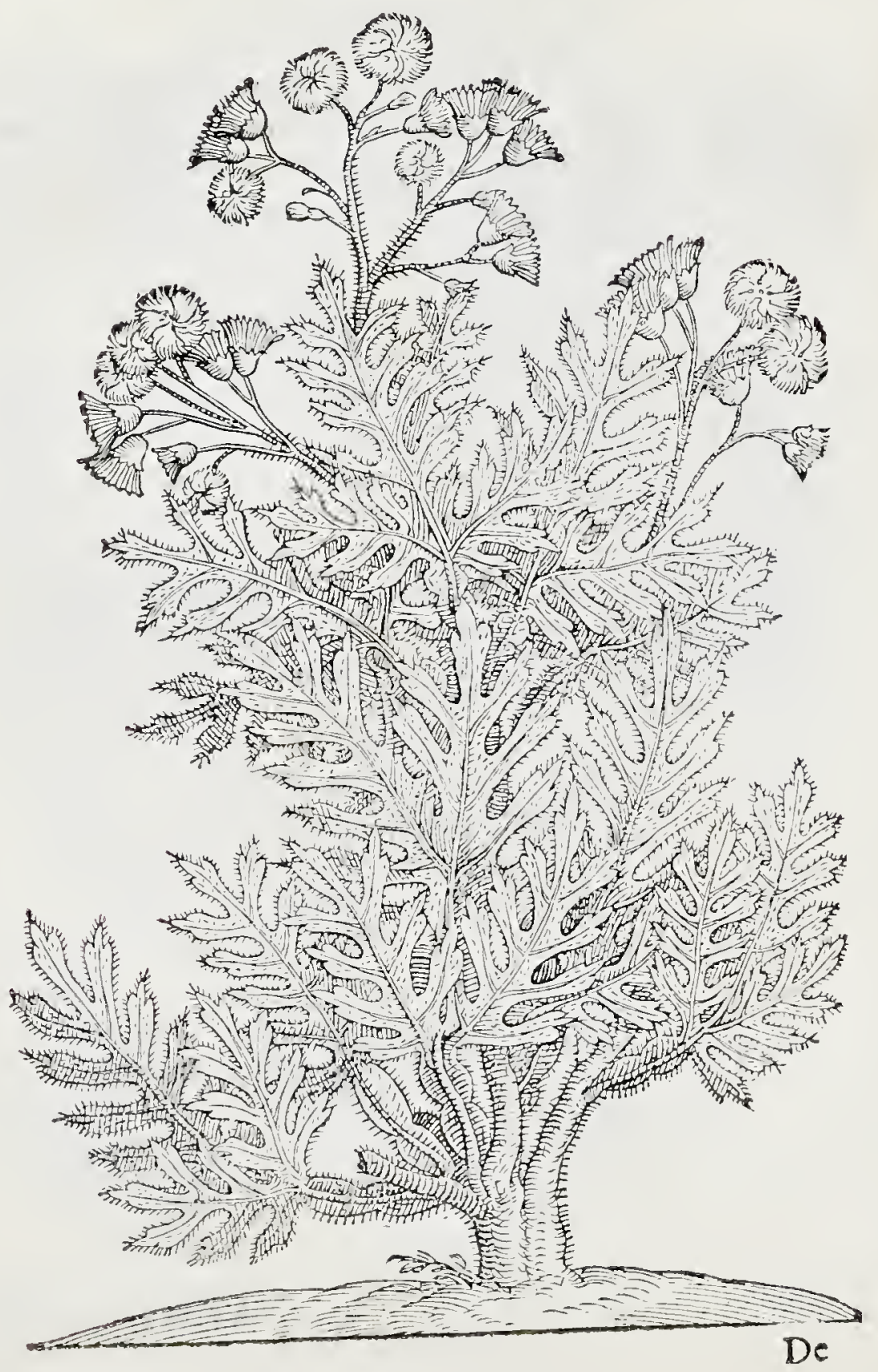




\section{I B E R. 38}

\section{DeBammia. Cap. XXVII.}

\section{A I P I N V S.}

A M M I A eft planta ad althex magnitudinem. folijs floribufque malue, aureis tamen, à quibus fruEtus funt, fimiles quibufdam paruulis cucumeribus, qui femina parua, fubnigra, rotunda continent . que apud illam gentem ad cibos in vfu exiftunt. ex quibus fuminibus non fecus quàm noftri ex phafeolis, pifis, alijfque leguminibus fercula parant. Frequentiffmeque his ferculis uefontur plerum. que in iure carnium paratis. folia, fructufque frigidos effe, \& hunidos in primo graduaiunt, habereque vim ipfos refoluentem, $2 \mathrm{C}$ emollientem. proinde pectoriac pulmonibus conuenire, ventrem emollire, a tque lubricum reddere fomenti uel emplattri modo fo lia appofita inflammationes refoluunt; dolores mirigant, tumores emolliunt, concoquunt, ac ad fuppurationem fuppurandos mouent. Mulieres ad uteri curitien, tum fomentis, tum emplaftris tum infeffionibus ex folijs ac fructibus procuratis, multa cum utili rate vtuntur. in renum uerò infaramatione, \& calculis, ex ijfdem paratum decoctum per os clm faccharo candido fumptum aliquibus diebus, pro électiflimo au xilio habent.ad ophtalmias etiam finita flu xione decoctum colirij modo fre quentant, atque cum eo fomentare latus dolentem

in pleuriticis folent.

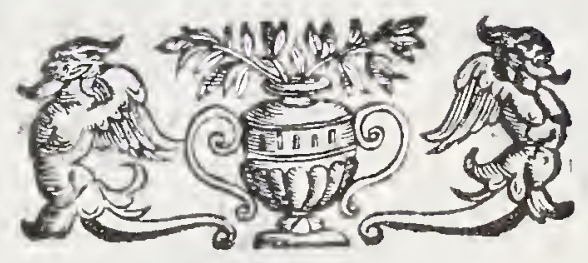

$K=$ BAMMIA. 


\section{DE PLANTIS AEGYPTI}

\section{B A M M I A。}

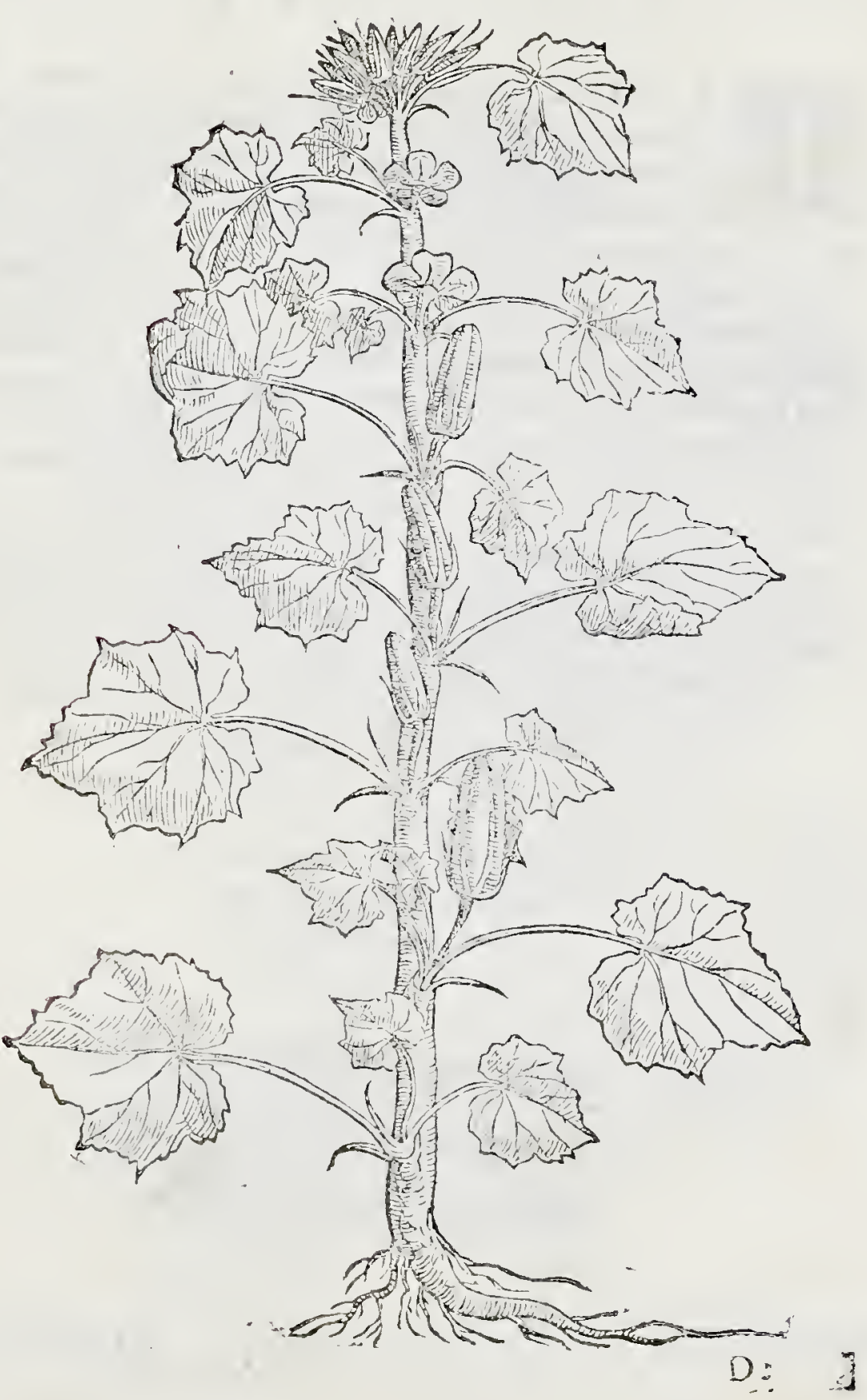




\section{I B E R.}

De Milocisia.

Cup.

XYYII\%

\section{A L P I IN $Y$ S}

5) 30 EL O CHI A cf herbablito perimilis, folia tamen anguliorag logiora, acutiorać, habens flores. cius funt parui, croceilucoris minoribus, e quibus femina parua, nigra melanthio proxima, in quadam oblicua cornua conclufa, producuntur. femina funt in inaximo apud eos vfu ad omnes affectus, quibus femina althex conducere compertum eft.nam melochia facultate planè fimilis althere videtur:proinde ad fuppriandos vel concoquendos, refoluendos, atque emolliendos thimores duros, eius maximus ufus eft . habet etiam maiorem vifciditatem cius mucilago, quam althea. In cibis nihil eft ipfa Acgyptijs familiarius, uel gratius:decoquint enim in aqua uel iure carnium, ut nos betam elixare folemus. Conuiuia carentia melo chix ferculis ab his parum reputantur . cibus quidem illis populis melochia eft familiariffimus, ex quo multi tamen male fe habent, nam parum nutrit, \& fuccum vifcidum gignit, ex quo in difficiles obftructiones vifcerum, qui cam in cibo frequentant, incurrunr, ni hilominus melochiam in cibis non omittunt, precipueque vifofiorem mucilaginem facientem, auide omnes efitant. Eft tamen

totius plantæ, uel maxime foliorum decoftum pectori amicum, ipfum enim humectat, ex quo ficcis, afperifque tusfibus prefentaneum cum faccharo candido eft auxilium.atque agre f pirantibus.Semi-

na quoque pondere duarum drachmaruin fumpta copiofisfime

purgant omnes humores. 


\section{DE PLANTIS AEGYPTI}

\section{$M$ E L O C H I A.}

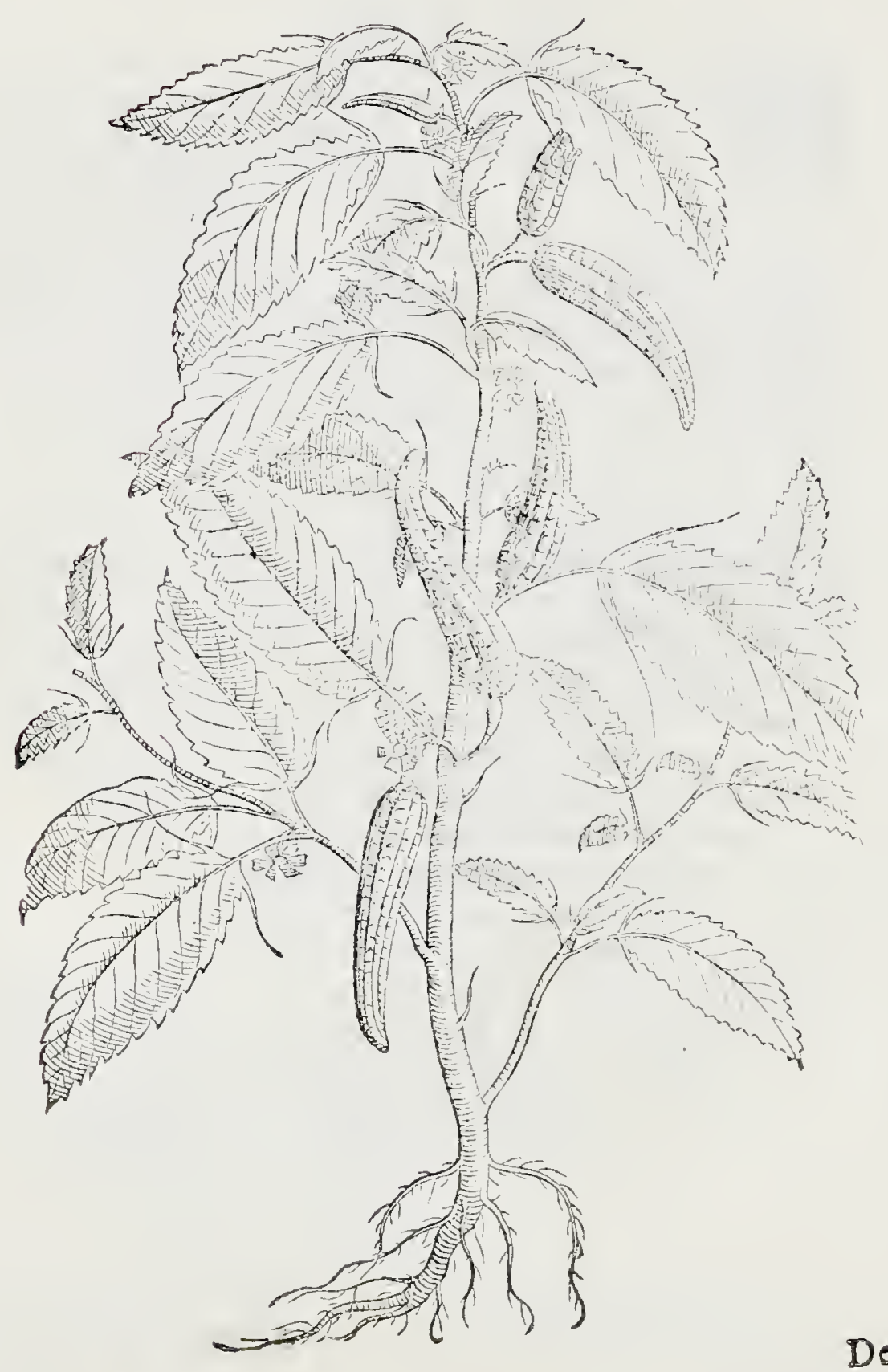




\section{I B E R: \\ De Zatarendi. \\ Cap.}

$X X \perp X$.

\section{A $\quad L \quad P \quad I \quad N \quad V \quad S$.}

VOcant ii quandam herbam Zatarendi ( quod ex India illuc co̊ portetu' ) parum crefcentem, foliis craflis, rorüdis, ac albis, fucco plenis, multü odoratis, qure neque flores, neq; fructus edit - quä multi, ut origanum, ficcatam pro obfonio comedunt. Audio apud multos ad tufim, fpirandique difficultatem, \&a ad prouocandam vrinam,ac menftruas purgationes in viu effe.

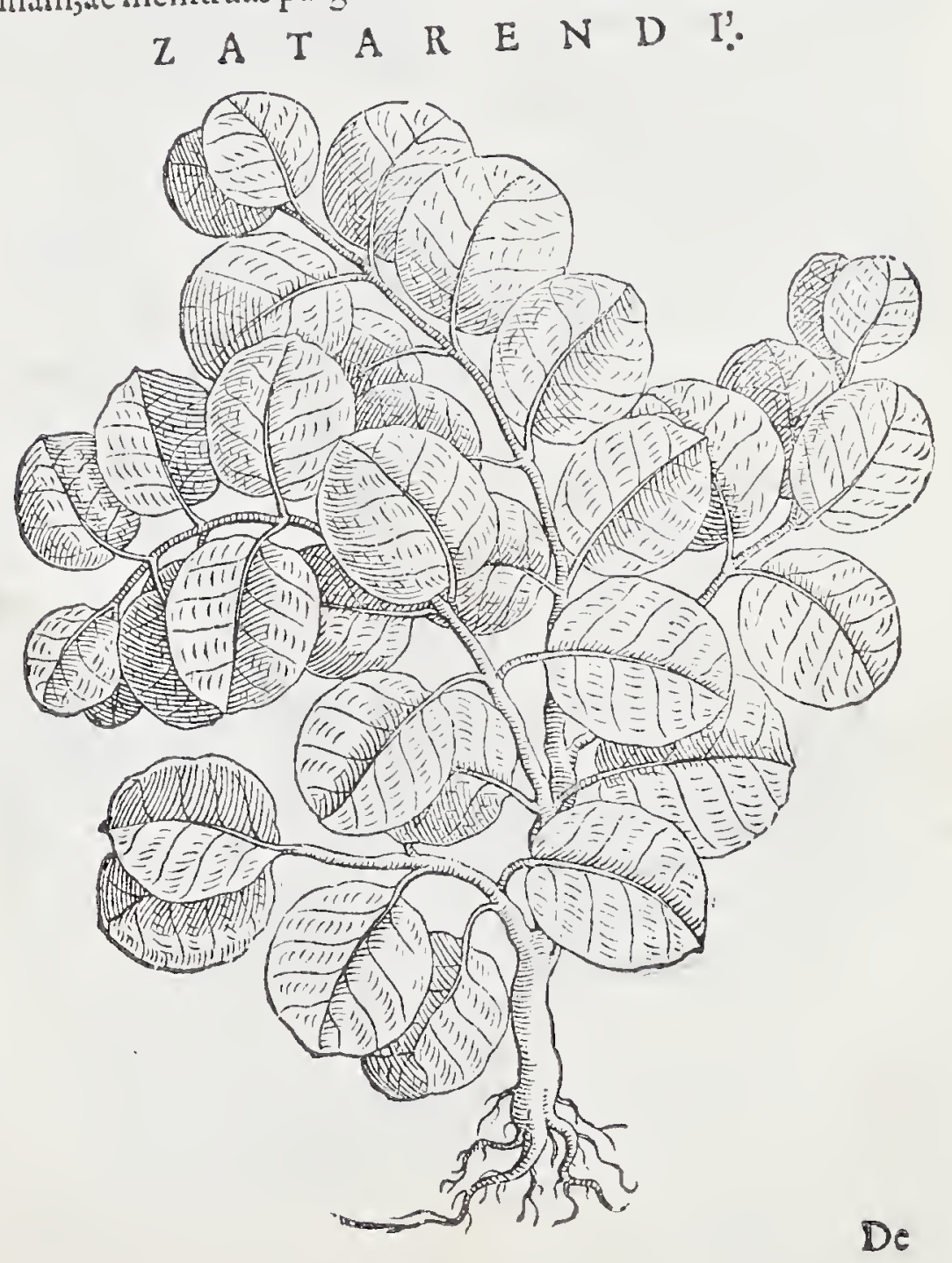




\section{TIE PLANTIS AEGYPTI \\ De pipere longo. \\ Cap. \\ $X X X$}

\section{A I $P$ I $N$ V S.}

Dese ST quedä herba in viriarijs quiburdi cuntodita, iunci 20 folis, fed craftoribus, è quibus fertis fuccus quidat fa01 Tô 10.5 lida in quarto gradu, magis quim piperexurens. Ea rtuntur emplatri modo appofta, ad coxendicis dolorem, nec non ad frigidos articulorum dolores, corrigunt vero nimim cius calo remoleo rofaceo, vel myrthino.

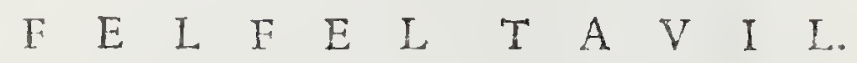

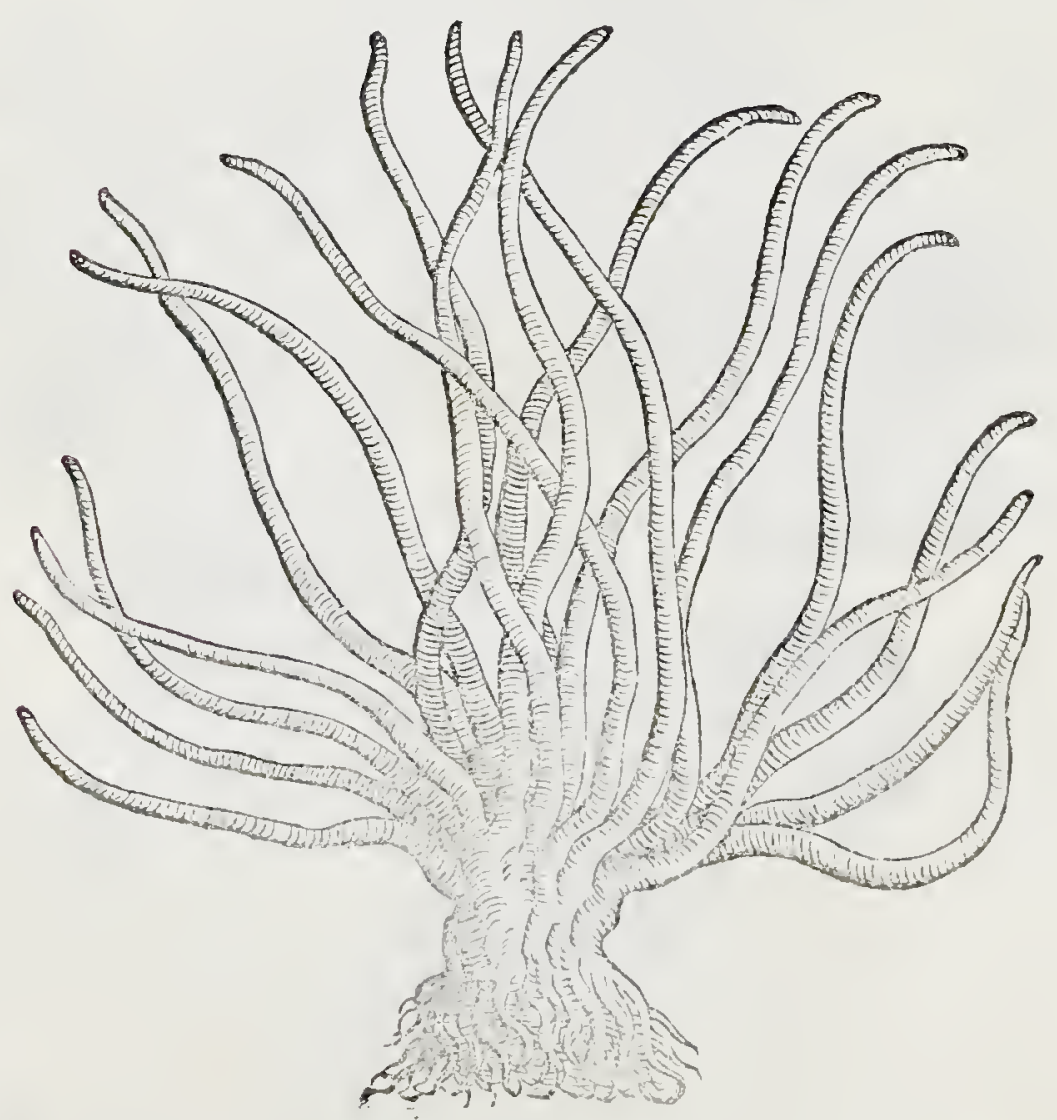




\section{I B E R。}
$A B S \vee S$.
De cAbfus. Capit. $X X X I$.

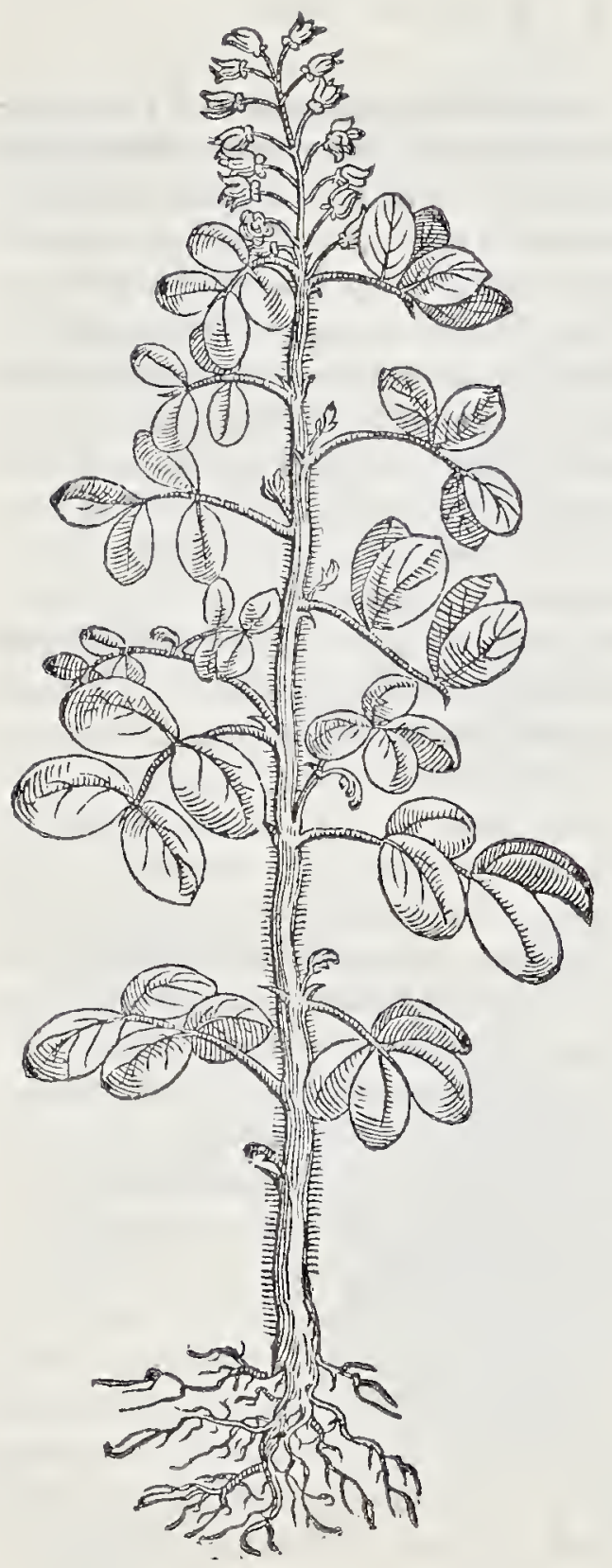

\section{A L P I N V S.} F S T etiam quaedam mi magnitudine, vel ali-s quăto maior, folijs trifo ternis fingul $x$ alæ appen fis. Flores paruos, albos, \& femina piri feminibus proxima ferens . quam Aegyptij Abfus yocant. lij, fed rocüdioribus, qua 


\section{DE PLANTIS AEGYPTI \\ Descfomo feu Sempen. Cap. XXX11.}

\section{A L P I N V S.}

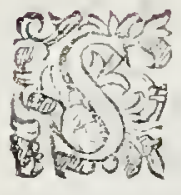

EMPSEN, à noftris fefamum, planta eft vinius calulis regti,fe at vaius cubiti altitudinem extollens, folijs denfis ordinatis totum caulen veftientibus, folatro prozimis, Aoribus albis parris'sa à quibus filiqux produ cuntur quadricoftas $x$, parux, femina tlaua, lini fimilia continent qux guftui dulcia exiftunt.ex quibus oleum, quod fitis appellant il li, quod ad cibos in frequentifimo viu eft, maiorique pretio, quàm oliuartm oleum ibi venditur. Folia, fmina, volcum fere cinfden facultatis effe experiunzur, quippè calider temperatr, atque humidę al fecundü gradum accedentis, refolientis, 花 cmollientis. Plan tæ decoet o utuntur ad ophtalmias refolued tes, fumenti modo ocu lis a lhibito. atque ad tufim, anhelitufque dificultatcm, pleuritidem, peripneumoniam, \& cumores duros feir hofos; mulieres pro uteri duritie infefiones, ex plära, ferminibusúu cun modico mel lis paratas frequentant: codem ad curis vitia vtuntur, quippe ad furfures capitis, liuorefque faciei, \& nigrotes ex fangune congela to exortos, calido fomenti modo fape appofito. ex planta \& feminibus in aqua concoctis cum modico mellis emplatera al tumores feirholos, atque ad exlic catos neruos parant, quibus utiliter fempar vi folent: quie etiam ad combuftas partes utiliter frequentant, noa minufquam ad calidas infammationes refoluendas, us fuppurandas.deco stum etiam inclyfteribus ad colicos do lorcs, \&xad em slitiendan aluum affectant- Múlieres ad mouendas menftuas purgationes, decostum ac iafurum in aqua paratum pro fecreto auxilio habentoneque fua $\mathrm{p}$ : hic, quibus precrafsitic fanguinis, venarumq́ue uteri obftrotione menfes non veniune, frufrantur. Saminis ad cibum ufus eic antiquatus apud omnes Acgypti accolas, pauci tamen eft nutrimenti, fed alimentum unetuofum ac craffun prebsecex quo, quam obrem ipforum frequenti efu muliares impinguefcant, facile deprehenditur . qux vero ipfanm corpora pinguefiri cupiant, femina ì corcice mundata comsdunt plus pinguefacit oleum ex feminibus exprefum, omniumgạe maxime fex olci thaine ab illis uocata. Oleunn fecemóuc cius

bibere, 


\section{I B E R.}

bibere, adhoc vt impinguefant, mulieres in balncis familiarifi. mü habent. Oleo etiam ad multa alia Aceypr juti confucucrunt, quippe ad cutis puftulas, afperitatem, ac omnem defedationen ex humore melächolico concitatam, tum epoto, tum in cibis freque tato, uel ipfo affectis paribus inuetis. Secretum apud quof dä auxi litim eft, ad cutis pruritus abolendos, cius quatuor untias multis diebus bibendam exhiberi. co etiam ij utuntur, ad anhelitus difficultatem, pleuritim defpratam, in qua nihil expuunt ægroti, atque ad peripneumoniam. necnon ad mouendos menfes, atque ad uehomentes ftomachi, inteitinorum, uterique dolorum cruciatus demulcendos, intus, extraque preftito . G V IL A N D. tibigratias multas habeo, qui mihi huiufce plantx tot tantafq; utilitates medicas ab ea gente compertas dixeris, quas dignas auribus ueAtrorum quoque medicorum cenfeo, quando non folis Aegyptijs hrec manifefta fuerint, fed multi alij preclarif mi medici cadé fere in pofterum memorię prodiderint, ut eft Rafis, Auicenas $\mathrm{Ha}$ ly, Serapio, atque alij. Sed nunc reftat,ut plantæe ichom nem fpectemus, \& an ea fit, quam aliqui pinxe-

runt, qui in illa dubij cx Theophrafti lectlone decepti uidentur , hanc plantam remprem appellant.

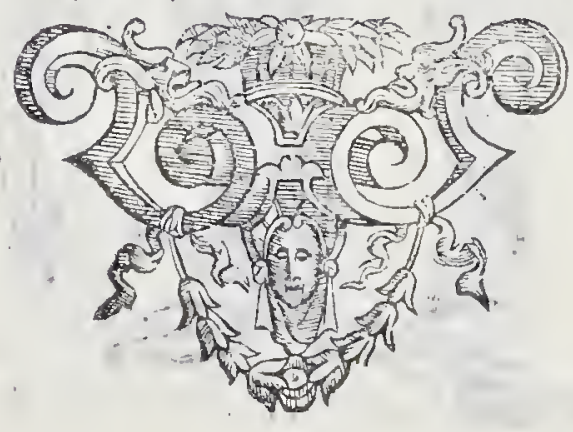

$1 \quad 2$ SEMPSEM 


\section{DE PLANTIS AEGYPTI}

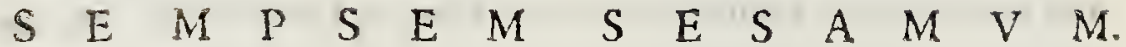

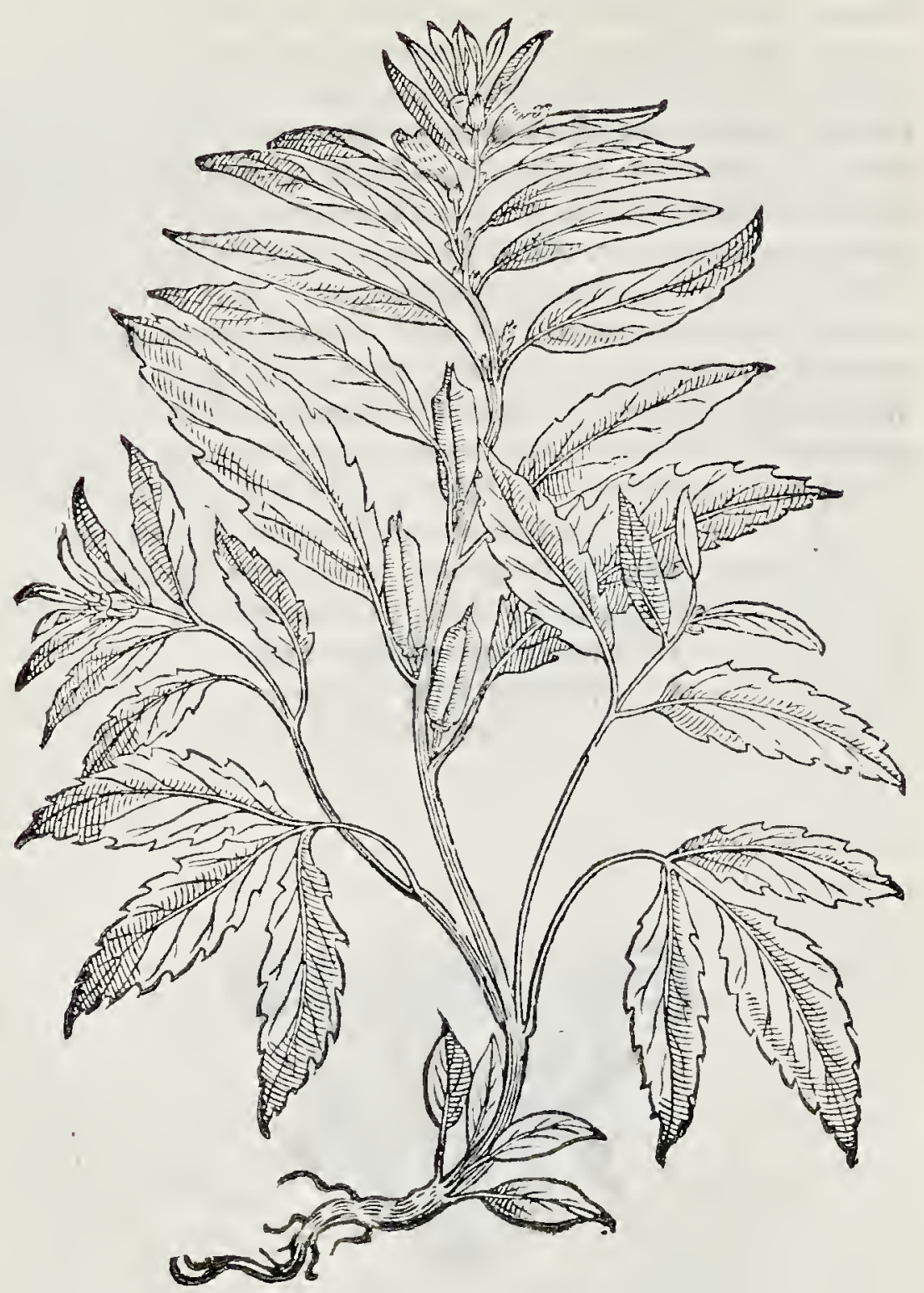


De Culcas fue colocaffra. Cap. XXX11\%.

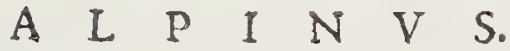

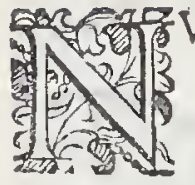

V L L A planta Aegyptijs colocafia, quam illi Culcas vocant, eft magis nota,neque magis in ufu, quando om nes radices huius plantę in iure coctas, atque alijs mul tis modis in cibis paratas affidue efretet. Nô fecufquàm noftri rapas.agri colocaffiis pleni ibi fpectantur, atque quod mira bilius uidetur,nemo illorum aliquam ipfarum plantarum floribus, uel fructibus ufquam pręditam uidit. Ego ex innumeris illis uiuentibus à me ępe infpectis, nullam unquam florentem uidere aut cum aliquo fructu, uel aliquo caule, potui.Ex quo dubitandum uideretur, eam plantam effe Gręcorum fabam Aegyptiam.planta hax ibi fpectatur folijs nenupharis,longioribus, ari proximis, fine caule, flore, at que fructu:eius radix magna, craffa chinę radicibus fi milis cernitur, fapore fubamaro acri cum aliqua uifcofitate, qua coeta dulcefcit.quotidie paffim toto anni tempore per urbem innumerẹ radices uenduntur, uiliori pretio. Hinc fanèmultum femper miratus fum,Diofcoridem, Aegyptian fabam fores, atque fru Etus ferre, \& eam item colocasfiam effe prodidiffe. Quam plan tam quoque co nomine Aegyptij nominät, quippe culcas. Quam nufquam foruiffe, nullumque fructum dediffe neque vidi,neque alìquem vidiffe unquàm audiui:cuius litem relinquo alijs libentif fime dirimendam. Eam tum crudam, tum coctam libentiffme ue neri indulgentes mandunt,tum quia putant femen multum gigne re,tum libidinem preualide mouere.

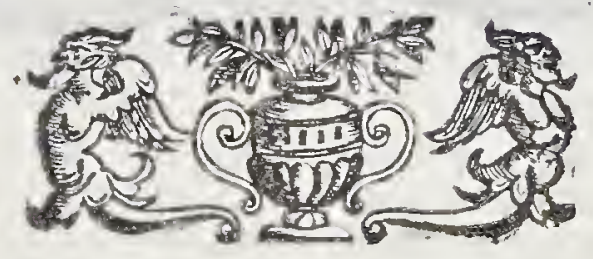




\section{DE PLANTIS AEGYPTI}

\section{CVLCAS FABA EEGYPTIA.}

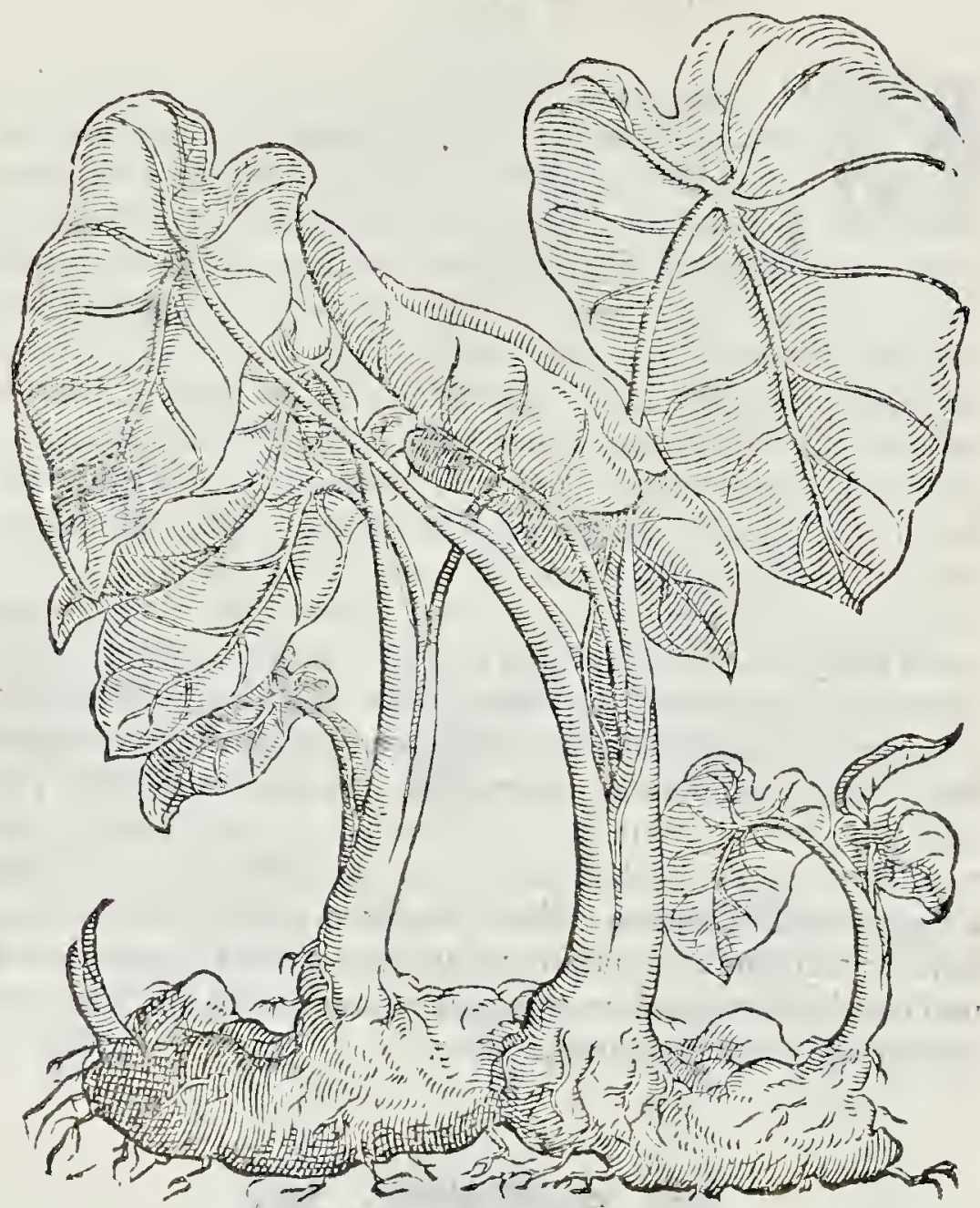




\section{I $B$ E R:}

De Loto clegig:io Nuphar vocata. Cap. $X X X 1111$.

\section{A $I$ L P I N $\mathrm{N}$ V $S$.}

2. ROXIMO de Colocafsia cognito errore, hic alius 1. 3 à nobis de Loto Acgyptio animaduertitur, quando 11 in hxe planta planè eadem fit, quam noftri nymphcam, atque Arabes Nuphar appellät. In toto quidem flumi mine Nilo Acgyptia loca lambente nulla alia planta eft inuenta qux notas loti prefeferat, quàm nymphea ipfa, qux profesto plan ta fimilis eit, ut de Loto affirmat D iof́corides, Colocafsire, feu Fabx Aegyptix, fioremque fert album (loquor de maiorinymphea) lilio valde frmilem, quam clarius exprefsit Theophraltus, qui dixi. \& flos candidus, lilijs foliorum angutia proximus;uere enim hic maioris nymphę flos eft, qui Sole occidente clauditur,atque fub aqua òccultatur, atque Oriente fupra aquam affurgit, \& foras exitsaperiturque. Quod non modo in Aegypto, verum in mult is Iralię locis in hac planta obferuatur, maximeque in locis omni bus circum Venetius lacunolis uel paluftribus. Valles fiquidem Margherę,ac Metri plurimas has plätas ferunt, in quibus quifque quod à Thcophrafto, Diofcoride, atque alijs multis de Loto dicitur,planè obferuari poteft. Et quid? non ne ctiam ex fore caput producitur, papurerum capitibus valde fimile? in quo femina multa minuta, qualia uere milij exiftunt, continentur, radixque craffa eft ? Nó poffum non vehementeradmirari Theophraltum, Diofcoridemq́ue, atq; alios, qui omnes a nymphea, diftinctilimis capitibus lotum Asgyptium feiunxerint, quando utraque vnum 2tque idem planèfit, \& mirandę ad folem conuerfiones de loto celebrate exdem fint, qux in communi nymphea ab omnibus animaducrtitur. Ipfa enim Occidente Sole florem claudit, deinde tota cum folijs fub aqua occultatur, eoque oriente, horé primo ex tra aquam demittit, aperit, atque paulo polt cum omnibus folijs fupra ipfam affurgit. Acgyptij caules crudos cum fuis capitibus per çtaris calores mädunt: fubdules enim funt,arque humidiad modumque refrigerant \& humectant, quos appellant Razelnil . G V I L A N D. Miror equidem non parum Plinij diligentiam, Lib $13 . \mathrm{C}_{3}$ qui hae feripferit.Mirum eft quod prater h.xe traditur. fole occi- ", dente 


\section{DE PLANTIS AEGYPTI}

feruentur, atque propè Meftrim ciuitaté in omnibus illis conuallibus. Ad Nympheę uel loti Acgyptii medicos vfus populis cogni tos nunc prodeas. A L P I N.V tuntur foribus \& follijs contufis ad omnes calidas inflammationes, arque etiam fucco, pręfertimáque ad demulcédos dolores,a calida caufra obortos, lacete atq; olco ro faceo mifto, eodéque itidế modo oleo, quod ex foribus parăt ad calidos dolores, inflammationes, exuftiones, ulcera, \& dolores ca. piti in febricitâtibus, uigilijs,tum exterius folia côtufa applicant, tum eius fucco cum olco \& aceto frontem \& tempora, illiniunt.ad conciliandum fomnum fyrupun ex eo paratum frequentant, atque tum ferminum, tum radicis puluerem ęrotis cum cius decocio exhibent. Vfus radicis,feminumg; fecreti loco habetur apud multos, ad gonorrhxam, \& in mulieribus ad album profluuium firman dum, \& ad dy fenteriam. Multi uero ab huius plantę ufu cauêt,cius loco alia fequentes, co timore ne eis cocundi tum defiderium, eum vires minuantur . apud eos etenim omnes cöpertum eft vfum feminum, atque radicis homines reddere ad venerem valde frigidos,ac tardos. Hinc vfum hunc multos ibi fanctos heremitas fequi audio, vt facilius uitam Calibem ducere queant. Fed iam ad papy rum fermo à nobis conucrtendus eft, quando hęc planta quoque in Nilo flumine nafcatur. Verum quoniam omnia de, hac planta tum ad cognitionem,tum ad vfum pertinentia te in Plinij capitis de papyro commentario (quod papyrum vocafti ) planè profe sutum fuiffe fcio,paucis de ea mihi nunc agendum puto. 


\section{B E R.}

De Stratiote, Haibalem maosi vocato.

Cap. $X X V$.

A L P I N V S.

EI. V S I V M nunc Damiata vocata, ciuitas in Acgy pti humiliori folo pofita eft . quo fie, ve Nilo Humine ad eam perlabente (quod pene ipfam fpacio quinque millia paffuum in mare mediterraneú cuomit) largius eius folum inundatur, \& ad libitum irrigaiur. Hincq́ue multa xtiora atque amoniffuna, quàm in toto Acgypto reperiantur pro pehanc vrbem, viridaria canijs, limonibus, mufis, vitibus confita, atque inter fe more Italico foffis (qua alibi in toto Acgypto nufquam reperiuntur) aqua fuminis decurrente plenis, diftinsta fpe etätur. In illis itaque forfs quxpram herba copiofe prouenit, aquar lenticula palutris modo fupernatans, fine caule, folijs Cynoglofi, breuioribus, latioribus, denftoribus, durioribus, hirfutioribufque ac albidioribus, à quibus pro radicibus exigua ac rara quędä lanu go pendet. Qux planta maiori fedo, vel femperuiuo eft finilis ; Quam appellant Hayhalem elmaoui, quari dixerint aquofum $\int_{c}-$ dum. Nullo odore en referta, eo excepto, quem ab aqua accipit.fa pore tamen adfringenti, ac ficco linguam ferit, non fecus quam acacia faciar. Ad eadem ipfa mala ij vtuntur, quibus plantaginem conducere compertum eft. Ex quo mulicres ruftic $x$, quas Bedoui vocant, ad frfedam fanguinis eruptionem ex utero, atque alijs par tibus, eius decoetum, vel fuccum, vel puluerem per os quotidie ad drachmę pondus fumunt. Ruftici quoque ad vuulnera fan anda fo lijs cótufis fuperpofitis vtuntur, mirificcóue ca fanant. eamq́ue fri gidam vfque ad primum gradum, \& ficcam fupra fecundum illief fe arbitrantur. GVILA N D. Hanc plantam verum effe Stratiotem antiquorum exiftimo, de qua Diofcorides hre nobis pro- Libit diderat: Stratiotes in aquis nafcens, aliquibus fuuiatilis Stratiotes nuncupatur; Aegyptijs 'Tibus, Magis Acluri fanguis. Aquis fupernatat, \& fine radice viuit, vnde cognomen traxir. Herba f.m peruiuo fimilis, ni maiora haberet folia. Ad eademq́ue mala, ad qux ea Aegyptios nunc vri dixift, prętare Diofcor.etiam fcribit, Itaque non erit dubitandum hanc herbam effe fratioré. Quod ap. ${ }^{8}$

M clarius 


\section{DE PLANTIS AEGYPTI}

clarius Plinius demonftraffe hifce verbis etiam vifus eft. Celebratur autem \& à Grecis Stratiotis, fed ea in Aegypto tantum, \& inú datione Nili nafcitur, aizoo fimilis, ni maiora haberet folia. A L P I N. Verum loqueris. Sed ad alia tranfeundum elt.

\section{HA YHALEM E L M A O VI I DES T Stratiotes.}

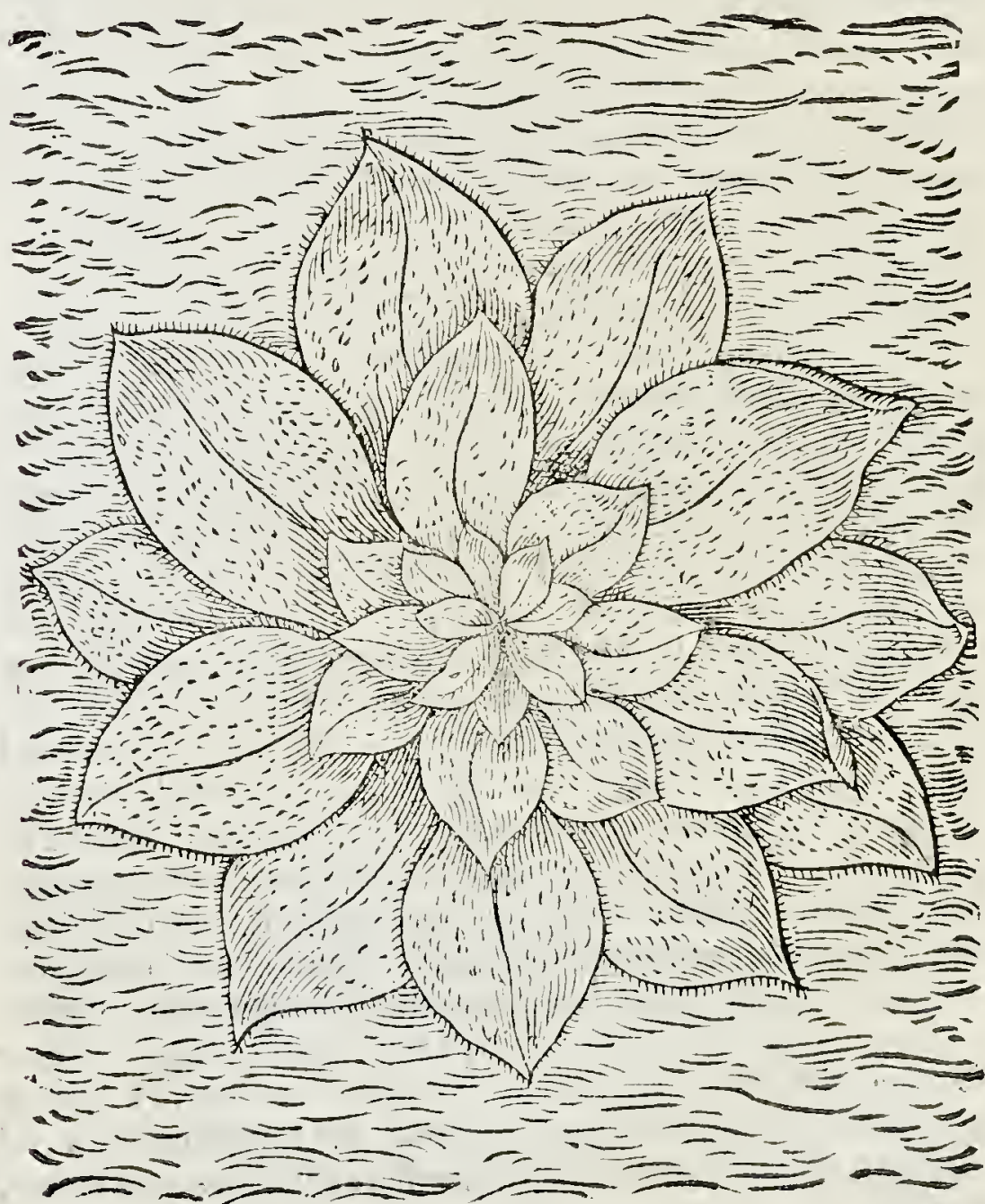




\section{I $B$ E}

\section{STRATIOTES AVERSIS FOLIIS.}

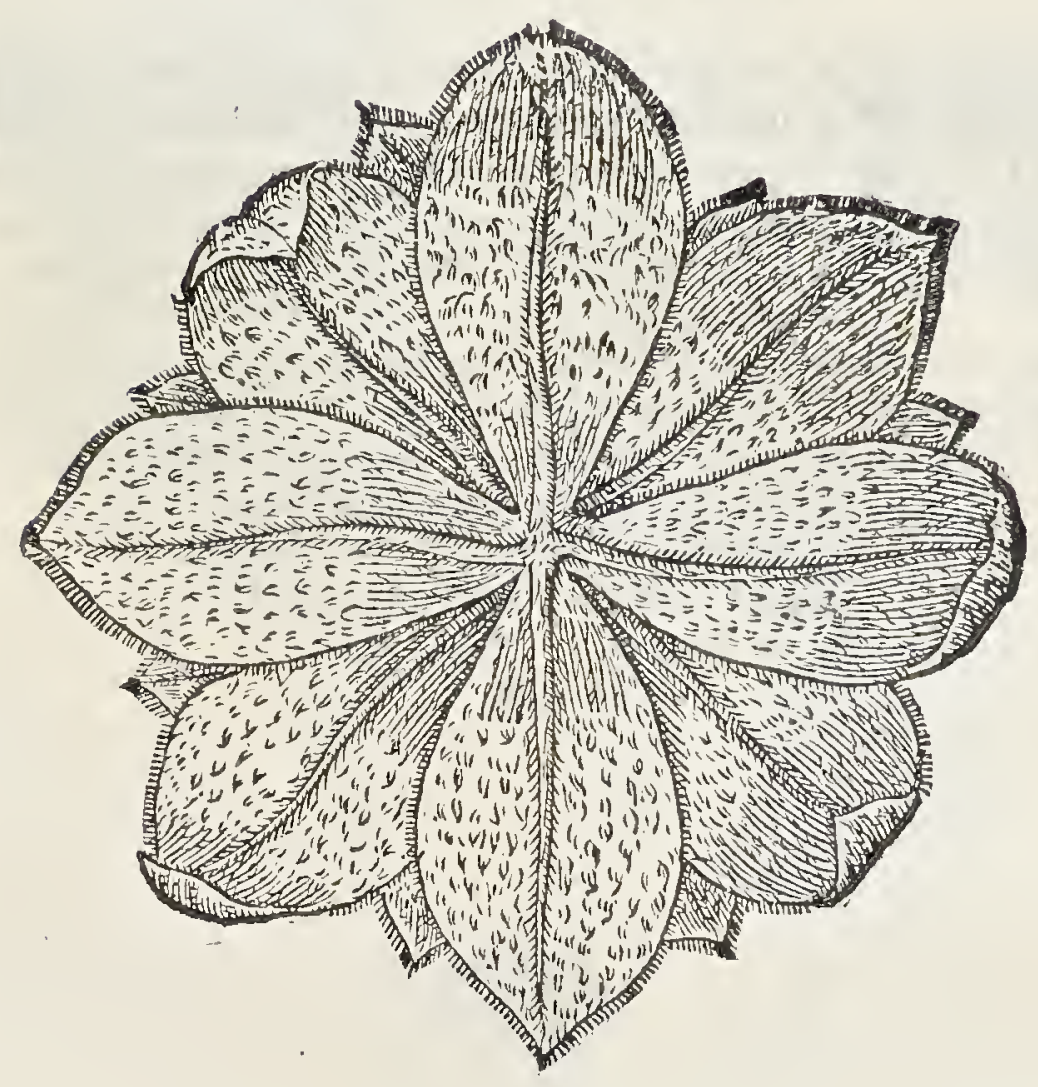

$M 2 D E$ 


\section{DE PLANTIS AEGYPTI \\ De PapyroBerdrocala. Cap. $X X X V l$. \\ $\begin{array}{llllllll}A & L & P & I & N & V & S \text {. }\end{array}$}

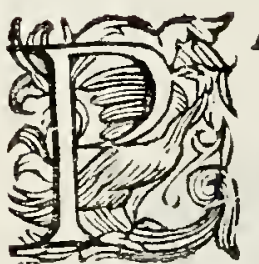

A P YR V S, quem berd Aegyptij nominant, eft planta fuminis Nili, binis aut pluribus caulibus re ctifimis fupra aquam fex, feptemuc cubitibus affur gens. Cauliumque in faftigijs fcapus inumeris cas pillamentis, longis, rectifque contextus, cernitur . Folijs quoque confat multis rectis, enfiformis, tifphr aliquatenus fimilibus. triangularibus, ac mollibus. Chyrurgi oliorum medulla viuntur ad vlcerum ora dilatanda. Ex fcapique combufto cinere, recentia vlecra curant qui ctiam maligna augeri (fi fxpe afpergatur) non finit. Ex fcapis recentibus aquam diftillant, ad oculorum fuffuriones, caligines, ac ob. fcuritates maxime pro. ficuam. 


\section{I B E R.}

$\begin{array}{lllllllllllll}P & A & P & Y & R & V & S & B & V & R & D & I .\end{array}$

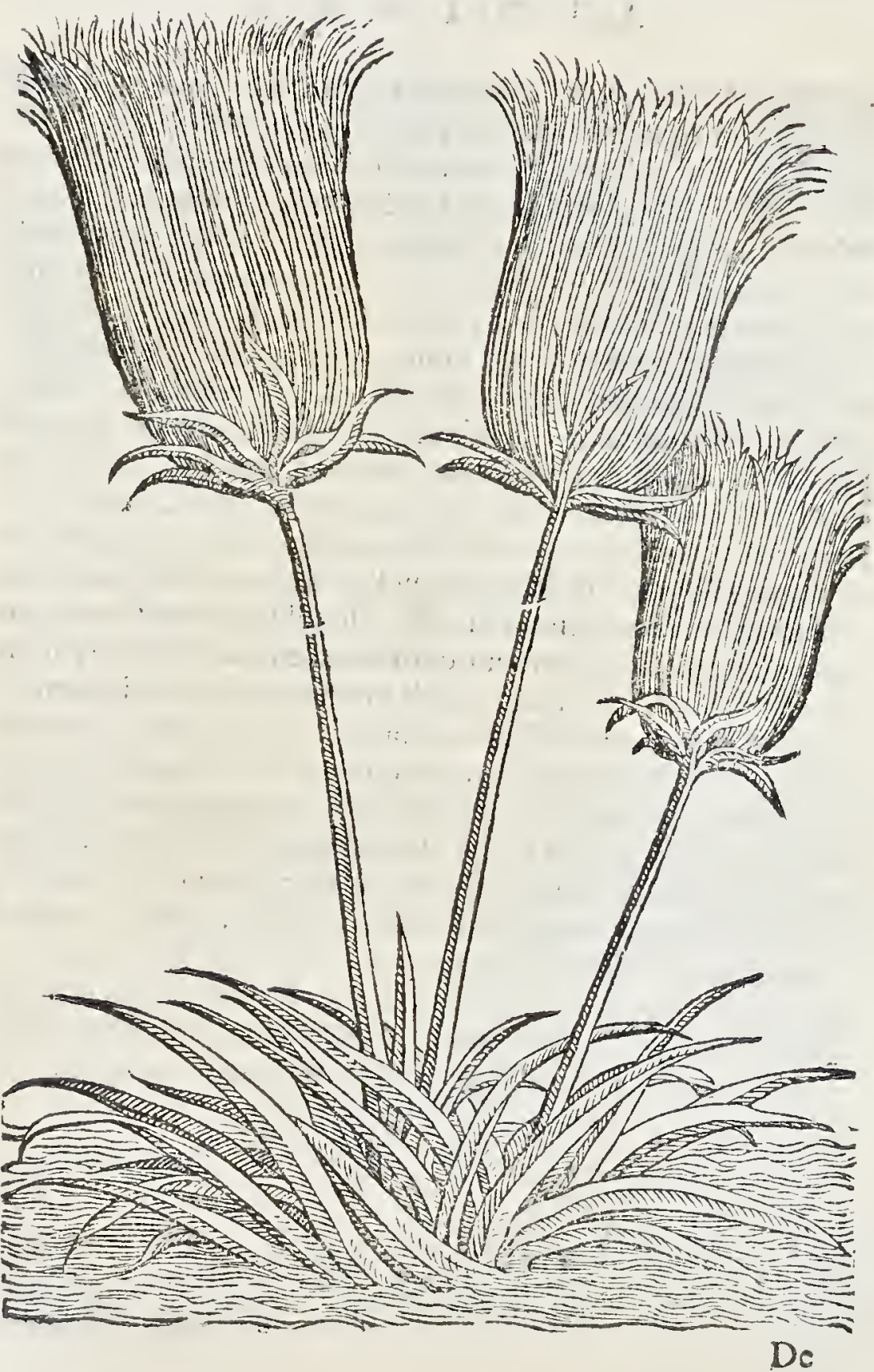




\section{DE PLANTIS AEGYPTI}

\section{DeCypero. Cap. XXXVII.}

\section{A L P I N V S。}

20. YPERVS rotundus, quem Acgyptij vocant hodueg, in Nilo fumine, atque in pluribus Acgypti lacubus vel locis paluftribus, copiofifimus peruenit porrs Con cubitali, angulofo, in cuilis cacumine funt folia aliqua ftellix modo radiantia, è quibus fpica aliqua piocedunt herbacci coloris femina continentes : radices funt nigræ, rotund $x$, magnę, oliux crafftie fpectantur, mulţ̨que uni radicis capillamento appenfx fimul cohęrentes, odoratę, atque acuti faporis, $\mathrm{Hę} \mathrm{calefaciunt,} \mathrm{exfic-}$ cant fine mordacitate, incidunt, attenuant, oraque uenarum aperiunt. Apud Aegyptios maximos ad medicinam vfus habent, pręcipueque ad vlcera oris, \& pudendorum fananda familiarifimum ipfarum tum puluis, tum combuftarum cinis, eft remedium.ex ipfis paratum decoctum uel puluis fomachum, cerebrum pulmones,vterum, neruos articulos, aliquibus diebus fumpta plurimum calfacit, frccat, roboratque naturalem calorem:ex quo om nibus morbis à cercbri tum frigida humidaque temperie, tum frigidorum humorum diftillatione concitatis, hę efficacifsimum funt auxilium:non minufque ftomachi cruditatibus, humiditatibus, fla tibus, anhelitufque difficultati, orthophneę, tuffr.necnon hyftericis ommbus mulieribus ex frigido humidoque utero effectis, aliifque morbis, ab iifdem uteri caufis obortis articulorum doloribus. Fa. miliare fatis remediun ad fuppreffos menfes cas effe ibi expertú eft.nam menfes efficacifsime reuocant. Decocto ac puluere ad fra gendum tum in renibus, tum in ueficalapidem, ac ad prouocand $\mathbf{a}$ urinam frequentifsime illi utuntur, quod etiā non minus in omni bus cronicis febribus, ac alijs diuturnis morbis frequentant. 


\section{I B E R \\ CYPERVS HODVEG。}

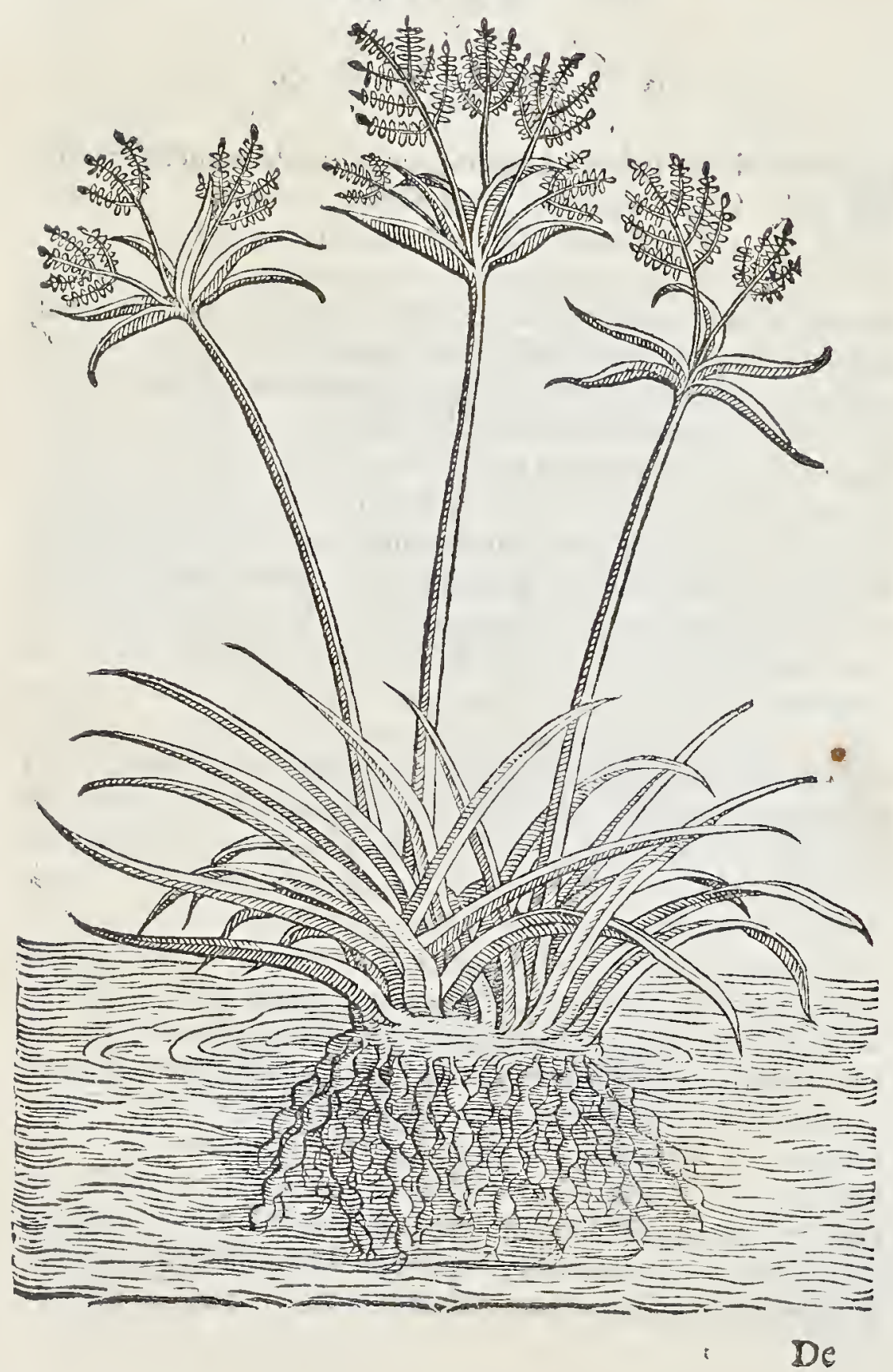




\section{DE PLANTIS AEGYPTI}

\section{De Chate', csbdellawi, of batecha el nawi. Cap. $X X X V 111$.}

\section{A L P I N V S.}

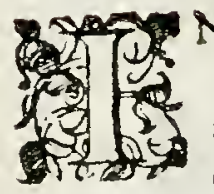

N vfuhabent Acgyptij genus quodam cucumerorum Chatè vocatum. qua planta à communi cucumere alia quidem re non differt, nifi magnitudine, colore, \& mollitic, quando Cucumis Acgyptia folia habeat minora, albiora, molliora, atque rotundiora, fruetufque producit admodum à noftratibus differentes, quando his longiores, viridio res fint, ac corticc plano molli, ęquali fpectentur.ouftuiq; funt dul ciores, atque concoctu faciliores. $H$ rum y fum corporibus in cibo ipfis tum crudis, tum coetis vefcétibus, falubrem efle apud omnes eorum locorum incolas creditur. Medici aliqui ibi nonnullis febricitantibus crudos etiam mandendos concedunt, profertimque perti affectis, quibus cucumeres hos crudos efrtatos lumine conducere omnibus (nefcio qua ratione) perfuafum fit . Coctos in ardentibus febribus, vtiles effe ratione confirmatur, quando re frigerent, atque humectent. In renum \& vefic $x$ calidis morbis, cum lacte coctos cucumeres multis diebus non fine multa vtilitaie in cibo fequuntur. lac eriam ipforum feminum pro ijfdem malis per os fumere fepe folent.ad oculorum vero, aliarumq́ue partium cali das inflammationes pulpa contufa cucumerorum lacti mifta vtun tur. Et ad fedandos podagricos dolores à caufa calida concitatos, fuccum lazte oleoque rofaceo miftum, partes liniendo, fequuntur. Stillatitiam aquam ad libram ad iecoris caliditatem corigendam \& ad fanandos renes tum inflammatos, tum ì calculis vexatos multis dicbus egrotos bibere confulunt, quibus ipfan fatis ijs con ferre experientia compercum eft. funt aliqui, qui ad hec eadem ma la aqua ftillatitia lasti eorundem cucumerorum feminum mifta, vtifolent.ex Mulonibus etiam quofdam à noftratibus planè diuer fos Acgyprij habent, quos Abdellaui uocant,ad differentiam aliorum, quos etiam Chaiar nominant. quorum vfus ad cibum haud multum iucundus percipitur, ceterifque omnibus infipidiores ac molliori pulpa obferuantur. Habent tamen femina, quax alijs omnibus 


\section{I B E R:}

48

nibus longè magis ad refrigerandum preftare pirant. Qua de res omnes ea plus alijs in vfu, frequent iori habent, alionum melo num remina parui faciontes. Planta nofracibus non mulum differe, fed fructus fert oblongos, acutos, cxercma, \& medim valde crafilim. habentes, Bahobab nuper narratis fructilus proximos. Haberat

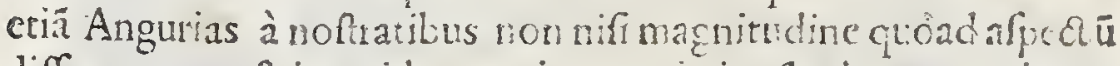
differentes: noftris quidem maiores, cortice flauiore, qui intus femina tatum, a aquam dulcifrmam continent. Quam ad fitiri arcendam, caloremqque multum in fomacho, ucl hepate, vel ren.: buscorrigendum largius epotant. Adfebres nonminns ardentes, \& tertinnas, vfus illiufe aqua fummopere laudatur, atque at, his ffequétatur. Sunt qui diftillatione aquam tenuiorem ad fiticulofos, tomachos biliofos, ad iecur renefque calidos, \& à calculis uexatos, eliciunt.quam certe ij multa vtilitat is cle cxperiuntur. Turc $x$ Aegyptij, Arabefque lafciuiorem vitam agentes, per aftatis fummos calores, harum anguriarum aquam in potu frequentant; eićił:äliqui modicü aquar rofacex, mofchi,atq; ambra mifcent. His Aduenas honorare confuctudo Acgyptiis eft, as filicetedendas obferentes. Illas per annum in paleis incorruptas conferuant: al iquandoć; fic cariori pretio ibi ad ęgrotos vêduntur,vi vinam

argenteo aureo venditam cognourerm. Sic vero eius zqua diuretica eft, ut ipfius ufum affiduc fequenribus, hernias, ad teftes de fluxa, incredibili magnitudine, facere folcat. hinc ibi plures herniolos fpcetare licet.

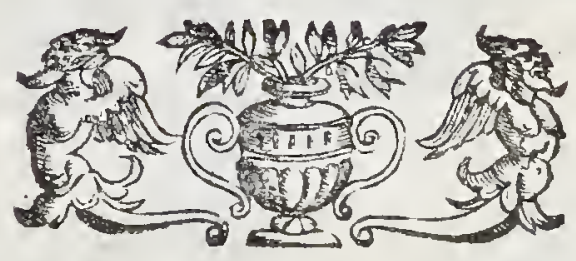

N CHATE. 


\section{DE PLANTIS AEGYPTI}

\section{H A T E:}

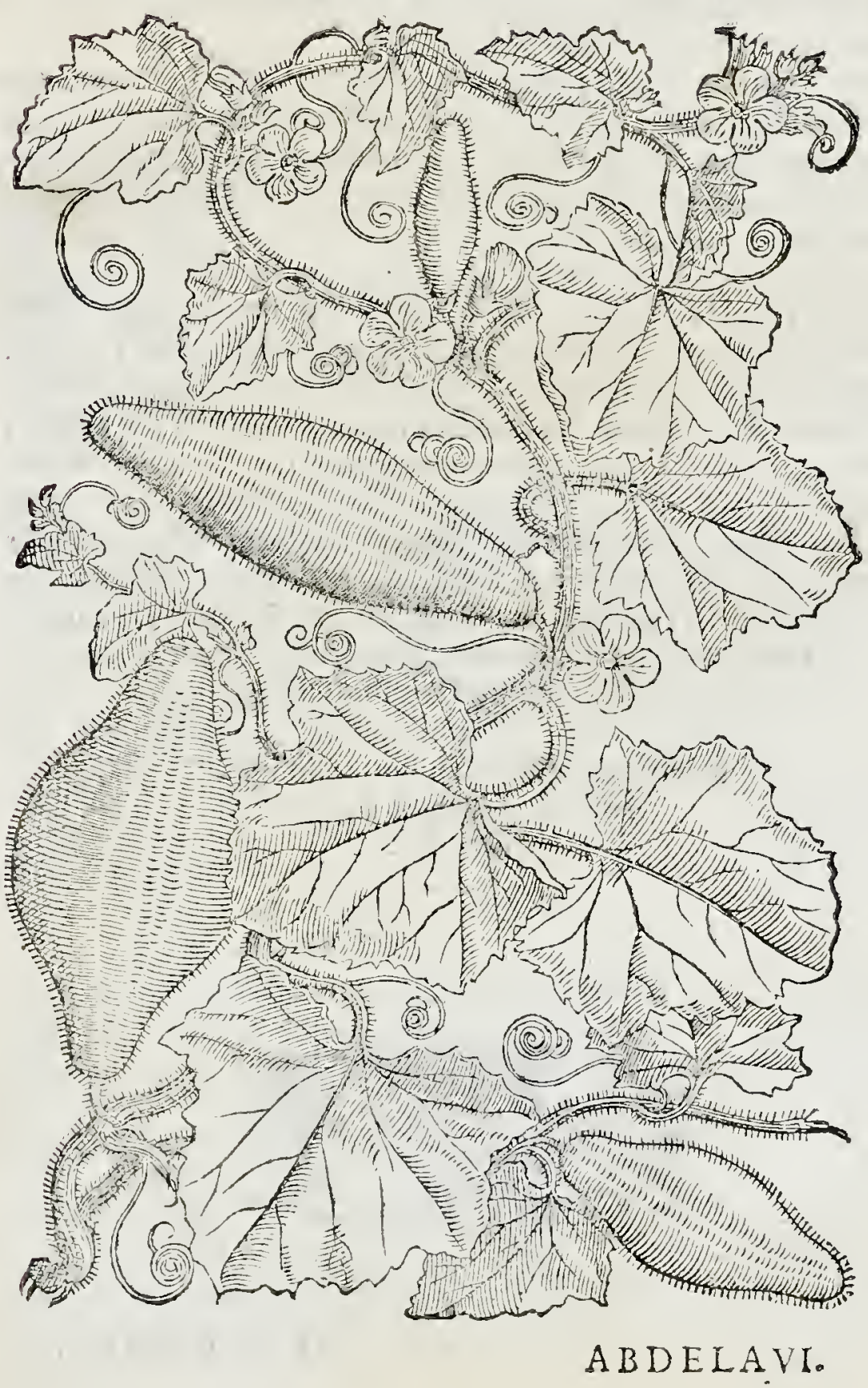




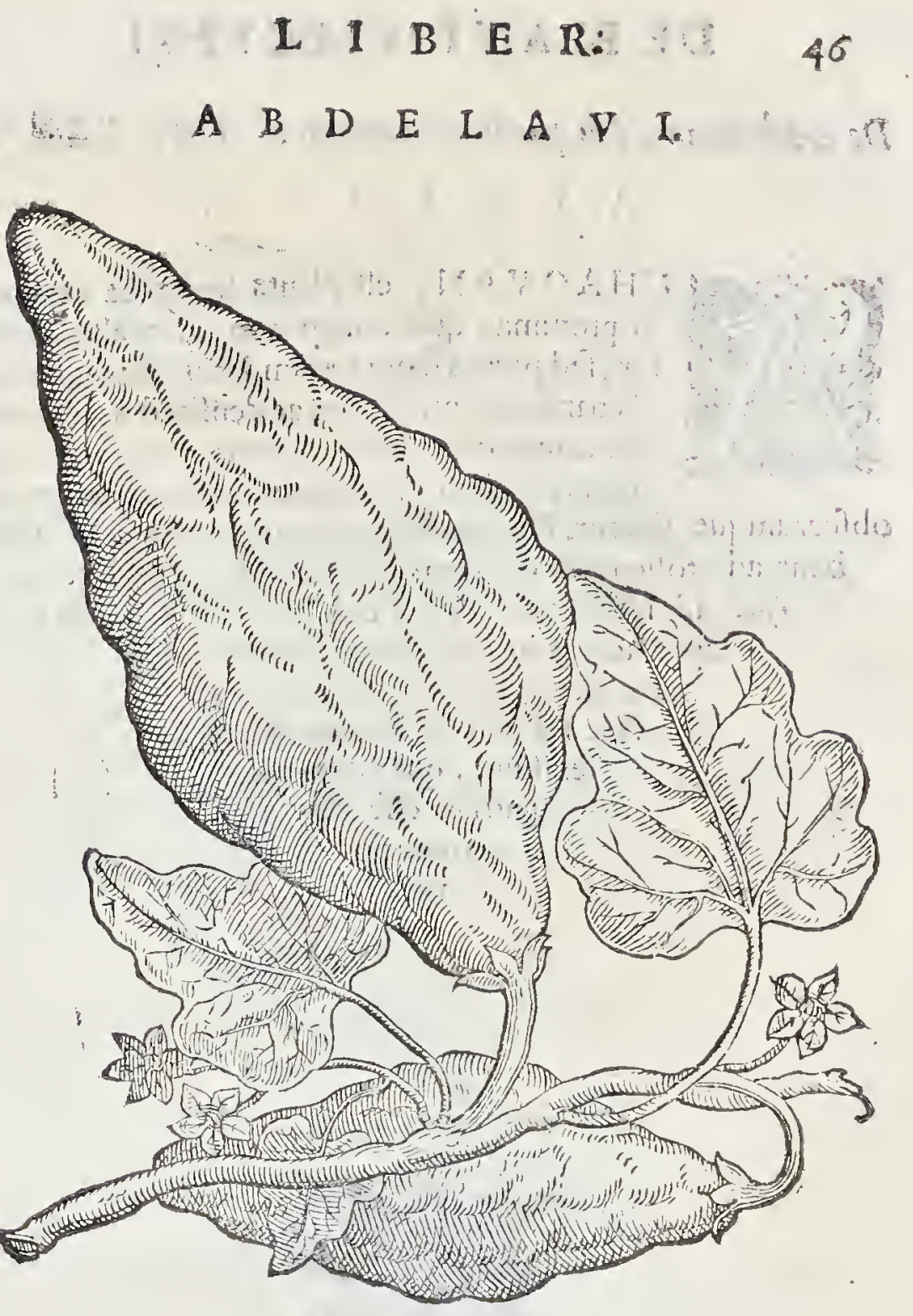

N 2 De 


\section{DE P.LANTIS AEGYBTI}

De escharuan, feu parthenio inodoro: Cap. XXXIX. A $L A C I N$ I

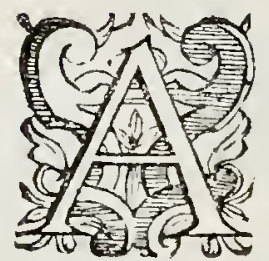

CHAOVAN, eft planta herbacea camome. lo proxima, qux tamera non adeo alta cxtollitur, fed parum fupra terram latius expanditur,fo. lijs parchenij, minoribus ac denfioribus, floribuf. que camomeli ęmulis. Herba faporis odorifque expers percipitur, fed flores odoren grauem, per obfcurumque fpirant. Florum, foliorunique decoetum in ufu habent ad tollendas vifcerum obftructiones, prefertimgुue ad IEtericos. GVILANDINVS. Si Sapor acutus in hac planta fentiretur, co. tula Serapionis, fine dubio effet. A L P IN V S Hrque plantx exiftunt, quas Aegypti patrias effe obieruare po thi.

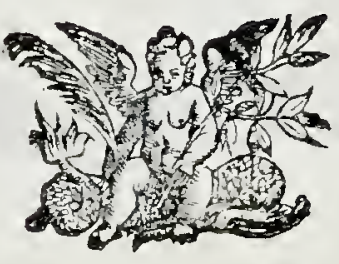




\section{I B E R.}

\section{ACHAOVAN PARTHENIVM INODORVM.}

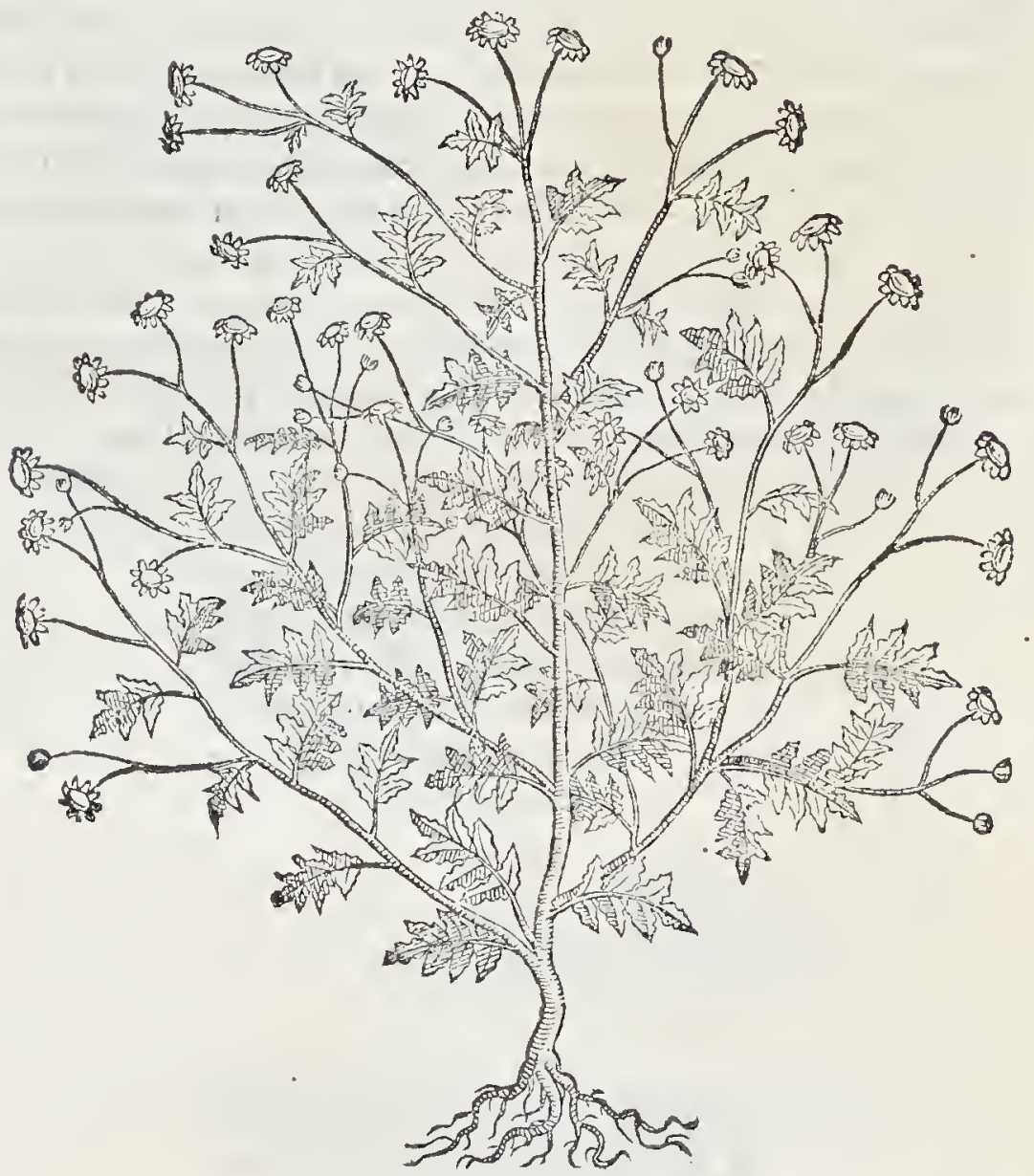

De Neiemelmfaltb frue gramine Crucis. Cap. XL:

\section{A I. P I $N$ V $S$.}

R R A E quoddam nafcitur exile,radicibus ferpens \$ albis,geniculatis, dulcibus, cum aliqquali acrimonia,có Q 3 is muni gramini prox in:s, digiti altitudine, geniculati, thamulis afturgens, fulijs communi gramini fimilibus fed minoribus, ramuli habent quotuor ficas, If chami,uel grami- 


\section{DE PLANTIS AEGYPTI}

nis fanguinarij fimiles, perfectam crucem figurantes, quam xque omnes vno modo formāt: ex quo ipfum Argyptij neicm el,uocãt quafi dixerint, gramen crucis, in quibus fiunt femina minutiffma feminibus communibus graminis fimilia. Maximum vfum femina apud omnes habent ad eos folicet, qui tum renum,ium vefice calculis laborant, atque ad frangendos lapides in uefica cöcretos. Quod genus morbi ibi ef familiariffimum, \& quaft endimit:m, ex caufis alias narracis. Mulieres radicis decoctum tum ad pueros variolis, atque morbillis correptos maxime fequuntur, tum ad feipfas, vbi cupiunt interceptas menftrias purgationes rurfim euocare. Sunt aliqui, qui pro fecreto auxilio habët decoetum, ex femi nibus modice contufis paratum, ad adiunanda exhantemata in fe bribus peftilentibus, quas peticulas noftri appellant. Ad vfum quoque vulnerum $\&$ vicerum, non paruum apud cos, tota herba, pręcipue radices, habent vfum. Aiunt radicem frigidam atque ficcam effe, tenuiffimartimq́ue partium. Quamob rem non defunt multi, qui ad monendum fudorem eius decocto familiarifs fime vtunธแน:

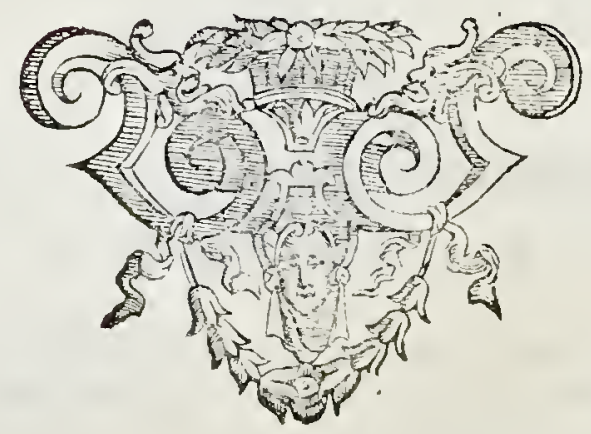




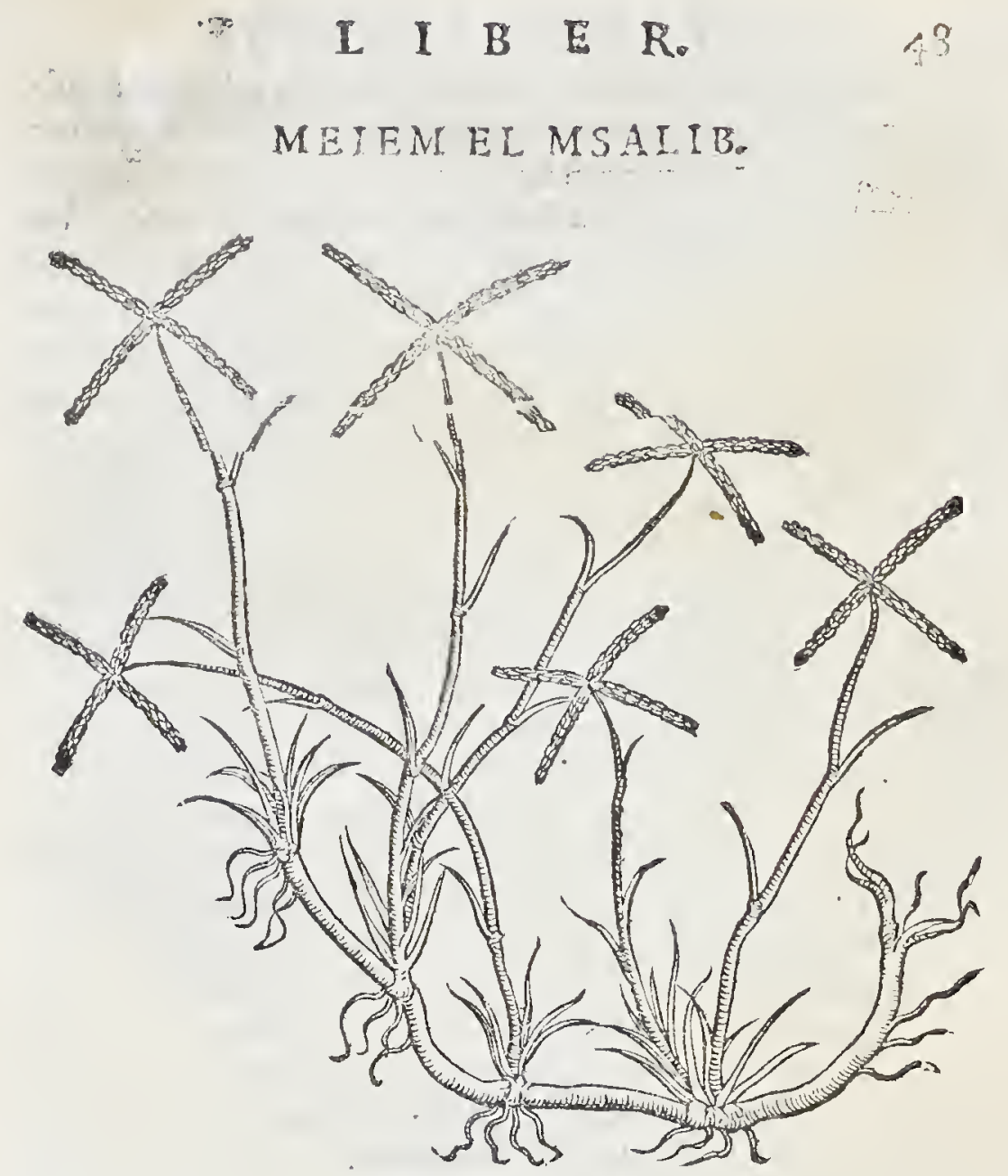

De Meliloto cAegyptio Alchimelech vocato: Cap. XL1.

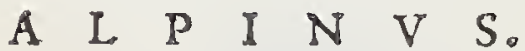

G G E I L O T V S, quo Aegyptij utuntur, femen minu(t) 13 tum eft rotundü, fubnigrum, declinans ad rubrum, odo 期

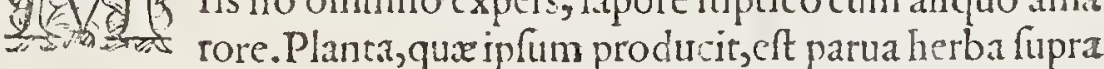
terram expanfa, modice repens, ferè nihil, aut partum in aleurm fe attolens, folljs trifolij filiquoli minoribus tamen, thoribufque par 


\section{DE PLANTIS AEGYPTI}

uis multis, longis, raccmi modo ordinatis, croceis, odoratis, à qui

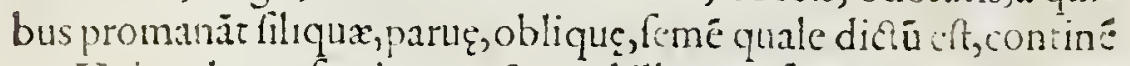
res. Huius plante femina tantu apud illos in wo exiftunt. Qux putär ij quoad caloré \& trigidina é efe tempcra:a, fed fecare, to folue re,ac fipticitate roborare, ex quo at hepatis amores ipformm viss apud illos eft frequentifimus: quoniam fine aliqua relaxatione diceriz \& refoluit. Ad omnes quoque dolores, quafram que cor

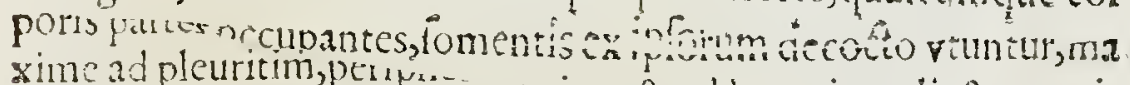
xime ad pleuritim,perup... - in o a heostis, coli, \& uentriculi dolorem . qubus dolore vexaris, iplorim accoctimadibra bis in die calidum bibunt. Mulieres quoque vieri Rrangulasionibus, flatibus, ac doloribus eo fubueniunt, prafertimǵue ex co etiā infellionibus paratis. qua etian foenugreci, liniq; feminibus, para ţ, \& camomeli foribus, efficatius ad illius, \& aliatem partium duros tumores a dminifrärur,atque ad cuocandos menfes retentos. Ad roborandum ventriculum, \& aperiendas obencustiones venarum decodo fumme proficue viuntul. 'G V I L. Nunc ex te verum effintelligo, apud Arabes melilori vfum efle feminum, queadmodum Græecinon femina, fed flores in vfum admittunt. An ve

ro hxc planta verus fit melilotus, aut potius ca, quam noftri lotum vrbanum,atq; fertulam camranam ( que elt plan

ta, magna fruticofa) appcllant, alias declarabi-

mus, huic enim difputationi hic non videtur effe locus. Ego tamen hoc tantum

dico,me libentius Aegyptiorum

opinioni declinaturum.

Sed Ichonem nunc

apponito. 


\section{I B B R.}

ALCHIMELECH, IDEST MELILOTVS.

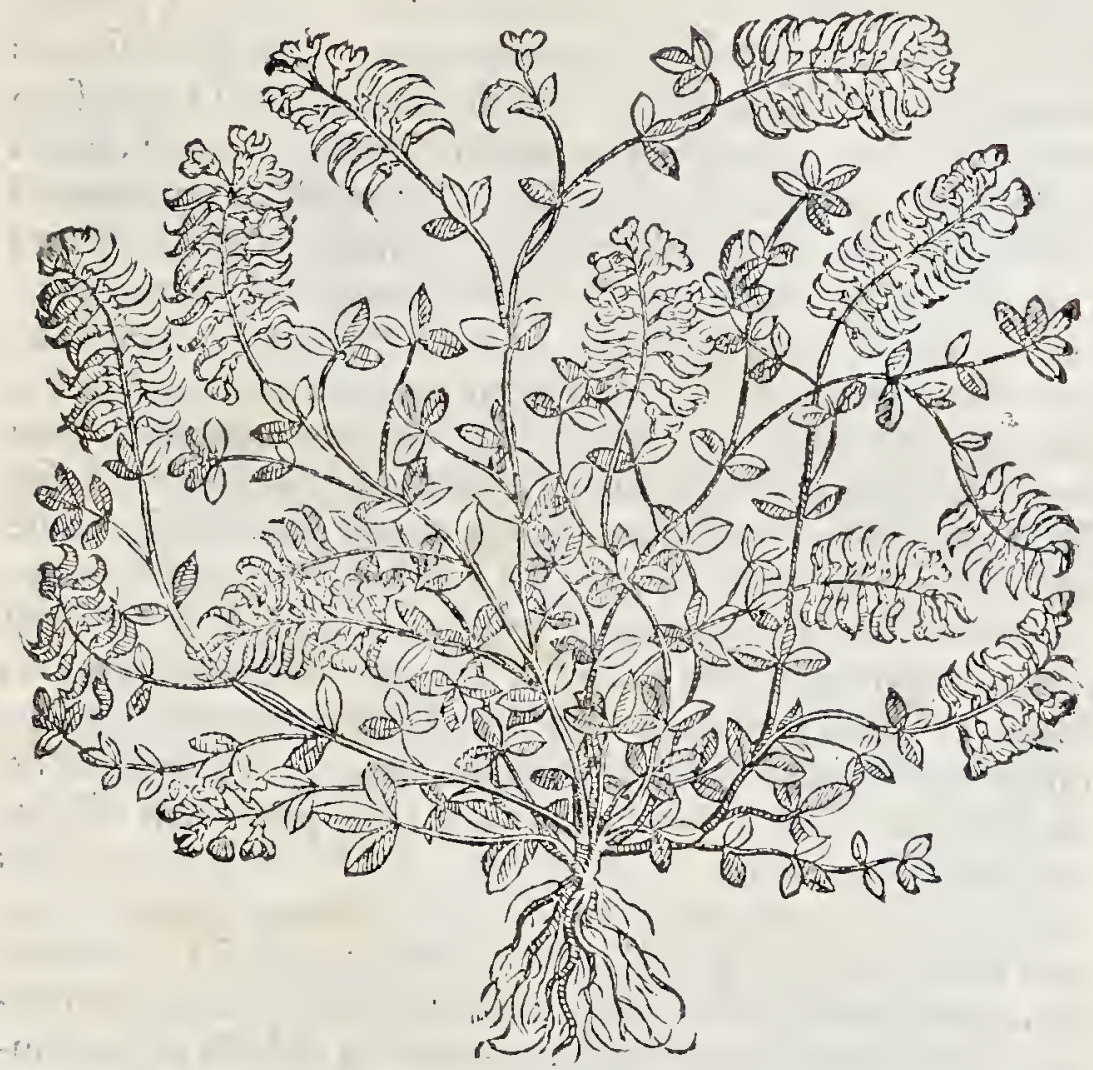

De Kelliu, p.yllio, Melanthio, cappare, urtica, folano, fomnifero, coriandro, ocymo, byof ciamo albo, conyza, nuce methela, Secamone. Cap. XLIl.

\section{A I P I N V S.}

20 R O P R I I S Aegypti à nobis hatenus cognitis plan V. 15 hunc fermonem claudamus, prextermittendx quidem non funt; maximcóue ex his, Kellù ab Acgyprijs uoca ta planta, à quibufdam Antyllis, pfyllium, Melanthium,capparis, urtica, folanum fomniferum, coriandrum, ocymus goriophyllatus

O albus 


\section{DE PLANTIS AEGYPTI}

albus hyofciamus, conyza, Srramonium, Secamonè,ricinus de his iplis igitur aliquid commentemur. GV I L." Aliquid te de his fcitu dignum difturum puto proinde ut lubet loquere. A L P IN. Kelli, noftri quoque Kalli, plantx tres vtique in Acoypto fpecies aluntur, ex quibus omnibus combuftis cineres fiunt, ad vitra, fapo nem, \& alia multa.prima fpecies eadem eft planta cum ca, quam noftri Kalli geniculatum, appellant. Altera eft, quam nonnulli album Kalli vocant, Tertiaque Aegyptijs magis propria, folijs con ftat paucis auge folijs proximis, fed ualde longioribus, uno, cauleque nó omnino recto, à quo tres, quatuorue cauliculi exoriuntur, qui rectefurfum feruntur, quiliberque ipformm in cacumine capum quin que aut plus folijs chamepythios proximis, at deorfum in arcum recuruatis, inclinantibus confacum, ì cuisus medio fofeu li rofarum fimiles exurgunt multi. Hx omnes plant $x$ falf $x$, atque acri fapore linguam feriunt. G V I L A N D. Sine dubio vtręqux hx plantx à te poftemo defcriptx fub anthyllidis fecund $x$ genere reponcndx funt. Diofcorid. liquidem ailigam docens fic; fcriplit : Herba in terra repens, incurua, folijs femperuiui minoris. multo tenuioribus, hirfutis \& pinguioribus, circum ramos denfis in capite vero de Antyllide ipfam aiuge folijs proximam effe ftasuit.Sed fequere reliqua enarrare. AL P IN. Ex his fanè tribus Sole in primis exiccatis, \& mox combuttis cineres ca parantur, qux illine Venetias conuehuntur ad uitra,atque alia conficienda. Aiunt multi illorum folia trium harum plantartum, fed maxi$m x$ fecundix atque tertix Kalli, in puluerem redacta,per os fumpta phlegma atque bilem exuftam purgare. Idemq́ue ex folijs expreffum fuccum facere. 


\section{K. A L I L I. I I I}

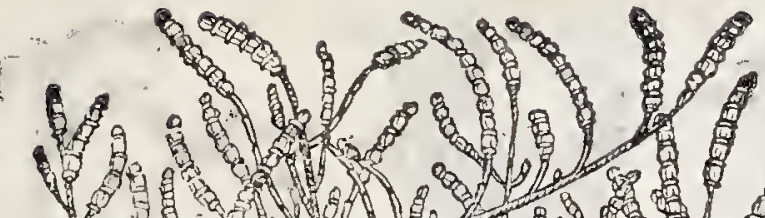

3.
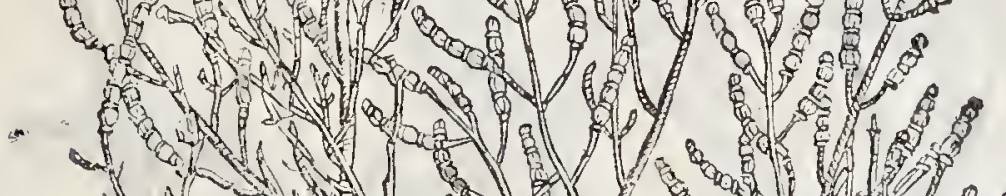

- in
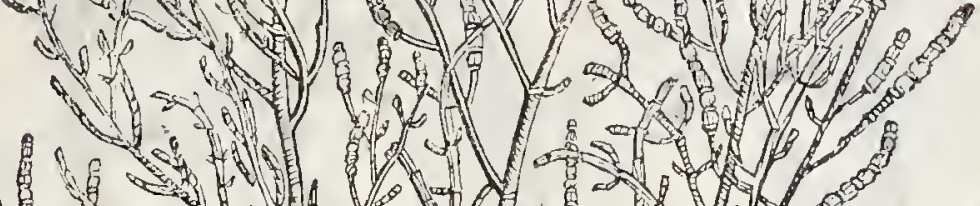

6

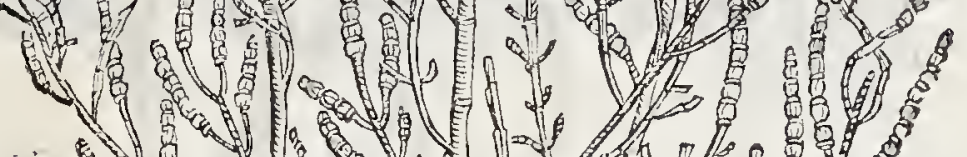

$\therefore$.

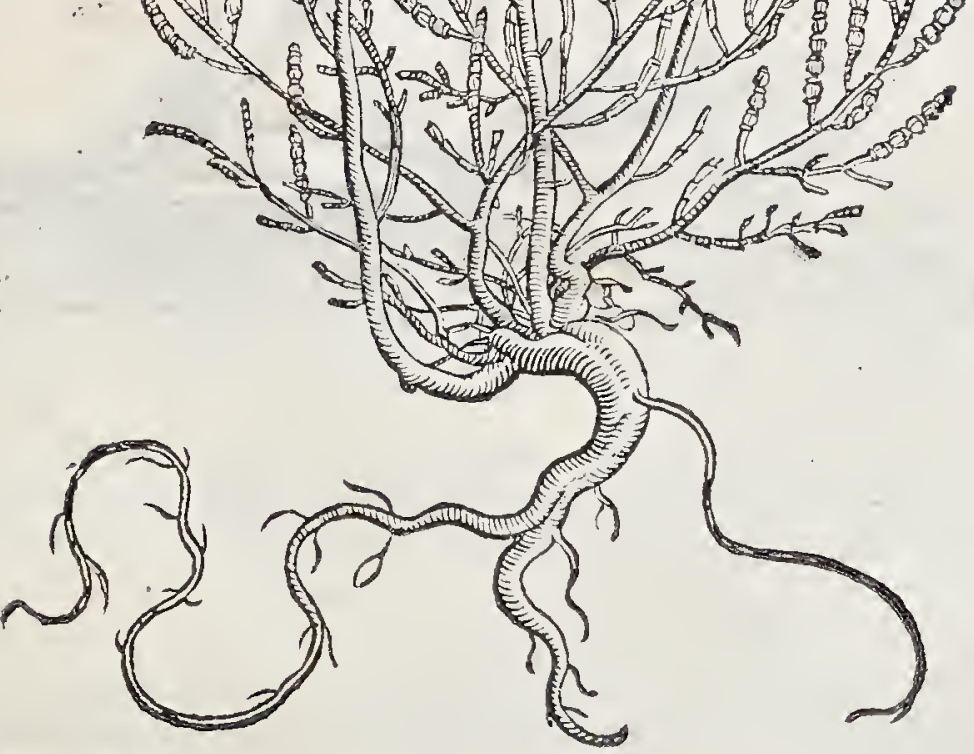

- 2 KALLI. 


\section{- DE PLANTIS AEGYPTI}

$$
\text { K } A \perp L I .
$$

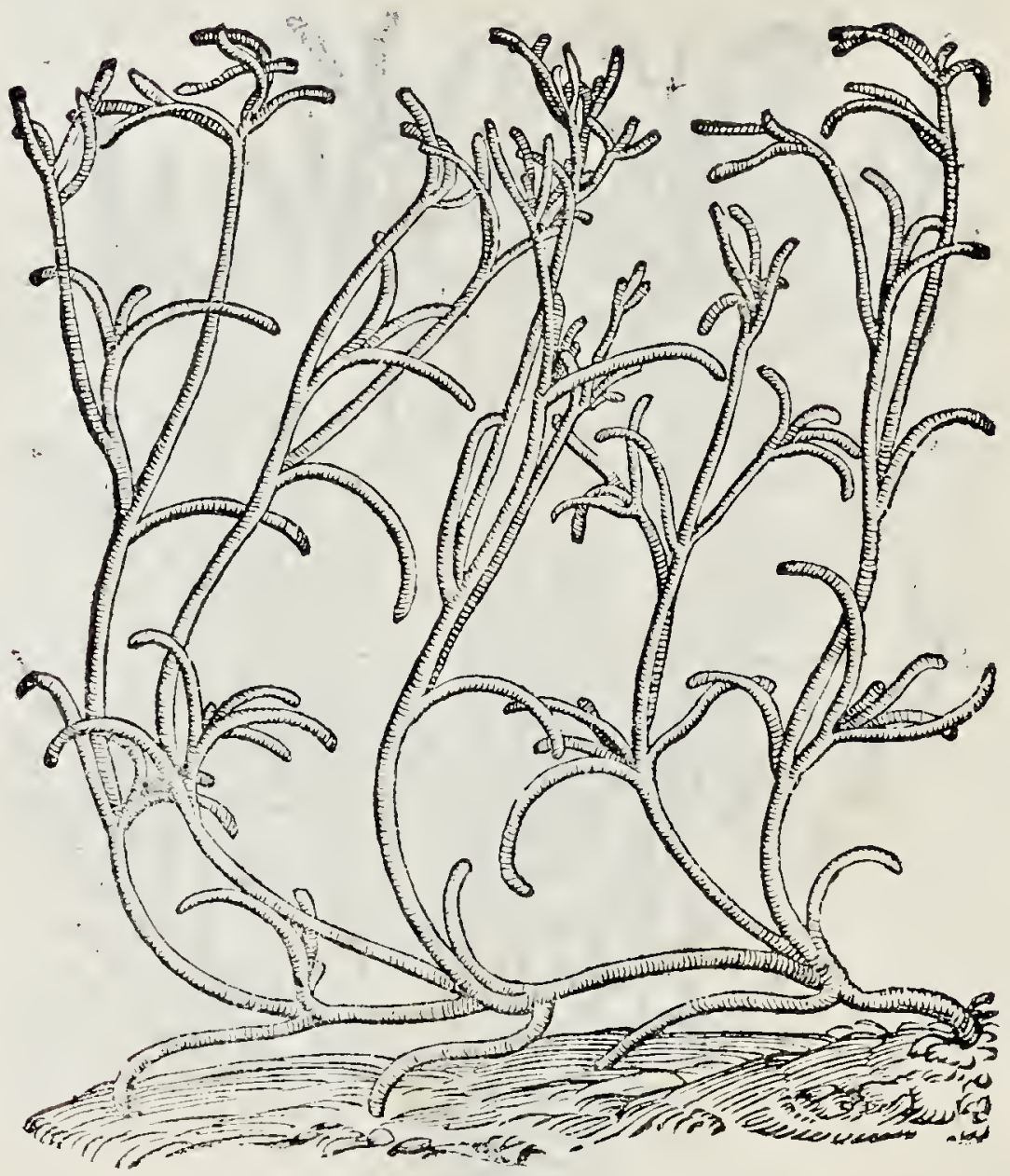

KALII. 


\section{1. $1 \mathrm{~B}$.}

$\mathbb{K}$ A I i I I I I D

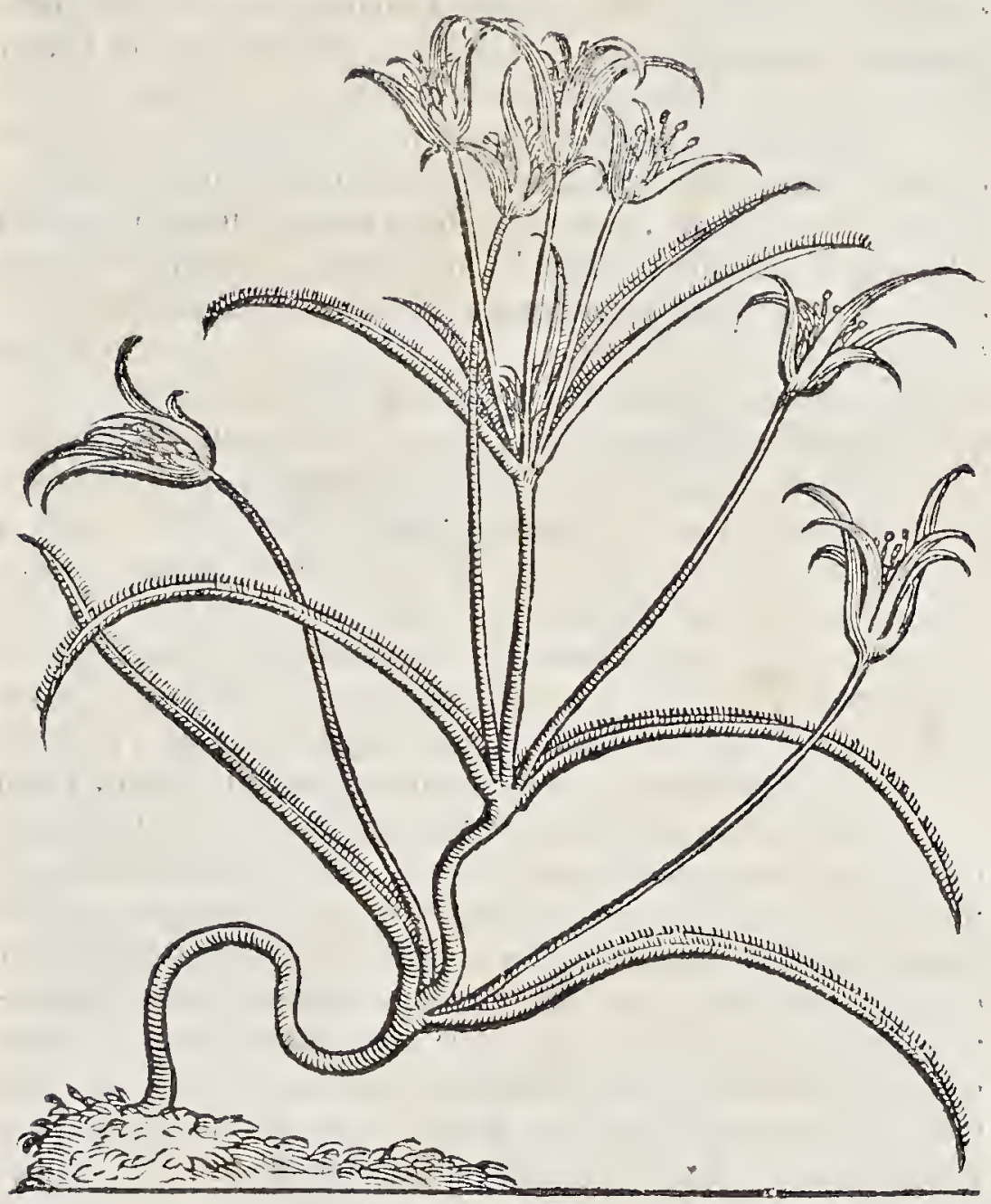

Pfyllium copiofiffme ibi prouenit. Cuius feminum apud eos vfus eft, præfertimáue mucilaginis ab ipfis paratç cum aqua rofacea, in omnibus febribus biliofis, ardentibus, in flammationibufque pectoris, vti in pleuritide \& peripneumonia. Sed extrahunt cum aqua hordei, \& cum faecharo candido exhibent. In aqua rofacea extracta Pfylij mucilagine ij utütur in biliofis dyarrh:eis, \& difenterijs.ad externafqg; omncs inflimationes, emplaftria fo: 


\section{DE PLANTIS AEGYPTI}

menti modo tum ex viridis plantę foliis, tum ex feminibus plyllij tota plania vtuntur. Quam plantam vocant Checùn. Nigclla ibi etiam pronenit, quoad fores pulcherrimam, quando floribus maioribus, ac numerofioribus folijs preditis fpectetur, eiufyue femen in vfu eft frequentifsimo in pueris, ad necandos vermes, contufifque feminibus cum aceto emplaftri modo al pinres cutis infeEtiones vitintur. Mulicres ctiam, qux non purcantur,co fi fuffiantur, maxime iulantur v vocantque hanc plantam fureg. Cappares Alexandrix maiores quàm alıbi inteniantur, proueniune, quos cappar quoque appeliant.cx quibus cortices rädicum in vfu habet frequentiff mo ad uermes necandos,ad mouendos menfes, atque a quofunque tumores duros;preferrimique lienis fanandos, pro quo indurato membro, exhibent decociũ per os multis dicbus,ex terius ex corticis puluere, \& aceto facto emplaftro, cui aliqui modicum mellis mifcent, quo prefidio veuntur ad cutis macnlas, $\&$ in fectionas, cas linientes Alexandrix Vitica prima, quam ij vocàne angiar, prouenit copiofiftme, \& proinde cius femina multos vfus ibi quoque habent, maximumque ad venerem excitandam, prafertimćuc in frigidis corporibus, fi cum vino dulci bibantur. Nonnulli ad idem ex feminibus ijs, radiceque buzcidam, ac melle componunt clectuarium, cuius femuntiam quotidie fumür. Vfun non minorem femina habét ad pectoris, pulmonumque vitia, eius enim decoeto cum melle parato in tuff, anhclitus difficultate, orthopnxa, \&z peripneumonia à craffo frigidoćue humore concita tis, funiliariffine vtütu: farina quoque cum melle eclegmatis mo do aci eadem mala, cuius vfum cum aceto cmplattri modo ad omnes difficiles cutis puftulas fequuntur, \& ad omnes maculas cutis ciufque infectiones, tumores duros non minus, pręfercimq́ue ad pa rotidas. Mulieres nihil habent, quo valentius vterum calefaciant; mundent, atque ab obftructionibus fanent, quam vrricia,, $\mathrm{x}$ quo ad mouendos menfes feminum decoet;, atque fuffici vfus eft apud ipfas frequentifsimus, maximeque addita myrrha. Cinere ex femini bus parato, ad omnia ulcera maligna \& cäcerofa vtuntur. Solanum fomniferum in Alexandrix ruderibus copiofiffme prouenit, ficó; crefcit, vt magnus frutex appareat. Vtuntur incolic radicum corticibus ad dragmam puluerizatis cum aqua lactucę, vel folatri, fumé tes ad fomnum cóciliandum. Huius plantx cortex non fecufquàm nux methel, fue framonij femina, apud plures malos nomines, vt aliguid 


\section{I B E R.}

aliquid mali faciant clam dum dormiunt, huius corticis in epulis ponunt . Folijs contufis emplattri modo ad calidas inflammationes vtuntur, atque illito cx ipformm fucco fronte, temporibus, ac alijs partibus corporis in quibus pulfus fentiuntur, vel ijfden con tufis emplaftri modo appofitis, ad fomaum familiariffime vtütur. non minufque ad exuftiones. Nux ctiam Methel ibi nafcitur, fed non vfq, adeo copiofi, vti folanum predictum.eftque verum Diofcoridis ftramonium . vfufque plane eofdem habere ij aiune, quos de folano fomnifero diximus. Adeft quocue hyofciamus albus admodum à communi figura differens, nafciturque Cayri propè pyramides, folijs communis longè grandioribus, latioribus, craffioribus, \& albidioribus. Quo vtuntur nó recus quam framonio. Vbi que vero in viridarijs coriandrum prouenit copiofiffimum, quod omnes Cusbarà appellär.Herbęćue virentis vius in cibo eft apud omnes Aegyptios familiariffimus. etenim ferculum non parant fi. ne folijs coriandri, quamqua ingrate oleat. G V I L. Quid audio? non ne ij ipfum mandentes maxime lreduntur, \& ab cius viu in phrenefim labuntur? quod Diofcorides, Auicennas, tum multi alij tradidere. A L P I N. Ridiculum . quis vnquam vidit aliqué, coriandrorũ caufa (quæ in vfu apud quofqne tum fanos, tum ægro tos familiariffimo exiftunt ) læfum fuiffe, aut ei aliquos fenfus turbatos, nifi immoderate eis fuerit vfus? Quid miraris? quaí eiufde cum Galeno non fis fententix, qui corjandrum palidum, refoluěs ac modice adftringens ftatuit.non ne demonttat Diofcorides vel hanc cius facultatem fateri cum dixerit, cheredas coriandro cum comento fanari? Quod nunquam à frigidis frigiditumores difcutiantur, ac curentur ; cum medicamenta aliàs ì Diofcoride ad fanandos duros tumores charada que pręfertim memorix pro dita, calida facultate fuerint. Neque uidetur planè hoc filuiffe Aui cena, cum dixerit, chearadas coriandro fanari,uel ex proprietate, quam ad illum fanandum tumorem habet, uel ex partium fubftai tia tenuitate, qua per meat profundę tum:dam partem. Sed quis ignorat $n$ ihil à frigido refolui, ctfi multa fiat permeatio partis tumefact $x$, fed omnia refoluentia calida effe? GVIL A N D. Verä fententiam recte defendifti, quam quis modo negabit, fcicns ex te Acgyptios uirentem coriandri herbam in cibo fequi citram aliquamnoxam? multo minus feminum ficcatorum ufus erit exinde timendus. Hincque erraffe non parum Arabes liquido conftabit 


\section{DE PLANTIS AEGYPTI}

qui coriandro frigidam faculaté narcoticam, fuporem inducente atque fenfus turbarion $m$ concitatem, ac exitium tribuerit . Idem que $\&$ de pryllio fuiffe apud illos à te compertum eft, quando pfyl lium pro ueneno à Diofcoride, atque alijs receptr:m, inoxic in febricutantibus frequenter non modicam rgrotis feminum mucagi nem exhibentes. Herbä in aqua elixatam $1 / l i$ efitant. Sed ea multo plus femina ad roborandum ftomachum ualere ii affirmant, debiles etenim uentriculos, ufu feminũ affiduo maxime roborant, eiufque calorem ipfa fouent,augent, flatusque refoluunt,ac difcutiunt proindeque in colico dolore, atque alijs à fatulento fpiritu conci ta:is ufum feminum fequuntur:ipfis filicet, uel in puluerem reductis, uel ex ipfis parato decoeto, utentes. Quo uteri quoque frigidi natibus, \& humiditatibus occurrunt . pręfertimque ad menfes immodice fluentes, \& ad gonorrhęan firmandam, quod infit illi quo què faculaas adıtringédi, ex quo puto apud cos plantam quoq; em plaftri modo, ad podagricos \& alios arriculorum dolores in maximo ibieffe ufu, quòd eas partes adfrictione, ne humorem partes recipiant, roboret, atque etiam contétos refoluat, dif cutiat, uel exprimat. Ocymus ibi in uiridariis copioffifimus crefcit ad altitudincm trinm \& plus cubitorum, foliis noftratis longioribus, tenuio ribus, colore rubro fuffuris, odoremque eximium fpirantibus. Suauitate enim odoris noftris omnibus preferendus meritò uidetur, ob quem illi hanc plantam Rihau appellarunt, quod idem eft, ac fi dixeris, odorem, ita, ut hic ocymus prę odoris iucunditate eximia odor per excellentiam ab ijs uocetur. Qua planta odoris caufa ij utuntur, medicos uero ufus apud eos ipfa paciens habet, qui ab aliis multis perdoeti funt. Nafcirur etiam fponce ibi ciędam plan ta repés, altius faliens, féque aliis arboribus contohés, folits duris Jongis, Sefeli Athiopici proximis, fed maioribus. Flores fere albos fyracis fmiles, à quibus producuntur fliqux; lungx ac cra Ty, qua les in ulcododendro cernuntu, plone 'anugine aiba, ac fem nubus parnis . cx hac planta fuccus, manat faums, urens quon ficcatum Asoyptij ulenter tenus humores purgare, at:mt. Hanc illi ef fefcamomonij fpecicm affrmant, quä fichimonè appol'ant cuius tamen nullus tifus in medicina spud cosnoui. G V I L. Fortafle hanc phanam eff Apocynum Dioforidis affrmare porcrimus.

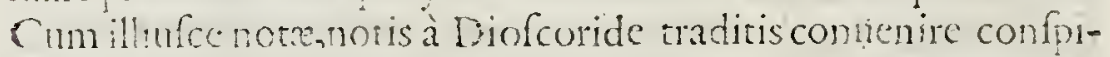

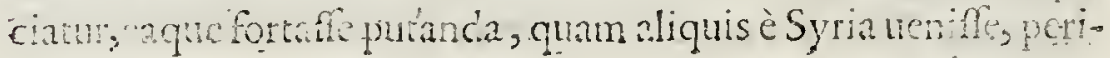




\section{I B E R.}

53

plocam uocatam, prodiderunt. At verum apocynum nunc in Italia cognitum eft.

\section{$S$ E C A M O N E.}

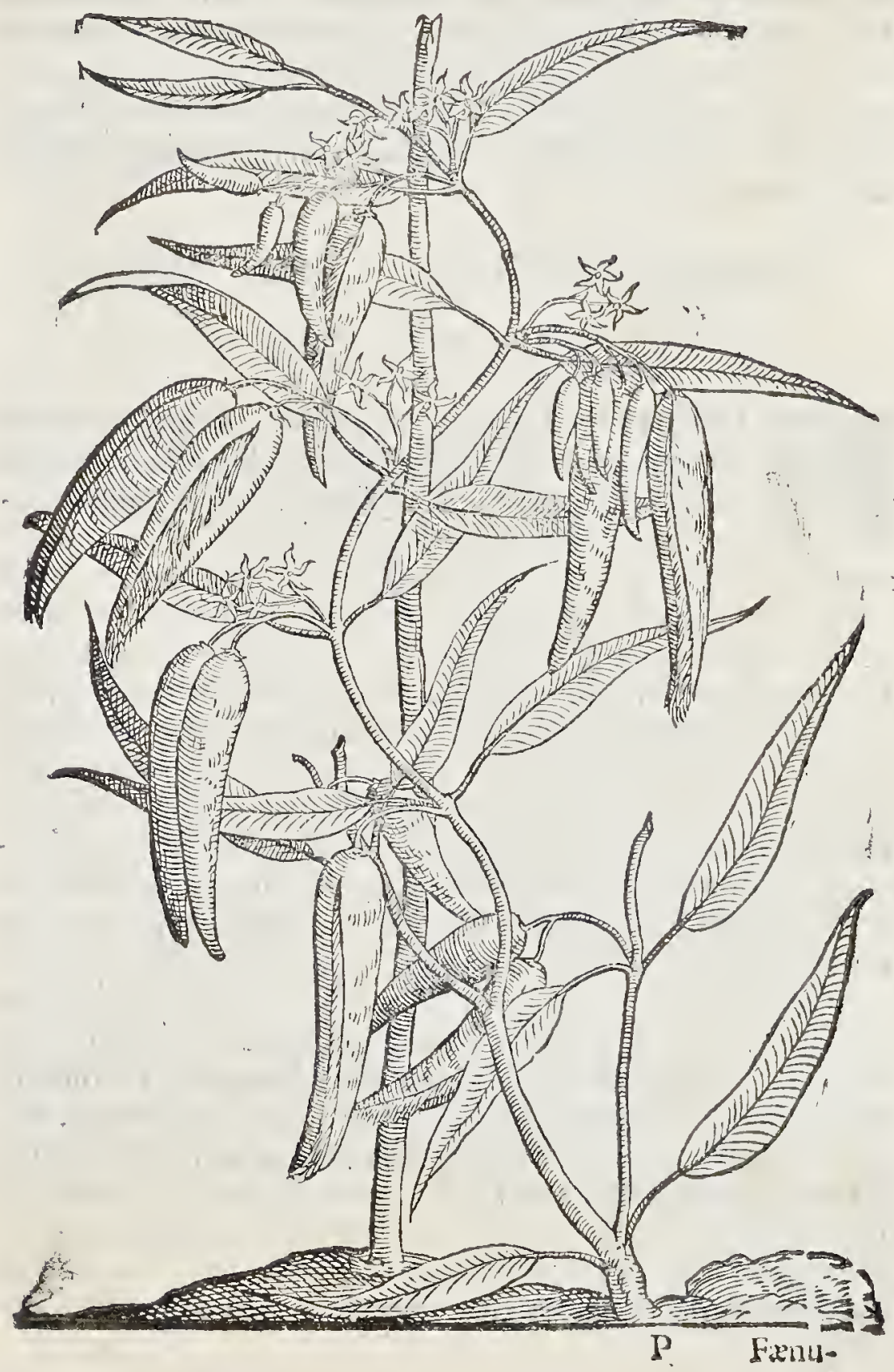




\section{DE PLANTIS AEGYPTI}

Finngreci germina mox è feminibus erumpentia ex ipfifque As im proflientia plebei concdunt, preferimque inulieres,pingueferi cupientes, per vrbem multas maffas tertę, plenas feminum recener produtis germinibus vendendas ij ferune. Plures alize funt plantx ibi nafcentes, quix cum pluribus alijs locis communes cxifant, non eft da iplis à nobus amplius femo proferendus. Sed ian d: madicina apud illos populos unicata, fernonem, déue pla tis illis in locis nafentibus clautere debemas; cum nihil fuperfit dicendum.

\section{Deplantis periterobferuatis. Cap. XL11.1. G V I L A N D I N V S.}

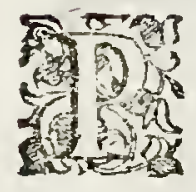

L V R I M A S gratias tibi refero, guod tantum labore hactenus mea caura fuftuleris. Nhilominus ne aliquid omitamus, quod vile ad hanc hiftoriam iudicem,cliperem,antequàm nos huic fermoni planè funem imponamus, vt de plantis ctiam per iter olim in Aegyptum ì te naugáa do varijs in locis obferuatis, aliquid diceres. A L P I N. Non arbitror te ignorare, noftro olim audito itincre, partm temporis ini hi per iterillud conceflum fuife, ad indagandas illorum locorum plantas:veruntamen, quas runc uiderim, quamequam neque tuis doctifinis auribus fatis dignas eas exiftimem, referre etiam nune non recufabo. Memiai me habarbari plantam Cocyre infpexiffe, in anciqui illufec propuguaculi quodam viridario quam quidam ex Syria iluc nau a duc tam habueras: quique ipfam à viro Pirfa Tiypolim olim fuifre adductam etiam affirmabat. Que plan ta plune folija rum ci uif eft proxima, que tamen erant lationa, cranion, lantgincque quadam alba obfita. In illa eadem infula inteni Cyperi radices 10 gas ad modum odorazas, \& Chamedrim arboream, ducrum fere cubitorum altitudine propè Burintum, viuencen, que filia diplo \& triplo Italicis maiora habcbat. Zacynth: oxalidem, qua cius infu! phamacopxi ad medicinam ute bantur, infoexi, admodum à nontris oxalidis omiribus diuerfam,

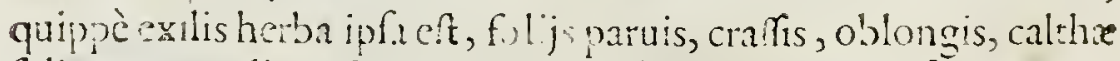
foliorum emslis, gutü non minus quàm noftra acido fapore farit. Ibi quogasecrefiracacia fecunda Mu:houli, quam ego forentem mañ 


\section{I B E R. $\quad 54$}

méfe Februario infpexi folijs, Aoribufque minoris anagyridıs pro ximis, qure guftata, fapore adfringenti feriunt, paucifque tamen ac mollhbus fpinis obfira. Neque arbitror effe ueram acaciam, quā in Capacocia \& Pontu nafici Diofcorides prodiderai, quòd minime conuenire cum rrima acacia, feu fpina Acgyptia videatur. Aliud agnoui in slla infula, quippè fmilacem a fperam offe veram falam parillam, qua medici veuntur ad fanandam lucm gallicam. G V I L. AN D. Copiofius quogue hanc plantam in quampluribus I alię locıs nafci fcio, quare iftud, quod ibi didicifit, noum apud me non eft. A L P I N. Verum dicis, etenim ipfan aliàs in mulcis aliis locis offenderam ac obferuaucram,verum perpetuo, an eff t talfaparilla, anceps, ac dubius fui. In hac vero infula ea fpectata, clarius cognoui veram eam vtique effe. GVILAND. Quamombrem in Italix locis cum eandem ipfam fpesaueris, ciufdem non fuift fententiæ, feilicet eam effe falfam parillam. A L P I N. Qunniam omnes fmilaces afperr, quas haztenus uideram, exiles admodum breuefque, ac capilla. res radices habebant, fed quam in Zacynto infula uideram,longas, craffas, afportatis Hyfpania radicibus falf $x$ parillæ omnino fimiles. Quo pato uero has agnouerim, ribi iam explicabo. Ego enim, ut ocium diuturnę morre effugerem, forte fortuna coll $\mathrm{m}$ illiufce infula perreptans, in valle quadam ad frepem oculos coniieci, lenthifcis ac multis afperis fmilacibus contextam, cuius ab ra dicibus omnibus terram impetuofa torrentis aqua fic abduxcrat, ut illarum plantarum fepem texentium omnes radices, non fecufquam ven $x$ arteriæ, \& nerui humani corporis à carne feparati, nu$\mathrm{d} x$ confpicerentur, Smilacefque afperie Iongos fanè ferpentes imi tate, alijfque radicibus conuolutx, mira longitudine, ac craffi. tie mihi fe obtulerunt. ita ut quafdam illarum duorum, \& amplius cubitorum longitudine, \& craftrite conmunium fáfie parilla radicum infpexcrim, ex qno continuo cas falfę parillę radi. ces effe iudicaui. Et dum hre fimul cum alijs, qui una ibi me cum aderant, confidero, augurium contingit opperruniornum.

Nam ex tranfeunte Gręco homine eius loci accola; \& a ricola, peto, quomodo ibi illa planta appellaretur, qui refpondit, fmilachiam nunclipari, ipfamq́ue in vfum apud ipfos effe procuranda Gallica lue : ex qubus uerbis exploratius eam confide. sans, uideo radices eius longifimas \& craflas, eadem fubftan 


\section{DE PLANTIS AEGY PTI}

tia præđitas, nullumq́uic pręfeferre faporem, uti radices falfęparilla : ex quibus colligo ftatim, fmilacem illam afperam ucram effe falfam parillain oharmacopola cius loci multum lucrife feciffe his radicibus nobis affrmauit, quod fxpe harum radicum ibi collectarum multos fafecs collegerit, \& in alia loca miferit, quas pro veris falfe parille radicibus fapifime vendiderat . Quam mercaturam clamagebat, ne eam plantam alij difcerent. Ad̈do Cayrime in fallẹ parillẹ fácibus cx Hyfpania afportatis uidiffe, fruftra radicum nodofarum, vel geniculatarũ afperę fmilacis, à qui bus procedunt radices, quibus medendo nos vtimur, cum folijs eiufdem plantx, tum ramulis fpinofis, fic manifefte, ut nemo, qui viderit, cos fafces falfeparcllę, effe ex fmilace afpèráfelectos, ne gare potuiffet hanc plantam candem effe cum falfaparilla.

G V I L A N D. Placuit multum mihi, te veritatem de fmilace afpera probè agnouiffe, cuius quidem fententiẍnon folum me fed quamplures alios fuiffe tibi perfuadcas volo, in primifque $G a$ briclem Fuloppium, herbarum materix doctiffmum, qui in libello de morbo (sallico, in cupite de falfaparila hęc prodidit. Alias credebam effe ndicem cbuli, \& perfiti in ca fententia plurimis debus, cionec Hipanus ad Ducem Florentiam integram afporta. uit plantam, \& hinc patuit error meus, \& uidi effe radicem fmilacis afpere - d z qua Diofcorides libro quarto, \& feriptores antiqui men tionem fecere. Quod magis confirmatui experientia, nam cum in monte Saneti Inliani Pilis vidifem fmilacem afperam, curaui effodiendam, \& fempervfus fum loco falf $x$ parilla \& per bienniü illud,quo ibi fiti, femper cum folici fuccefiu plurimos à lue Galli ca liberani. Quam etiam fententiam confrmat Amatus Lufitanis medicus, quamuis Hebreus, non fpernendus in libro quinto, fuarü centuriarum. Quare te hac de re euchi non oporet, quando alij ante te milti eam nouerint. Sed quomodo afferere poffumus cius infule frilacem, probè falfam parillan delineatam demonftrare, minimeque illam, quam Inalix loca ferunt atque alunt. Quòd tamen fieri putotere, qua ipfa ferpit, diucricate, etcnim in duro folo reco, \& fqualido efforsan fmilaccm videbimus radices mino res, graciliorefque falfaparilla habere, \& in molliffimo folo, quod in eo facile queant ferpere, longiores, craflorefque, fall xe parillix planè proximas. Ea fiquidem finilacis planta, quam in ça infula olim cum in illis locis diuerfarer, infpexi, folo mollifimo, pingui 


\section{I B. E R.}

2c humido nutriebatur, ex quo mirum non eft, fil longis, crafifque radicibus fuit inuéta; in ficco vero duro, nequeuntibus, terre duririe obfiftente, radicibus libere ferpere ac meare, fmilax afpera radicibus breuioribus, tenuioribuffque appärebit. Quạles à me obferuatæ fuere in Zacynthi.infules, Corcyrx, Cretxóue locis faxofis \& durioribus." Addo multos decipi in agnofenda falfa parilla ex fmilace afpera, non' ómnes fmilacis, falfiequir radices animaduertentes, ac obferuantes. 'Etènim in afpera fmilace dur radicín differentix fpectantur. Ipfa fiquidem in primis ex ftipite radices procedentes habet albas, rotundas, nodofas, digiti crafitie, cannulis paruis perfimiles, que fanè radices non admodum longx cxiftunt.cx quarum geniculis vel nodis alix proficifontur atque exi liunt à primis planè diuerfę, in duroque folo paruę, breues, tenuefque,non fecus quàm capillamenta quępiam cernuntur. atque in molli longe, craffx, quales in falfa parilla, inueniuntur. Ex qno apparet radicum finilacis differentia, qux itidem in falię parille planta ex Hifpania adueeta facile obferuatur ac reperitur,adeo vt, quęue harum plantarum habeat primas radices à ftipite fta tim procedentes albas, nodis ęqualibus interuallis diftinctas, cannis proximas, non tamen intus peruias, fed plenas, digiti minoris craflitie, refertas, \& fecundas ab harum nodis vii capillamenta exilientes ac exeuntes, longas, primis graciliores, equales, nodis carentes, fiue non geniculatas . Qui itaque negant fmilacem afperam veram effe falifam parillam, dicunt radices vtriufque plantę effe inter fe differentes, forma quippè ac etiam magnitudine, forma quidem, quoniam fmilacis tantum primas radices nodofas albas, breues, craflas fpeetantes, fecundis à primarum nodis nafcentibus longis, gracilibus, non nodofis, ęqualibus comparantes, manifentif fimam inter has differentiam faciunt . quam confirmant etiam ex eo, quod primę craffx, \& breues, hęque graciles, longę exiftant . Errant quidem ifti non recte radices inuicem, vt pareffet comparantes, quoniam fi radices falfxparillę graciles longas, quę funt fe cundę radices, non primis fmilacis afperx craffis, nodofis, candi dis, breuibus, ac fecundis à nodis primarum nafcentibus comparaffent, fine dubio nullam differentiam inueniffent, hac excepta, quod fmilacis radices fecunde, falfę parillx radicibus breuiores graciliores loci caufa obferuantur. Quam differentiam foliterreue mollitiei, \& duritici ratione, vel eiufdem diusfitate, ac fortafle 


\section{DE PLANTIS AEGYPTI}

exiam cęlocalidiori feri nobis perfuafum êt. In duro enim folo atque in frigidiori colo radices non ica crefeunt, \& craffefcunt . A L P IN. Veritarem attigint, atque iftec emmia ad radicum fmi lacis artinentia à re prodita, ego oculatim in Zacynthi Infu!a fedu lo obferuaui,atque cognoui. Quę veritas ex plantę e uiuo delineata ichone planè clara elucefiet. in quo virxque tum primę radices nodofe, craffx, breues, tum fecundę alię ab harum nodis nafcentes, longe graciles, equales fne gen iculis manifeftiffime fpecta ri porfunt. GVILAND. Ex vifa fmilacis huius Ichone, atque ex ijs, quę tu de ipfa hactus dixift, facule cam fmilacem, quam tu in Zacynthi Infula nafci prodidint, effe i fmilace afpera Italię in locis inuenta multum diffrentem, cognofcitur,tum ex folijs bre. ui oribus, tum ex diuerfa foliorum figura, tum multo magis ex radicibus illis nodofis, qux in alijs fmilacibus afpe ris non inueniuntur . 


\section{I B E R.}

\section{SMILAX ASPERA。}

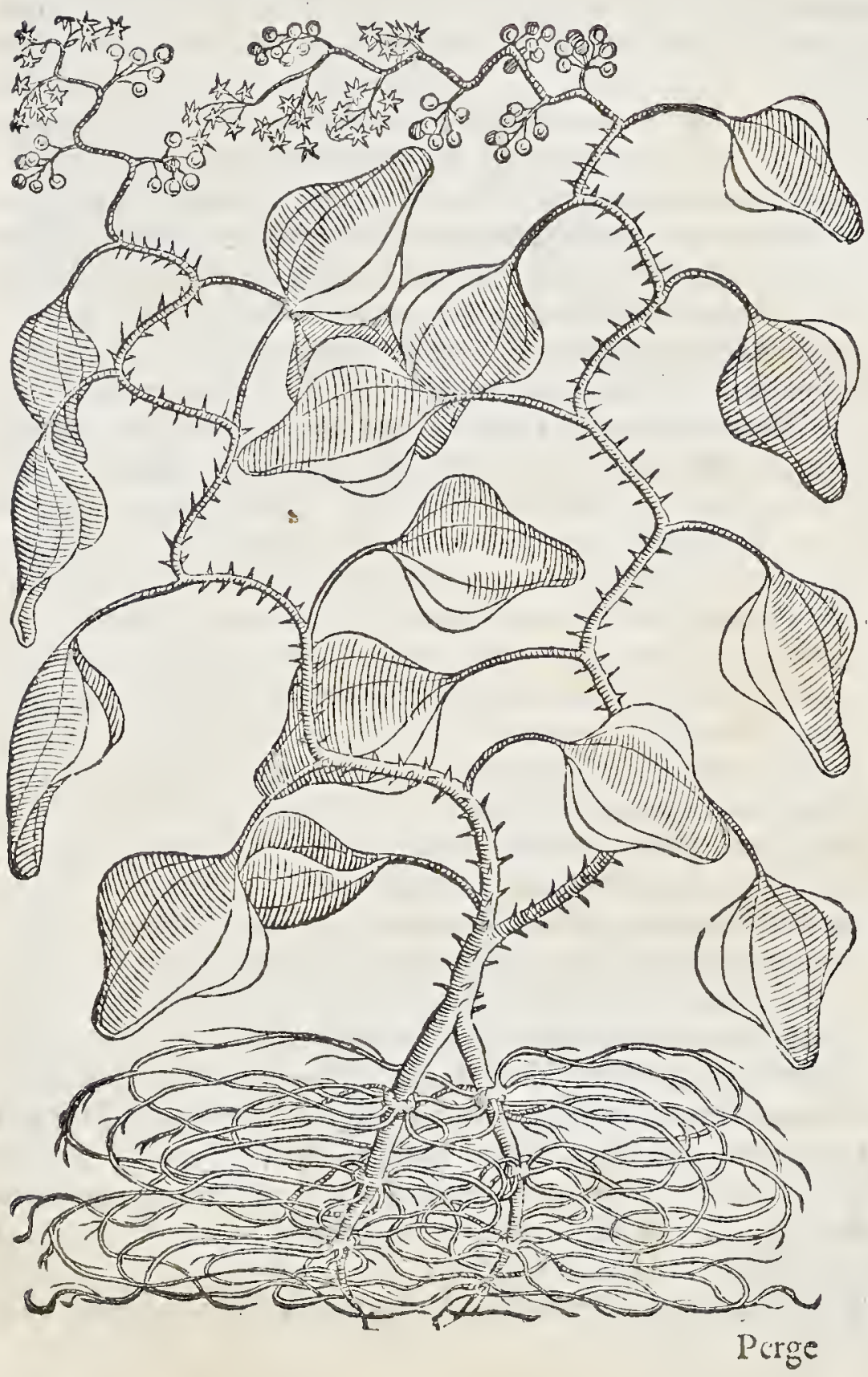




\section{DE PLANTIS AE GYPTI}

Perge modo reliquarum à te confpectarum plantarum narrationem ac hyforiam abfoluere, cum nobis de hac planta nihil dubij relictum fit, quin credamus ipfam veram efe falfamperillam. A L P I N.In Creta infula inter alias plantas ibi Thymü, thymbram, epyth:mum, marum, ladanum, afpalathum, fyracem offendi. Thymum verumq́ue vidi, quippe magnum ac paruum, magnum ef planta farmentofa folijs fatureiç proximis, fed aliqua tenus afperioribus, latioribus, \& viridioribus, fapore valde acri ac odorato:quam plantam falfo multi tragoriganum effe Diofcoridisfratuunt. thymus fecundus minoribus folijs, tanuioribus, albio ribufque totr Italię cft notifimus. Tymbra eft planta in Creta In fula nafcens copiofiffma, fimilis thymo maiori, ramulis duris lignolis, folijs thymi latioribus, mollioribus, herbacei coloris, non ordinatim, ut aliqui prodiderunt, nafcentibus : neque inter hęc alia foliola nafcuntur . ex qua planta communiter pro fecunda thymbra delincata, non veram effe conijcitur, quam ibi uidi cum epythimo, admo dum differentem. Epythimum vero in loco eius In fule Frafchya vocato, cufcutę modo, thymo, thymbrę, atque alijs plantis conuolutum inueni. ex quo falfum effe duas effe epithymi fpecies, dignoui, quippè vnam thimi florem, at quefecundam capillarem hanc herban cufcure cmulam: Epithymum nanque nigram bilem purgare omncs affirmant, thymi vero fores id prxitare nemo dicet. Aliqui ex Cretenfibus aiunt cpithymum, atque epithymbram purgare fanguinem calore exuftum, multofque inter fe differentes morbosex illius capillaris herbe fupra varias plantas inuentę vfu fanari etenim, quę orjgano conuoluta collecta eft, morbis omnibus purgatione con. ducere affrmant, quibus origanum per fe folum fubuenire compertum eft. ficque in alijs plantis repertam \& ab ipfis exceptam uel colletam, vin habere purgandi humores, è quibus concita tis morbis he plante fuccurrere, atque auxiliarifacultate folent. Marum apud aliquos Cretéfes vidi, noltro amaraco planè fimile. etfi tamen gracilioribus, minoribus, afperioribufque folijs amara coconftet, multoqúc noftro amaraco fit odoratior, \& prętantior, quam plantam, fyluefte amaracum, \& non marum nuncupan dam iudico. Plantam uero, ex qua ladanum Cretenfes colligunt plane difieron: ab ea, quam hacenus fere omnes prodidere, in fpexi, Hęc fignize Cyfto fominę perfimilis cot, folijs tamen cylti lon- 


\section{I B E R.}

longioribns pradita, faluizque nroxinis. Florefque fert fylueftrie bus rofis omnino finiles, qui rofe eriam colore, quippe communium rofartim fuffuli fpectantur. Qux planta a cylto foemina Porum tantum magnitudine differe uiderur. Decepcufque fuit Mattheolus Diofcoride dicente, lodanum effe cyfti genus longio ribus folijs nigrioribufque refertm . qux notx in cyfto, ex quo Cretenfes lodantm colligunt,utique omnes obferuantur.quando hec planta omnino cyfto foming fit fimilis, cum ijftem folijs fo ribuff; frectetur, ctli maioribus. Afpalathurn, etiam ut aliàs quoque disum eft, copiofifimum propè Frafihya portum in quod colle uirentem atque florentem fępe infpexi, odorifque eximia fua uitas ex huiufce plantr Aoribus ad me delata, fuit in caufa, ut ipfum agnoticrim. Qure planta eft frutex denfis ramis, fpinis alb is du ris horridis cortice caudicis albo, ad trium cubitorum \& plus altitudinem in altum affurgens . forbus muleis paruis, croceis fpartij frmilibus, fed fumme odoratis. Huius arbufti radices durx, longx crafre, colore flauo, atque cortice fimme odorato tunc te mpo ris a me fuere obferuatx. Mulafque meus pharmacopxus decerphit, Cayrumq́ue ad vfum medicinę meo iufu detulit. Piures flyra cis arbores ibi quoque infpexi prope illius loci rinum viretes, qua rum mulcas mecum in Aegypto detuli. Quo in loco coll caufa non vixerunt.Sed quid te amplius de cius Infulx plantis, tibi plufquàn mihi notifimis? Quę enim Grecic pars nunc ent, quam tu plantarum defiderio fępius non peragraueris? Et hęc de plantis Acgypti à nobis dica fufficiant. Quibus abfolutis ad alia tranfeun dum eft, \& fortafle ad fudium de ambiguis nonisullis fimplicibus medicamentis agnofendis, frepe à me defideratum. Diu enim fummopere defideraui inter nos abfolutifimam de omnibus prifcorum medicorum vfitatis medicamentis fimplicibus, qux hacte nus apud plerofque noftrom medicorum dubia habentur, haberi difputationem. GVI L AND. Iam hiforiam de Aceyptio. rum tum ufitata medicina, tum plantis illis in locis nafecrotibus finem habuife video. qua dere,ac de itto mea caufa fufcepto labo re, tibi cgo plurimum dum viuam de bebo . max'męq́uc nunc tibi à me agendx funt gratix, perpetuoque habendx. Difputatio ve ro à te de fimplicium medicamentorum, dubij aliquid penè no. ftros medicos habentium, ratione propofira, digniff ma fanè videtur, quę à nobis perpendatur. Hoc tamen in pręfentia faciondum 


\section{DE PLANTIS AEGYPTI}

non puto:Sole crim iam ad Antipodes defcendente, parum huius dicinobis fupereft. Quamobrem fermo hic in aliud tempus nobis accommodatitis, remittendus eft. Interim nos metipfos pau lulum à labore laxabimus, quietis ac ocij aliquantulum ani: mis concedentes. Quamprimum tamen tempus opportunum ad eum formonem tibl videbitur, ad me redibis, ut hac cie re aliquid dignum commentemur. A L P I N V S. Ita faciam, fed antequam nox ingruat, me domum redire confultius eft.

Vale atque me, ve foles, amato. GVILAND.

Vbi mecum manere non eft animus, vt lubet,

hinc difeede. Interim mei femper efto

memor, tibique me effe addictifi-

mum, atque tui obferuan-

tiflimum, fcias velim. i foclix.

\section{FINIS IIBRI DE PLANTIS.}


P R O S P E R I A $\quad L \quad P \quad I \quad N$ I

D E B A L S A M O,

D I A L O G $V \quad S$.

IN $2 V O V E R I S S I M C A B C A L S C A M I$ plants, opobalfami, carpobalfams, of xiloballami cognitso, plerifque antiquorum at que iuniorum medicorum occulta, nunc eluce fcit.

$A \quad D \quad I \quad L L V S T R I S S I M O S$

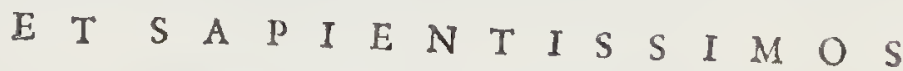
Patauinæ Academix Curatores.

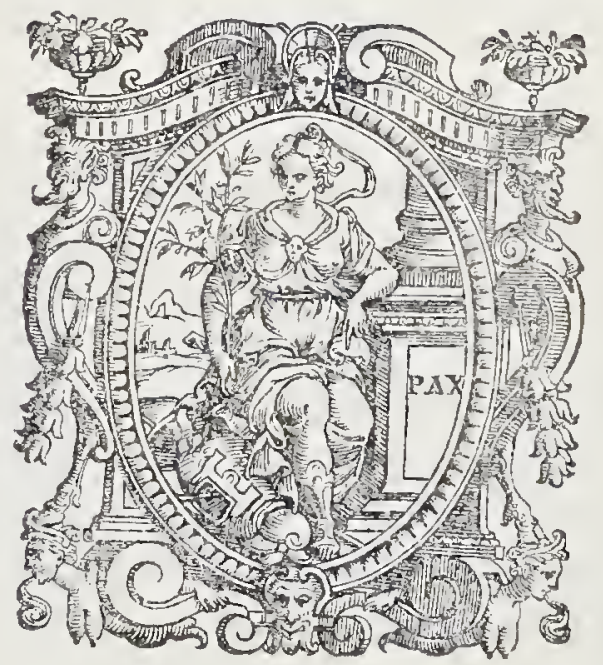

VENETIIS, M. D. XCII.

A pud Francifcum de Francifcis Seneneria. 

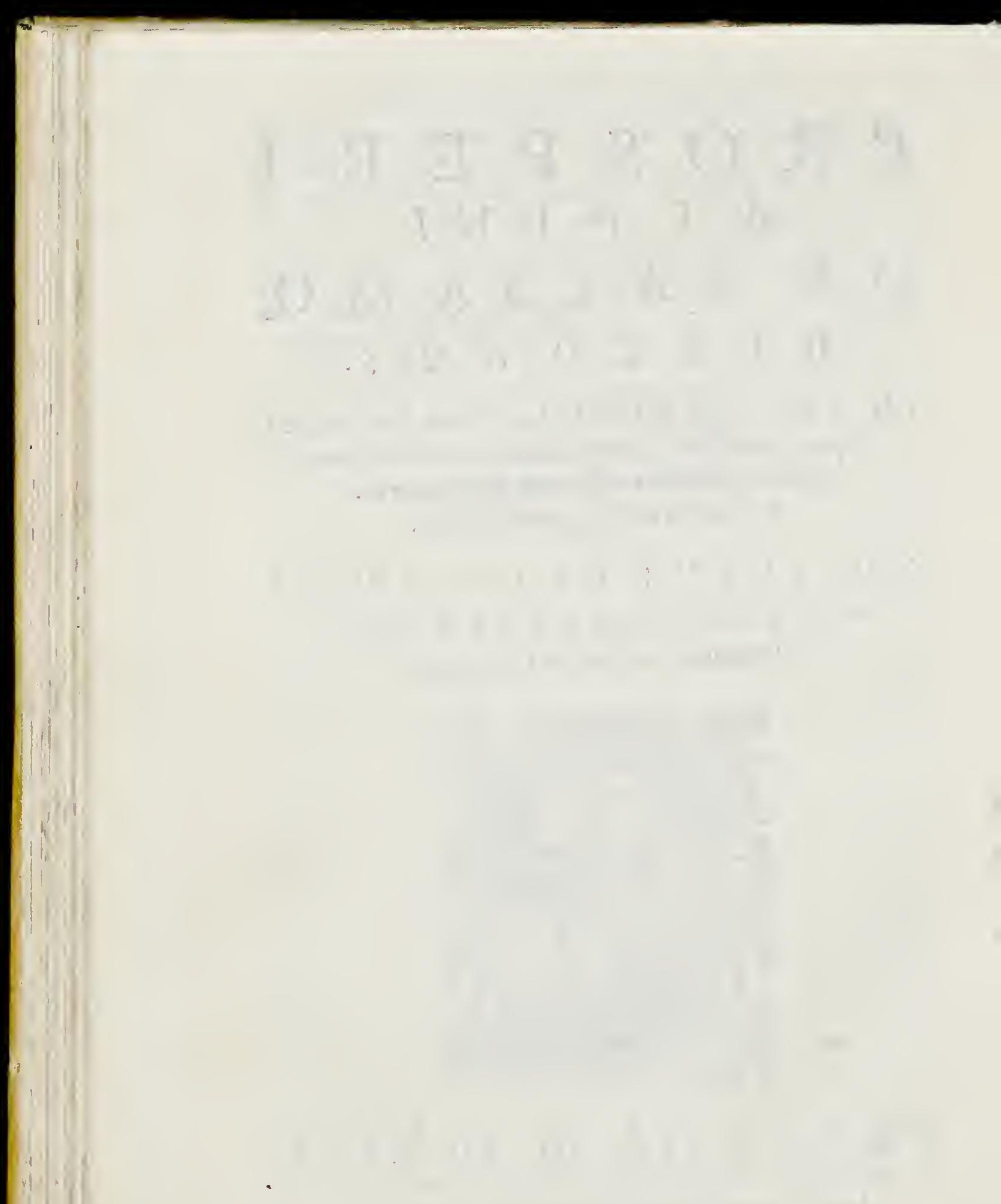


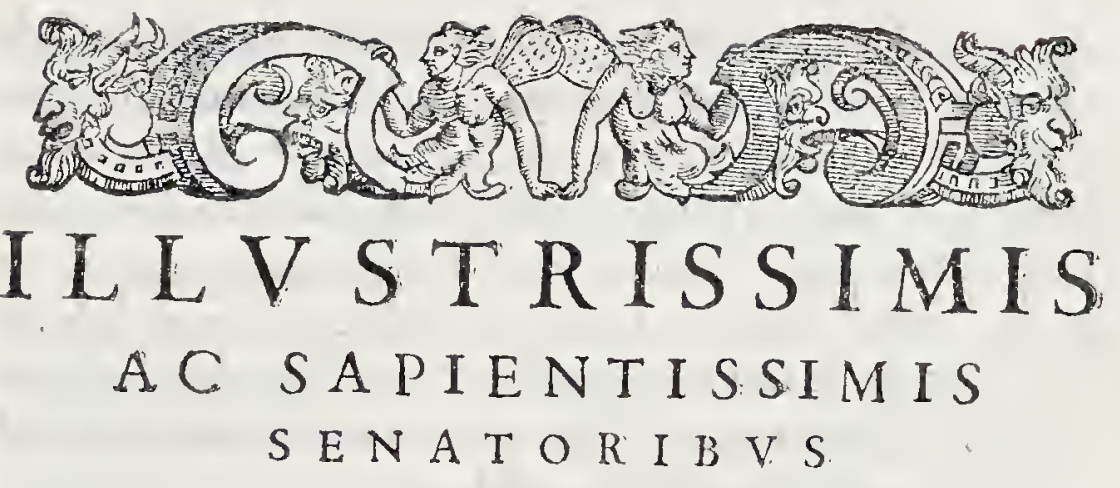

FRANCISCO PRIOLO DIVI MARCI

$\begin{array}{lllllllllll}\text { p. } & R & O & C & V & R & A & T & O & R & I_{2} \text {. }\end{array}$ Zacharix Contareno,

AC LEONARDO DONATO EQVITI \& Diui Marci Procuratori.

Patasina cAcademic Curatoribus.

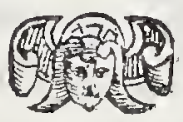

PROSPER ALPINVS. S. D.

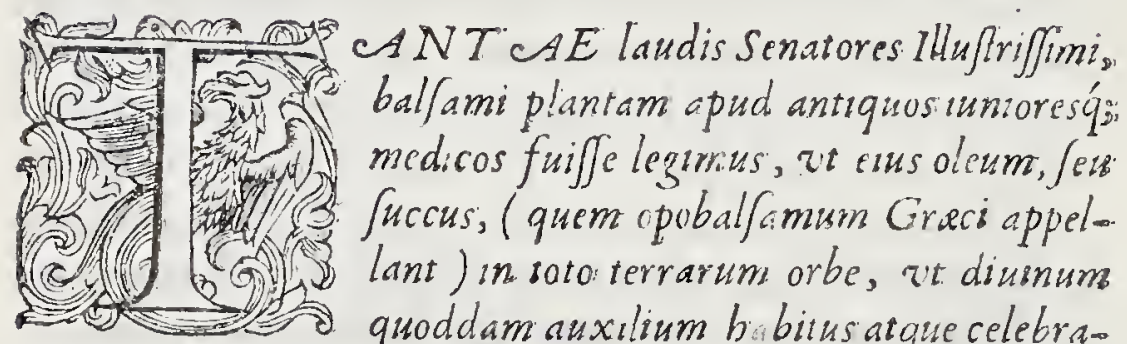
tus fuerit. Vulgusetiam rem aliquam vebementer ad fanitatem accommodatam, balfamum vocare folet. Et qudemnibil in oniuerfa fimplicium medicamentorum (ylua prafanins, $\sigma^{\circ}$ dignius unensri prodsum eft: nequerd bercle sminervio. Quis. bus 
bus enim in arte medendi verfatis ad vlcera, vulneraq́; fananda illius virtus eft ignota? quantum lethalibus venenis, fcorpionumq́; ictubus, ¿'o aperarum morfibus obfftat? Quibus etiam buiws Jucci nobulutas, in pefte, pofiferisq́; febribus arcendis mira efficacia eft occulta? quendoguidem regum corpora co olim im putria feruari multorum teftimonio conftet non ne putrida febies fape funt boc adempta prefidio? Quid? non ne exbalfamo boninis corpus à cute ad vifcera v/ $q$; inuari experientia docuit? Niuleres co fibi illitamfaciem pulcherrimam efficiunt, obortasq́; incute rugas abigunt. Atque hinc iutentutem diu fertari exul gatiffimum oft. Et vt paucis rom colligam, acperfringam,caput,fomachum, bepar, licnem, me entereum, pulmones, renes, ve ficam, vicrum, fpinam, nertios, mufulos, articulasq́; omnespluri msimiuat. Etenim obortam oculorum caliginem nbftergit, wi Sumq́; vitiatum, rel deperditum reftituit; aures dolentes, $\mathcal{O}$ in ipfistinnitum fanat. Praterea conuulfis, epylepticis, vertiginofis, refolutis, atque trementibus mirum in modum prodeft: tum refpirandidiffcultati, tuffs, orthopnose, pulmonum frigiditatibus, fuxionibus, đo doloribus fubuenit. Stomachi calorem valde fouct, auget, atque roborit, ¿riccirco eins cruditatibus, ac flatbus à diminuto calore excitatis, prafentaneum"ef auxilium. Meferaicarum veroàiecore, acliene venarum obftuitiones aufert, regiumq́; morbum curat. Interceptam Sepe vrinim prowocat, calculosq́; valenter frangit, ¿o ipfos à renibus abfergit, atque per vrinain expellit. Uterum magis, quamcetera niembia refpicit, atque omnibus cius à frigiditate obortis malis preftantifsime fuccurrit; Menfes cit, partus, fecundasc; cducit, prefocationibus, ¿T flatibus tuto medetur. Et quod non minus a multis defiderari, atque expeti folet, faminam ijfdem excaufis effectam fterilem, facundam reddit. Cumá; tam exima balfami dotes exiftant, ab antiquis etiamprat clariffimis me ticis olern memorie tradita, mirum non eft tantope 
re Romanis Imperatoribus Ve p. funis cuarieam arboremexsitiffe, einsq́; caufa ab ipfiscrim ludais aliquando dimicatum fuil fe. Maximum ofm in sialicina babuife /uccum, fructus, ate ligna apudomnes liquicio confat. Perficit enim multorum antidotorum compofrtiones, prefertimg; Theriacam, at que Mitbrida tium, qua a noftris, co fublato, non fne artis dedecore parantur. Cum bac aliquando bic inueniri poffe ignorent, aidaciffimé; ob. latum fape ip/is buins arboris verum fuccum, frubtus o ligna, vera effe negent. Non poffum igitur non multum prefentem balfamicalamitatem cum buinfce temporis medicis dolere; cim of fin multa Italic loca ex Aerypto, ac Syria buinfe plintice Juccus, fructus, lignaq́; nunc vere comportentur, hac tomen agnofcere noftri medici renuant. quinimo plerigue affirment boc tempore veram balfami plantam nufquam gentium inueniri, minimcó; eius fuccum, fruitus, of iirgas ( que opobilfimum, carpobalfamum, of xilobalfamum Greci appellant) adnos ve ras comportari. Atgue borum alij afferunt fieri quidem non pof. $\int e$, ut ucri opobalfami fatis, cuius quantitas non pauca fepe in bis locis circumfertur, inueniatur, cum Aegyptuj, ac Syita balfomi plantis omnium confenfununc careart. quando ctiam prifcis faculis ex tota cAeg ypto multis ÿdacm plantis referta, modicum quippiam illiufe liquoris haberetur. Alij ex Folicic Arabia huc illum delatum fcientes, fyncerum efje opobalfamum negant, afferentes folum c4eg yptum, ac Syriam illum olim babuiffe, neque alibi inuentum plantarum friptores prodidiffe. Hisq́; riso. sonibus perfuafum eft eis, fyncerum opobalfamum bis temporibus non reperiri, guod fi aliguando fibi à quibufamex cAegypto, hel Syria uenientibus offeratur, cos irridentes, negant uerum effe, atque à fe reijcinnt, $\sigma$ in parandis Theriaca, Mitbridatio, ¿\%alïs nobiliffomis compofitis, eo baudquaquam uti nolint. Quod ego cum mea quidem fententiapefsme, ac non fine arlis magno dedecore ab ÿs factum indicauerim, cum que al nos logiti. 
mum fuccum arboris, qua à prifcis herbarïs balfamus appellata eft, ligna atque fructus ex pluribus locis afportari certo fiam, non potut ron fummop re fforum ignoranitim, ac crrorem fummum admirari, $\sigma$ butus cos erroris adductis rationibus redurguere, cumprafertim medicos omnes Agyptios, Ara bes, ¿\% Syrios eundem fuccum, frustusíj eof dem, atgue eadem ligna wno omnium confenfu, citra wllam contradictionem, wel hefit tronem in componenda Theriaca, Mitbida:i), aly gue nobilibus antidotis, commendare, atgue arripere cognouerum; qui aliu nunquam fuifje opobalfumum, reque alos fructus, aut alialigna admedicina $v$ um recepta, atgie apud illos votata affirmant. Anvero quis ctegyp!js, Syris, of cArabibus incom rundem medicamentorum cognitione, $v / u$, $\sigma$ expèrientia praferendos contendet Italos noftros? qui neque locum, in quo arbufollum vixerit, neque alibi illum viucre infpexerint? an potius this credendum erit, qui in eodem loco cumiftac planta multos mnos vixere, $\sigma$ illam fepefepius tum viderunt, tum fedulo obferiarunt? Qnando ctiam primi Balcffam plantam eam nomi norint. Quo nomine aly omnes o Graci o Latini libertiffime 2. f funt. Cum igitur illi ltalis, cotcrisq́; omnibus nutionibus in butufce plante, fucci, fructum, ¿ro vorgarum cognitione iure preferantur, atque hec vera ab ip/s credantur; o protegitimis, ac veris ad omnu componenda medicamenta vtantur, fuccumq́; exeAczypto, vel Syriahuc aduedtum, nobısq́; interdum oblaium, uerum cpobaljamum effe affirment: Cur nos iffdemuti, at que in aledicina ufum eadem recipere recufemus, potius quam aliud pro ip 3 s ad componenda medicamenta fubfttuere? Hinc-que mult: murari non debent, fi Theriaca, Mitbridatiumq́; buiufce temporis antiquam amplus illam praftantiam, ac nobiluatem non retineant, neque cximic llle wires a feniore Andromachodecaniate conferwertur. 
Hac fidens ętu perrura vagabere Cxfar

In Lybico quamuis progrediare folo.

Quis enim medicorum erit, qui à wiperis, Acoyptijsq́; cum a.pi dibus, tum fcorpionibus, vel ab alÿs buin mocis ferpentibus demorfos fola Theriaca, vel Milhridatio curare hac alate confidat? velhorum fpe aconitum, vel napellum, uel toxicum inno xiè affumere audeat? Unde eft, quod Theriaca vel à noftris omni cura, ac diligentia confecta magnis illis careat omnino doti bus? Nifi quic antidotus hac multadefiderat ingredientia, quibus antiquis illis temporibus parabatur. Inter que principem fanè locum obtinent opobalfamum, carpobalfamum, atque xilobalfamum, quorum loco noftri pharmacopole alia medicamenta Jubfituunt. Quamobrem multi Aegyptiacam Theriacam longe praftantiorem predicant, quod vera, ac recentia nuper dicta medicamenta in eius compoftione recipiantur. Id igitur ego, cum in eAcgypto aliguot annos medicine caufa moratus, animaducrtifjemverćq ; cognouifjem, vera illa medicamenta ad nos ex yjs locis non raro alportari, qua à nofris non fine componendo rum medicamentorü ingenti iactura ab v $\int$ medicina reijc:ütur, falfáq; uel adulterata efJe dicuntur, Decreui ueritatus crgno/cen da ftudio, de bal fami planta, Jucco,frictibus, $\sigma$ uirgis, qua Junt admedicine ufum à ucteribus medicis litteris tradita, aiq; nunc apud noftros ferè obfoleta, librum olim in cAeg ypto confcriptum, quo omnium iftorum cognitio comprebenditur, vobis Illufir fflmis, ac Sapientiffimis uris legendum ac Jpectandum dicare; Ex quo, balfaminertate perfpcita ac cognita, operam detis, ut l.ec preclaramedicamenta; urfira oninium cpera, ac a ctoritate ab omnibus medicine amatorikus dignof caniur, atque in praflinum medicine ufum renocentur: Anno falutis brimaras. M. D. XCII.

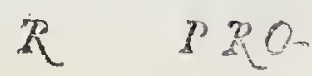




\section{PROSPER ALPINVS L E C T O R I.}
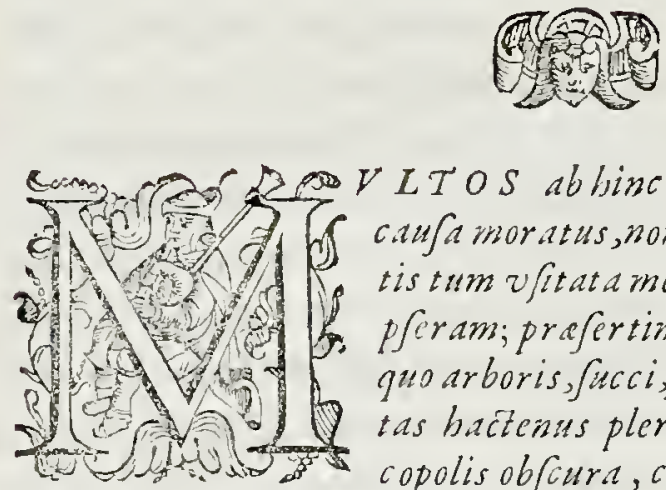

LTOS ab bine annos in Aegypto medicine caufa vroratus, nonnullos libros de illiufe gen tis tum veltatarnedicina, tum plantis confiri peram; prafertimg de balfamo dialogum,ex quo arboris, fucci, fructumin, virgarumg, veri tas bactcons plerisg medicis, \& pharmacopolis obfcura, cognofieretur, claragi eluce feret. Quos omnes fanè libros fimul in lucem prodere cogitabain. At bortatu quorundam amicorum, quime aliorum librorum cditionem non ita breui tempore publicaturum putarent, fententiam nutaui,maximegin noninulls doctifsimis pharmacopolis obnixe fuadenti bus,qui Theriacam, Mithridatium gu,nuc paraturi, ab Excellentif. fimobuius inclyte urbis medicorum Collegio veri opobalfami,carpo balfami, ci xilobalfami veritatem, dubiforiam agnofi exoptant, ut bis ad predict a praida medicamenta,at $q$; ad alia libere uti poffent. Non immerito Theriacam Mithridatiumg his ablatis ab antigua fua excellentia, non parum deficere dubitantes. Ne itaque istorum defiderio me obfequi nolle uidear, libcllun hune prius emittere non fum veritus. Hancgíl, wius celeriseditionis canfam Candide lector weran effe putato. Interim libros alios de medicina Aegyptiogum uocatos ( $/ 2$ modo bunc meum libellum medicine fudiofis aliquo pacto arriffe intellexero) propediem in lucemuenturos expectabis.Tugetian quo animo ego balfami difputationem lanc, weritasis pantum agnofende fudio, at que iuwandi defiderio fum profecusiss. codem legendamaccipies. Vale. 


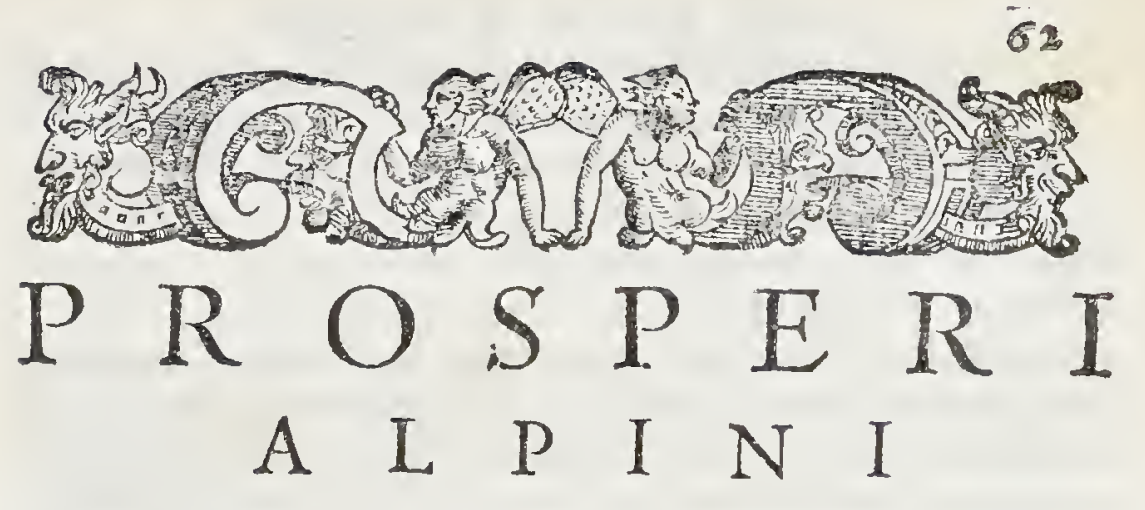

\section{DE BALSAMO DIALOGVS.}

\section{$D E B C A L S A M I P L A N T C A, S V C C O$, fructibus, \&virgis effeloguendum. Cap: 1.}

\section{A B D E L L A Medicus Acgyptius, A B D A C H I M, Hebreus,\& A L P INVS Italus.}

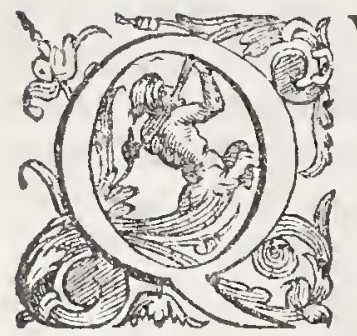

VEM ego nunc hominem confpicio per hoc viridarium el Mattharia greflus mouentem? is certe meis oculis Abdachim Medi cus videtur, vir honeftifimis moribus ( quam uis Hebreus ) præeditus', mihiq́uc multum familiaris : cum igitur conueniam, \& falutabo. Salue Abdachim, Quàm diluculò hoc viridarium es ingreffus; Quid tibi vero negotij eft, vt tam fummo ma ne huc te recipias. A B D A C H.Te nunc huc conueniff; valde letor, quando iam diu te exoptatuerim videre, ac tecum colloqui, Tibi optata hęc fit dies, Ego ve viridarij huius amœnitate, fuauiffrmoq́ue florum cafiarum odore, auraq́ue matutina frigidiufcula me aliquantulum recrearem, huc accefferam. A B DE L. Cur vero viridarij iftius plantas vndique obferuas, neque te humi ftratum fub ficus huius Aegyptix latiffimis ramis confpicio, ut quie tius ita tum animum, tum etiam corpus recrearcs. A B D ACH.

$$
R \cdot 2 \text { Oculus }
$$




\section{E B A L S A M O}

oculos hinc inde dimouebam, fi aliquam balfami plantan viten rem potuifr m infpicete, cuius odore cximio olfactu animales fpi ritus deleatem, quas cufodum negligentia exaruife comperi, quod fats agre patior, plurimumque me tędet hoc viridarium il lis nunc carcre piantis, multumque ornamenti hac de caufa hic de effe videtur. A BDEL. Ne te ob id excrucies, quandoquidem frpe aliàs aliunde afportatie, atque he infertix plante perie rint, que nunc forane, alijs adhuc iufu prefecti aduectis, citò reroubuntur, vt froe alias fietum eft. Sed quem video ad nos venientem? An Alpinus Veneti Confulis Medicus? ABDACH. Ipfe ef, cui nos obuiam ire honeftum eft, quod humanus hic fanè vir ent,arque affabilis. A B D E L. Quid iftud elt Alpine, quod nostehic nunc off ndimus? twus aduentus pluribus de caufis eft nobis iucundifimus. A L P I N. Viridarium hoc fpectandi gra tia huc me contuli, vobisq́ue pro veftra crga me humanitate, plitrimum debeo, neque partim gaudeo, quod ambos vos hic offon derim, am diu enim uos videre deficerabam, nec immeritò, cun vospluribus nominibus tantopere obferucm, Neque cft quod vefram ego num in arte medica do trinam coram cxtollam, neque quantum à vobis in ea profecerim, veludicerim: A D D E L. Bonus es cum hrec cxiftimas, vecumque res fe habeat, à te amari nos fummopere expetimus. A L P I N. Gratias habeo, fed timzo ne importuno mzo aduentu iam ceptos veftros fermones in

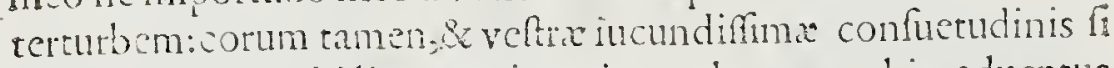
ficri particeps mihiliceret, mirum in modum meus hic aduentus mihi uoluptati foret. A B D E L. Gratifmum nobis erit, nunc tecum vir doctifime colloqui, à quo pro tua doctrina plurimum noftros fermones claritatis recepturos fperabimus. A L P IN. Vobis gratian habeo. Quidiftud autem eft, de quo fermonem inftitueratis. A $3 \mathrm{D}$ A C $\mathrm{H}$. Debalfam planta, quam in hoc viridario aruiff comperi, internos commentabamur, Cuiusiagturam mihi xgre frenti Abdella noftex in plantarum materia exercitatifimus,animü reftituit, multas c̀ Mecha olim etiam pluries delatas huc, infitafque fuiffe, \& planè reuixiffe narrans, atque etiam hoc modo frpe balfami plantas renouatas fuiffe, ut fperan dum fit, nunc etiam prefecti Aegypti iuffu, vbi ad illius aures harum iactura aliquando peruenerit, denuo inftaurari pofse. A LPIN. Quid audio? illas plantas huc aliunde fuifse afportatas, co. 


\section{A L O G S .}

que modo perpetuò infauratas? quafi Acgyptus illis proprium folum non fuerit. non in fermonem inanem fpero me nunc incidifse, de balfamo inceptum: de quo non pauca uobifcum loqui iam diu defideraui, que fi vobis nunc grata fore putarcm, libenter proponerem: A B D E L. Gratam nobis rem facies $f$ hac de re difputationem aliquam promouer is : ex qua plurimum emolume ti pro tua doctrina, atque humanitate nos efse confecuturos f peramus, proinde quicquid eft, quod à nobis fcire velis, nunc in me dium profer. AL PIN. Multum vobis pro hac re debeo, vete rumq́ue Acgyptiorum fapientiam \& humanitatem agnofco. Verum ne longius verbis rem producam, de balfami planta, fucco, frus ctibus, lignis nunc uboifcum difputare defidero, quando ego hacte nus foriptorum uarietate anceps, ac dubius fuerim. A B D A C H. Neminem Aegyptiorum, uel Arabum efse nunc arbitror noltro Abdella in re plantaria magis uerfatum : pluribus ijfdem plantis abeo cum hic, rum alibi infpectis, ac omni fudio obferuatis, fed ut de hac reclarius differamus, in capita redigere te oportet, des quibus fit figillatim difserendum. Quare iftec omnia nunc in medium profer. A L P I N. Dicendum à uobis primo cenfeo, an balfami planta hoc tempore alicubi uiuat, quando in hoc uiridario, in quò hactenus à prifcis illis temporibus ufque adhuc uixit, planè exaruerit; atque non minus, an ab ea collectus fuccus, fruEtus, lignáque ad nos perferantur, uel potius una cum arbore cun exa perierint. Hec in primis à uobis enarrari mihi cupio, quibas cognitis figillatim de fingulis agemus.

An balfamiplanta, einsq; fuccus, fructus ac virga nunc reperiantur, $\mathcal{O}$ in guibus locis proueniant.

$$
\text { Cap. } 11 \text {. }
$$

\section{$A . B \quad D E L L A$.}

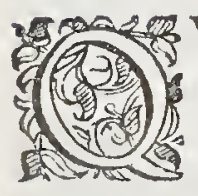

VAMPLVRES balfani arbores in multis Arabix locis nunc uiuere, quarum fuccus, fructus, ac uirge huc ad nos à multis afportantur, ceriffimum eft. Neque id Aegyptios, Syros, Turcas, Bx aliarum nationnm homines multos, Arabiz loca peragrantes later, quinimmo om- 


\section{E B. A L S A M O}

nes annis fingulis Mecham, \& Medinam primarias Arabix foelicis vrbes, peregrinationis gratia adcuntes, quantus in illis locis fit cx arbore balfami prouentus, planè fateri pofunt . Nam Mecham hinc euntibus, \& ad uillam quandam Bcorunia ab his vocatam, quie diftat ab urbe Cayri fpacio dierum quindecim, accedenti bus, mons pergrädis, arenofus propè eam villam pofitus continuò confpicicur, balfami innumeris arbufculis refertus, quas ibi Mahe metis miraculo ortas noftrorum multis fuafum ent; Sed vecumque ibi nate fuerint, nobis id fufficiet, omnes ea loca quotannis peragrantes, innumeras ibi viuere comperiffe; idque à quamplurimis huiufce urbis incolis, qui olim, \& proximo etiam clapfo anno ca loca peragrarunt, audire, atque ucrum effe fire poteris. Multis quoque rationibus hec ueritas tibi à me perfuaderi pofser, fed fi huius uiridarij balfamis olim multis refertifimi terram aliquado olfeceris, balfami ctiam nunc fuatifimum odorem redolere fenties, bisq́ale, vel ter tantum, Sol fuum peragrauit orbem, poftquam. hx plantre cuftodum negligencia periere. At quid taces Abdachim, quem millies hic te illas infpexiffe certo fcio? vel cur me I talo Medico incredulo veritatem hanc fuadentem minimè adiu uas? ABD A C H. Quid? An hune noftum fodalem medie cum, multos annos hic monatum, plantarumque omnium fuctiofum, hanc ueriatem ignorafe dubitas? Ego certè balfami plantas innumans diuertis tomporbus ex Arabiaduectas, hicque infitas vixiff, certo fcio, quas mulci criam alij Cayri incolx infpexerunt. AL P INVS. Nephas effe, ac inubanum putarim, tantorum medicortum teftimonio non moneri, qui prxter herbarum peritiam, in qua illuftres apud plerosquue Aegyptios habirifunt, van clim balfumo in eadem terra nati, uixcrunt. Sed, ut ingenuè fatear, quamquam ego cum viris in medicina clariffmis plane fentiam, huiusque rei ueritatem omnino cognofcam, tamen hac ucritas non adeò ufquequaque mihi fatiffacit, ut posfim aiijs permultis Italiz, aliorumq́ue Europx lo. corum medicis, atque pharmacopolis increaulis hoc, ut cuperem, perfuadere, qui abfolutè affrmant, balfumi plantam nullibi hoc tempore repcriri, camque planè periffe, ex quo fuccim, fructus, \& uirgas hinc in Italiam afportatas falfas etiam cfictatuunt. Atque prifcis feculic,cumbalfamum tantum in Acgypto \&Iudea uixine Diofcondes ac alijprodiderint, quibus in locis 


\section{I A l O G V S.}

64

nunc èm plantam cum amplius uiuere nemo referat, planè omni bus in locis perijffe colligunt. Quam fententian ipfiperuicaciffimè defendunt, neque omnino carere uidentur argumentis, q!Iibus proprium errorem tucantur. A B D E L. Quomodo quafo iftud effe poteft? tantos ne medicos, dottisfimosá; herbarum pro feffores ita obcreatos effe, qui non viderint, neque cognouerint, balfami plantas neutiquam in fuo natiuo folo perijne? Quodautem Aegyptium, ac Iudaicum falfo Diofcorides, atque alij credide rint, ex me paulo poft cognofes. Neque optimi illi funt philofophi, qui ita facile vegetabilium fpecies, qux iuxta philofophorum placita perpeture exiftunt, tolli omnino poffe, putent: Cẹlo eten im nullis canfis ad generationem facientibus nunc deftituto,terraque ac creteris alijs elementis eodem modo nunc, vt olim, fe habentibus, cur terram cafdem nunc ferre plantas, vt olim facicbat, non poffe dicemus? Graue tibi non fit, quefo, illos, quibalfamum perijfe affirmant, mihi referre, \& quibus etiam rationibus in tam falfam opinionem uenerint, explicare. A L P I N. Parum intereffe arbitror, te hofe homines nominatim cognofere, fed ipforum potius rationes audire, quibus negant hoc tempore balfami arbo res, atque ipfarum fuccum, fruetus, \& virgas apud nos inueniri; id vero incepte difputationi fat crit. Horum fiquidem non pauci exifunt, qui non modo ad nos in Italiam prediata ucra compor tari negent; fed arbores quoque, è quibus illa colliguntur,prorfus perijfe predicent. Quam fententiam ualde auxere Amatus Lura tanus Medicus in alijs non fpernendus, \& Nicolaus Monardus Hi foanus, qui Syriacum atque Aegyptiacum balfamum perijfse affirmantes, aliud genus balfami in Occidentalibus Indijs nafci, prodiderunt: Balfamumúue à Diofcoride, Theophrafto, Plinio,ac a multis alijs herbarum antiquis feriptoribus celebratum, ac defcripium,eò affirmant perijfse, quod predictorum antiquorum fcriptorum teftimonio conftet, olim duobus tantum Iudee viridarijs concefsum fuifse, vt inter cęteros Plin. \& Theoph. teftantur, poftea verò quam Iudea à Ptolemeo primo Rege Aegypti, ac à Vefpafiano deuaftata eft, balfamum in vallem Hiericum appellatan tranfplantatum firifs, ibique vixifse Iutino, Strabone, Solin oque Polythore id affirmantibus, tatume. Et ab Artaxerfe Perfarum rege primo,2c mox à Romanis Adriano Cxfare ruffum totaca re gione bello euerfa, prorfus balfami plantam perijse. Tandemq́ue 


\section{DE B A L S A M O}

in Acgypto paucas hoc in uiridario adferuatas vixifse. Quo in loco non tantum prifcis foculis balfamum vixit, fed multo etiam pontea, quafi ad hre vfque tempora plantam hanc hic conferua. sim fuifse afserunt. Nunc uero, à multis, qui hoc tempore Aegy peum peragrarunt, hic quoque demum eam aruifse, confirmatur. Qua hic extincta, cum Diofcorides, alijque in Iudea tantum, \& Acgypto balfamum uixife prodiderint, cui dubium erit, nufquam gentium eam amplius inueniri pofse ? Ex quo fuccum, fructus, uir gas, pro uero opobalfamo, carpobalfamo, \& xilobalfamo, ab Aegypto, uel Syria in Italiam afportata, uera efse quo pacto aftirmabinus. Meritò igitur hęc omnia falfa nos affirmafse uide. mur. Hincq́ue tanta incredulitas, ac pertinacia inuafit eorum animos, ut potius in erroribus perfeucrare, ueráne fibiipfis oblata reijcere, quàm opinioncm mutare uelint. A BD E L. Vix me continere potui, quin fufceptum tum formonem interrumperem, ufque adeo animumaduerfus illos concitafti meum, nullis rationibus, fed meris nugis balfami omnes plantas perijfse, opo balfamumque etiam, carpobalfamum, \& xilobalfamú apud nos in uentum falfum effe afferentes, ut tanta illorum impudentia excitus, quafi quid loqual nefciam : ac ne differam illis refpondere, dico,ac edico tibi, balfani frutices neque etiam in Aegypto planè perijtse, dici polse, quando fxpe iufsu prefecti Cayri, quem Befsa appellant, plantx multe ex foelici Arabia delatæ in ifto viri dario inferantur. Et nunc uix tertius agitur annus, cum Meffino ris perid temporis Aegypti præfecti iufsu, quadraginta è Mecha adueft $x$, hic infertx fucrunt; qux tamen cum per annum uixerint, rurfum cuftodum negligentia periere; qux facilè erian denuo renouari pofsunt. In Arabię uero multis locis in numerx propemo dum mgno cum illiufe gentis lucro, aluntur: neque fatis diu eft, quad apud Arabes utilitas, \&e lucrum hoc cognof citur;etenim opo balfami quantitas multa in Orientis loca comportatur, quibus in locis eum fuccum in fummo pretio efse, multi ex Arabibus, nunc Cayrum habitantibus, narrant . Cuius fucci lucro ab ijs cognito omnes certarim mules balfami frutices ex arenofis, montuofisć; locis in morbida uiridaria transferre conantur. Quamobrem ibi innumera pulcherima balfameta cernuntur. Lege tamen ijs po pulis interdieim eft, ne pręter fifcum quis eam plantam ferere queat,neque ficcum, uel fores, uel ramulos, uel fructus fine publi- 


\section{A.OG V.S.}

comandato quis capiat. Idemq́ue ibi de baliani arboribus, ate que hic de carlijs folutiuis accidit. Solet etenim hic alicui calliarum negotium locari, \& ideo non licet quemquam cariam ex arborecapere, vendere, emre, aut cmptam aliquo deferre. Quod itidem de balfamo in Arabix locis obfruari, ex Arabum relarione planè conflat. At quidilli A:gyptiarum ac Arabicarum piantarum ignari herbarij dicĕe, ducbus ne tantun locis, quippè A cgy pto ac Sycix balfamum olim (Diofcoride, Theophrafto. Plinio, Iuftinoǵue id docentibus) conceflum fuiffe? quaí aliorum antiquorum feriptorum teftimonio non confer, in pluribris alijs etian locis olim huiufmodi p!antam vixifienonne Dionorus Siculws 2. hiftoriarum libro, in quadam Valle Arabix balfamum nafe, \& non alibi memorix prodidit? Conftantinus vero in lib.de gradib. ait, nafci in India ; \& Iofeph etiam in lib.8.de antiq. Iudaicis, Sa bam Reginam ballami plantan ex Arabia in Iudeam tulife, Salo monique eam dono dediffe, ex qua ibi alix poftea plantẹ propaga tx fuere : \& S:rabo in lib.fux Geograph. I 6 .hec fcripfit : His pro xima eft foclicifima Sabeorum terra, que miaxima nario eft. Apud hos thus \& myrrha, \& cinnamomum nafcitur, in ora etiom balfa. mum, \& alia quxdam herbula valcie oderata: Necnon \& Paufanias idem in lib. g. his verbis confirmauit, dicens: De viperis vero ijs,qux in Arabia inter balfami arbores verfantur, diuerfum quidem accepi. Id huiufmodi eft. Sunt balfami arbores er, qua mirthi ftirpis magnitudine. Folia illis, qualia herbre amaraco. Theophraftus vero in Afra ctiam nafei prodidit. Incolx quoque Bafliani montis Liban, olim Alexi Gręcis imperante, in quotam loco illius montis Solis ortui expofiro balfami plantas non paucas, è quibus tantim opobalfami fufcipicbarur, quantum in A egy pto hic colligi confuetum fuerat, diu vixiffe narrant. Ex quibus cer te fciri poteft, olim non folum Aegyptum ac Iudcam, fed etiam foe licé Arahiä,\& alia loca balfamü aluif: at q; habuifse. Que verias etiam ex ipfomet Dioforide confirmari videtur, feribente, carpo balfamü, iden ballami fructus fuo tếpore adulterari feminibus hyperici fimilibus, ex Petra oppido delatis ex quo cerro colligitur balfami plantan alibi quàm in Aegypto viuere, atque f mina pro ducere. Preterea verum quoque hoc eff cx meadies, non in Aegyptum ex Ludea, vt aliqui fomniarunt, ipfum veniff, Ced ex Folici Arabia femper fuife delatum : Aegyptiumq́ue fulum ve- 


\section{$D$ B B A L S A M O}

liti ncque Indaicum, nunquam proprim, ac natirum ei fuife, in his iocis balfamum perpetuò peregrinam plantam extitife haud lcue inditium en, cam vbique viridaria tantum aluife, in ipfifque tancum vixiffe, te Theophraftus, Plinius, Strabo, alc Solinus meminerunt. Plinius enim hac hijfec verbis fignifeaivit, dicens: nonne omoes offumat plantas peregrinas in viridarijs tancum: ali,ac cultodir, quedan vero cx patrijs tametr etiam in viridaris.

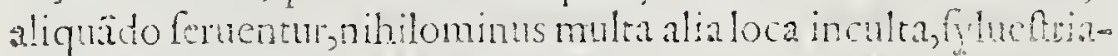
que jifdem fponte natis non carere obfrumer? Atpercgnan in vindarij tantum macno fudio, ac diligentia aluntur \&econferuantur; quod in inculis, fylueftrbusque locis frone nafenentquam confrici folent. Hic vero balfum pluntamperectò al. acnam, vel peregrinam fuffe, \& perpetuò ex Tolicis Anbia locis aduectam, phures vni nobifcum Cayrum nunc habitanes cer a fide confumare poteunt, qui omocs, plantas balfami, guas hatenus hoc habut vididarm, exinde comporatas fuife varijstcmporibus di.ruarunt. Multoqule labore, ac cuftodum di-

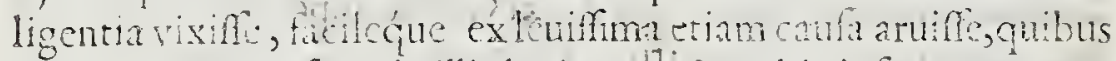
arefacts alins turfum ab illis locis ext age, hic inferas renouztasćue; \& hoc modo alrema is uicibus batamum in hocurricario hatenus conferuatun fuiff. N-non plantas ianto labore ac

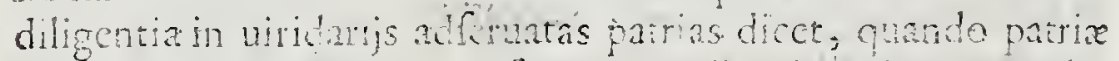

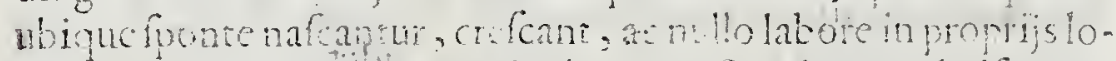

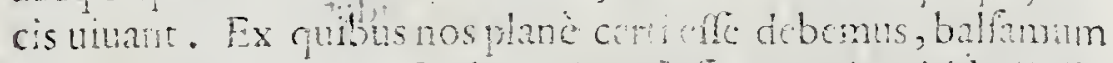

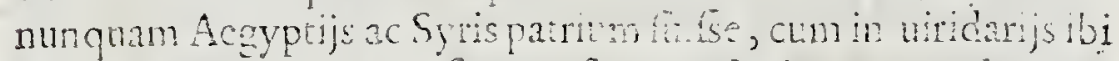
multadiligentia, ac curafemper fierit cutodium quod amen de Arabia Folici, cum balfamm ibi perpetuò vinat, minimè ui-

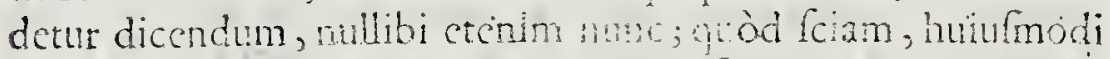
planta nifi Folici tancum Arabe concelsa repoutur. Qtan regionem Diodori Siculi, Strabonis, Patunixque teftimonio; 


\section{I L I G V S.}

vinuper dictum eft, conftat balfami olim feracem fuilse, quę ca: dem modo etiam nunc innumcras eius plantas fponte natas alit. Quam balfami fertilitatem omnes Acgyptijatque al iarum nationum homines annis fngulis Mecham Folicis Arabixurbem ad: cuntes, ueram plance efse confirmant. Copiamque ibi opobalfa: minfignem annis fugulis colligi, fructuumque non minus, \& uirgarum (cumbalfami frutices fape quotannis putent) quxad. uarias orbis partes uendenda ab his demandatur. A B D A C H. At ifrec uera efse concedentes, dicent, quam pro balfamo tu,atque noftri Folicem Arabian nunc alere inquiunt, non efse balfa mum, fed aliam plantam. A L P IN. Notze huius plant $x$ ab an: tiquis fcriptoribus defcriptx ac memorię traditę,iftud recte doce re poterunt. Nim omnes contenifse uidentur, ( ut ex te fpero me magis difincte cogniturum ) balfami plantam fruticcm , cfe, non admodum magnum, folijs ruta proximis, perpetuò virentibus, atque exftipitis cortice farificato liquorem in primis album oleo fimilen, eximio, acutoq́ue odore preditum, manare. A B D A C H. Millies tecum Abdella fruticem hunc ex Alpino defcriptum me infpexiffe in hoc viridario feio. Verum qui huiufce plantx notas quarie, quibus nam hominibus magis credere debebit, Italis ne, an nobis Aegyptijs, qui unà cum balfamo in hac ciuitate haetenus viximus, camq́ue arborem fepius in hoc viridario infpeximus? Nemo certe ita fatuus erit, qui hac de re vobis, quàm nobis libentius credere, ac fidere maluerit. Hanc verò plantam pro ucra arbore, cure ab antiquis balfamus appellata. eft, \& in pofterum memorix prodita,noftri omnes Arabes hucufque confantifime habuerunt, Aliamq́ue pro balfarno ab alijs montratam nemo noftrum vfuiam offendit, vel vidit, wel alim quem uidiffe vnquam audiuit. His addo nòmen huiufee plantę, quod eft Baleffar à noftris ei fuife impofitum, à quo \& Gixci b littera carentes, in u, mutata, bàr oup. dixere, atque ab ipfis Latini Balfamum. Curicitur Italis magis, quàm noltratibus de hac planta credendum crit quando a noltris \& Itali, a Graci, vel nomen ipfus plantx acceptum, didicerint. Quapropter Balfami co. gnitionem à Diofcoride, Theophrafto, at que ab aliis antiquis fori ptoribus minimè petendam iudico, red ab Acgyptiis \& Arabibus, qui loca, in quibus balfami plantre omnium confenfu olim uixcrunt, habitarunt. Si Aegyptij Arabes; Syri, atque alii om-.

$$
\mathrm{S}_{2} \text { nes }
$$




\section{E B A L S A MO}

nes Arabica lingua utentes medici citra ullam diffcultatem tarem fruticem nunc in Folicis Arabix locis cultis, atque incultis, domefticis, atque fylueftribus nafcentem, tanquam verum balfa mum recipiunt, codenqú tum fucco, tum fructibus, tum uirgis, pro uero opobalfamo, carpobalfano, \& xilobalfamo, ncmine ipforum helitante, ad componenda medicamenta, utuntur: Cue Itali ctiam, atque alij aliarum nationum medici ab illis, qui magis quam noftri funt in ea cognitione, coq́tue ufu, exercitati, ac doeti, idem facere recufant? Certe indignum facinus ceft, nos hanc ueritatem nö fateri, fed potius, quo minus ì multis ca digno fcatur, operam dare. A L P I N. Hxc doetiffime à uobis prodi ta fuifie arbitror, ueruntamen quonian cum medicis, pharmaco polifque incredulis difpuratio agitur, quxio fi quid aliud apud uos urique fit, quod hanc ueritatem ad huc etiam illuftrare polfit, ne uos me iftud quoque docere, pigeat, ut poftea quam ego in parriam, Deo concedente, redicro, facilius id incredulis illis hominibus poffum fuadere. A B D E L. Cum anno à Beatifimę Virgimis partu M. D. LXX V. Petro Michacle uiro Cirriffino, pro Screniffma Veneta Republica confulatum hic agente, Eunuchus Mefir dietus, Acgypti Prxfectus, Cayri cinitatis liuius quxpiam loca inuiferet, huncque prxfertim locum el Mattharia. nuncupaturn deuntion is gratia ( quando hane in proximam domunculam olin Beatiffmam Virgincm cum puero filio Herodis. iram fugiendo fe recepiffe, multofque annos in ea manfiffe omnes Aegyptij opinentur, atque ob i d hunc locum in fumma ha. beant uencratione ) fingulis hebdomadis die Veneris, facrum, uencrandtimque hunc locum trifitans, wiridaritim hoc proxime pofitum aliquando animi gratia ingrefius, uidit omnes balfami plantas cultodum negligentia aruine; qua re commotus, ut e Mc cha quadraginta planta afferrentur curauit, eamque operam cuidam militum, ac peregrinorum duci, Mechan fing ilis annis deutionis gratia proficifentim, Haly Bei nomize locaut; qui mihi admodum domefticus; atque fantiaris fuerat, eumque $f_{\text {- }}$ pe ex renum calculo peffme agrotantem inuiferam, ac curaucrä; planiafque illas quadraginta pręcifis ramis detulit, qux in confue to hurus viridari loco infertę fuerunt, dunque fererentur, ego unà cum Paulo Moriano eo tempore pro Gallorum Rege Confu lè medicinę quoque caúa mihi familiari,ătgue cum multis ctiam 


\section{I A L O G V S.}

Cayrinis medicis in re plantaria valde excritatis interfui. Ex ípfo autem Haly Bei Cayrum rencro veri opobalfami binas vntias dono habui, atque ab alio, qui polt hunc illud iter confecerat vntiastres. Horrem Bei alius Carauanx peregrinonm dux meus amicifimus, cuius in domo fiepe tum ipfius, thim aliorum caufa me dicinam feceram, peregreanno M. D. LXXX. Mecham profectus, atque fic à me rogatus, attulit multa femina, \& ramulos eximium odorem fpirantes, atque multum opobalfami i Serpip Meche partim acceptum, cuius modicam portionem dono dedit Francifco Priolo, tunc tempons Cayri pro Vencra Natione Con fule Clariffmo, \& partim ab ijs, quibus balfami negotium locatum ef, emptum. Poftmodum Scander quidan \& ipfe dux militum, Medinam Folicis Arabix vrbem pro prixtore ì Baffa miffus, mihi non minus quàm alij, medicinę caufa familiaris,atque ctiama quia ex Infula Zacintho à Segurorum familia ortum duxerat, bal fami recentes ramos, fruetus, ac fuccum mifit, ac per literas fua manu fcriptas, fignificauit proprijs manibus ibi ea collegife, qux omnir apud me adhuc afferuantur. Omnes predicti nobiles Tur cie uno ore afirmant, propè Mechn \& Medinan, in montibus, planis, cultis, atque incultis locis innumeras balfami plantas fpó te natas fpectari . plurimafque eriam in arenofis, fterilibufque locis, qux tamen vel nihil, vel minimum fucci producebant. Mule ta tamen femina feunt, quorum multa copia ad nos quoque ve denda mittitur. Quales funt in monte arenofo apud Bedruniam Villam polito. Nihil hx, atque alix in arenofis, ferilibufque locis viuentes opobalfami ferunt, idco incolę cas excerpunt, atque pingui in folo infermnt, focundiffmafque reddere fudent. Ad?... dunc,apud omnes. Arabes vererum memorijs conftare, paffim in pluribus Folicis Arabię locis innumeras fponte nafcentes, at que crefeentes balfami plantas perpetuò vixiffe, nunquamóne illa io cajjs caruiffe. Non multum temporis tamen effe, ex quo plurimi cas colere lincri caufa cxperunt, cum foilicet opobalfami facul tas ac vires ad quam plurimas Orientis regiones concefierint. Narrant adhuc ijdem omnes Arabes, vti balfamifucco, fruetibus, ac virgis ad componenda ipforim ominia medicamenta, atque ad alios medicinę ufus, quare eadem planc̀ exifunt, quibus Aegyptij Syri ad ufum nune recipiunt, queque à uhis uatia in Enrope lo ca hinc aducta, negliguntur, atque rejointur, falfácuc corm mulis 


\section{E B A L S A M O}

multi (re auetore) pertinaciter,ac inutiliter effe difputant . AL. PIN. Ex his, quęte uera dixiffe arbitror, me non parum pudet, quod cum illis tot annos in tanto errore permanferin. quem ex te nume probè cognouiffe fatcor. Cupio igitur plantam hanc fuis notis à quoque deferibi, in quam atcollatur manitudin em, qua libufque foribus, \& fructibus obferuaia a uobis fit,quo pact oque ctian ab ea planta opobalfamum diftillet, fponte ne, an, ut multi disu, arte potius elicitum. A B D A C H. Hic nullas, quas ego uiderm crefere, flores, uel femina tulife unqum fpectare potui, exfífuccus interim paucus à cortice ftipitis fcarifica o aliquan do ditillanerit. Verm hac de re Abdellam audiamus, qui hrec ex ploratius, \& reliqua docebit. Interimque dum loquimur, mandes uelim mancipio tuo, ut wob is hic è domo huifue plante icho nem, que apud te eft, deferat, ut Alpinus nofter ueram Balfami Ichonem uideat. A B D E L. Recte mones, libenterquefaciam. A L P I N. Ego uero utrique ueftrum multas hac de caufa gratias referam. Mihique iftuc acceptifimum femper crit.

Plante, que ab antiquis cetrabie medicis Baleffan, à Gracis Biraquor, Gò Latinis Balfamum nocabalur, fiuctum,

$$
\text { fuccíg; defriptio. Cap. } 111 .
$$

\section{A B D E L L A.}

F A S A M V arbufculum cit, quod crefcit ad alri Sulinem hanne; ucl ligutri, uel cytifi, folia paucifiU. 1 ma gerens rute proxima, non tamen is candidiora, Wow ut Diofedocuerat, fed potive colore uiridi fubalbido, perpetuòque urentia. Eius lignum gummofimm leneque apparet, colore exterius fubrubro, cuius ramuli eodem colore confpi cuifunt longi, recti, graciles, paucis foliis inordinatim referti, foliaque fimul terna, aut quina, aut feptena ale adnata, aliquo paco etiam lenth fei foliorum xmula. fune ramuli odorati gummo fi,digitifque contrefati cis tenaciter adherentes. Flores fert parnos, abos, acacix proximos, ternos fingulis alis appenfos, quan in unbellę forma, fumme odoratos, ì quibus femina promanint, Anta, folliculis nigris fububefcentibus contenta, ualde odorata, inturque 


\section{A L O GVS.}

intufque humorem flauun melli perfimilem habentia, fapofefib2maro, parum que acri linguam ferientia, opobalfamumque redò Ientia, Terebinthi frustum figurre, \& magnitudinis ęnula, cxrema aculcata, \& medium craflum obtinentia. Cui defcriptioni maxime quadrare uidetur illa, quę fuit à Conftantino Aphricano tradita, que his uerbis apud ipfurn in libro de grad.legitur. Balla- , mus eft arbor in India crefecens, faliês fuper terram menfura vnius brachij,uel parum plus. Cuius rami rubeo viridique colore perfuri "s quafi rami thitymali tenues funt, \& colorem viridem habentes. "s Faciuntóue in capite quafi gemmas, paruaćq grana in modum pis s peris producentes. Ex fifluris ramorum huius arboris, egreditur quidam liquor in canicularibus dicbus, ficut lac ex thitymalo. Opobalfamum menfibus, Iunio, Iulio, Augufto, partim fponte, \& parcim nipite ferro fcarificato, diftillat, in vitreaq́ue vafcula recipitur; quod ftatim eductum, vt audio, colore eft albo, qui paulo poft in viriden, tertio in aureun, \& demum in melleum mutatur. Eius fucci ctiam fubfantia in primis, turbida crafaque, vt oleum Atrim ab oliuis exprefim cernitur, poftea tenuifima atque clatifima, demum tercbinthi modo craffefcit . Odore eximio in primis atque acutifimo tercbinthum redolens, cum fuaviori odoris fragtantia ob feruatur, faporcque amaro, acri, \& adftringenti. Leuifimum en in primis diebus, atque vque adeo validi, \& acuti odoris, vt aliquibus inter odorandum, fanguis è naribus eruperit, \& pram mina ciusleuitate in aquam ftllatum non defidet, fed ex alto in ca proiectum parumper in ipfa mergitur, fereque continuò affurgens, fupra totam aqua fuperficiem totum expanditur, cique mifetur, \& ciriffme ita in ea diffoluitur, vt ab aqua maxima cum difficulate feparatum fecernarur. in qua paulo poft concrefcit, atque coagulatur, coagnlatumque filo totnm ab aqua eximitur, quod tunc colore laetefcit, fue album quale lac uifitur. Quanto hic fuccus annofror, cò fit inodoratior, atque ad motum fegnior. In primis itaque fatim albo colore confpicitur, qui color pauciffimis ulicbus in viridem, vt mper etian dixi, mutatur, oleig; craffric comitur, qui poftea lungo comporis intemallo deptratur,

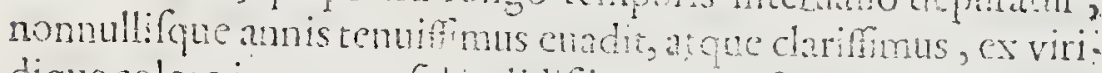
dique colore in aurcum fplendidifintm thuntr. Senio vero con-

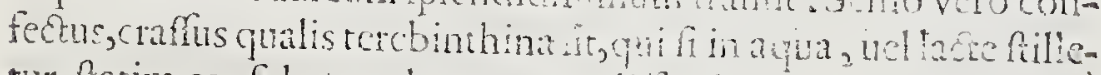
tur, Ratim confider, mulatque cun diffculate, ${ }_{2}$ non nifi !.jgo 


\section{DE B A L S A MO}

rempore denuò fupra aquam fertur, tardifímeque in ea diffoluzur. Quare non fecus quam in animalibus omnbus quatuor conAtituntur etates, quie in ipfis maximam differentiam faciunt, ¿alfami fucco, quod opobalfamum dicitur, proculáubio à nofris quatuor tempora tribunntur. Quandoquidem ille fuccus abarboris ftipite continuò elicitus ufque ac quintum circiter annum acutifimi, validifimique odoris percipitur, leuifimufque vfque adeo obferuatur, vt in aquam ftillatus, nihil,vel parum confidat, facillimeque diluanr, quod eius calor in annis infantix phisimus exiftens, ei acuticm a que vehementiam preftet, Crafiori quoque fubftantia tunc cernitur, \& tubida, quod cum multus in co exuberet crudus humor, co ob calorem in ipfo agentem valde agitato, inftar vrine turbid $x$, qux in peftilentibus febribus fieri folent apparet, \& quemadmodum puerorum corpora multa humiditate, atque multo calore predita craffa, ac fere tumentia videncui, ita opobalfamum in pueritie annis conftitutum à multa humiditate excrementitia, cum validifimo calore in ipfa agente, craffum, ac turbidum apparet, quod in grandiori ęate ab ea purgatur, tenuiffimumque fit, \& aureo colore clarifimo fpectatur; in quo Itatu, confiftentia iprus $x$ tate continuante, conferuatur,pofteaq; calore eius natino ailiquatenus refoluto, ac imminuto, fenefcens craff in infar terebinine enadit, folitoque tum odore eximio tum leuitate deficit. Proinde neque fupra aquam enatat, neque mulum, \&ianiterolet. Hxcque de balfami planta, fructibus, lignis, fucco tibi dicta funciant. A L P I N. Quefo ne te pigeat, ad nomulla adhuc, qux a nottris, balfami defcriptioni repugnantia proferuntur, refipondere, ac fatisfacere, quando ea non parum huifce planteco snitam veritatem obfcurare, ancipitefque nos reddere videantir. Antiqui etenm omnes balfami foriptores inter fo in illiufe plasa, fucc, fructum, virgarumque deforiptione difcrepare uidentur, ex qubus non videtur, tutum fatis effe illomum cognitionem perquiridebere. Qui fuere in caufa, vt noftri ipforum traditonibus imbui, verum fibi oblatum opobalfumum, fuctus, virgas, vens efienon crediderin: A B DEL. Summm fimper erroucm ofe putatiomines plantę huius, fucci, fructum, virgarumque cognitionem à Diofcoricie, Theoph. vel alijs antiquis feriptoribus velle exporete, quando ifta inter eos in feriben.

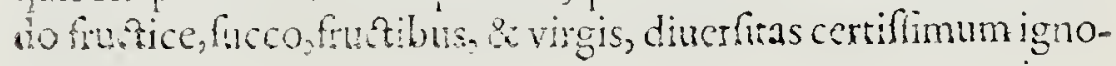
rantix 


\section{I A I GVS.}

wantix argumentum nobis fuerit. Ego fum husus fententiæ, neminem illorum fortalsi accurate arborem hanc vidiffe, ex audituque omnia de eis ab ipfis litteris prodita fuiffe. Olimenim non erae ita facile hominibus loca, in quibus balfamum nafcebatur, ex lon-o gioribus difficilioribusque natuigationibns, quibus eo tempore antiqui utebantur,adire, proinde multa Diorcorides, Theophraftus, atque alij multi ex hominum potius relatione, quam ex infpe stione de balfamo fcripfere. Hincque mirum non eft, fi in pluri= bus noftri ipforum fententix inhrrentes decepti fint, quando \& iplos à falfis alio rum relationibus deceptos fuiffe putandum eft . An non Diofcoridem, Theophraftum, atque alios affirmantes. Balfami plantæ Acgyptum, vel Iud ęam patriam fuiffe, cum dixerint eam folum in Aegypto \& valle Iudęa viuere, maximè erraffe fuperius demonftratum eft, cum illam plantam ex Acgyptiorum relatione perpetuò ex Arabia fœelici in Acgyptum venifle certiffimè conftet? Ex quibus mirum quoque non effet, in alijs eofdem deceptos fuiffe, prafertimque in fucci, fructuumque cognitione. Hincque his herbarum feriptoribus omnes medicos pharmacopolafque planè fidentes, erraffe mirari non debemus, quando nor ab illis, ut etiam dixi, led ab Aegyptijs, \& Arabibus, qui tum primi balfamum cognouerunt, atque obferuarüt, tum etiam cum huiufmodi planta in eodem folo nati fint, atque eadem loca, in quibus viuit \& vixit balfamum, habitarunt, iftorum cognitio effet petenda. Sed qux ea cxiftunt, quæ nobis repugnent, fac vt ex te iam audiamus. A LP I N. Qux de balfami arbore a multis olim litteris tradita fuere, nunc in medium afferam; Reliqua verò de fuc$\mathrm{co}$, fructibus, virgis, ad vfum medicin $x$ memorix proditis, pofterius à me recenfenda arbitror . Multa igitur,variaque de huiufce ftirpis magnitudine, figura, fitu, folijfque à multis prodita funt, que non parum ueritatem obfcurant, hominefq; ancipites, ac rem hác totam incertam efficiunt. Aliqui fiquidem plantę iftius magnitu* dinem lycij, pyracanthx, vel Cytifi, vel therebinthi magnitudini compararunt, vt Diofcorides, Straboque dixere. Theophraftus vero dixit ea magnitudine balfamum fpectari, qua magna mali punici arbor obferuatur. Iuftinus fimilem piceis arboribus affirmauit, \& Paufanias mirtho; Plinius, Solinus, atque Africxe defcriptionis auctor, viti, hanc plantam compararunt. De eius folijs non minor eft apud illos diuerfitas, deque arboris figura . Quãdo Dio$T$ fcorides 


\section{$D E=B A L S A M O$}

fcorides, Theoph.Plin. Auicenas, Simeon Sethus balfami folia rutx proxima effe ftatucrint, \& Paufanias amaraco, Iultinus piceis, Solinusque \& auctor Aphricix vitium folijs. De forma ctian vel figura arboris, alij arbuftum, alij frueicem faciunt . Plinius cnim s" de co dixit: In totum alia eft natura, quam noftri, externiq́; prodiderunt, quippe viti fimilior eft, quan myrtho; Quod ctiam Solinum dixiffe ab illufe verbis conftat, qux hac exifunt : Similes vitibus ftirpes habent: ac Iuftinus; Siquidem palmeto \& opobalfamo diftinguitur arborem opobalfami formam fumilem piceis arboribus habent: \& Strabo: Qux arbor eft fruticofa Cytifo \& Terebintho perfimilis. Nonnulli ctiam affirmant, plantam hanc ali aqua, illaque tantum, qux in proxima fonte illiufce proximx domunculre fcaurire cernitur, aiuntóue miraculo id fieri; quando ipfa fit pluribus virturibus predica, quod Virgo Beatiffima olim ibi multos annos morata, ea aqua, tum ad potum, tum ad cibum, tum ad mundandos panniculos I efi Chrifti pucruli va fuerit : $\mathrm{ex}$ quo tanta in veneratione cmnes viri mulieresq́ue Acoyptię, Arabes etiam Mahometis affeclie eam habucrunt, vt ipfa ad multorü etiam morborum curationem confidenter vtantur. Multique ex longinguis, remotifimifque locis hue veniunt, vt ex huiufmodi aqua accipiant : quare nonnulli balfamum huius aqux beneficio hactenus hic vixiffe aiunt. Hęcque funt, qux de arbore ifti dicunt. A B D E L. De balfami fruticis altitudine, figura, ac folijs, ea quæ ex te nunc propofira funt nihil veritatem hanc obfurare poffunt. Namque Diofer.atque alij, cui hanc plantam magnitudne fimilem effe lycio, cytifo, terebintho, \& pyracan hax, affimarunt, minime crrarunt, cum hxc omnia arbufta magnitidine non multum interfe differant, eifque planta balfami maior non fit, fed hic nulle cernuntur arbores balfami, qux ita magnę fpectentur; fiquidem grandiores, quas hic aliàs viderim, non affurgunt ad maiorem triü cubitorum altitudinem. Audio tamen in Arabix folo eas plantas ad predictorum arbufculorum alcitudinem, \& maiorem etiam excrefecre. In Acgypto, \& Arabia mali puniciarbores paruxexiftunt, ita, vt inter arbufculorum fruticumque numero ibi connu$m=r e n t i r$, nequic ad tantam affurgunt altitudinem, quales in Italiç locis obferuantur, Quare neque Thephraltus reprehendédus erit, quòd fripferit, ffe magne punic $x$ arboribalfamum fimile, quando hx noftrix Italicis longe fint humiliores. Iuftinum uero, quod 


\section{I A L G V S .}

picei arbori plantam balfami fimilem aftirat, deceptum omnino fuiffe, credendum eft. Ex ipfufque verbis error apparet conifpicuus; nam piceis arboribus balfamum frmilen cfe dicens, lubdit, $\&$ in vinearum more excoluntur : quis tamen ufpiam vidit pices arborem viti fimilem, \& in vinearum more excolt? Inter quas quanta fit differentia, non eft, quod nunc demonftetur. Fu fre vero balfami plantam ramulis fruticofis, ac farmentofis viti fim $1 \mathrm{lcm}$ dubium quidem non eft, vt neque etiam, equemadmodum vites, an nis fingulis putari, quod fit adinodum fruticc $\sqrt{2}$, \& farmsntora. Non tamen quod ad folia attinet, viti éa planta eft frmilis,cum folijs referta fit rute aliquatenus proximis, prefertim vero extr. ma tria foliola, qure in fingulis virgr balfami alis cernuntur, quando ipfa fimillima fint tribus ijs foliolis in extremo virga alę rutx pofitis; colore excepto: Neque abfurdum eft, Paufanian dixiffe balfamum folia habere amaraci $x$ mula, quoniam fufpicor ego ipfum plantam balfami non adultam, fed tantum rccenter ex eius feminibus natam infpexiffe, quę folio, magnitudine, ac figura ama raci folijs omnino funt fimilia, excepra earum craffitic, ac colore, quibus ea folia inuicem differunt, nam in amaraco funt graciliora, \& albidiora. Balfamum, quod ex feminibus nafcitur, bina folia in primis habet, bifolijs nafcétis vitis maxime fimilia, \& qux polt hæe, que funt tria, quatuor, vel quinque, produntur, amaraci folijs funt proxima; Quxe vero tertio nafcuntur fingula trina cxiftunt, rutreque proxima cernuntur . Repeto, prima nafcentia folia bina funt, fecundo nata, his multum diuerfa produntur, inordinatimque in virga. Tertio producta trina cuilibet ale appenfa, cernuntur, qux rutie funt proxima, tribus inquam foliolis in extremo al ̨ virge rute confpicuis. Quarto, que nafcuntur in virga balfami, func quina, \& poltea feptena. Hreque funt balfami folia, aliter quam friptores antiqui deferipferint in hoc viridario in fruticibus balfami fxpiflime vifa, ex quibus atque alijs fortaffe Diofcoridem, atque alios multos antiquos feriptores viuentem balfami plätam non infpexiffe, iure fufpicamur. Hanc etiam arborem in hoc viridario vixiffe certum eft, aqua ex hoc proximo fonte, in quo Bcatiffimam Virginem panniculos Saluatoris nofri pueri olim perpe tuo lauife noftri omnes autumant, irrigatam; tamen in arenofis, fqualidifque locis non paucre reperiuntur, qux tamen quo : opobalfamum fteriles exiftunt. Arque hec obiter de balitani

$$
\text { I 2. plan }
$$




\section{E B A L S A M O}

planta dicta a nobis fint. Nunc ad opobalfamum deueniendum. Sedbalfami plantx ramos, quos mihi domo mancipium detulit, abfoluto de ipfo fermone fpectabimus.

\section{Veri opolalfami cognitio unde fumatur, f'r qui ex antiguis verè bunc fuccum litteris prodiderint. Cap. $\quad 1111$.}

\section{$A B D E L I A$.}

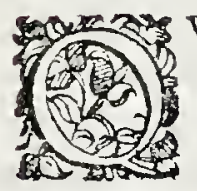

VID inquies Alpine de Balfami planta ? nonne à no bis probc̀,ut ueritas exigebat defcripta eft, deque eius folijs, floribus, fructibus, ac uirgis, quę dicta a me funt, uera tibieffe uidentur? A L P I N. Omnia fanè rectiffime, ac ueriffime es profecutus, fed fuperfunt tamen quępiä de fucco quoque, fruetibus, ac uirgis dicenda, cum antiqui foripto res, qui de balfamo feripfere, fimul in horum deferiptione inter fe nihil ferè cóuenife uifi fint:quorum diuerfitas, ut de arbore etiam nuper dictumi eft, fuit caufa, vt multi negarint, quẹ pro opobalfamo, carpobalfamo, \& xilobalfamo monftrantur, vera utique effe, nullumque ob id ipfos credere, fyncer um ac legitimum opobalfa mum ad nos afportari : de quo primo fermonem a nobis haberi cupio, mox de ceteris. De opobalfamo igitur multi huius funt opinionis, ut arbitrentur, fyncerum ad nos non aduchi, neque iniuria, quando ex te defcriptum opobal famum, a nobifque fepius infpectum, diuerfum fanè videatur abco, quod omnes prifci rei herbarix feriptores memorix mandarunt. In primis enim album mulit ipforum effe prodidere, Strabo fiquidem dicebat:eius cor"ticem feindentes fuccum in vafis fufcipiunt tenaci lacti perfimilem : \& Plinius, fucclis è plaga manat, quem opobalfamum vocant eximire fuatuitatis, fed tenui gutta ploratu lanis parua colligitur in cornu, ex his nouo fictili conditur, craffiori fimilis oleo, \& in mufto "candida. Er Simeon Sethus vir in balfami hiftoria alijs non poftponendus dixit: Succufque inde manabat omni oleo vifu fimilis, quodideo balfami oleum nominatur, fuccus his aggregatus vafculis excipiebatur, \& id quidem, quod fupernatabat, album ac tenue erat, \& ideo preciolius: Alij funt rurfis afferentes, hunc fuc 


\section{I A L O G V S.}

cum non effe tenuem, fed craflum,veluti qui dixere in conchis $\int$ feptum coagulari: Cum vero opobalfamum, quod tu defcripfifti, \& nos fępe infpeximus, vel viride, vel aureum, vel mellis colore obferuetur, interdumq́ue turbidum, interdum clarum, ac te nue, aliquandoque vt terebinthina craffum cernatur, (nemo enim. noftrum eft, qui eum fuccum tot predictis differentijs euariatum non viderit fcilicet olcofum, viride, aureum, ac melleum, clarum, turbidum,tenue, craffum, de ipfo varios, \& dubios effe mirum nö erit. A B D A C H. Facile has ambiguitates nofter Abdella ex animis nofris abiget. Profertim cum harum explicatio exij pendeat, qua dudùm ipfe attulit. Dixit enim opobalfamum iuxta ejus retates varias, variari \& ipfum, quo ad colorem, fubftantiam, perfpicuitatem, odorem, \&lcuitatem; continuoque à ftipite inftillatum ac exceptum, albo colore confpici, preferrimq́ue quod fupra enatat, veluri minus quod fubfidet, qui color paululo momento in fubuiridem oleofum mutatur, qui poft quinquen nium, ve fuperius etiam difum meminimus, aureus fit, ac demum fenio confectus craffefens, mellis colorem, obfcuriorem tamen accipit.Tot etiam mutationes in perfpicuitate, fubftantia, odore, leuitate, cius varias atates fucere aliàs dictum eft, quando opobal famum recenter eductum per quinquennium turbidum maneat, quo tempore clarefcere incipit, per decenniumque ferè ipfum clarifimum, ac vt aurum folendefcere obferuatur;poftea fenefcens turbidum rurfum euadit. A ftipite etiam fatim exceptum tenuiffimum eft, pauloq́ue poft parum craffefcit, atque hinc Sirabo di. xit, fufceptum in conchis coagulari, peractoq́ue quinquennio, quod tempus pueritix datur,purgatur, fiecemq́ue in fundum valis deponit, tenuifimumáue fit, \& totidem geminatis peractis annis fenefcens craflum, craffiufque eft, quo annofius. Odornon minus \& fapor, in recentiffimo validiffimus eft, in medio tempore odor fit fuauior, thus ac terebinthum redolens cum fuauiori tames odoris fragrantia, fupor eft amarus, fub acris, atque adfringcns . Demum in fenio omnia hac maxime remiffa percipiuntur. Hincque Plinium deceptum, fuiffe arbitror, qui putauerit, optimi huius fuccilachrymam fricando percipi odoratam. Siquidem opobal famum fenio folummodo confectum inodoratum fit, vt tunc folumfrictione dignofci queat. In principio etiam hic fuccus leuiflmus eft, qui quam maxima difficultare in aqua, vel alio liquo 


\section{$D E$ B A L S A M O}

re inflillatus confidat, fed contimuò in aqua fuperficicm feratur, citoque cum aqua diffoluitur : annis vero confiftentix medio fe habet modo, fenefcéfque, colore eius imminuto, crafkefcit, quo fit vt fubico in aquam proiectus confidat, tardiffimeque furfum in aqua fuperticie feratur, difficillimeq́; ac tardifline cü ea diffoluztur. Hreque etfinon ita concinna oratione, tamen ad tuarum diffcultatum explicationcm accommodata faris cfe Abdclla nofter iudicabit. AB D E L. Ego vero fic ea vera iudico,vt omnes, quide opobalfamo feribentes, aut loquentes ab his diffenferint, rem prorfus ignorent, ex quibus Plinium ex uarijs coloribus, ac fubftantijs in opobalfamo infpectis, uarias eiufce fuccidifferenrias vel fpecies facientem erraffe clarifime patet ; dixerat enim il" le: Lachrymx probatio, ut fit pinguis, tenuis, ac modiccruffa,

$" \&$ in fricando odorata, fecundus candidus color peior viridis,

" crafufque peffimus niger. Nemo Aegyptiorum, vel Arabum album opobalfamum nifi ex arbore recentilime fillatum vidit, qui ramen color quam paucifimis dicbus cuancfeit, atque, ut dictum eft, in olci colorem vertitur, atque ab co colore in aureum, \& de nique in melleum obfcuriorem. Nigrum vero nunquam ab aliquo nofrorum,uel Arabum vifum eft, neque auditum. Nifi fortaffe produceretur nouifime ab Occidentalibus Indijs delatum, à quibufám pro legitimo opobalfamo, ut fuperius quoque meminimus, receptum. Quod tamen fallum efle planèconftat, cum ij, qui cius hiftoriam fcripfere, affument illum fuccum improprie opobalfamum vocatum, in Occidentalibus Indijs ex procera, ac magna arbore nafci, qua quidem magnitudine, figura, ramis, folijs, fructibus à vera balfami arbore longifime differt. Quod ijs qui vtramque norunt arborem, nō erit dificile fuadere.ALPIN. Simeon Sethus confirmare \& ipfe videtur, optimum opobalfamú recentifime à ftipite difillatum album colorem habere, nec non, \& Strabo,qui opobalfamum laeti fimilem effe feribic. Sed quam quam huiufe fuccialbus color pauculis dicbus a f:llatione cuanefcat, atque in alium colorcm mutetur, nihilominus, quod non paucis valde admirandum videbitur, opobalfamum oleofo colore infpeftum, in aqua vel lafte ftillatum, album rurfum videri : \& idem ctiam faccre aureum, \& melleum. Perpetuoque verum opobalfanum cuitufumque coloris fit, in aqua, vel laste Riilatü, ac liquatum album fpectabitur. Hincque Diofcorides doctifine dixi:: 


\section{I $\mathrm{A}$ L O G V S.}

92

dixit: Quin eriam fyncerus in aqua, aut lacte celerrime liquatur, " coloreçue lactefcit . Nunquam quifquam opobalfamum uifui " non album, album effe iudicarit, quod tamen verum effe experien tia docebit, fi inquam quis finet ftillatum in aqua, liquari,ac coagulari, ipfum etenim liquatum fupra aquam ita album redditur, ut vix ab aqua diftinguatur, fed paululo momento in ea coagulatur, eique inftar telx albę incumbere, \& in ca fupernatare cernitur, ma nifeftiorq́ue cius ábus color fiet, fi coagulatum filo quopiam ab aqua cximatur, allt extrahatur. Sed hac illius fucci experientia per: ieftatis tempus eft facienda, uel $f i$ byeme, prope ignem, opobal fimo probe prius calore attenuato. At cur ex albo tam citò in aliü colorem mutatur? A B DEL. An quod lactei illiufce coloris fubftátia mollis, ac tenuiffima, quam citò refoluitur ac diffipatur? vel quia nondum eius calor praualidus in eum fuccú agendo ipfum turbauit? Idem in Zebet obferuatur, etenim ftatim è teftibus extractus lacteo colore inficitur, pauloớ; ebullire incipiens,uirefcit, \& tandem fubnigrefcit. A L P I N. Reetè funt a te haetenus explicata, \& enarrata omnia. Nunc igitur ego idem a te fieri cupio, pro indagandis, ac docendis notis vel fignis, quibus uerum a non uero, fyncerum ab adulterato restè diftinguatur.

\section{De notis, quibus verum opobalfamum à non uero, Syncicrum ab adulterato tuto cognof citur, ac difcernitur. Cap $V$.}

\section{$A$ B D E L L A.}

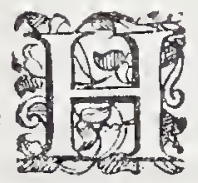

IS notis quifque probè ac exactiffime verum hunc fuccum, a non uero, \& legitimum ab adulterato dignofeet, neque ab aliquo ita facile decipi poterit, etenim fuccus is, qui nondum ad fenium, inclinare cęperit, colore albo confpicitur ( quod rarifsime, \& non nifi dum ip fum è ftipite ftillat, vel recentifsime edustum uidere contingit ) vel tuiridis elt, oleofus fubturbidus, oleoǵue fubftantia \& colore valde fimilis, uel aureus fulgentifsimus, tenuifsimus, atque clariffimus. Qui fanè omnes has notas habcbit,uchementis erit odoris, \& quo magis etiam recens eft, acutioris, terebinthum cum alio fua 


\section{E B A L S A M O}

uiori odore redolentis, gratiffimufque olfactui erit . Gutu etiam fubamar!ns, adfringens, \& modice mordens percipietur, lauis, diluique facilis, qux nota, co inftillato in aqua vel lacte dignofce. tur, laxuis enim extabit, \& vel nihil fub aqua morabitur, uel parum, \& quafi continuó fupra eam furfum affurget. In qua citò diluitur, vel liquatur, nil vnctuofi retinens, vel olcofi, tenax, frue lentore aliquo preditus eft.hifque omnibus notis uerum, fyncerumque opobalfamum femper omnibus apparebit. ALPIN.poffir ne quis aliquod factitium oleum ita fimile opobalfamo parare, ut eo mulcos decipiat? A B D E L. Sine dubro, cum Gal. fuo rempore etiam ipfum vque adeo adulterari dixerit, vt vix adulteratum cognoferetur. Veruntamen quod adulteratur, neccfie eft, ut aliquo liquore, vel oleo, vel vnguento vitictur. Diofcorides dixit, opobalfamum vitiari poffe admifto teribinthi, cypri, lentifci, balanique vngucnto, \& fufmo, metopio, melle, cypria- que cera liquida. Serapio his addidit oleum rofaceum, myrtinü, \&x de alcanna, quod cyprum appellant. Plinius ex feminibus veri balfami, qux vocant carpobalfamum, extrahi fimile oleum afferit, qua via multi ex ipfis oleum exprimunt,uero o pobalfamo admodimn fimi!e; quod tamen ab eo difcernitur amariore fapore, odoreque opobalfami longe ob furiore. Prodit etiam ipfum adulterari poffe oleo rofaceo, cyperino, lenthifcino, balanino, terebinthino, myrtino, refina, galbano, \& cera cypria, qua fanè eadcm exifunt, quorum nuperrime Diofcoridem fubnomine vnguentorum meminiffe, dictum eft. Sed forfitan melius ipfe dixiffet, oleis, quàm unguentis adulterari poffe, quod ille fuccus tenuis perinde ac oleum fit, minimèque craffus, nifi fenio fuerit confectus. His jgitur opobalfamum vitiari poteft, cuius maleficium facile deprehenditur, oleoque adulteratum trifariam detegitur, atque in primis, quod digitis contrcetarü, nullo lentore, vel vifcofitate adh $x$ reat, quando verus balfami fuccus lentore, ac vifcofitate quapiam non cirere à nobis aliàs dietum fit, à multisćue ex antiquis fcriptoribus confrmatum, olco fiquidem refinarum omnium tenacitatem abigi omnibus manifeftum eft. In aqua preterea inftillasum fupra eius fiperficiem orbiculorum formis expandi nemo no frum ignorat. Quod fyncertum opobalfamum non facere polterius doccbitur. Demum in panno olco infecto macula relinquisur, qux \& difficile aufertur, \& quotidic etiam magis maiorem 


\section{I A L O G V S.}

in circulum expanditur, quòd non fit in fyncero opobalfamo: His igitur notis opobalfamum oleo vitiatum cuique patere poterit. His etiam comperietur vitium, fi vnguenta ijfdem oleis com pofita mifccantur, fed hoc amplius ijs aderit, quod in opobalfamo parui temporis fpario in fundo vafis vnguenta fidere necerfe eft. Cera vero mítum comprehendecur turbido colore, nunquan cla refcente. Melle etiam infeetum dulcis fapor detegit, atque ad ipfum, ve Plinius quoque teftatur, mufcas allicict. R china adultera tum in carbones inftillatum, nigtiorem flammam edit, fubftantiaque crafiore quàm in fyncero fit, fpectabitur. Syncertum vero his notis innotefect, namque preter ea ligna, que illum iuxta varias $x$ tates prexfefere diximus, hre etiam addidimus, filicet preterquam quodfit validiodoris, in aquil etiam ftllatum, tameti parua fatis fit gutta, fupra totam aqua fuperficiem expandi, camque liquatum totam fupernatare, ac obtegere, atque in ipfa etiam citò coagulari, lactifque colorem adipifici; ac non minus ex ipfas coagulatum totum ftilo quopiam excipi, ac auferri, quodque fufum in lancam veftem, cam, vt olcum non inficit, quamqquamei adhrercat . Lacćuc coagulat, etfi non ita, vt coagulum ficit, quia lac non perfecte coagulat, quinimo cum ipfo coagulatur. ALPIN. Multo plura, quàm tu de fynceri opobalfami, ac vitiati notis com plexus es,apud multos leguntur. Diofcorides fiquidem hace vtique nobis prodiderat. Succi probatio eft, vt fit recens, validi odo ris, Syncerus, non ad a corem vergens, dilui facilis, lixuis adftringens, ac modice mordens guftu. Et vbi ca, qu quibus opobalfamú ", poteft adulterari memincrat, hęc fubiunxit . Namque merus in ", lancam veftem fufus neque maculam facit, neque li cluatur notä " relinquit. Vitiatus autcm inhxret, \& lac inftillatus coagulat, quod" adulteratur non efficit . Quin etiam fyncerus in aqua, aut late ce" lerrime liquatur, coloreque laetefcit, vitiatus vero olci modo in-", natat, fe conuoluens, aut in fellie modum diffundens, fyncerus ", fenefcens craflefeit, deteriorọuc redditur. Hallucinantur, qui " a qua concretum peffum ire \& ad ima fidere, arbitrantur,poftea dif " fiparum fupernatare. Et Plinius ait, fyncerum inherefcere, \& in tepida aqua cius guttam coagulari \& ad ima fidereglac coagulare, $\&$ in veftem maculam non facere. Et Auicennas: lac coagulare, aquícue ipfum mifecri, \& in ipfa denfari, denfatumque conferuari, atque à goffypio receptum ablui poffe. Scrapio cadco ì V Dio- 


\section{E B A L S A M O}

"Diofcoride iam recitata, de ipfo nobis prodidit. Simeon vero "Scthus hxe \& ipfe feripfit . At vero nonnulli hac ratione probant, " quod furum eo inúctum ignique ad motum incande car, ia quod "\& olco caphurx, alijfque dietis olcis accidit. Alij quod in " aquam datim minimefipenatet, fed tatim fundum petat, vere ", hoc quidem, fed enim quando hrec duo concumtant, uidelice fertem ili relinquens. Hxe omnia, ac inter fe admodum diuerfa cum apud hos grauifimos plantarum faiptores legerm, atrue opobal famum, quod tu ucre fyncerum afrim is, and me fit, hon omnia que ab his feriptoribus de co perdosta, reprehefentet, quinimo aliqua fnt, quibus ipfum planč non refpondere videatur; quamquam cnim ipfum recens ít, minimcque ad ullum acorem uergens; ualidique odoris, olcof coloris, turbidum in primis cius annis obferuatum, mox clarum, aurcum fubamatum, adtringens, \& modicc mordens gutum, tenax, lcue, dilui facile, lacque coagulet, \& linteum non inficiat, atcue ut ait Aucenas, aquæetiam ftillatum, mifceatur, in ipfaque coaguletur, fupraque aquam coa gulatum enatet, atque co ctian ferrum, hit Sethus ipfum hacexperientia cognofendum uoluit : inunctum probè in ignem pofs. tun candeat, Tamen, quod apud omnes predictos antiquos friptores affirmatur, quippè ipfum lanex nefti inftillatum aqua ablutum, omnino ab ea abigi poffe, nilikque ei adherere, nunquam potui obferuare. Nulum cnim reperitur opobalfamum, quod inftllatum in pannun,ei aliquatenus non ad hrerear: cx quo cgo etiam puto, nullum uerum opohalfanum ean exprentian facere poffe, quando ipfum ; ut in aligs cmmbus refinis obferuatur (cum fuccus refinofus fit, inter efinafyue poffe tine crrore re cenferi) wifcoftatis ac lentorisnon fi: cxpers. Ex qubus ualde de huius fucci fgno, al antiquis ferè omibus an maducrfo dubius, ac anceps fum. Cupioque tuam hac in re fententiam audire, ut in ca randem acquicfan. A B D EL. Dignus es cum ifto tuo frupulo non parua reprehentione, gui uno figno magis quàn plusibus, quibus thum opobalfamum omnibus pro- 


\section{I A L O G S .}

bè refpondere feis, fidere uolucris, quod neque uerum 74 huius fucci dicendum effe puro, fiquic hintus fuccidicendum efle puto, fiquidem quo pado hic fuccus lentoris, ac uifcofitatis non cxpers, (cum ipfe nihl quidem aliud quam refina quxpiam (it) lineo, uel lanco panno, uel goflopio inftillatum aliquantulum non adhxrebit? Etenim non modo fuccus ifte tenax eft, fed ramuli quoque uirides, fi digitis contrecten tur, eis proculdubio adhrent, quod non nos modo, fed ctiam aliquos antiquorum nouiffe certum eft, nonne Strabo dixit : Eius corticem fcindentes fuccum in vafis fufcipiunt tenaci lacti perfimilem. Quid? nonne Plinius notas fynceri opobalfami docens dixit? Succum balfami fyncerum debere inharefere? At ne amplius remorer defiderium tuum, paucis de nota hac a Diofcoride propofita dicam, quid fentiam. Puto enim fyncerum opobalfamum non aliam ob caufam, Diofcoridem, atque una cum co alios dixiffe, ueftibus uel panno non adhærere, nifi ut nos docerent miftum aliquo olco, uel quopiam unguento hinc deprehendi, quoniam, ut ego nuper etiam uos docui ( quod à plerifque oleo co tempore uitiaretur) olco uitiatum in pannum infillatum, laneumq́ue præfertim, quod facilius fit ad emaculandum, inftar olei inficit, eique perpetuò non modo adhwret, fed quotidie magis in eo recepta macula augetur, ac dilatatur. At fyncerum, quamquam paululum panno ctian inftillatum inhereat, tamen ipfum ut oleum non inficit, neque maculam relinquit, quinimo fecus atque oleum panno adherefens quotidie decrefeit, ufqucquo tandem omnino aliquo tempore fponte diffoluatur, atque cuanefat. Quamobrem fyncerum opobalfamum panno quidem, at non olei modo adheret, neque aliquam maculam relinquit. Quod fxpe uobis meum opobalfamum in mcam ueftem inftillatum oftendit. Verum non debet hoc experiri in pannis ijs, quos uos in Italia paratis, noftris longe craffioribus, in quibus fortassè cum olim ueftri hi ciafli panni lana parati ex ItaJia huc nó afportarentur, neque noftri his, ut nunc faciunt, uteren tur, Dioferides in his periculum faciendum, non fentit, fed in noltris ijs longe gracilioribus. Clarius verò hoc fignum Plinius docuiffe eft uifus, cum dixit, \& in uefte maculas non faciat, non autem, ut in Diofcoride habetur, uefti non adhęreat. Verius forraffe Sethus opobalfami cognitionem ex hoc figno ha. bendam tradidit, quod his uerbis apud ipfum legitur: Linteo in

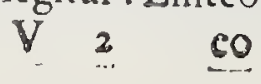




\section{E B A L S A M O}

es irricato, ac poltea fublato ì linteo totum recedit, non coloré, fed odoris duntaxat fuauitatem relinquens : quod planè in noltro fic ad unguem obferuari licebit. Coeterum ex his, que ita diucrfe de notis uerum opobalfamum a falfo diftinguentibus, apud di uerfos antiquos feriptores lcguntur; dubitandum non immeritò a nobis exiftimo, hofe authores nunquam fortaffe, neque uiuentem plantam ufpiam offendiffe, atque multo minus fyncerum cius fuccum infpexiffe, cunetaque potius aliorum relatione, quàm ura obferuatione de co ab his prodita fuiffe. Qua de caufa non ab antiquis foriptoribus, inter fe de balfami hiftoria difcordantibus ucritas, hęc petenda effet, fed ab his populis, prxfertimque medicis, qui loca in quibus balfamum,omnium fetiptorum cöfenfu, uixit, perpetnò habitarunt, \& fepifime obferuarunt. His ctenim iuremerito de ipfo firmior fides habenda crit. Hi funt Acgyptij, at que Arabes, qui omnes uno confenfu afferunt, hoc excepto opobalfamo, quod uos uerum effe non creditis, nullum aliud ufyuam uel in toto Acgypto, uel in tota Arabia, uel Syria, fuiffe cognitum, aut ufitatum. Cuius ueritatis clarifimum ac certifsimum fignu m erit;aliud opobalfami genus ab hoc diuerfum, apud Turca rum Regem ijs locis imperantem, atque apud plures Turcas; qui uarijs temporibus his omnibus prędietis locis,pręfertimque Acgy pto prefuerunt, nunquam fuifie repertum, quinimo apud hos inuentum idem planè effe cum noftro, atque nihil ab ifto comnuniter recepto, differre. Rex cnim Turcarum fingulis annis à Scriph Mechx, atque Medinę domino binas, \& plures etiam opobalfami libras dono miffas accipit, perperuoque, poftquam Acgypto impe raut, ab ipfo opobalfamum recepit. Quod fanè idcm planè eft $c$ ü co, quo omnes Acgyptij, Arabes, Syri, atque alij utuntur. ALPIN. Verum dicis; Nam ego certo fio idem cfle opobalfanum uu!go receptum cum eo, quod apud multos dominos Turcas Confulefque Venctos habctur, quibus à prefecto Acgypti : ac alijs nobilibus Turcis dono datum fuit, idemque cum en, quod apud Serenifsimum Francifum Medicem Ducem Florentis à Turcarum Rege olim ei dono datum, hodic conficicint. quod cú mzo ciam opobalfamoex Aegypto, adpredictum Suenifs. Du cem anno fuperiori mifio, rectè ab irfo comparatum, icem planè effe, certum cit. Quamobrem omnes; qui negant unlgo receptum verum ene, fi ipfum cum opobalfamo comparent, quod apud mul- 


\section{I A L O G V S.}

ros extat, Venetos, olim huius loci Confules Clarifsimos, atque apud alios plures, qui olim hac loca peragrarunt, \& opobalfamú à nonnullis Dominis Turcis acceptum illuc coimportarunt, probè an ipfum verum fit, cognofcent. ABDEL. Multum tamen Auicenam admiror, qui dixerit,à goffypio, hunc fuccum aqua ablui poffe, cum tamen fuperius dixcrit, ipfum in aquam infilla. tum coagulari ac denfari: quod cum verum fit, quomodo in goffypio receptum, ac imbibitum, aqua ab ipfo ablui poterit? hoc enim ficri non poffe cuique patebir. Ent deinum al terum opobalfamum ex feminibns balfami cxpreffim, cuius eriam inter adulterata nuper recenfuimus, quod pro vero fucco opobalfami aliquando venditur, quod tamen fucile, vt dictum eft, ex obleurio re cius odore, amarioreque fapore à vero diuerfum ab his effe comprehenditur. Ac de opobalfamo hac à nobis dicta fufficiant. Reftat modo, vt de balfami fructibus, \& virgis loquamur, quando inulti quoque non defint, qui contendant verum neque carpobalfamum,neque xiloballamum effe.

Veri carpobalfami, or xilobalfamicognitio, $\sigma$ conft-
deratio. . . Cap. VI.

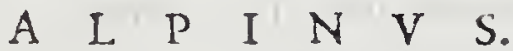

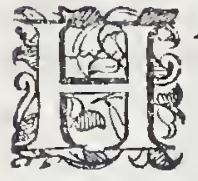

A C T EN V S balfami plantx, atq; ab ea educti fueci ambiguitates omnes vir doetiffime diffoluift, veritatcmq́ue ita claram effecifti,vt de arbore, ac fucco nofri amplius contendere non debeãt, fed ipfum potius agnofere, atque in vfum medicinx reftituere, quod quidem facientes fumma laude digni erunt, tantum auxilium in vfum renocantes, atque recipientes. Cum nemo noftum dubitet amplius veri opobalfami ex Acgypto, \& Syria in Italiam cóportari, quod facile à nuper adductis notis ibi an fyncerum fit, cognofcetur . Reftat modo,vt de eiufdem plantx fruetibus, \& virgis, quod apud noftros dubij fuperfit ab illorum animis euellas . Quando vuigiria femina, pro vulgari falfo carpobalfamo ì multis recepta, quorum ad nos fingulis annis multa copia aduehitur, vcrum effe antiquorum carpobalfamum me iudice ctiam affrmandum fit. Animaduertendum tamen eft, duplex genus carpobalfami circunfer- 


\section{DE B A L S A M O}

ri \& verumque pro balfami feminibus apud nonnullos recipi, quo rum vntim femen eft terebinthi magnitudine, atque ferè etiä forma, rotundumq́ue \& oblongum, ouo finile, in extremis acutun, Alaum, folliculo nigro rubefente vndique contectum ; Hocque verum eft antiquorum carpobalfamum . Alterum vero pfeudocarpobalfamum huic aḍmodum magnitudine, colore, figurać; eft fimile; duffert tamen ì vero, quia ipfo eft oblongius, ex medierare tantum folliculo contectum eft, nam illud cxtremum, quod fuo pe diculo appenfum eft, folliculo caret, minimeque eo totum contegitur, fed tantum ad eius vf que medietatem, de hoc uero, quod falsò pro balfami fcmine me ilidice recipitur, non loquimur. quáquam odoratum fit , atque aromaticum. Illudque fortafsè cffet, quod olim Diofcoridis tempore ex Petra oppido Arabiẹ pro carpobalfamo afportabatur, \& quo uerum carpobalfamum adulterabatur, fi piperis faporcm prefeferret. De altero ucro ab hoc prędictis notis difcrepante, quod prexfertim à falfo differt, quia totum folliculo fuo conteetum eft, quando falfi, ut iam dictum eft, tătum medieras folliculo conte ta appareat, a nobis fermo habedus en. Audio nunc Venetijs omnes pharmacopolas confilio excellentiffimi collcoij medicorim in componenda theriaca, atque mitridatio,pro ueris balfani frubtbus Iunipcri frubtus fubftituere e quod quanta dignum reprehenfione fit ac in quanto illi nerfentur errore, uobis doctirmis uiris nunquam latuit. Et utinam nunc perfpeetis rationibus ijdem non permittant fine his tanto artis cum dedecore (quando hec omnia non fit difficile apud eos reperiri) Theriacam atque alia medicamenta amplius parari; fed ucreor, ne magis in antiquis erroribus perfiftere, quam rei ueritatem amplect uelint, A B D E L. Qwid ctiam ne fructus balfami, quorü in Italiam; aliaque loca hinc copia multa aduecta, illis non deeft, negant ueros effe, atque pro eis in componenda theriaca alijfque medicamentis baccas I uniperi fubftituunt? quid de te audio ? puder me tantorum medicorum, qui hos hatenus ucros fruktus neglexerint, minimeque his utantur. Sed quibus rationibus addu Et, negant ifta femina meritò ex te pro uero antiquorum carpobalamo recepta, heros effe frufus balfami. An non ipforum nagnitudo,color \& forma ad cos recognofcendos fatis illis erunt? Theophraftus dixit: illos effe fimiles therebinthi frustibus magni tudine, figura ac colore. Et clarius Scrapio ex Diofcoridis mente 


\section{A L O GV 5 .}

hunc in modo cos defcriplit: Et granum quidem tofus, quod no ${ }^{\infty}$ minatur carpobalfamum, eft granum rotundum ad longitudinem aliquantulum tendens ad acuitatem in ambobus capitibus, in me" dio ucro groffus . Cuius color tendit ad rubicunditatem, \& eft " plenum, graue, mordés linguam inordicatione aliqua non multa," ", \& quando frangitur interius habet humiditatem finilem melli, \& ", eius odor et bonus. At Diofcorides addidit hoc femen redolere opobalfamum. Certè, ut ucrum fatear, fructus balfami ab I alis tuis medicis, atque pharmacopeis neglecti,tum Serapion is defori ptioni omnino refpondere cognofuntur, tum etiā notis à Theophrato allatis, quando hi colore, figura, atque magnithdine uere fructibus terebinthi proximi fpectentur. Serapio uero cos multo diligentius ac exquifitius declarauit, qui ip fos grana effe rotunda ftatuit, oblongi, cxtrem is acutis, \& medio cralliore, ad coloremq; fubrubrum tendentia, gráuia plenaque effe, ac modice gufum mordentia, que intus fubftantiam melli fimilem habent. Ex quibus notis vulgare carpobalfamum uerum omnino effe certiffime oftenditur, fed quamobrem ifti negant hos, neros balfami cffe fru otus, filicet carpobalfamum antiquorum? A L P I N. Omnes uno ore predicant predicta femina non una, at omnibus carere prexdictis notis, quibus ea predita effe Diofcorides omnium anti Guorum in plantarum defcriptione facile primus, memorix olim prodicterat, hisćue fpeciatim verbis. Quare eligatur faum, plenum, grande,ponderofum, mordens guftü, feruens in ore modice, ", opobalfamum olens. Dicunt itaque iftre femina à vobis pro car-" " pobalfamo monftrata, non faua, vt Diofcor.docuit, fed nigra fubrubefentia fpectari, vacuaq́ue non plena offe, leuia \& non grauia, parua \& non magna, neque guftum aliquo pacto mordere, neque opobalfamum olere. Hisque rationibus negant illa femina verum carpobalfamum antiquorum effe, fed poins ea, qux olim ex Petra oppido Arabix aduecta, verum carpobalfamú adulterari Diofcorides animaduertit, quod ipfe hifce verbis docuit, dicés: Adulteratur femine hyperico fimili, quod a Pecra oppido defertur, fed ") coarguitur magnitudine, inanitate, virium ignauia, faporc piperis. " Idemq́ue ferc̀ Plinius teftatum reliquit : arque bęc funt aduerfus" " balfami vulgares fructus à quamp'uribus Italix, aliarumq́ue natio num medicis, \& pharmacopeis difputata. A B D A CH. Ex his duobus alterum ucrum efle arbitror, vel illos filicet viros à te re. 


\section{E B A L S A MO}

citatas carpobalfami notas nuriquam probè cognouifle, aut nurquam hos fruetus, vel femina, qux pre oculis omnes hi pharmaco polx quotidie habent, infpexiffe, quod fi illi hxc aliquando infpeziffent, ac rectè obferuaffent, proculdubio fieri non potuiffet, vt ex omnibus notis ipfos non agnouiffent, veros effe balfami fructus, quando non folum falfum lit ipfos omnibus notis à Diofcor.tradi tis carere, fed ne vnam quidem illis deeffe. Nam iftec femina funt humiditate melli fimili plena, quorum $\mathrm{f}$ multa fracta intus ij infpexiffent, nifi cæci omnino fuiffent, fieri nullo modo poterat yt non id animaduertiffent. Cernuntur etiam longe hyperici feminibus maiora, fune grauia, cum aliqua mordicatione, atque opobalfamiodoris fragrantia, quorum faporem ; atque odoreus unufquifque guftu, ac olfactu minime deftituto, poterit cognofere. Nemo mea quidem fententia erit, qui prius opobalfamum olfecerit, ac guftaucrit, mox ifta: fracta femina olfaciendo $\$$ gufando, in ipfis cundem faporem, atque odorem opobal fami aper tiffime non cognofeat. A BDE L. Veriflima predicas, neque indigna, vt ab illis medicis audirentur, ac animaduerterentur . Nam hxe femina vulgaria à nobis pro carpobalfamo recepta,cadem effe, qux in multis Arabix Folicis locis fupra balfamifrutices colliguntur, omnes, qui illa loca peragrarunt, vere teftan-
tur : neque vllis unquam alijs Aegyptij pharmacopxi pro balfimi fruetibus ad componenda medicamenta uf fuere. Neque aliorum Aegyptiorum memoria conftat, vncuam ex Petra oppido, quod nunc Mecha dicitur, alios, quàm hos fruetus pro carpobal famo ad nos delatos fuife. Neque Galenus exiftimat homines in corum feminum cognitione hallucinari, ac decipi poffe, quan do in libro de Antid. dixerit, carpobalfamum non poffe adultera ri, idque merito, cum minime fieri poffe videatur, vt aliquis, qui vera balfani femina femel tantum viderit, poffet ab alijs decipi; fed concedatur pofte adulterari, tamen cognoferetur id filtem, ut Diofcor.docuerat, inanitate, paruitate, \& fapore piperis. Verum non poflum non vehementer illos medicos admirari, dicentes, notas à Diofcoride nobis carpobalfami eo traditas fuiffe, ut ifta frmina ab ali,s diftinguererur, quando ipfe illas notas non ob) id tratiderit, fed porius, vt ijs homines perdocti felligerent $e x$ : feminibus balfani, ca, qux fala exiftunt, plena, maiora, grauia, fapore, atque odore opobalfami predita, quoniam hxc cxteris meliora 


\section{I A L O G V S.}

meliora exiftunt . Quis ignorat, agricolas etiam ipfos aliqua femi na ementes, fiue triticum fit, fiuc hordeum, feligere plena, magna, ponderofa, optimi faporis, atque odoris, abijcereque inania, parua, lcuia? Quamobrem iftud ? quia hxc inutilia, illa optima exiftunt. ALP IN. Dicunt, flaulm colorem, quo vera femina balfami fpectari Diofcor. tradidit, in iftis feminibus non confpici, cum ipfa fubrubra potius, \& nigrefcentia cernantur . A B D E L. Reetè dicunt, fed hinc conijcitur, ipfos minime effe in horum feminum obferuatione excrcitatos, feduloque nunquam ea infpexifie, quoniam fi frepe muitta fedulo, varijfque modis oberuaffent,procildubio duplici colore referta effe cognouiffent, quippè nigro rubefente, fuis folliculis veftita, hifque fpoliz tal, ac nulata, filuo. Ex qua obferuntione, nec Diofcoridem, docentem illud femen faum cfie, nce Theophaftum cum Sera. pione fubrubrum nigrefcens, falfum prodidiffe, patet. Quando hi femen veftitim fuo folliculo, quod nigrum fubrubefens cernit11r: \& Diofcor. folliculo fpoliatum, guod flaum eft, intellexerint. Hecque à nobis de carpobalfamo dieta fufficiant. De xilobalfano vero non puto à nobis multa cféc dicenda, quando nó ita om ibus, vt carpobalfamum, ignotum vidcatur . cfie illas virgas communiter ab omnibus pharmacopieis pro carpobalfamo re ceptas, etri ijs tamen non vtantur, argumentum crit certiffmum, ipfas redolcre odorem opobalfami, \& carpobalfumi, cundemque guftui faporem etiam preffeferre. Optimx autem exiftunt, farmen tofx, tenucs, fulux, \&xirecenter excife, odorem opobalfami manifeftiffimum foirantes. Queri odoren cximium fpirare a Theophrafto ac Serapione proditum eft. His vero recentibus pharmacopxi vti debent, cum paruo etiam tempore onní odore ac fapore deftituantur; tanta eft enim illius humida fubftantix, in qua odor, faporque fundantur, tenuitas, vi cito exoluatur, frmulque cum ea fapor, atque odor euancfeat. A L P I N. Fafeem recentiffinarum virgarum Dominicus à $R$ cge nofter pharmacopola ab amico fuo Turea, apud oppidum Sues, illuc Mecha aduectum habuit, qui multum opobalfami odorem fpirabat, qui tamen pauo cis menfibus ferè omnino exolutus eft. Multas virgas recentes habui, qux apud me adhuc affertuantur; quas comparatas cum ijs, qux apud Venetos pharmacopolas funt, cafdem vtique offe fine dubio cognofcitur, qux fi recentes conferuarentur, ueritas 


\section{E B A L S A M O}

hec omnibus eflet manifeftifrma, ita ualidus, ac manifeftus in ijs odor opobalfami perciperetur, ex quo omne dubium ex ipforum animis fponte excidiffet. A B D E L. Tibi fufficiat, hac de bal. fani planta, fucco, fruatibus, virgis, ex nobis audiuife, atque didiciff, veramque hanc huius plantx ichonem, nunc Alpine fpectare poteris, atque ex dictis ipfan recognofere. Sed abfoluto de ijs fermone, cum iam Sol fupra orizontem multum afcenderit, aeremque inflammare coperit, fatius erit nos hinc abire, \& in vr bem redire, priufquam augeatur caloris xltus. ALPIN. Re Ete fuades,abeamus, vobifque, quod tantum hactenus fufceperitis laboré, multas gratias refero, meq; vt pro veltra humanitate ametis, quemadino dum facitis, ctiam,atque etiam rogo. valete. $A B D E L$.Atq; tu interim vale. mementoq; nos tui effe fudioffifimos, te q; multum, arq; multum ob feruare.

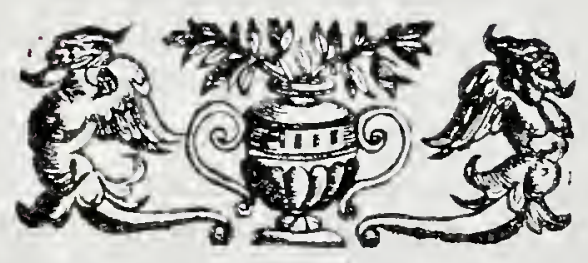




\section{I A L O G V S.}

B A L S A M V M.

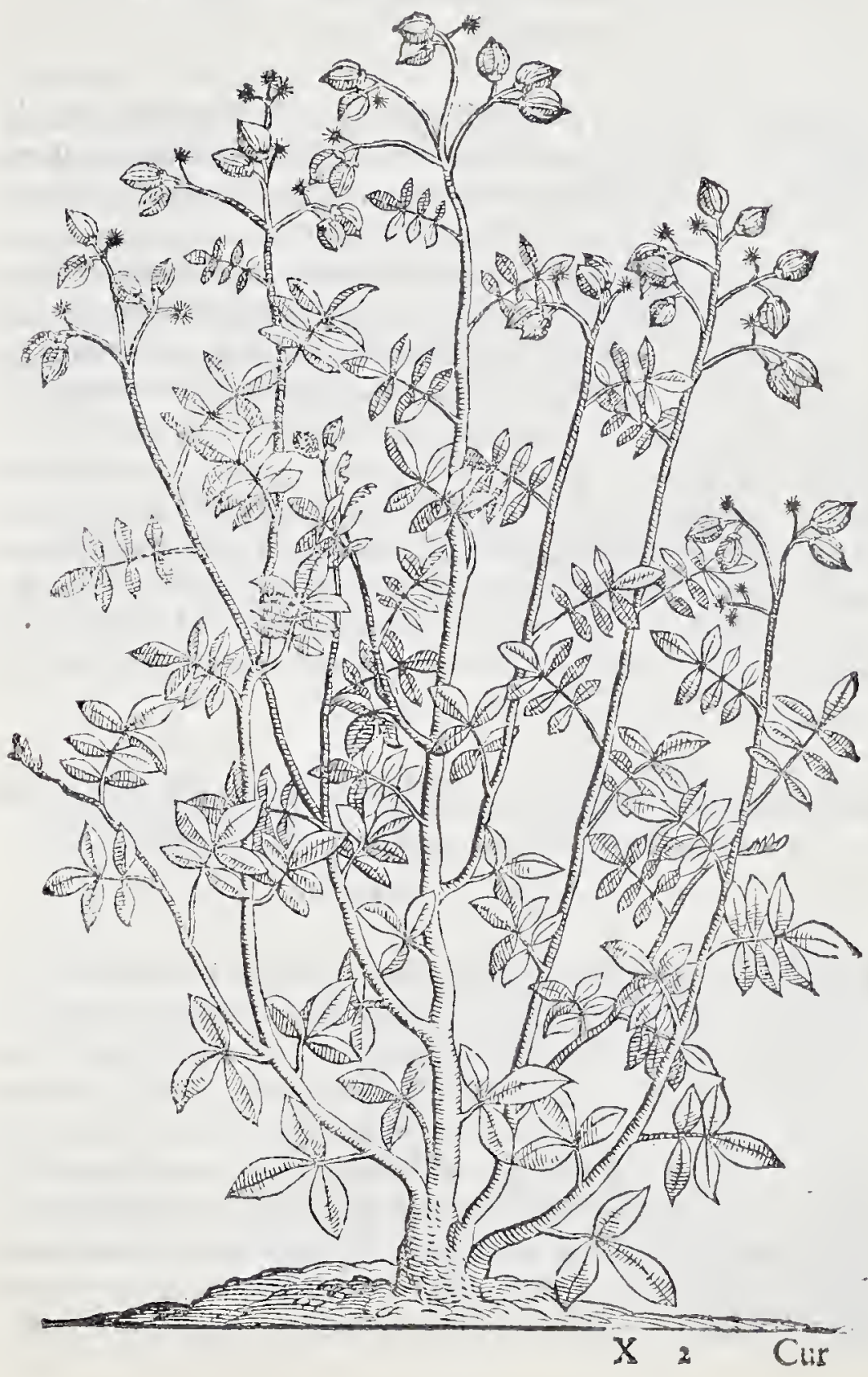




\section{E B A L S A M O}

Cur Petri Bellonÿ obferuationes in eAgypto circa balfami plantam facte bic adnotate fint. cap. VII.

30 V MI hife diebus libum olim in Acgypto a ne de fo, balfamo confriptum in publicum cniffurus effcm, Ecce in manus meas perueniunt doetiffim $x$ itincraric obferuationes a Petro Bellonio Cenomano, uiro tum in alijs,tum in plantarum materia doctifsimo, ante annos ab hinc quadraginta litteris traditie, atque hoc tantum anno in lucem edi tæ. In quibus cum balfami nonnullarum plantarum olim in Acgypto uiuentim diligentifsimam obferuationern ab co rectif. fime exaratam, ac deferiptam legerim, optimum fore putaui, fi eí fub fine huius libelli adijecrem, Siquidem fperaui ex tanti uri in plantarum materia exercitatifimi lectione, ca, qux dicta funt à no bis a ac litteris de balfami hiftoria mandata, poffe haud parum animos legentium confirmare, quod is omnia fere complexus fii, qux in meo libello leguntur. Hxcóuc,priufquam balfami obfer glationem Ballonij hic adiecifem, prefari libuit;ne ex abrupto hic ca inferta candido lectori uidurentur.

Acgytijbalfamiobfermatio a Petro Bellonio in libro I1. itine rariarum obferuationum, capite XXXYX.collecta.

$$
\text { Cap. VIII. }
$$

3. $70 \mathrm{~N}$ quodam pago fpectarum iumus hortum balfami (t) (4) fruticibus contrum, qui ì Cayro longius haud abert, 1 Et quan Lendit i Lutctia. Quoniam porro balfamiplanGtz ta admodum colebris,preciofararaque eft;hic feribere Iibuit quidquid ad cius hiforiam pertinere arbitrati frmus. Quof dam effe fcimus, qui Matarex Balfamum ex Iudea delatum effe putent : rem autem haud ita fe habere, poltea demonftrabimus. In magno quodam horto funt, fed angufto loco muris conclufe, quos cxtructos fuiffe aiune, poftquam Turca Acgyptum Sulrano ademit: Bacha ante à Turcartm Imperatore huic regio- 


\section{I A 1,O G V S.}

ni prefectun, ca arbufta digna exiftimaffe, qux peculiari loco con cluderentur. Cum iftic effemus, noucins, aut dece duntaxat frutices cius aderant, qui nullum liquorem prabebant. Inter notas a veteribus proditas, quibus balfinum dignofci poffir,una eft, vt perpetuo uireat: illud tamen in Materea, apud Cayrum, pauca admodum folia Septembri mente habebat: quod nobis infolens vi fum eft. Nam reliqua arbores, qux hyeme virere folent, folia fofum nouo vere abijcinnt, cum videlicet noua germina produxerunt : folcntque autumno magis vitere, quim nouo vere. At reliqux, qux folia abijciunt, id fub hyemem facere folcnt, vt atlate noua adquirant. Ideoque nobis preter naturam videbatur, balfamum folia abijcere, vt hyeme nou germina produceret : nobis cnim id obferuantibus, quxecumque habuit folia, tecens nata crát. Eius iuftan magnitudinem tradere nequimus; nam quotquor cius frutices in horto aderant, ftipitem folum habebant pedis lon oitudine, \& poilicari craffitic, tenubus ramulis praditum, raris foliis obfitis. Vbicuncue autem tandem nafeanturgduonm alut triú cubitorum altitudinem non fuperät; \& pedali altitudine cum fint, in mulcos graciles ramulos anferinx peme caule haud craffores finduntur. Balfamifrutices Matace iam recens putati fuerant, fic yt foli ftipites fupereffent, qui ramulcrum rudimenta produceban: Eiudem etenin ef balfanum cum vite naturx, quam fingulis annis putare neceff: eft, alioqui degenerat. Noua illa balAmi cermina fub wbente cortice erät tecta, foliaque viridia habe bant, lentifinosun foliorm modo formata, hoc utrinque in nes uo nata, ut in refarm, velfaxini, veliuglandis folijs videre ent, ciceris tamen folioram magnitudinem non excedcbant, ficque cö feruta crat corum frics, ut poltremum foliolum extimam alam. occupans, impuren numerum cfficeret : nan totins alk foliolis nu meratis, tema, quina, aut feptena inucniuntur, feptenaritm certe numerim fuperare aix anmadurtimus : extremum autem folioLum reliquis mains eft, fatro etentm ab illo progreffu, reliqua fenfim minutiona funt, vt in rutx folijs. Plinius in cius hiftoria Theo phralkum per omnia fequutus eft, quemadmodú etiana Diofcorides, eiulque veftigijs infitentes, balfami folia rum folijs compara runt: quod veritati confonum effe deprehendimus. Duoniam autem primum in Mararea illud exacte non obferuaucramus, denuo illud fpetarum iurmus, ciufgue ramulum nati, ip fum, atque illius 


\section{E B A L S A M O}

illius folia deguftauimus, qux facultatis non nihil adfriotorix efic comperimus, pinguifque aliquantulum faporis, atque aromati ci, ramulorum autem cortex his odoratior eft. Gemino cortice proditi funt ramuli, extimo foris fnbrubente, qui ut membrana intimum viridem operit. Is guftatus inter Thus, \& Terebinthi folium fapir, fatureir fylueftri fapore fmili admodum grato, atque digitis tritus cardamomum olet: ipfun lignú candicat, odorifque \& laporis expers eft, non fecus atque aliud inutile lignum. Iplius virga recta funt \& graciles, rarifque foliorum alis fparfim $\&$ con fufo ordine nafcentibus obfepte, qux (vt diximus) ternis, quinis, aut feptenis foliolis cóftant. Varix funt auktorum, qui de balfamo feripferunt opiniones : \& nifi nofpefi plantam confpexifimus, ni hil poft illos de eo fribere ans fuilfemus : atque in eam fere opinionem inclinaremus, illud Hierico pianis nunquam cultum fuiffe. Quia autem ipfum fruticem vidimus, diligenterçic obferuauimus, de co, tanquam de re qua diligenti obfernatione digna, diflerere libuit . Experientia autem didicimus, lignum illud vulgo xilobalfamum ntincupatum, quod ex Folici Arabia delarum à mercatoribus venditur, cum Aegyptio quod in Matarea colitur, conuenire : nam deficcatum noftum balfami ra mum cum eo, quod in officinis venale reperitur contulimus, atque omnibus notis refpondere, deprehendimus : eftque ex duobus alterum neceflarum, aut xilobalfamum \& carpobalfamum, quale in officinis venditur, a dulerinum efre, aut illud A egyptium, quod colitur in Matarex horto, legitimumque balfamum effe cenfetur Nam cum in omnibus conteniant, cerrique fmus idem cfre, afferimus, \& concludimus id, quod hoc nomine uenale reperitur, fi mile ei effe, quod ab omni antiquirate in ufu fuit.Balfamum nunc temporis in fola Aegypto colitur apud Cayrum. Et licet Theophartus in ea opinionefit, id fylueftre \& Pponte nafci non inueniri : afferere tamen audemus, ab omni zuo in folici Arabia fuiffe, aique ctiam nunc nafi, cuius lignum; \& frustus etiam olim ad nos perlata fuerint cum alijs Arabix mercibus. Atque demonfta re uolum: ea non minus cognita fuiffe mercatoribus, quàm reliqua aromata, vt ex madicamentorum, quibus perpetuo inijcifo lita ftn:, cöpofitionibus apparet. An non Mithridates in fuĩ medi cam?ntü intulit? An non in officinis uenalia repericbátur? Id ex fola Diofcauntoritate probari potent, qui in fua ctare carpobalfa- 


\section{I A I O GV S.}

mủ adulterari cóquericur. Carpobalfumū (inquit) adulterarur fe- „, minc hyperico fimili, quodia Petra oppido defertur per Petrá oppi ", dü Mecia inteiligimus, atci; de xilobalfamo:è ligni genere, quod xi " lobalfamũ vocant,probatur recens, farmento tenui, fuluă odoratũ, "s quadatenus opobalfamum fpirans. Ex his liquido apparet vulgaris vfus inter reliqua aromata fuife. Sed \& ex Diodori Siculive. tuftifsimi feriptoris Arabia fęlicis opes entmeräris, uerbis, manife fto liquet. Maritimis enim locis balfumum producere ait. Cultum igitur id efse non intelligit, fed fponte nafens. Paufanias etia tradit balfamum Arabix fruticem efse. Plerique tanen auktores debalfamo agentes, inter fe non conueniunt . Nam Strabo prodit in Syria nafci apud lacum Genezareth, inter montem Libanü 8z Antilibanum. Reliqui volunt folam Iudęam regionem id pro ducere, ciufque ramos of seo cultro, aut uitro duntaxat vulnerandos else ad liquorem eliciendum, alioqui fi ferro cedantur, itatim emori, Connelius Tacitus fribit, ferro iuxa adpolito, mecu exhor refere, idcirco alijs quam ferreis inftumentis uuherandum; fili quorem elicere quis cupiat. Percontantes a mercatoribus Cayri de balfamo, cum noftum ramulum conferremus, nobis affrma runt, quidquid xilobalfami, uel carpobalfami unquam uendidif

fent, id omne ex Meca cum alijs aromatibus accepifsc;

atque mem'nifse fuo tempore balfami frutices, qui nunc in Matarea coluntur, ex Arabia folici delatos cfse, magnis fumpribus Sulta. ni. Qunniam vero id nobis tam muli affirmarme, exiftimauimus fine ullo ferupulo aut difsimulatione nobis licere idferibe re. Laus Deo Opt. Max.

\section{F I N I S.}




\title{
I $N D E \cdot X$
}

\section{EORVM OMNIVM, QVAEIN TOTOOPERE}

\author{
C O N T I N E T VR.
}

Aduertant lectores, numerum foliorum, $37,38,39$, 40, typographi incuria effe duplicatum. Proinde primos in indice littera $K$ adnotauimus, Cum fint folij eadem

littera fignati, numeri.

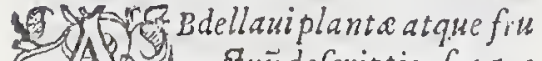
co os Eundefcriptio.f.45.a A Abdellaui melonis icbö. 然政 10 fol. 4 G.a

Abifina Caffia que, er eins vfus. fol.2.b

Abrus defcriptio. Abrus seu pbafeoli rubri ichon.

fol. $32 . a$

sbfus berba.

fol. $37 . a$

Acatia quibus in locis proueniat . fol.4.a

Acatiz arboris defcriptio. fol.4.a Acativa arborum differentive. fol.4.6 Acatia fuccus.

Acatie Ichon.

fol. 4.6

Acative fucci ufus apud Aegyptios. fol. 5.6

Acatice fucciloco,quem fuccum Itali parent.

fol.4.6.

Acatia maris of femine defcriptio. fol. 4.6

Acative quando flores ed.at. fol.4.6. Acatiam effe arborem facundiffimam.

fol. 4.6 Acatia fert grimmam quam Arabicam medici pocant.

fol.s.a Acatir, qua Species in Zacyntbo InSula promeniat. acatic Zacynthinc de fcriptio.fo. $54 . a$ acetofe Zacyntbine defcriptio.

fol. 53.6

acbrouan defcriptio . fol. 46.6 atque usus ad medicinam. fol.46.6 acbaokan I cboino fo!. 46.6 acbaouan abiat, feu artemificalb.e defcriptio.

fol.37.a.K acbaouamabiat, Cineraria, Iacobwa marinaidem. fol.37.a.K acbaouam abiat, sires \& ufus. fol.37.a.K

acbroam sbiat Ichon. fol.37.b.K ad aluifuxiones acatic ufus. fol.5.b ad anum, oterumque foras prolabentemacatixutilitas. fol.5.6 ad articulos roborandos acatie $\nu$ fus. fol.5.6

ad augendam Veneremelecuarium . fol.5 . 6

ad peitorispulmonumque morbos semina urtice conferre. fol.5 I.b ad cutis infectiones nigelle utilitas. ful. 5 r. $b$

ad mulieres, que non purgant ur nigel l.e $\mathrm{p}$ fus. fol. 5 ז. 6 ad cutis infectionem ualere femina urtice. fol.si.b ad febres ownefque calidos affict:s 


\section{N D E X.}

aqua augurierum el maoui utilis. fol.45.a

ad neruos ficcatos; do firrbofos tumoresfefami ufus. fol. 37.6 ad podagricosacatic usus. fol. 5.6 ad Donum calidos morbos chatè 4 us utilis. fol. 44.6 nd fomnum conciliandum solanifomniferiufus. fol.st.b.6 $52 . a$ ad.uteri flu.rum confert acatia.fol. 5.6 ad fanguinis Sputum confert acatia. fol.5.b

ad uteri duritiem Mümia. fol. 38. a K ad ulcracancerofa Cinerem Jeminum ortica conferre.

fol. 5 1. $b$ aegyptiarum plantarum btilitas ad medicinam.

fol. I.a aegyptios per calfrarñ loca mane odorisgratia obambulare. fol.t.b aegiptij calfie pulpa al quosmorbos v!antur. fol. 2.6 açyptü cassiis non utuntur antequar tum men/em. fol. 2.6 ae"yptios mel carnub ex filiquis exFreffum in ofum habere. fol. 3.6 aegyptï quxcondiunt melle cartute. fol. 3.6

aegypï̈ fuccum ex acatia quomodo partut, é eo ad qua utätur.fol. $4 . b$ aegyptus acatin exccpta alys arboribus gummas ferentibus caret. fol.s.a

aegypti locus, qui olim balfamim. aluit.

fol. $6=.6$

aegyptum Indcam folum balfam non habuiffe fedmulta alia loce. fol.65.a

segypium runquaw balfamo patrium ac natiuum fuißc. fol 65. a aegyptij feminibus melonis, quidicitur Abdellaui tantum utuntur. fol.45.à

ainge defcriptio ox Diofcoride Kelli an conueniat.

fol. 49.6

agiabadalid arboris defcriptio. fol. $16 . a$

agiabalid folionm ufus. fol.16.a agiabalid an lycium.

agiabalid lchon.

fol. $16 . a$ fol. 16.6 albedine opobalfami in aqua fillati propriancfes. alexandria segypti Cappares producit.

amatum Lufitanum of Nicolaum Manurdum planè balfami plantā perijse affirmare.

amaracum fyluestrem creticum.

fol. 56.6

antiquos friptores de balsamo fuiffe omnes inter fe opinione differentes. fol.68.6

antiquis friptoribus de balfamo planenonefjefidendum. fol.68.b antiquos foriptores fuife in call w, we noftri non credunt, opotalfumo, carpobalfamo, do xilobalfano ex Srabia delatis.

fol.68.6 antiquorum de balfamo diserfitatcm figntmeße eorüignorätice. fol.69.a antiquos de baifamomulta ex andituliteristratidise. fol.69.a antiquos non uidiffe opobalfamum, eße dubitandun!. fol. 74.6 antiquos deceptos, dum crederent bal-

famumolimtanthm legypto, atque Inde friffe cöcefium fol.60. andieas Mattheolus in acatig cognitione deceptus.

anguric aquo es. fol. $5 \cdot a$ anguriar, clmaouiaquefacuitas, at que, nhis.

fol.to a artoylidis fpeciem Kelith the. fol.to. 6

angurys omnes Aegyptijlibenter nefeuntur. fol.ti.a apocyn werü nafci i Italia. fol. $53 . a$ aqua ex cucumeribus chatèdifillate utilitas. 


\section{-I N}

queab angurïs destillate btilitas. fol.45.a

equa anguriarum quos morbos iusunt.

fol. $45 . a$

equa anguriarum diuretica. fol.45.a aqua macbalef.

fol. 25.4 aquecalaffacultas, ac ufus. ful. $25 . a$ - quafontis, quo olimufa fuit BeatifSima Virgo, Ealfamum ali, feu irrigari, atque eius mire facultates. fol.69.6

aque fontis .Mattharea, qua uirtutes ab Acgyptijs tribute fint. fol. 69.6 arabum uita, atque mores. fol.21.b arabes lucri caufa ceperunt balfami arbores colere, or quando. fol. 6.6 rabiam folicem balfami feractm. fol.66.a

arabiam falicem perpetuo fuiffe locumproprium Balfarni. fol.zo.a arabiam folicem perpetuo Balfamum babuiffe.

crabiam felicem inaumeras balfan plantasmun alere. plantas nunc alere. fol.64.6 arabes omnes ad componenda medicamenta, opubalfamo, carpobalfamo, xilobal fomoque vulgari ac benali, uti.

fol.67.a

arbores balfami qux in Aegypto alun tur, ad quam magnitudinem crefount.

fol.69.b

abores balfani in Arabia uiuentes qua magniudine $\int p e$ bentur, $\int e u$ crefcant. fol.69.6

arboies balfami multos in Arabia ninere.

fol. $63 . a$

arborem balfaniefje fiuticofam, do farmentofom.

fol. 70.4

aboris balfami Aegyptï, ef Indi difjerentix.

fol. 71.6

erbor "lhanne tamarendieft ligufrü Aegyptium.

fol. 18.6

arcbenda puluis, quid atque ciusufus fol.19.1
D - E X.

arbor ab Aegyptÿs sant nocatd eft uera acatia.

arbor palme Dacheinacatur. fol. It. a

arbores carub in multis Italix 10cis uinere.

atemifa alba. fol. 3.6 affalatum Cretcenafi. fol. 57.4 apalati Cretenfis diforiotio. fol. 57.4

afperam Smilacem duas radicum differentiasbabere.

atle estiamarifius.

auctor ciur de baifan fol. $14 . a$ alios libros imprimi curauerit. fol. 65.6

\section{B}

1 Abobab fol. 26. 6 atque eius A) fol. 27.4 Babobab ef fructus Letbiopis iucundiffimus.

Bubobabichon.

Babobab fructusichone. fol.28.a

Balfami plantas Felicem Arabian perpetwo aluiffe. fol.67.a

Balfamiplures plantas Bedrunia Ara bie,locusnunc alit. fol. $6_{3} .6$

Balfami inumcras plantas Bedrunia locum Arabia arenofum miraculo Mabometis alere Aegyptij illius ajecleputant. fol.63.6

Balfami inumeras plantas fponte natas in Arabir locis uituere, multorum teftzmonio confaire. fol.63.6 Balfami plàt.as quando Cayri exarue rint.

Balfamum quinegant boc tempore reperivi. fol. 63.6

Balfamiplantam cur omnibus in locis perijfermulti affirment. fol.6+a Ealfami plantam Sabam Reginam primo Regi solomoni dono tulifje. fol.20b

$$
\text { a } 2 \text { Balfami }
$$




\section{N D E X.}

Eulfomi platise, quas Aegyptus

Balafjan nomen ab Arabibus lialsa rinit, sude uenerint. fol.zco 0

Ealfami plantas multasex Arabia, in $\mathcal{A}$ ag'pto infertas. fol.zo.b

Balfam iferacem fuife Arabiam falicesn.

fol.2 $21 . a$

Ralfamiplantis quibusrationibus, on niza loca nunc caicie fuadeatur. fol. 64.6

Balfamiplanto multex ex aiabia adise ale quando in Aegypto fuerint inSertex.

fol. $6+6$

Balsami plantam num in Aegypto non wiuere.

fol.20.a

balsami planta perpetuo in Arabic wiuit. fol.20.a

balfami folim proprium Aegyptum tel Iudęan munquimfinife. fol. $20 . a$

balfamum Antiquos rectenonise of dubinin.

fol. $=0 . a$

Balfamum in Mrabianafci $\varepsilon x$ Paufania, es strabone. fol.zia

Ealfomicx Conflantino africanodefiriptio.

fol.68.a

Balfami plantas in monte arenofo Arabic falicis multas miraculo nine re peregrini afirmant. fol.z I. $b$

Ealfameta innumera in Arabia Spectari. fol.64.6

B.alfamiarbores in Arabia à Seripbo alicul locari, vt Cayri fit de Caf. fiis.

fol.64.6

B.llumi plantam Romanis Imperatoribus cur.e fuiße. fol. 2 I. a epifole dedic.

Balfonntm quibus ationibus negant vertam reperivi.fol. a a epist.

B.alfamm verum icperiri.fo. 2.6.epi. Balfamum nafci in Arabia ex Diodo ro ficalo arque multis aliys. f0. $2 \mathrm{I}$. Balfamiplante iclon. fol.77.a Balfami plantex in Inder quomodo proposuter fuerint. fol.65.a

mi planta primo impofitumftisSe. fol.66.a

Eulfamum ex ladijs occidentalibus delatum. fol.64.

Balfomi planta quibus in locis tontumoliminarit. fol.6-1.z

Ealfami planis quomodo dit in Aigypto conferiatid fuerint. fol.65.6

Balfamumnunc in Arabia folicitan tum uizere. fol.65.6

Balfami plantasin Aegyptum aliunde aduebi. fol. 62.6

Balfami planta quo pacto in Aegy'pto longo tempore fint propagatis. fol.62.6

Ballamiplantas è Mecch.a omncsin: Aegyptumveniff. ful.6zb

Ealfani plantis Aegyptium folum. proprizm nunquan fuife fol. 63.0

Balfsimum Iudea atque. Aegypti pla tam fuilfe peregrinam que fundeant.

fol.65.6

Dalsornum femper tum in Aceypto tum in Indea in viridariys mixifte, or non alibi.

fol. 65.6

Balfamum non in Aegyptum Ex Iudea Sed ex Arabia folici ucniffe. fol.65.a

Balsami plantas nuti in Arabias qui ex forptoribus, piodiderins. fol 65.1.

Ballami plantas Arabesex fylus fri bus locis in morbida viridaria trä ferre.

fol. $6 \div .6$

Balfami plantamatibus flartis Dot-

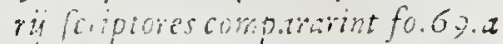
Lalfami dinerfiras de magnitudivefol.69.a

Eullamidiuerfitas de formira. fol.69.a Bulfamidiueifitas de folys. fol.69 6 Balfami plantam fruticen eßee. fol.co.us

\section{Balfami}




\section{$I N D E X$.}

Ballami plantedefcriptio. fol.66.a fol.c.3.b

$67 . b 22 . a$

Lalfaniplantan in Aegypto olim ui uentem pro legitimo balfamo Arabes atque Legyptios omnes perpecuobabisifge.

fol.66.a

Balfomicognitio à quibus petendi. fol.65.a

8.tifami arbusti foliänon effc (ut Diofcorides ait)alba. fol.67.b

Palfosmi quot frutices Cayri Bellonisssolm infpeverit.. fol.79. a

Dalfamim perpetuo utrere. fol.79.a

Balfami firticusn Cayri infpectorum defcriptio.

fol.79.a

Lalfantm fingulis annis putatur . fol.79.a

Balifmi planteuirgu. fol.77.a

s.ilami fructus Therebinthi fructiins fimiles. fol. 75.6

Bulfamiex feminibus nafcentis obfer llitin. fol. $70 . a$

Batfanidotesiecenfentusr. fol r.b rpistolededicatorite.

Bammic defcriptio atque ufus . fol. $33.2 k$

Bammie facultas, of quos snoiboscu ret.

Bummixichon. fol. $38.2 k$

Ban furcalaf fuiveio ful $38.6 k$ Ban vilitus atquenfiss. $\quad 01.2 \cdots$ Ban fer calafibon. fil. 25.6 Ean aliud fen bon.

Beidelfar deforiptio. Beidelfar plantaquid. fol, 35.6 Beidelfar ufus. fol.35.b Beidelfar plantaluticiniofa.fo.35.b Beidelforlabtis furultas. fol. 35.6 Beidelfar ladisufus. fol.35.6 Deidelfarichon... fol.36.a Beidelfar fiuctus atque ichon ipsorum.

fol. 36.6

Bedrunia locus Arabie folicis qui balfami multas plantas alit.

Bellaudadtilimaturi.

fol. I 1. a

Bessi Meflinor uocaius curafje fiantas balfami in Aegypto renonari. fol.64.6

Bon feu ban defcriptio. fo?.26.a Bon icbon. fol.26.6 $\begin{array}{ll}\text { Bon icbon. } & \text { fol.26.6 } \\ \text { Lyjus quid. } & \text { ful. } 28.6\end{array}$

\section{C}

CLoaquid atque ufus. fol.25.6 Caroa decoctum menfes imainutosiunare. fol. $26 . a$

Capparesqui in Aegypto proueniunt fol.5 5.6

Capparorumufusqui. fol.5 1.b

Carbones quibus Aegyptus eir . Aiabia utitur, ex Tamarifoo paratu. fol. $13 . b$

Carpobalfamum ucrum. fol.75.a

Carpobalfaniduplex genus circum ferri. fol.75.as

Carpobalfaris veri defuipsio. $f .75 . b$

Carpobaljami copian in Italia ex Aerypto conuebi. fol.75.6

Corpobalfaminote. fol.75.6

Carpobalfamum uenale uerume cfe: fol. $77 . a$

Carpobalfami defcriptio cr serapione. fol.76.a

Carpobalfarni uerinote ex Diofcoride. fol.76.a

carpobalfamum uenale, quibus ratio nilus aliqui demonfient uemms nonefie.

fol. $76 . a$

Carpobalfamum uenale omnes notas babere, quaslegitimo Diofcorids tribuit.

fol. 76.6

Carpobalsamumex Galeno non polt adulterari. ful.76.b

Carpobulfami loco quid fubsiruant Venetipharmacapole. fol. 75.6 cappobalfami ufus ab Meguptiiscogniti. 


\section{$1 \mathrm{~N} D \mathrm{E} X$.}

antit. fol.23.6

carrb uel carsub arboris defcriptio. fol 3.6

rarub arbores in multis Italin locis uinere. fol. $3 . b$ Caljic arboris defcriptio. fol.1:6 cafix arborem nuciefse fimilsm. fol.1.b

caffiarum fifials.

Caffic arbores quo tempore florent. fol. $2 . a$

Caffas recentes inmaturas Acgyptiy condiunt.

fol. $2 . a$

Caffix Cayri, alexandrieque nafen ies, quiles.

fol.z.a

Cafsie pelufii naforntes quales.f. $2 . a$

cassiarum quc catcrisbonitaie prexslent.

camubilion.

fol. $2 . a$

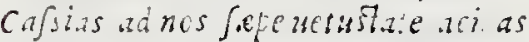
aduch?

Cafsitoptime qux.

fol. 2.2

fol. 2.6

Cafsies immaturas non colligi. fo. 2.a

caflamm iecentium ufus no.rius atque inutilis.

fol.2.6

C.essiarum ufus apud Aegyptios qra lis.

fol.2.b

Calsang facultas, atoue utilias. fol. =. $b$

Cafsinum differentio.

fol. $2 \cdot a$ cafsix quos morbos fanent. fol.2.b Cafsinimmerabion. fol.z.i caymer cafsias cuceris omnibus pretAantioutesfort.

fol.2..2

chate cucumerisichon. fol.t5.a chatequid, atque eins ufes. fol.4t.b chatecucumcrorum ad varins morbosufus utiles. fol. $4+b$ chatecucumerorüdefcriptio. f. $4+4.6$ chamedriosarborea greo in loco proueniat fol. 53.6 atnue eius deforiptio.

ibit.

cineres à quibus parent sezypin. fol. 49.6 cineris feminum urtice ufus ad qux. fo!. $51 . \dot{b}$

clyfterium ex decobto acatix usus: fol. 5.6

Colocafsiam neque florem neque fruEtum ullum edere. fol.39.a

Colocasfa caule, floribus fruftibusq; carct. fol. 39.2

colocas sie radicis ufus ad cibums. fol. 39.4

Confules renetos multos uero opobal famo non carere. fol. $7+.6$

conceptiones palmarumadmirabiles. fol. 10.6

Confnanirus dixit, balfomm nasci in India.

fol.65.a

Coriarif cayrinifuccoacativitiad he niurandas felles. fol.4.6

Corticum Capparis usus ad medicinain. fol. 5 ז. 6

Corticum frutuum Mauz ifius. fol. 32.6

Corisndro berba Aeguptios uefci. fol. 52.2

Coriandrü berbasn wirentum eflatam nibilmalifacere. fol. 52.0

Cornandriberbead cibum apud segy prios w/rss.

fol. 52.6

coriandrifeminusnufus. fol.52.6

Coriandrorum $\mathrm{s}$ us neminem laftum. fol.5 $2 . a$

Coriandrifaculatem efecalidam.fol. $52 . a$

ccriandilm bominiuenenum falfum. fol $52 . a$

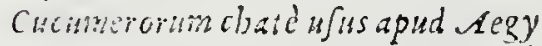
ptios qualis.

fol. 44.6

cucumereschatèuos morbos inuet. fol. 44.6

Culcas fine celocajpe defcriptio. ful. $39 . a$

culcafife radicum uf um conferre ad uencrem.

colocafia wera Icbon. fol. $39 . a$ fol. 39.6 


\section{N}

Car nofli in cognitione balfami decepti fint, atque di quilus. fol.69.a Cyperi rotundidefcriptio. fol. 43.6 cyperi radicum facultas atque ufus. fol. 43.6

cyperirotunde radices, quos morbos iunent. fol. 43.6

Cyperi in Aegypto pronentus. fol. 43.6

cyperirotundi multam copiam Nilum flumen producere. fol.43.b

cyperus rotunda ad morbos frigidos utilis.

Cyperirotundeicbon. fol.44.a

Cyprum Plini effe liguftrum of elhan ne Aegyptiorum. fol. I g.a cypridefcriptio ex Plinio. fol.19.a

\section{$D$}

1) webel rocant Arabes pal-
mam. Dactilorum differentie. fol.io.a Dateilorum immaturorum ufus ad medicinam. fol. I i.a

Dactilorum maturortm ad medici nam ufus.

fol.i1.a

Damiata Mufurum fectinda.fol. 32.6 Damiata olim Telufum. fol. 376 Damiatc cimitatisfitus. fol.4I.a Decoltumuel in fufumpulpatamarin dor um ad quos murbos Aegiptij $\int e-$ quantur. fol.15.a

Decoeti el caoanocati utilitas, eo ufus.

fol.26.a

Decoeti exmufis utilitas. fol.32.b

Decodi tamarici utilitas atque ufus. foll. 13.6

Decocti ex filiquis dulcibus parati utilitas \&o ufus. fol. 3.6

Decoili ex lignotamarici parati utilitas, es usus. fol.r 3.6

Diofcorides cur de bulfamo dixerit ipfum pannoadbarere. fol. 74.8
D. E X.

Diofrorides etiam balfamum alibiquam in Aegypto of Iudgu viuere affrmare videtur. fol.65.a

Dialogus del Ballamo Cayri confcriptus.

fol.20.a

Diodorns ficulus balfamum nafci in Arabia frripfit.

fol.21.a

Dus inuolucrumdattilorum. fol. I 1.a

\section{E}

F Lectuarium ad augendam neneEl banne Seu tamarendi in quo differat àligufro. fol. I 8.6 El banne Aegiptiorum eirsdemeße facultatiscumligustro. fol.18.6 Elbanne ex folys archenda nocato puluis paratur, atque eius usus. fol. 19.6

El banne Seu ligufri Aegyptï Ichon. fol. r 9.6

Emplaftrum ad tunnorem lienis. fol. $51 . b$

Epytibimum.

fol. 56.6

Epytbimi er epythimbra utilitas. fol. 56.6

$F$

THá Aegyptia an culcas fit. fol. Fabę Aegyptia feu colocaffie ufus ue nericonfert.

fol. 39.2

Fonugreciufus apud Aegyptios. fol. 53.6

Fxcem olei fe fami maxime pinguefacere.

fol. 37.6

Ficus Aegyptia, Sycomorusidems. fol. 8.6

Ficum Aegyptiam eße bafiffmimo arboiem.

fol.8.6

Ficuum sycomori ufus atque utilitas. fol.9.a

Fistum 


\section{$I N D E \cdot X$.}

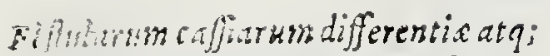
prothontice. fol.z.a

Fifillas callarum, non colligiimmaturas.

Elores balfami.

Flores Gelfimi. Arabici.

Fiorum calaf utilitas.

Flores caffarum odorati.

fo!.2.6

fol.67.b

fol. 29.6

fol.25.a

fol. 1.6

Folia belfami qualia Spetcrim . fol. $67.670 . a$

Folia balfami quomodo foligs rute proximafont dicenda. fol.70.a

Foliorum balfami deferiptio. fol. $79 . a$

Falionim palsiarum usus apud Aegy ptios.

fol. 10.6

Folia quarum plantarum folem ins Acoypto fequintur. fol.15..

Folia Tamarindi folcm continne legin.

fol.15.:

Tolion umligustic comercis. foll a $8, b$

Eranc. Triolus conful alegyti. fol.67.a

Fruckusbubobatiobon. fol.28.a

Fricus datuz facultas of whis. fol. $z=.6$

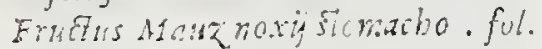
32.6

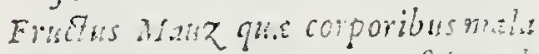
inductint.

fol. 32.6

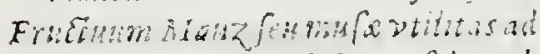
turitentes fufpriofofgue. fol. $32 . b$ FruElusbolfamiqui.

fol. 75.6

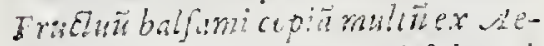
gypto in Italia afpertarifol. 75.6 Frifumm sebesten ofus ad medicin.am.

Frofunm Tamaiciughs. fol.13.6

\section{G}

Culenum non ricte apobaifomi

I vjusviderimonje. fol.22.b Gabrielern Fricptinan cognonife a)peram fmilacem e $\beta$ Se fallumparillam. fol.54.b Gelfimini Arabici Ichon. fol. $30 . a$ Gelfimini Arabicidefcriptio. $f .29 .6$ Gelfimini florüusus apud Aegyptios. ful. 29.6

Georgius Hemus Confu! Aezypti, Ciumez Legyptionum eft Syconcrus. firl.g.a

colppï arboreiIcbon. fol.29.

Golfipium, quo stuntur Aegipty aliun de aduebunt. fol. 28.6

Gofipius arboreum. fol.28.6

Colfipy usus apud Aegyptios. fo. 28.6 Coll:pufeminumufus. fol.28.b Gruminis crucis defcriptio. fol.47.b

Graminis Crucis ad medicinam wiss. fol. +7.6

Graninis feminum decolum fecretü ole ad adiunanda exantberratios in febribus pestilentibus. fol.47.6

Gramen ad vicra, pulneraquevtile, cfje.

fol. 47.6

Cruminis radicen fudorcm monere. fol. +7.6

Cinminis Crucis Ilbon. fol.48.a Gianinis derono inislieres adrarbolus morbillos pherorum, atque men frworters fupprelfionem. fol.a7.b Crectid latera curent. fol.66.n Guminam arabicam ese gummame Aiborisucatix. fol.5.a Cummam Arabicam in Aegypto ve ran colligiexacatüs. fol.5.a Gummancerie qualis fit. fol.5.a Gurma srabica non tota eft vermicularisacalba. fol.s.a Gurme Arabice cognitio. fol.5.a Gummarum copirm quecr ollegandrin webitur, cffe totwm acsate. fol. 5.6

\section{iI}

5 Tlybei quadraginta balsami

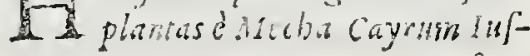


Cuprofucti tulit.

\section{$I N D E X$.}

Ierniarum multarum per Aegyptum nagantiam caufa. fol.45.a Hiericum Balfamum olim babuifle. fol.64.a

Hiftoria peregrinorum Meccham, of Medinam euntiam. fol.21.a

Horrcm Bei dux Carananx peregrirorusm. ful.67.a

Horrem Beiè Mecla multum opobalJumi, xilobalfami Carpobalfami cayrum detuliff: fol.63.a Hortus balfami fruticibus confins mbi. fol. 78.6 Hortus balfami in Aegypto defcriptio. fol. 78.6

Hyofciamus albus qui in Aegypto pro nenit. fol. $52 . a$

\section{I}

Chonesplantarum Aegyptiarum. nullum recte piodidije. fol. I.a Incole Bafliani montis Libani ibi oline Balfamum wixifje affirmant. fol.65.a

Iofeph, Sabam Arabia Reginam Sa lomoni in Iudxa balfami plantam dono tuliße.

fol.65.a

Itineris ex Aegypto in Arabiam feli cem narratio.

fol. 21.6

Iuflinum de balfamo arbore deceptu . fol. $70 . a$

Jussentutem conferuare opobalsamum, é quomodo illo utantur. fol. 23.6

Iuniperi fructus pro carpobal famo ve netos pharmacopolas fubfituere. fol. 75.6

\section{$K$}

Alligeniculatum. fol. 49.6
Kallialbum. kellù feu kalli tertie fpecieidefcriptio.

kellixomnes falfas to acres gustui. fol. 49.6 kelli, kslli tres fpeciei. fol.49.6

kelliplante ususad cineres. fol. 49.6

Kellit jisbqua anthyllidis pecicreponatur.

fol. 49.6

kellu facultaspurgairix. fol.49.6

kelliseukallipriniichon. fol.50.a

kallu fectindi icbon. fol. 5 c.l.

kellis tertÿ, quod Aegyptiproprium. ridetur, ichon. fol.5 I.a I

Tablab ef phafeoli fpeties atque 1 eiusufus. fol.20.6 Lablab feuplsafeolinigriichon. fol. $30 . l \mathrm{~b}$

Lact is beidelfar utilitas ad cutis infeEtiones.

fol. 35.6

Laitis beidelfar v/us. fol. 35.6

Lactis beidelfar facultas folutina que fol. 35.6

Lac beidelfar dy fenterias facere. fol. 35.6

Lapides renum atque uefice cur $\mathcal{H e}$ gyprijs fint familiares. fol. 47.6

Iignumbalsamiquale. fol.77.a

Lignibalsamiufus. fol.24.a

Ligustrum Aegyptium. fol.18.6

Ligistri Aegypty icbon. fol. I 9.6

Liguftrifoliorsm atque florumest ufus, apud Aegyptios. fol. I $9 . a$ Iigufri utilitates ex Diofcor. f. 19.6

Linimentum ex acatia pro articulis debilitatis.

Loca, que balfamum olim aluerint. fol. I s.a

Locus Legypti, ubi Virgo Beatifime multos annos uixit, ac menfes.fol. 66.6

Lodanum plantam effeplane differentem ab ea quxe baktenus berbarÿs fuit cognita.

fol. 56.6

Iodaniplant o cretenfis defcriptio. fol. $57 \cdot a$

Lodanum eße ceftum femin ä. fol.57. 


\section{N D E X.}

Lodanumin quo à ciflo femina diffe- Maнzichon.

rat. $\quad$ fol. 57.0

Iotus Aegyptius quid. fol.40.a

Iotum Aezyptiume ffe nympbiams. fol.40.a

Iotum in Italis locis copiofe proteni re, es in quibus.

fol. 40.8

Loti mirabiles ad folcm conuerfiones in Marghera lacubus o.' feruari. fol. 40.6

Lotiufres ad Cibum apud Aegyptios fol.40.8

Loti Caules Aezyptiy crudos mandunt.

ful.to.a

Licïindi arboris defcriptio. fol. I $7 . a$

Iycio uero nonuti Aegyptios. fol. 17.2

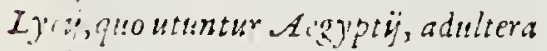
tinot.e. fol. $17 . x$

Lycimm indum, quo in loco Aesypti proniniat.

Ifciffuinltas.

Iysif fuccuulus.

$M$ fol. 17.6 fol. 17.6 fol. 17.6

A Abemetispeudoproph tw Tur IV carm jipulciorim ubi jot. ful. 2 r.a

Martm Creticum quid. fol.56. baique cius defcriptio.

ibidem

Marum Cretenfe ese amaracum. ful. 56.6

Mattisolus de Lodano deceptus. fol. $57 \cdot 2$

Matthareg locus inquo Beatiflma uir go sintitos amos cü prero eius filio inanfit.

fol. 66.6

Matchariaest locus Cayri Ciuitatis, in grociat balsamipläta. fol.6? a diatiburialocum inguo aleu ulur bal farmuriz, izunc co carere. fol.oz.b Manzlew mufedefcriptio. fol. $3: . b$ sa... fuliorum mira magnitudu. fol. 32.6

Ma!s findus wenere augere.fol. $32 . b$
Mentichor fol. 33.4

Meclua ciuitas Arabix falicis f. 2 1.a

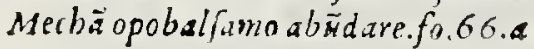
Medina drabir falicis cimitas. fol. 67.2

Melantbij Seu nigello ufus apud Aegi ptios. fol.5i. Meliloti Aezyptï defcriptio. fol 48.2 Meliloti feminum apud aegyptios ef feufum. fol. 4 ?. 6

Melex filiquis dulcibus Carub Aegy ptios colligere.

fol. 3.6

Melle jeliquarum dulcium faccharilo co Aesyprios nti. fol. 3.6 Melliscanub ur fus, et utilitas. fol.j.b siel drlciunn foliquarum fuse carnub quos morbos inuet. Meluchedefcripio. fol.z ak fol. 3.6 miliarius.

fol. $39.4 . k$

Melncbia facultas atque ufius fol. 39. a.k

Melocbix ufus quas offenfas faciat. fol.39.a

Melachic Semina puriane ful 39 a.k Melochicichon.

Melones sebdeliatiquid. fol..$+ b$ Melonum Abutlaui fiminum faultas, of uilitios. fol.4sia Mercatores Cayricarpolaliami, or xilubalfomi totum quat habent

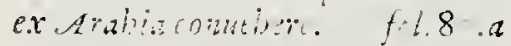
Meffir Eunucbus atcoypti prefientis. fol.66.6

Mucagine, feu mucilagine pryllij Aegyptit ad quos morbos vemer. fol.51.a

Mucilaginam pryla conferroddyrar

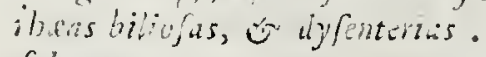
fol.si.a

Muribuginis feminis gof:py vftts. fit.: $2 b$

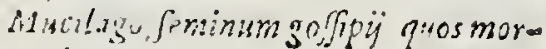
bos $\int x$ sint. 


\section{N D E X.}

Mulieres Balfamande nuid moliantur.

fol.23.6

dulieres urtice feninilus utuntur ad promowendosmenfes. fol.51.6

Min wine fle infitionem Canno Sacrha rind fupra colocazlism.

1ufufrubus qui.

fol.8.b

fol. 32.6

\section{N}

Thboa fructus apud Turcase?.

1 in masnopretio. fol.7.e

Nabca bis in anno fructus edunt. fol.7.8

Nabea, Paliurum, Canorum, idim, efoe.

fol. $7 \cdot a$

Nabca ef paliurus atbenei. fol.7.a

Nabcalcbon.

Nigrum cpobalfamum an detur. fol.71.b

Nigella, que in segypto prowenit. fo. 51.6

Nigcllue fenina yermes necare. fol.51.b

2 Kot.e fynceriopobalfami $x$ Diofcoride atque alys traditg. fol. 73.6

N $11 x$ Metheleft stramonism. fol. 52.15

Nymphex uel loti Aegyptij ufus ad Medicinam. fol. ; $\circ b$

Nymphes ofus ad fomnuriz conciliandum. fol.40.6

Nymphederadicis ufispro fecreto ad gonorrba a ,et ad dy fenteriä.f. 40.6

$$
0
$$

muits cosiferre.

fol.:29.b

olewn ix s. bisnini fluribus que nis do partats. $\int e .29 .6$

Opobalfamiccpammuliam in iraliafelicicoligi. fol.65.a

opobalfan.um chidan in Aitubia d feriphlecari.

fol. 21.6

Opob.rlfamicopiam Lrabes in mulia

Orientis loca compirtare lacri conica. fol. $6+6$ opobalj imum ex feminibus balfami elici.

fol.75.2

Opobalfamibisioria. fol. $27 . a$

opobalsminote.f. 22.6 .093 a,ct $72 . a$ opobalfamifacultas. fol.22.6 opobalfamum vcrum nusquam irsenivimulti affimant. fol. 70.6 quanobiem id fratioidcm.

Opobalfam:an qromodo album meslib prodiderint.fnctini. fol.70.6 opcbalfamo quas notas mulit tribuant. fol.71.a opobalfamimutationes ex barüs cirs atatibus.

fol. Tr.e $^{\mathrm{s}}$ opobalfamum quanio tenuiffinum, do clarifimum. fol.71.a opobalfaminotx. fublita opobalfumm serenifs. Ducis Floren ti.e uerum effe. fol. 74.6 opobalfamum quomodo ex arbore cliciant, of quando, of quale fit. fill 63.6

Opobalfamum Flatim edustum quale. fol.68.a

opobalfamidefcriptio. fol.68. opobalfami warietus eratale et alij. ful.si.e

Opobalfamum fenio confe dzum quale. foi.65.a

Opobalfano quatuor clates ut anima li,conuenire. fol.68.6

Opobalfamo etirm Galeni twmporibus adulteraium. fol 72.6 opobalomum gubusadulieietur. $b 2$ fol. 


\section{$I \quad \mathrm{~N} \quad \mathrm{D} \quad \mathrm{E} \quad \mathrm{X}$.}

fol. 72.6

Opobaifami adulterati cognitio. fol.72.b

opobalfami olio vitiati cognitio. fol.72.b

opobalfamisyncericoznitio. fol.73.6 opobalfamüs omne in aqua fillatü $\mathcal{F}$ coagulatum album videri.fol. $7 \cdot .6$ opobalfami ufus apud agyptios cogniti. fol. 23.8 Opobalfamo Petrum Marianum ex oulneve capitis effatu digno curatum.

fol. $23 . a$

Opobalfarmum quos morbos speciatim fanet. fol. $23 . a$ opobalfalmum ferilitatem curat . fol.23.a

Opobal famo quomodo utantur mulieres ad iusentutem in facie feruandam:

fol. $23 \cdot b$

Oralis Zacyntbina in quo ab Italica differat. fol. 53.6 $T^{2}$

D Almi frutuum defcriptio is serapione.

fol. 7.6

Paliuri fruitumm facultas ex serapione.

fol. 7.6

Palisriofus.

fol. 7.6

Talimum nouit Atbeneuser. Agatorle.

fol. $7 . a$

Paliuridefriptio ex $\mathscr{A}$ gatocle. f.7.a Paliurus Aibenti eft N.tpca Aesyptionm. fol. 7.7

Paliuri.Atbeneidefcriptio. fol.7.a Taliuri A benei Ichou. fol.8.a Palme defcriptio. fol. $10 . a$

Pulme frubuum Seu dactilorum diffe renti.e.

Palme Ichon. fol.10.a Talmaquando fruetus ferat fol. I O.a mando fruetus feral.fol.10.4 Palmarn aere nutriri putant Aegyptï. fol. 10.6 Talme ufus apud Aervptios. fo. 10.6 Palina breuifrmis radicibusconfare.

fol. 10.6

Talmarum mas, of famina.fol. 10. Palmarum conceptiones non fierivadicumcontactu.

fol. 10.6

Palman faminam fine mare non con cipere, neq; frudt us cdere. fol. $10 . a$

Palmas facundas quomodo segyptij efficiant.

fol. $10 . a$

Palme Sleriles qux in 1egypto. fol. I o.a

Palmefoliorum vtilitas. fol.10.6 Palmecaudicis ofus. fol. 10.6 Palmx fructuum utilitas atque ufus. fol. 10.6

Palme partes ad vfum medicinx. fol. 10.6

Partes palmarum, quibus Aegyptï ad medicinx u Jum, utäur. fol. $10 . b$ Papiridefcriptio atque vfus. fol. 4.6 Papyri squad ad oculorum fuffifiones caligines, of obfuritates. fol. $42 . b$ Tapyri Ichon. fol. +3.6

Taulus Marianus Fenetus pro Galw. lorum Regeconful. fol.66.b Taufanias balfarmum in Arabian.afci prodidit. fol.65.4 Pelufum Caffas fercbonitate Cayri nis inferiores. fol.2.a

Pelufinune Damiateciutatis niridisriat.

fol.tilas

Pefle infefis opobalfamum aritio effe.

fol. 23.2

Petrus Bellonius.

fol. 78.6

Petr' Michael cofut Aegypti. f.66.b Petrus Marianus ex vulnere effatu dignoopobalfamo fanatus. fol. $23 \cdot a$

Pbaleolizubri Abrus uocati defcriprio.

fol. 31.6 Thafeolirubrichon. fol. $32 . a$ Pbafeolorum rubeormm wfys. $f \cdot 31.6$ Phafcoli nigri lablab uocati defiriptio. fol. 30.6 Plonfelonim nigronum ufus fu. 30.6 Pbajeoli 


\section{N D E X.}

Phafeolinigriarborei icbon. fo. 3 i.a pinguefcere.mulieres ufu feminum, Selami.

fol. $37 . b$

Piperlongum, facultas, ufus, atque, eiusicbon.

fol. $40.6 \mathrm{~K}$

Plante balfami olim Cayri uimentis difcriptio à Petro Bellonio. fol. 79.a

Plantas peregrinas in uiridarijs $\mathrm{Cu}$ Fodiri.

fol.zo.b

Plant.ts locorum patrias ubiquenafici. fol. 20.6

Plante balfami in Aegyptum aliunde aduebi. fol.62.6

Plante quadraginta balfami è mechadelate atque Cayri in loco qua do inferte.

fol.66.6

Plantu b.ulfami in locis ferilibus uiuentes quo ad opobalfanum Aeriles.

fol. $70 . \pi$

Plantas balfami plane non periffe. fol. $6+a$

Planta peregrine feruantur in uridarÿs. fol.65.6

Plant.as patri.us non in uiridarijs, $\int c d$ ubique uiuere.

fol.65.6

Plantic Aegyptix.

fol.r.a

Jlantie Aegyptie, folis fequia. fol. 15.4

Plantarum Aegystiarumad nedicinan utilitas.

fol. I.a

Planartsm Aigyptiarum ichones ue r.zs nullos delineaßse.

plinins de balfamo.

fol.1.a

Plinius in gro de opobalfamo dece-

Plinius in quo de opobalfarno deceptus.

fol.71.a

Podugricos dolores maxime iuuariacatia. fol. 5.6

ISeudocarpobalfamum, et eins defcri ptio.

fol. 75.6

Pfyllium copiofefime in Aegypto pro uenire.

fol.sia

T.jylly u fus ad medicinam. fol. 5 I.b

Tyjlliumin Aegypto non rJe uene-

num.

fol. $5: .6$

Pueris in sparto palmarum indentiufus.

- fol. II.e

Tulpa babobab ufus ad medicinam. fol.27.a

Tulpe cafjarum ufus ér utilit.us. fol. 2.6

D Amicb nocant dactilum pend

Ol immaturum. fol. II.a

Rotob dactili fubputridi. fol. I I.a Rhabarbari planted de friptio. $f .53 .6$

$\mathcal{A}$ dar serapionis eft $N$ abca $\mathcal{A}$ D rabum ac $\mathcal{A}$ gyptiorum.fol.7. salfa parilla Zacynibi quomodo inuenta. fol.st.a Samarbicbquid. fol.ria

Sanguinem expueñtibus fuccumacati.e auxilio effe. fol. $5 . \dot{b}$

Sant arboremab Aesyptijs wocatam effe veram Acatiom. fol.4.6

scander Bei Medine ciuitatis pretor ex Zacynibo Infula a Segrarorsm familia ortus balfamirams recers tes, fiuchus, ac fuccum Cayrum demifife. fol.67.a

sebelen arboris duplex genus. fol. II.

Sebeften arboris domefici of sylsestris defcriptio. fol.1 $2 . a$

Sebeften icbones. fol. 12.6 \& fol. I 2.2 secamonèdefripito. fol. 52.6 Secamonè Jucci facultas. fol.5:.6 secamone quid. fol. $\$ 1.6$ secamone an fit aporynum. fol. 52.6 secamonè ichon. fol.53.a secretum adpruritum tollendum ex oleofefami. fol.38.a seminum gofipijufus. fol.2s.6 seminum urtican ufus. fo!.51.6 Semina urtice quos morbos fanent. fol.s 1.6

Semina balfani copiofb/fina ex felici - Lrabia in Aegypum deforri. fol. $67 \cdot a$ 


\section{I $N$ D E X.}

Semina balfamiqualia. fol.76.a semina procarpobalfamo vulgo rece pta, efse scrum cappobalfamum. fol.75.a

semina balsamicum foliculo eße nigra $\int u b$ rubefccitia. fol. $77 . a$

Seminump $\int y l i \ddot{y} u \int u s$ apud degyptios fol. $\$ 2 . a$

Stminum fe fami ufus ad cibü.fo. $37 . b$ scrininum coriandriufus. fol. 52.6 seminumbon socatorum facultas, et nfus. fol. 26.6

semina dbdellarimellonis in refrige randocateris proflare. fol.45 a

semina loti feu N ymphes bomines ad weneré impotentes facere.f. 0.6

seminum meliloti facklias of ufus. fol. 48.6

serapio de carpobalfamo. fül.j6.a semph Recche Dominus. ful.2 I.b scriph Mecibe quec riunera mittat Iurcarum Rrax.

fol.21.6

Teripb Mecibe es Medinaplurimum acricpobalfami Regi Turcarnsn. fingulis annis dono stitiere.f. $7+6$ Sefami plantedefriptio. fol.j7.a sifanifoliorsm, fominumque fac:iltas. fol. $37 ., b$ sefami fute sempsemicbon fol. 386 Sifanid decolto in quibus morbis at 4 .6n tur.

fol. 370 Sefami $v$ fus apud mulieres. fol. $37 . b$ sefami ufus ad pinguefaciendac cor oro.

sesuan defcriptio. sesban ufus in segypro. fol. 33.6 sesbonfiminum ufus.

sesban icbon.

sesbanichon. fol.j4.a

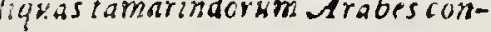
diunt, atque if farum uj us. fol. 1 s.a

siliguarum caffiarm differentio, do pidstanita.

fol. 2.4

siliguas caffia immaturas non colligi ful.2.a siliquas caffia recentes of paruas Aegyptü condiumt.

fol.2.a

siliquarum conditarum utilitas ein ujus.

fol.2.6

siliquas caljarum recentes ad $2 \int 1 \mathrm{~m}$ puserorum segyptü condiunt.f. $2 . \dot{0}$

siliquas carrb apud legyptius efice in $u$ Su.

fol. 3.0

siliquarum dulcimm cainb mccatorï ufus admedicinare. fol.4.a

smilacisaspera Zacy? itbina defcriptio.

smilax apera quilus notis falfafarillackse, dignofrabur. fol. $5 \div . b$

Smilacis ifperx radices Zaciulbicias fas doblongas Sperturi, es è rontia in Italica.

fol. 54.6

Smilacem afperam in ficcis durifque locis inventam cur non repribefen set falfam parillam. fol $5+7.6$

smilacis afpere duxiadicum diffeien tia.

smilacem afperam Zacymlit prouewiètem ab ïs qua in lialia rafeun tureffe difficintem. fol.55.6

smilacis afpere Zacyntbirecicloun. ful. 56.02

Smilacma aferam effe fallamparillam. fol. $54 . a$

Smilices afperus Italas à falja paril la differie.

fol. $5+.2$

Soluniradicum corticibus ad qux de

syptl wantur.

scpbera. fol. 34 bichon 35. a fil. 1.6 Solaimm femnificrum, quod pronenit Alcrandria. ful. 51.6 Solanifomniferiug fus. fil.51.6 species regetabilinu eflepirpatha fol. 6 +.at

Stratiotes cx Dinforide. f\%l.41.a Stratiotis Diofcuradis icbon.fo.t .6 stratiotes quibus in luces atruypti nafertur. fol $+i . g$

strationimquomodo dey yly atrus स. 


\section{N D E X.}

Erabes appelient. fol.qI.a stratiotes ad fiflendam quescumque bumoris fluxionem multum alere.

Strutiote ad quos morbo Aegyptï Mtantur.

fol. 41.6

Stratiot is facultas, of ufus. fol.4I.

strabo balfama ait in Arabianafir. fol.65.a

Stramonili ufus.

fol. 52.4

Styorin Cretalnfula. fol.57.a

succo ex prmis syluefribus ltalos pro acatianti.

Succus acatie quomodo ab. ptijs paretur. fol. 4.6

fol. 4.6

succi acatia precipue uires. fol. 5.6

Succic acatia rus apud Aegypt. fo! $6 . a$

succ" ac.tiz quos morbos fanet. f. 5.6

sucu frichum palutiatbenei usus fol: $7: b$

Slus lione careve qui cibum in uafis a Tumarifco palatis cibum afjumant.

fol.1 3.6

Si:fitus ex seminibus prtice ad promouendosmenfes.

Sycomoridefcriptio.

Sycononi Galmeminit.

fol. 51.6 fol.8.6 fol.8.6

Sycomonum illingitionem fri fupra morrim.

fol.8.6

Sycomorum cur in arnolis Aegypti iocis Dersprodisxit. fol.8. conorum apud Matharea nunc viSyuere, quem olim Christism seruator:m nosirum puerulum occultafe, Asyptij dicunt.

fol. 9.8

sycomorus fecundifjima arbor. ful. $9 . a$

sycomorus firetus ron fert ni prius verberibus mu'tis laceretur. fol.g.a

sycomorus quopropagetur. fol. o. a

sycomori ficuum ufus, os ntilitas. fol.g a

Sycomori Ichon. syrupumex dablilis immaturis Aezy prïparant, at $\dot{g}$; eius ufus fol. I l.a $T$

Alla quid. fol.5 tia
Tamaindiaboris deforiptio. fol.1 $5 . a$

Tamuindum Liabes pocant Dereb. jide.

fol.15.a

T amarindi folia folẽ fequi. fol. I 5 . a

$T$ amarindi arboresn ali in Deferto.D. Machary.

fol. I 5.a

Tamarindi foliorum ufiss. fol.15.a

Tamarindorum flinguas conaibilad us wiatorumper africe loca.fol. 15 . a

Tamarindorumpulpaulus. fol. I s.a

Tamarindi arboris Icbon. fol.15..2

Tamar daEtlificcimaturi. fol. I 5.a Tamarilcus Italic qui ignotus.f. I 3.6 Tamarifous fylasestivs r.bi prosentat. fol. 13.6

Tamarifcus domeflica quibus in locis pronciniat.

fol. 13.6

Tamarici arboris deferiptio. fol. 13.6

Tamaricifrubtus, qui. fol.: 3.6

Tamariciarborisufus. fol. 13.6

Tamaricifoliorum utilitas. fol 13.6

Tambitilichon. fol.1 $+b$

7 heoploraftusde balfamo. fol 65.6

Theophrafus redo carpoba!fumbmo descrip/it.

fol. $75 \mathrm{~b}$

Theopbrastum et Diofcoridem de loco deceptos. fol.4.a.a

Thuriaca busus temporis cur ea, que antiquitus parabatur, Jit imperfeEtior.

fol.6 1.a

Theriacam buiustemporis demorfos a ferpentibusnon curare. ful.6 I.a Theriaca buizs temporis nemo venenatoscurare confidit. fol.G I.a Thymi.Crotenfis defcriptio. fol. 56.6 Thymus fecundus crete inuentus. fol.56.6

Tymbra.

fol. 556

fol.g.b Tricas, of Arabes ommes aljwinare 


\title{
I N D E X.
}

imnumeras balfami plantas omnia Arabire culta o inculta loca alere. fol.67.a

Turcarmm Rex unide plurimum opobalfamibabeat.

fol. 74.6

Turea yuomodo angurijs stantur ad cibura.

fol. 45 a

Tumores duros fefamum fanare. fol. 37.6

Iuflentibus conferre oleum gelfiminum.

fol.3.

$$
y
$$

$\mathrm{V}^{\mathrm{s}}$ Enenatis

$\begin{array}{ll}\text { effe. } & \text { fol.23.a } \\ \text { Virgaris baliamidefcripio. fol.77.a }\end{array}$ Vifci ex frudtibus sebelen proparatio.

fol. I $2 . a$

I'ifcoad quosmorbos aezyptijutan tur. fol. $12 . a$ Vifcifacultas atque $\Rightarrow$ sus. fol. I z.a Vrtica qua Alexandria prowenit. fol.51.6
Vitica Seminum ofus. $V$ teri duritiem fanari bammies. fol. $38.4 \mathrm{~K}$

Yzeg arboris defcriptio.

Vzegeße Lycium Indum. fol. I7.. $y$ zeg bel Lycij Indi Icbor. fol.I 4 .a

\section{$X$}

$\mathrm{X}$ Ilobaisami cognitio. fol.77.a Xiloualfamum cisò odorem efaporem omneris. relinquerc, es quamobrem fust.

fol.77.6

Xilobalfamim ex Eellonio venale iden efjecum Aegyptio. fol.79.6 Xilobalfami ofis Aegyptys noti. fol. 23.6

\section{$-Z$}

Taffunt foliapalmarü.fo. I . A Eatar endideforiptio, of vos. fol.40.a.K

Zatarendizchon. fol.to.s. Zevet album nafici mox turbari. fol.7 $1 . a$

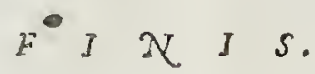

\section{ERRATA SIC CORRIGITO.}

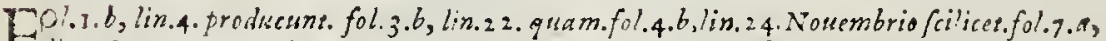

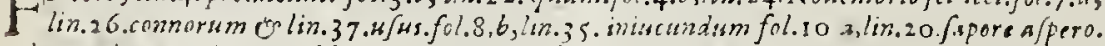

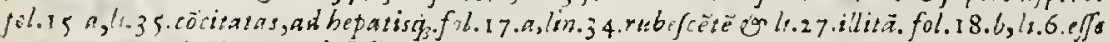

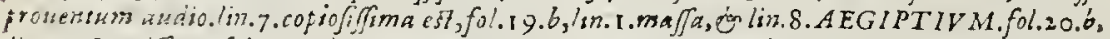

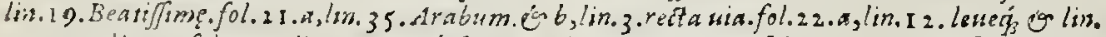

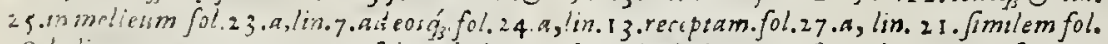

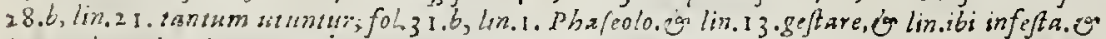

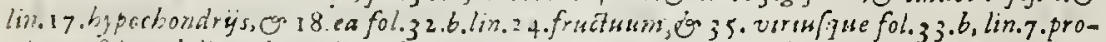

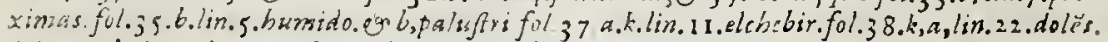

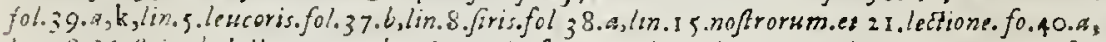

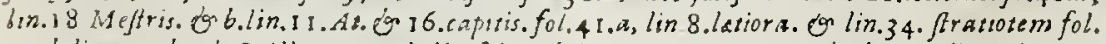

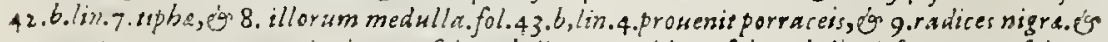

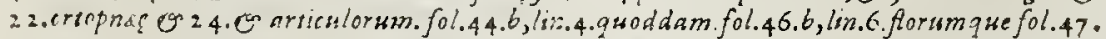

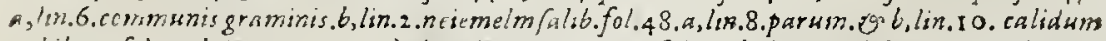

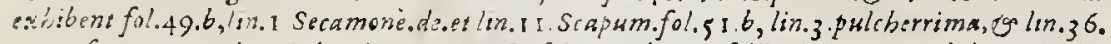

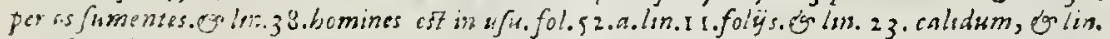

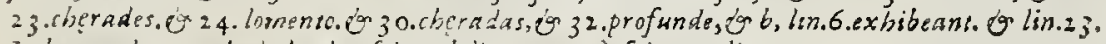

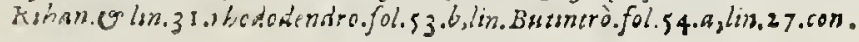





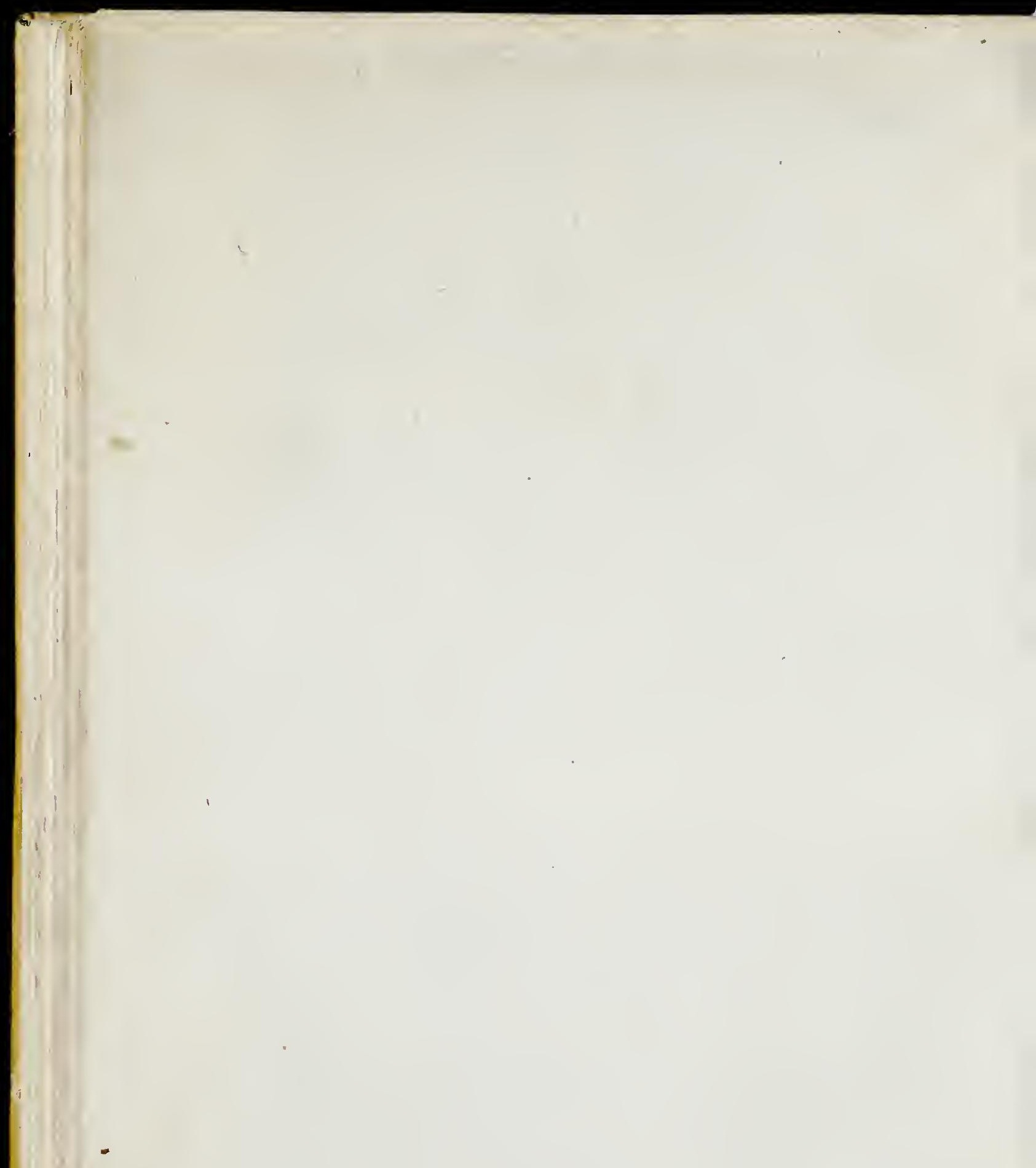






\section{Telephone :}

BAYsWATER 8585 .

Cable Address:

"Avoriolor, Wesdo, London."
c/O NATIONAL PROVINCIAL BANK,

8, NOTTING HILL GATE, LONDON, W.11.

Charles P. Berolzheiner

Ca.lifoornia Cedar Product

DAVIS \& ORIOLI

(Prop: J. I. DAVIS)

7.4 .55

Stockton, Lalitornia. USA

Antiquarian Booksellers

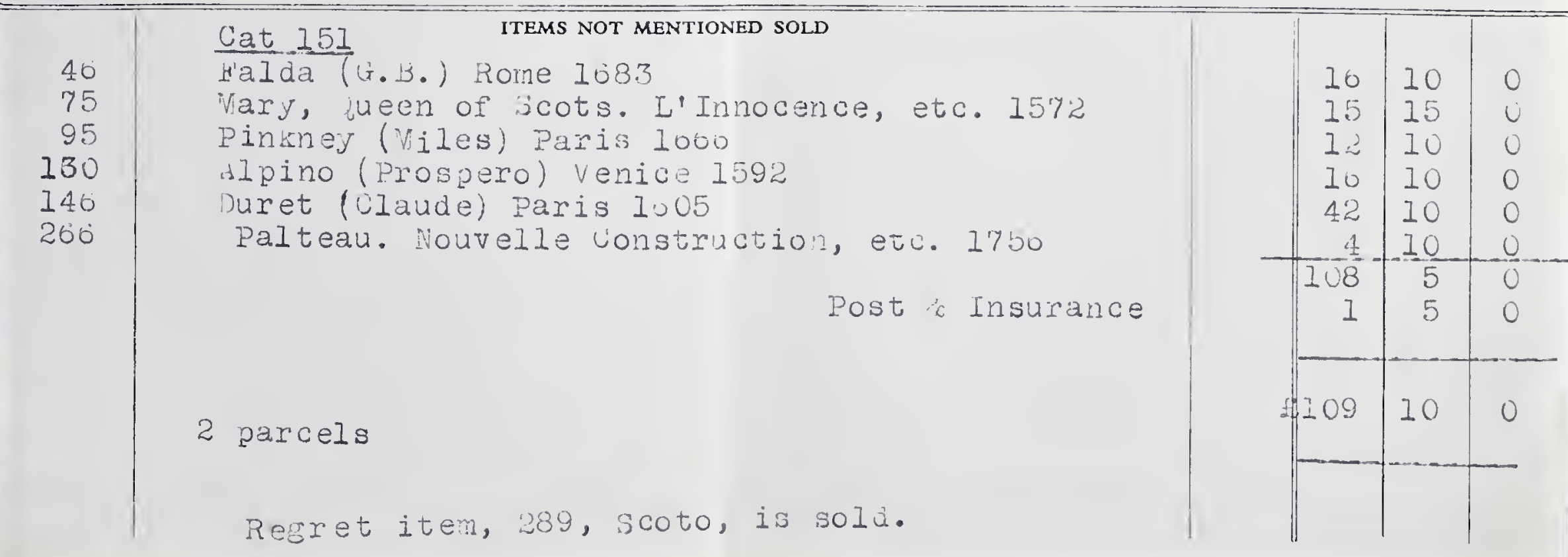

